\title{
Food intake meeting energy and reward homeostasis
}

Citation for published version (APA):

Lemmens, S. G. T. (2011). Food intake meeting energy and reward homeostasis. [Doctoral Thesis, Maastricht University]. Maastricht University Press. https://doi.org/10.26481/dis.20110317sl

Document status and date:

Published: 01/01/2011

DOI:

10.26481/dis.20110317sl

Document Version:

Publisher's PDF, also known as Version of record

\section{Please check the document version of this publication:}

- A submitted manuscript is the version of the article upon submission and before peer-review. There can be important differences between the submitted version and the official published version of record.

People interested in the research are advised to contact the author for the final version of the publication, or visit the DOI to the publisher's website.

- The final author version and the galley proof are versions of the publication after peer review.

- The final published version features the final layout of the paper including the volume, issue and page numbers.

Link to publication

\footnotetext{
General rights rights.

- You may freely distribute the URL identifying the publication in the public portal. please follow below link for the End User Agreement:

www.umlib.nl/taverne-license

Take down policy

If you believe that this document breaches copyright please contact us at:

repository@maastrichtuniversity.nl

providing details and we will investigate your claim.
}

Copyright and moral rights for the publications made accessible in the public portal are retained by the authors and/or other copyright owners and it is a condition of accessing publications that users recognise and abide by the legal requirements associated with these

- Users may download and print one copy of any publication from the public portal for the purpose of private study or research.

- You may not further distribute the material or use it for any profit-making activity or commercial gain

If the publication is distributed under the terms of Article $25 \mathrm{fa}$ of the Dutch Copyright Act, indicated by the "Taverne" license above, 
Food intake meeting energy and reward homeostasis 

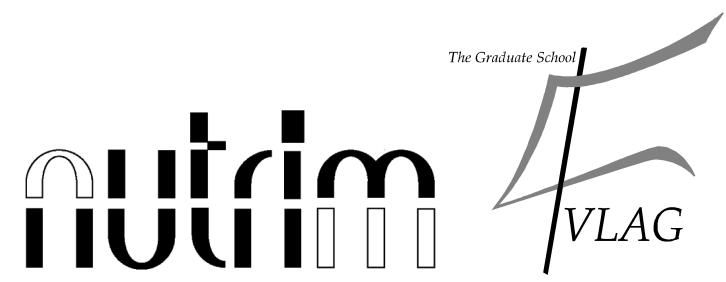

The study presented in this thesis was performed within NUTRIM School for Nutrition, Toxicology and Metabolism, which participates in the Graduate School VLAG (Food Technology, Agrobiotechnology, Nutrition and Health Sciences), accredited by the Royal Netherlands Academy of Arts and Sciences.

Cover design: Sara Lemmens

Layout: Sofie Lemmens

Printed by: Datawyse, Universitaire Pers Maastricht

(C) Copyright Sofie Lemmens, Maastricht 2011

ISBN 9789461590077 


\title{
Food intake meeting energy and reward homeostasis
}

\author{
PROEFSCHRIFT \\ ter verkrijging van de graad van doctor aan de Universiteit Maastricht, \\ op gezag van de Rector Magnificus, Prof. Mr. G.P.M.F. Mols, \\ volgens het besluit van het College van Decanen, \\ in het openbaar te verdedigen op \\ donderdag 17 maart 2011 om 12.00 uur
}

door

Sofie Ghislaine Theresia Lemmens

Geboren te Oupeye op 3 november 1983

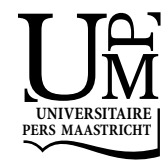




\section{Promotor}

Prof. dr. M.S. Westerterp-Plantenga

\section{Beoordelingscommissie}

Prof. dr. K.R. Westerterp (voorzitter)

Prof. dr. H.R. Berthoud (Louisiana State University System, USA)

Prof. dr. M. Laville (Université de Lyon, France)

Prof. dr. A.A. Masclee

Prof. dr. R.P. Mensink 


\section{Table of contents}

$\begin{array}{lll}\text { Chapter } 1 & \text { General Introduction } & 7\end{array}$

Chapter 2 Changes in gut hormone and glucose concentrations in 21 relation to hunger and fullness

Chapter 3 Eating what you like induces a stronger decrease of 39 'wanting' to eat

Chapter 4 Dietary restraint and control over 'wanting' following $\quad 59$ consumption of 'forbidden' food

Chapter 5 Staggered meal consumption facilitates appetite control $\quad 75$ without affecting postprandial energy intake

Chapter 6 Stress augments food 'wanting' and energy intake in visceral overweight subjects in the absence of hunger

Chapter 7 Influence of consumption of a high-protein vs. highcarbohydrate meal on the physiological cortisol and psychological mood response in men and women

Chapter 8 Eating in the absence of hunger: interaction between stress, macronutrient intake and disinhibition

Chapter 9 General discussion

Summary

Samenvatting

Dankwoord 

Chapter 1

General Introduction 
The prevalence of overweight and obesity has increased worldwide to epidemic proportions, and severe obesity is a risk factor for many diseases, including type 2 diabetes, cardiovascular diseases, and hypertension (1). Overweight and obesity result from a positive energy balance, with energy intake exceeding energy expenditure, leading to the storage of the excessive energy as fat (1). It has been shown that physical activity energy expenditure in Europe and North America did not decrease between the 1980s and 2005, a period during which obesity rates increased (2). This suggests that the recent rise in obesity may not result from a lowered physical activity, but rather from an increased energy intake. The regulation of energy intake is a complex process involving numerous factors such as genetic, physiological, environmental, and cognitive factors (3, 4). This thesis encompasses the role of hormone and appetite dynamics, in relation to meal pattern, as well as the concept of reward, and hypothalamus pituitary adrenal (HPA) axis activity, in food intake behavior.

\section{Energy homeostasis and reward homeostasis}

Energy homeostasis is reached when energy intake meets energy expenditure. On a day-to-day basis food intake is highly variable and correlates poorly with energy expenditure (5). On a weekly basis, however, energy homeostasis is precise, resulting in a stable body weight in most adults (5).

The regulation of food intake and energy homeostasis involves 'hunger' and 'satiety' signals, produced in the hypothalamus as well as in peripheral organs, (6). 'Hunger' signals, such as ghrelin and neuropeptide $Y$, often drive the initiation of a meal, while 'satiety' peptides, like glucagon-like peptide (GLP)-1, and peptide tyrosine-tyrosine (PYY), insulin and leptin, cause consumption to cease (6).

The search for physiological biomarkers of appetite is currently very active. Relevant potential biomarkers related to appetite, may be the anorexigenic peptides GLP-1 and PYY, the orexigenic gut peptide ghrelin, and glucose and insulin (7-9). GLP-1 and PYY are released from the endocrine $L$ cells of the ileum and the colon, and appear to reduce appetite (8). Intravenous infusion of GLP-1 and PYY demonstrates decreases in energy intake $(10,11)$. GLP-1 and PYY plasma concentrations are low in the fasting state and rise during a meal (12). Ghrelin is a peptide secreted primarily by the stomach, and appears to increase appetite, as it has been shown that intravenous infusion of ghrelin in humans increases food intake $(13,14)$. Ghrelin plasma concentrations peak before a meal and rapidly drop postprandially (8). Ghrelin responses are dependent on caloric intake and circulating nutritional signals $(15,16)$. Glucose has a central role in the regulation of energy metabolism, and is the only energy source for the central nervous system $(7,17)$. Circulating glucose concentrations are tightly monitored, from the time glucose is ingested to its absorption in the gut and its increase or decrease in blood concentration (17). Glucose has been hypothesized to play a 
role in meal initiation, as feeding is usually preceded by a decrease in blood glucose concentrations $(18,19)$. Glucose triggers insulin secretion by the $\beta$ cells of the pancreatic islets (17). Insulin stimulates the uptake of glucose by peripheral tissues and suppresses hepatic glucose production (7). Similar to blood glucose, insulin has been hypothesized to be involved in appetite regulation $(20,21)$.

Measured feelings of appetite expressed as ratings on visual analogue scales (VAS) have shown to be highly reproducible and therefore reliable (22). However, a possible association between VAS ratings of appetite and physiological measures remains subject of debate. Several studies (23-25) showed no relationship between appetite ratings and the endogenous gastrointestinal hormone concentrations, while other studies $(10,26-28)$ found significant correlations $\left(p<0.05, R^{2}<0.3\right)$. The latter papers suggest a relationship between VAS ratings of appetite and hormone concentrations, although correlation coefficients are mostly too low to presume that the concentrations of gastrointestinal hormones may serve as a reliable biomarker. Regarding glucose and insulin, the meta-analysis by Flint et al. showed that insulin concentrations were inversely correlated with feelings of hunger $\left(p<0.02, R^{2}<0.1\right)$, while glucose concentrations were not correlated with feelings of hunger or satiety (9). Literature has indicated that it is not clear whether blood glucose and insulin concentrations can act as a biomarker of appetite sensations as the relation is confounded or moderated by many metabolic processes (7).

The regulation of food intake and energy homeostasis involves, besides 'hunger' and 'satiety' signals, factors such as food reward, environmental cues, and cognitive factors, processed in cortico-limbic structures (e.g. prefrontal cortex, amygdala, ventral striatum) (29). Both pathways (hypothalamic and corticolimbic) interact in the neuro-regulatory control of feeding (29-31). In some situations, e.g. the abundance of palatable foods, the food reward system may overrule and promote excessive food intake and consequently in the long-term a positive energy balance $(6,32)$. Unraveling this food reward system may help us understand partly the factors that influence the excessive food intake associated with obesity $(30,33,34)$.

According to the incentive salience theory it is hypothesized that the process of reward consists of two components, i.e. 'liking' and 'wanting' (35). 'Liking' is the hedonic or affective component and refers to the pleasure derived from orosensory stimulation of food $(36,37)$. 'Wanting' is the motivational incentive component and refers to craving or the motivation to obtain food $(30,35-38)$. Often 'liking' and 'wanting' go hand-in-hand: we want what we like and like what we want (35). However, humans habitually may select less liked food items, as for example restrained eaters do: they cognitively restrict their food intake to loose weight or to prevent weight gain $(37,39)$. Furthermore, in research on drug addiction a distinction between the two components of reward was observed: some drug addicts are driven to take drugs without liking their effects $(40,41)$. Moreover, 'liking' and 'wanting' are thought to be controlled by different brain 
mechanisms according to the incentive salience model $(38,42)$. Mouse models showed that the brain mechanism attributed to 'liking' involves the neurotransmission of mu-opioid in the nucleus accumbens, ventral pallidum, parabrachial nucleus, and nucleus of the solitary tract (30). The brain mechanism attributed to 'wanting' involves the neurotransmission of dopamine in the prefrontal cortex, amygdala, hypothalamus, and projections from the ventral tegmental area to the nucleus accumbens (30). Taking the above into account, it is of importance to differentiate between the possible influence of 'liking' and 'wanting' on food intake (43).

Findings regarding brain reward circuitry in relation to obesity seem somewhat inconsistent (44). At present, two hypotheses concerning the involvement of the reward system in overeating are considered: the reward sensitivity hypothesis and the reward deficiency hypothesis (45-47). It has been shown that food intake increases extracellular dopamine concentration in the nucleus acumbens (48). According to the reward sensitivity hypothesis individuals with increased reward sensitivity are thought to have a more reactive striatal dopamine system (49). Consequently those individuals may have a greater capacity for reward and a stronger drive to engage in eating behavior (50). According to the reward deficiency hypothesis individuals with low levels of dopamine D2 receptors may increase their food consumption to compensate for the reward deficiency (51, 52). In severely obese individuals it has been shown that their BMI was inversely correlated with the dopamine D2 receptor availability in the striatum (51). However, it is still not clear whether the brain changes in obese individuals are a consequence or a cause of obesity, as alternatively, frequent eating may result in chronic extracellular dopaminergic overstimulation leading to downregulation of the dopamine D2 receptors (51).

Davis and Fox proposed an inverted- $U$ relationship between reward sensitivity and BMI (46). They indicated a positive relationship between reward sensitivity and BMI in normal weight and overweight subjects, and a negative relationship in moderately and morbidly obese subjects. On the one hand, low sensitivity to reward may induce a depressed appetite because of the low food reward and consequently a lower body weight (46). On the other hand, low sensitivity to reward may promote food intake to compensate for the dopamine deficiency in obese individuals (46). This overeating may result in an additional decrease in reward circuitry responsivity, thereby increasing risk for future weight gain (53). Individuals with high reward sensitivity may be prone to hedonic overeating, which may over time lead to weight gain and possibly a down-regulation of dopamine pathways and reward sensitivity (46).

Neuro-imaging data indicated that obese compared with lean subjects showed greater activation in the gustatory cortex (insula/frontal operculum) and oral somatosensory regions (parietal operculum and Rolandic operculum) in response to anticipation and consumption of food, but showed weaker activation in the striatum during consumption of palatable foods and reduced striatal dopamine D2 receptor density (44). Moreover, data indicated that BMI correlated 
with response inhibition: overweight compared with leaner subjects showed hypoactivation of frontal inhibitory regions, including superior frontal gyrus, middle frontal gyrus, ventrolateral prefrontal cortex, medial prefrontal cortex, and orbitofrontal cortex, and greater behavioral impulsivity in response to appetizing food-specific go/no-go task (54).

Taken together, it appears that the homeostasis of reward may be as important as energy homeostasis, or may be even more of importance in certain subject groups or under certain conditions.

\section{Measuring reward, i.e. 'liking' and 'wanting'}

Recent human studies have observed and characterized the distinction between the two components of reward, i.e. 'liking' and 'wanting' (37). 'Liking' has been measured by either subjective ratings on VAS or objective measures of facial affective expressions $(34,36,55)$. 'Wanting' has been measured by for example the forced choice methodology whereby food items were presented in pairs and responded to according to which food item was most wanted at that moment (33, 36). An alternative indirect measure for motivation was the assessment of the reinforcing value of food using progressive schedules of reinforcement $(34,56)$. The motivation was expressed as the willingness to work for amounts of a food of choice or alternate reinforcers such as money or sedentary activities. According to this approach the reinforcing value of food is associated with the 'wanting' of food (3).

When current methods for measurements of 'liking' and 'wanting' are applied in humans, culture specific motivation and reinforcement may have to be taken into account. This is especially of importance since distinguishing 'liking' from 'wanting' seems to be present to a different extent among cultures (57).

\section{Role of meal pattern in relation to hormone and appetite dynamics, and reward}

Among environmental and cognitive factors, which play a role in the development of obesity, eating out has become an important aspect (58). Out-ofhome consumption, compared with eating at home, often results in a larger food intake, which may be due to external factors such as meal duration, the availability of palatable high caloric foods, large portion sizes, the atmosphere, the presence of other people, or distraction, which lowers the possibility of estimating the energy density of the foods resulting in less well adaptation of portion sizes (59-62). On the other hand, physiological factors such as the dynamics of hunger and satiety and of related hormones during the meal may exert their feedback already during the meal and consequently influence food and energy intake. 
In habitual situations, e.g. at home, people consume a standard three- or fourcourse meal in about half-an-hour, but when people are having their meal served in a restaurant, consumption of the meal takes longer, e.g. two hours with withinmeal pauses of 20-30 min. Meal pattern manipulation might influence the homeostatic control system, involving 'hunger' and 'satiety' signals, as well as the concept of reward.

Relevant hormones that may sustain these patterns are GLP-1, PYY, and ghrelin. Regarding hormone dynamics, several studies have investigated the hormonal effects of different meal patterns, and overall they revealed greater hormone fluctuations following larger meals (non-staggered meal pattern), than after equi-energetic smaller, more frequent meals (staggered meal pattern) (6367). Regarding energy intake, a lower ad libitum energy-intake following a staggered meal pattern compared with a non-staggered meal pattern has been reported, as well as no difference between both meal patterns (68-70). Taking the above into account, there are still inconsistencies in the literature concerning the effects of meal pattern manipulation. On the one hand eating slowly by increasing meal duration can exert more control over food and energy intake through physiological feedback signals that appear already during the meal (65, $66,68,69)$. On the other hand, increased meal duration when eating out can exert less control over food and energy intake $(58,62)$. The question remains whether stimulated food intake through the social context of eating out is facilitated by a slower appearance of satiation signals, or whether it takes place despite greater appetite control by possibly more sustained satiety signals.

\section{Role of hypothalamus pituitary adrenal (HPA) axis activity in relation to reward}

The homeostasis of reward may appear more clearly in certain subject groups, such as the visceral obese, or under certain circumstances, such as stress (32, 71-76). Here the activity of the HPA axis in relation to the reward system comes into focus (32). The HPA axis is a neuro-endocrine system involved in the stress response, by regulating the secretion of its end-product cortisol (77). Chronic stress is associated with hyperactivity of the HPA axis and consequently increased cortisol levels, which have been associated with visceral fat accumulation and obesity (78-80).

Stress may influence food intake in two ways: in some individuals, such as individuals scoring high on dietary restraint or disinhibition, it increases food intake, while in other's it decreases food intake $(32,81-83)$. It appears that psychosocial stress is associated with greater weight gain among subjects who are overweight or obese, but less among subjects who are normal weight or underweight $(32,84,85)$.

It has been shown that acute psychological stress can lead to eating in the absence of hunger (83), which can be described as eating beyond energy 
homeostasis. Evidence for the involvement of the reward system, i.e. 'liking' and 'wanting', in stress-induced eating can be found in both rodent and human studies (73-76). Research regarding the endogenous opioid system, possibly involved in the process of 'liking', showed that administration of corticosterone in mice increased the expression of the $\mu$-opioid receptor and that mild stress in rats increased food intake by the enhanced release of opioids $(86,87)$. With respect to the dopamine system, possibly involved in the process of 'wanting', human research has shown mesolimbic dopamine release in response to an aversive stressful task (88). Moreover, in healthy normal weight subjects the tendency to eat when emotionally stressed was negatively correlated with dopamine D2 receptor availability (89). An fMRI study assessing the effects of acute stress on food choice and food choice reward related brain activity in normal weight women, showed a lower activation in the amygdala, hippocampus and cingulate cortex and an increased energy intake in the stress condition compared with the control condition postprandially (72). It seems that stress decreases the sensitivity of the reward system to food cues, which was reflected in a decreased activation of food reward associated brain areas, leading to an increased energy intake (72). Taking the above into account, it is likely that there is a relationship, though still complex, between HPA axis activity, reward and eating behavior.

The food choice in stress is often shifted towards sweet and fat foods, possibly because they are perceived as highly rewarding (83, 90-92). Consumption of those 'comfort foods' may be a way to cope with stress (93). However the risk is that chronic stress combined with a high-fat, high-carbohydrate diet may lead to abdominal obesity (93). Moreover, several endocrinological human and rodent studies showed that some of these preferred or highly rewarding foods, namely carbohydrates, may not reduce but even increase HPA-axis activity (94-96). They indicated that the cortisol response to consumption of carbohydrates was higher than the cortisol response to consumption of fats and/or proteins. Other studies, in contrast, showed increased cortisol levels induced by a protein-rich meal $(97,98)$, or neither a macronutrient-related difference in cortisol levels, nor a cortisol response to meal consumption $(99,100)$.

Consumption of foods, and more specifically foods with a certain macronutrient content, may influence, besides the HPA axis, the stress-induced psychological mood response (101). Increases in negative mood in response to stressors can lead to greater food intake $(83,102)$. Consumption of foods that improve the stress-induced mood state may prevent further intake of energy-dense foods. It has been shown that carbohydrate-rich, protein-poor foods improve mood and stress coping following acute stress-inducing tasks, only in stress-vulnerable subjects, possibly due to increased levels of brain tryptophan and serotonin $(103,104)$. Furthermore it has been shown that intake of tryptophan-rich hydrolyzed protein increased positive mood and dampened the cortisol response to acute stress (105). In our everyday life where stress is a pervasive factor, the 
development of functional foods, able to regulate the stress response, would be helpful to improve or maintain quality of life (106). However, taking the above into account, it is clear that the effects of macronutrients on the response of the HPA axis and on the psychological mood response are still controversial, and more research is needed.

\section{Outline of the thesis}

The research presented in this thesis deals with 'food intake meeting energy and reward homeostasis'.

The search for physiological biomarkers of appetite is currently very active. However, previous studies $(10,11,23-27)$ have based their correlation analyses of VAS ratings for appetite and gut hormone and glucose concentrations upon the calculated area under the curve or on the measured values per time point, not taking into account the factor time. For validation of VAS ratings with gut hormone and glucose concentrations we used a statistical approach including the factor time by concentrating on the within-subject relations of these observations. Moreover, we investigated whether changes in VAS scores are synchronized with, or lag behind or in front of changes in gut hormone and glucose concentrations (Chapter 2).

Regarding the concept of reward, we needed a valid tool to measure the rewarding value of food, i.e. 'liking' and 'wanting', in a Dutch study population and applicable in different study designs. Chapter 3 describes the validation of the computer test we developed to measure 'liking' and 'wanting'. In addition, we assessed how the rewarding value of a consumed food item possibly affects the rewarding value of any other food item in general. Unraveling such a relationship may explain the subject's subsequent food choice and consumption (Chapter 3 ). Subsequently, the computer test was applied in the assessment of the role of dietary restraint in control over 'wanting' following consumption of 'forbidden' food (Chapter 4).

Chapter 5 describes the role of meal pattern manipulation (staggered vs. nonstaggered meal consumption) on hormone and appetite dynamics, as well as on the concept of reward and energy intake. We tested the hypothesis that the hormonal release is less pronounced and steadier in the condition of staggered meal consumption compared with the condition of non-staggered meal consumption, thereby sustaining the appetite profile and decreasing subsequent food 'wanting' and energy intake.

Besides meal pattern manipulation, the activity of the HPA axis ('stress') may play a role in excessive energy intake, in relation to the food reward system. We hypothesized that visceral overweight subjects, compared with normal weight subjects, are more vulnerable to stress-induced eating and consequently the development of obesity. In those visceral overweight subjects acute stress may diminish food reward, inducing an increased intake of high caloric foods to obtain 
the same reward. Therefore we assessed in visceral overweight vs. normal weight subjects the effects of acute psychological stress on the rewarding value of food, in terms of 'liking' and 'wanting', and on food intake in a fasted as well as satiated state (Chapter 6).

In our everyday life where stress is a pervasive factor, the development of functional foods, able to regulate the physiological and psychological stress response, would be helpful to improve or maintain quality of life. There are still inconsistencies regarding the possible effects of macronutrients on HPA axis activity and on the stress-induced mood response. Therefore we investigated whether consumption of comparable iso-energetic meals with different macronutrient contents (high-protein vs. high-carbohydrate) affects the physiological cortisol and psychological mood response (Chapter 7). Moreover we investigated how consumption of high-protein vs. high-carbohydrate foods influences the rewarding value of food, i.e. 'liking' and 'wanting', and food choice and food intake, in an acute stressful situation (Chapter 8).

Finally, the results of the above-described studies are summarized and discussed in Chapter 9. 


\section{References}

1. Caballero B. The Global Epidemic of Obesity: An Overview. Epidemiol Rev. 2007 January 1, 2007;29(1):1-5.

2. Westerterp KR, Speakman JR. Physical activity energy expenditure has not declined since the 1980s and matches energy expenditures of wild mammals. Int J Obes. 2008;32:1256-63.

3. Giskes K, Van Lenthe F, Avendano-Pabon M, Brug J. A systematic review of environmental factors and obesogenic dietary intakes among adults: are we getting closer to understanding obesogenic environments? Obes Rev. 2010.

4. Mattes RD, Hollis J, Hayes D, Stunkard AJ. Appetite: Measurement and Manipulation Misgivings. J Am Diet Assoc. 2005;105(5, Supplement 1):87-97.

5. Edholm OG. Energy balance in man studies carried out by the Division of Human Physiology, National Institute for Medical Research. J Hum Nutr Diet. 1977;31(6):413-31.

6. Erlanson-Albertsson C. How palatable food disrupts appetite regulation. Basic Clin Pharmacol Toxicol. 2005 Aug;97(2):61-73.

7. de Graaf C, Blom WAM, Smeets PAM, Stafleu A, Hendriks HFJ. Biomarkers of satiation and satiety. Am J Clin Nutr. 2004 June 1, 2004;79(6):946-61.

8. Delzenne N, Blundell J, Brouns F, Cunningham K, De Graaf K, Erkner A, et al. Gastrointestinal targets of appetite regulation in humans. Obes Rev. 2010;11(3):234-50.

9. Flint A, Gregersen NT, Gluud LL, Møller BK, Raben A, Tetens I, et al. Associations between postprandial insulin and blood glucose responses, appetite sensations and energy intake in normal weight and overweight individuals: a meta-analysis of test meal studies. $\mathrm{Br} \mathrm{J}$ Nutr. 2007;95(1):17-25.

10. le Roux CW, Batterham RL, Aylwin SJB, Patterson M, Borg CM, Wynne KJ, et al. Attenuated Peptide YY Release in Obese Subjects Is Associated with Reduced Satiety. Endocrinology. 2006 January 1, 2006;147(1):3-8.

11. Verdich C, Flint A, Gutzwiller JP, Naslund E, Beglinger C, Hellstrom PM, et al. A Meta-Analysis of the Effect of Glucagon-Like Peptide-1 (7-36) Amide on Ad Libitum Energy Intake in Humans. J Clin Endocrinol Metab. 2001 September 1, 2001;86(9):4382-9.

12. Steinert RE, Poller B, Castelli MC, Drewe J, Beglinger C. Oral administration of glucagon-like peptide 1 or peptide YY 3-36 affects food intake in healthy male subjects. Am J Clin Nutr. 2010 August 18, 2010;92(4):810-7.

13. Druce MR, Neary NM, Small CJ, Milton J, Monteiro M, Patterson M, et al. Subcutaneous administration of ghrelin stimulates energy intake in healthy lean human volunteers. Int $\mathrm{J}$ Obes (Lond). 2006;30(2):293-6.

14. Druce MR, Wren AM, Park AJ, Milton JE, Patterson M, Frost G, et al. Ghrelin increases food intake in obese as well as lean subjects. Int J Obes (Lond). 2005;29(9):1130-6.

15. Blom WAM, Lluch A, Stafleu A, Vinoy S, Holst JJ, Schaafsma G, et al. Effect of a high-protein breakfast on the postprandial ghrelin response. Am J Clin Nutr. 2006 February 1, 2006;83(2):211-20.

16. Callahan HS, Cummings DE, Pepe MS, Breen PA, Matthys CC, Weigle DS. Postprandial Suppression of Plasma Ghrelin Level Is Proportional to Ingested Caloric Load but Does Not Predict Intermeal Interval in Humans. J Clin Endocrinol Metab. 2004 March 1, 2004;89(3):131924.

17. Thorens B. Glucose sensing and the pathogenesis of obesity and type 2 diabetes. Int $\mathrm{J}$ Obes (Lond). 2008;32 Suppl 6:S62-71.

18. Mayer J. Regulation of energy intake and the body weight: the glucostatic theory and the lipostatic hypothesis. Ann N Y Acad Sci. 1955;63(1):15-43.

19. Campfield LA, Smith FJ, Rosenbaum M, Hirsch J. Human eating: evidence for a physiological basis using a modified paradigm. Neurosci Biobehav Rev. 1996;20(1):133-7. 
20. Lavin JH, Wittert G, Sun WM, Horowitz M, Morley JE, Read NW. Appetite regulation by carbohydrate: role of blood glucose and gastrointestinal hormones. Am J Physiol Endocrinol Metab. 1996;271(2 Pt 1):E209-14.

21. Verdich $\mathrm{C}$, Toubro S, Buemann B, Lysgård Madsen J, Juul Holst J, Astrup A. The role of postprandial releases of insulin and incretin hormones in meal-induced satiety-effect of obesity and weight reduction. Int J Obes Relat Metab Disord. 2001;25(8):1206-14.

22. Flint A, Raben A, Blundell JE, Astrup A. Reproducibility, power and validity of visual analogue scales in assessment of appetite sensations in single test meal studies. Int $\mathrm{J}$ Obes Relat Metab Disord. 2000;25(1):38-48.

23. Diepvens K, Haberer D, Westerterp-Plantenga M. Different proteins and biopeptides differently affect satiety and anorexigenic/orexigenic hormones in healthy humans. Int $\mathrm{J}$ Obes (Lond). 2008 Mar;32(3):510-8.

24. Maffeis C, Surano MG, Cordioli S, Gasperotti S, Corradi M, Pinelli L. A High-fat vs. a Moderatefat Meal in Obese Boys: Nutrient Balance, Appetite, and Gastrointestinal Hormone Changes. Obesity. 2009;18(3):449-55.

25. Smeets AJ, Soenen S, Luscombe-Marsh ND, Ueland O, Westerterp-Plantenga MS. Energy Expenditure, Satiety, and Plasma Ghrelin, Glucagon-Like Peptide 1, and Peptide TyrosineTyrosine Concentrations following a Single High-Protein Lunch. J Nutr. 2008 April 1, 2008;138(4):698-702.

26. Erdmann J, Hebeisen Y, Lippl F, Wagenpfeil S, Schusdziarra V. Food intake and plasma ghrelin response during potato-, rice- and pasta-rich test meals. Eur J Nutr. 2007;46(4):196-203.

27. Guo Y, Ma L, Enriori PJ, Koska J, Franks PW, Brookshire T, et al. Physiological Evidence for the Involvement of Peptide $\mathrm{YY}$ in the Regulation of Energy Homeostasis in Humans. Obesity. 2006;14(9):1562-70.

28. Adam TC, Westerterp-Plantenga MS. Nutrient-stimulated GLP-1 release in normal-weight men and women. Horm Metab Res. 2005;37(2):111-7.

29. Berthoud HR. Homeostatic and non-homeostatic pathways involved in the control of food intake and energy balance. Obesity (Silver Spring). 2006 Aug;14 Suppl 5:197S-200S.

30. Berthoud HR. Neural control of appetite: cross-talk between homeostatic and non-homeostatic systems. Appetite. 2004 Dec;43(3):315-7.

31. Blundell JE, Finlayson $\mathrm{G}$. Is susceptibility to weight gain characterized by homeostatic or hedonic risk factors for overconsumption? Physiol Behav. 2004 Aug;82(1):21-5.

32. Dallman MF. Stress-induced obesity and the emotional nervous system. Trends Endocrinol Metab. 2010;21(3):159-65.

33. Finlayson G, King N, Blundell JE. Liking vs. wanting food: Importance for human appetite control and weight regulation. Neurosci Biobehav Rev. 2007 Mar 27.

34. Epstein LH, Truesdale R, Wojcik A, Paluch RA, Raynor HA. Effects of deprivation on hedonics and reinforcing value of food. Physiol Behav. 2003 Feb;78(2):221-7.

35. Berridge KC. Food reward: brain substrates of wanting and liking. Neurosci Biobehav Rev. 1996;20(1):1-25.

36. Finlayson G, King N, Blundell JE. Is it possible to dissociate 'liking' and 'wanting' for foods in humans? A novel experimental procedure. Physiol Behav. 2007 Jan 30;90(1):36-42.

37. Mela DJ. Eating for pleasure or just wanting to eat? Reconsidering sensory hedonic responses as a driver of obesity. Appetite. 2006 Jul;47(1):10-7.

38. Berridge KC. Motivation concepts in behavioral neuroscience. Physiol Behav. 2004 Apr;81(2):179-209.

39. Stunkard AJ, Messick S. The three-factor eating questionnaire to measure dietary restraint, disinhibition and hunger. J Psychosom Res. 1985;29(1):71-83.

40. Robinson TE, Berridge KC. Incentive-sensitization and addiction. Addiction. 2001 Jan;96(1):10314.

41. Berridge KC, Robinson TE. The Mind of an Addicted Brain: Neural Sensitization of Wanting Versus Liking. Current Directions in Psychological Science. 1995;4(3):71-6. 
42. Berridge KC, Ho CY, Richard JM, DiFeliceantonio AG. The tempted brain eats: pleasure and desire circuits in obesity and eating disorders. Brain Res. 2010;1350:53-64.

43. Epstein LH, Wright SM, Paluch RA, Leddy J, Hawk LW, Jr., Jaroni JL, et al. Food hedonics and reinforcement as determinants of laboratory food intake in smokers. Physiol Behav. 2004 May;81(3):511-7.

44. Stice E, Spoor S, Ng J, Zald DH. Relation of obesity to consummatory and anticipatory food reward. Physiol Behav. 2009;97(5):551-60.

45. Franken IHA, Muris P. Individual differences in reward sensitivity are related to food craving and relative body weight in healthy women. Appetite. 2005;45(2):198-201.

46. Davis C, Fox J. Sensitivity to reward and body mass index (BMI): Evidence for a non-linear relationship. Appetite. 2008;50(1):43-9.

47. Stice E, Yokum S, Bohon C, Marti N, Smolen A. Reward circuitry responsivity to food predicts future increases in body mass: Moderating effects of DRD2 and DRD4. Neuroimage. 2010;50(4):1618-25.

48. Bassareo V, Di Chiara G. Differential responsiveness of dopamine transmission to food-stimuli in nucleus accumbens shell/core compartments. Neuroscience. 1999;89(3):637-41.

49. Pickering AD, Gray JA. Dopamine, appetitive reinforcement, and the neuropsychology of human learning: An individual differences approach. A Eliasz, \& A Angleitner (Eds), Advances in individual differences research Lengerich, Germany: PABST Science Publishers. 2001:113-49.

50. Cohen MX, Young J, Baek J-M, Kessler C, Ranganath C. Individual differences in extraversion and dopamine genetics predict neural reward responses. Cogn Brain Res. 2005;25(3):851-61 .

51. Wang GJ, Volkow ND, Logan J, Pappas NR, Wong CT, Zhu W, et al. Brain dopamine and obesity. Lancet. 2001 Feb 3;357(9253):354-7.

52. Blum K, Braverman ER, Holder JM, Lubar JF, Monastra VJ, Miller D, et al. Reward deficiency syndrome: a biogenetic model for the diagnosis and treatment of impulsive, addictive, and compulsive behaviors. J Psychoactive Drugs. 2000;32 Suppl:i-iv:1-112.

53. Stice E, Yokum S, Blum K, Bohon C. Weight Gain Is Associated with Reduced Striatal Response to Palatable Food. J Neurosci. 2010 September 29, 2010;30(39):13105-9.

54. Batterink L, Yokum S, Stice E. Body mass correlates inversely with inhibitory control in response to food among adolescent girls: An fMRI study. Neurolmage. 2010;52(4):1696-703.

55. Steiner JE. Human facial expressions in response to taste and smell stimulation. Adv Child Dev Behav. 1979;13:257-95.

56. Lappalainen R, Epstein LH. A behavioral economics analysis of food choice in humans. Appetite. 1990 Apr;14(2):81-93.

57. Hofstede G. Culture's Consequences, Comparing Values, Behaviors, Institutions, and Organizations Across Nations. Thousand Oaks CA: Sage Publications; 2001.

58. Naska A, Orfanos P, Trichopoulou A, May AM, Overvad K, Jakobsen MU, et al. Eating out, weight and weight gain. A cross-sectional and prospective analysis in the context of the EPICPANACEA study. Int J Obes. 2010.

59. Hetherington MM, Anderson AS, Norton GN, Newson L. Situational effects on meal intake: A comparison of eating alone and eating with others. Physiol Behav. 2006 Jul 30;88(4-5):498-505.

60. Hetherington MM. Cues to overeat: psychological factors influencing overconsumption. Proc Nutr Soc. 2007 Feb;66(1):113-23.

61. Bellisle F, Dalix AM, Slama G. Non food-related environmental stimuli induce increased meal intake in healthy women: comparison of television viewing versus listening to a recorded story in laboratory settings. Appetite. 2004;43(2):175-80.

62. Stroebele N, De Castro JM. Effect of ambience on food intake and food choice. Nutrition. 2004;20(9):821-38.

63. Jenkins DJ, Ocana A, Jenkins AL, Wolever TM, Vuksan V, Katzman L, et al. Metabolic advantages of spreading the nutrient load: effects of increased meal frequency in non-insulindependent diabetes. Am J Clin Nutr. 1992 February 1, 1992;55(2):461-7. 
64. Jenkins DJA, Wolever TMS, Vuksan V, Brighenti F, Cunnane SC, Rao AV, et al. Nibbling versus Gorging: Metabolic Advantages of Increased Meal Frequency. N Engl J Med. 1989;321(14):92934.

65. Kokkinos A, le Roux CW, Alexiadou K, Tentolouris N, Vincent RP, Kyriaki D, et al. Eating slowly increases the postprandial response of the anorexigenic gut hormones, peptide $Y Y$ and glucagon-like peptide-1. J Clin Endocrinol Metab. 2010 Jan;95(1):333-7.

66. Solomon TP, Chambers ES, Jeukendrup AE, Toogood AA, Blannin AK. The effect of feeding frequency on insulin and ghrelin responses in human subjects. Br J Nutr. 2008 Oct;100(4):810-9.

67. Wolever TMS. Metabolic effects of continuous feeding. Metabolism. 1990;39(9):947-51.

68. Speechly DP, Buffenstein R. Greater appetite control associated with an increased frequency of eating in lean males. Appetite. 1999 Dec;33(3):285-97.

69. Speechly DP, Rogers GG, Buffenstein R. Acute appetite reduction associated with an increased frequency of eating in obese males. Int J Obes Relat Metab Disord. 1999 Nov;23(11):1151-9.

70. Taylor MA, Garrow JS. Compared with nibbling, neither gorging nor a morning fast affect shortterm energy balance in obese patients in a chamber calorimeter. Int $\mathrm{J}$ Obes Relat Metab Disord. 2001 Apr;25(4):519-28.

71. Rutters F, Nieuwenhuizen AG, Lemmens SG, Born JM, Westerterp-Plantenga MS. Hypothalamic-Pituitary-Adrenal (HPA) axis functioning in relation to body fat distribution. Clin Endocrinol (Oxf). 2010;72(6):738-43.

72. Born JM, Lemmens SGT, Rutters F, Nieuwenhuizen AG, Formisano E, Goebel R, et al. Acute stress and food-related reward activation in the brain during food choice during eating in the absence of hunger. Int J Obes. 2009 Oct 20.

73. Volkow ND, Wang GJ, Fowler JS, Telang F. Overlapping neuronal circuits in addiction and obesity: evidence of systems pathology. Philos Trans $R$ Soc Lond B Biol Sci. 2008;363(1507):3191-200.

74. Berridge KC. 'Liking' and 'wanting' food rewards: Brain substrates and roles in eating disorders. Physiology \& Behav. 2009;97(5):537-50.

75. Dallman MF, Pecoraro NC, La Fleur SE, Warne JP, Ginsberg AB, Akana SF, et al. Glucocorticoids, chronic stress, and obesity. Prog Brain Res. 2006;153:75-105.

76. Reynolds SM, Berridge KC. Emotional environments retune the valence of appetitive versus fearful functions in nucleus accumbens. Nat Neurosci. 2008;11(4):423-5.

77. Nieuwenhuizen AG, Rutters F. The hypothalamic-pituitary-adrenal-axis in the regulation of energy balance. Physiol Behav. 2007 Dec 23;94(2):169-77.

78. Torres SJ, Nowson CA. Relationship between stress, eating behavior, and obesity. Nutrition. 2007 Nov-Dec;23(11-12):887-94.

79. Bjorntorp P, Rosmond R. Obesity and cortisol. Nutrition. 2000 Oct;16(10):924-36.

80. Bjorntorp P. Do stress reactions cause abdominal obesity and comorbidities? Obes Rev. 2001 May;2(2):73-86.

81. Adam TC, Epel ES. Stress, eating and the reward system. Physiol Behav. 2007 Apr $14 ; 91(4): 449-58$.

82. Heatherton TF, Herman CP, Polivy J. Effects of Physical Threat and Ego Threat on Eating Behavior. J Pers Soc Psychol. 1991;60(1):138-43.

83. Rutters F, Nieuwenhuizen AG, Lemmens SG, Born JM, Westerterp-Plantenga MS. Acute stressrelated changes in eating in the absence of hunger. Obesity (Silver Spring). 2009 Jan;17(1):72-7.

84. Block JP, He Y, Zaslavsky AM, Ding L, Ayanian JZ. Psychosocial stress and change in weight among US adults. Am J Epidemiol. 2009;170(2):181-92.

85. Kivimäki M, Head J, Ferrie JE, Shipley MJ, Brunner EJ, Vahtera J, et al. Work stress, weight gain and weight loss: evidence for bidirectional effects of job strain on body mass index in the Whitehall II study. Int J Obes (Lond). 2006;30(6):982-7.

86. O'Hare E, Shaw DL, Tierney KJ, E-M K, Levine AS, Shephard RA. Behavioral and neurochemical mechanisms of the action of mild stress in the enhancement of feeding. Behav Neurosci. 2004 Feb;118(1):173-7. 
87. Yoshida M, Koyanagi S, Matsuo A, Fujioka T, To H, Higuchi S, et al. Glucocorticoid hormone regulates the circadian coordination of micro-opioid receptor expression in mouse brainstem. $J$ Pharmacol Exp Ther. 2005 Dec;315(3):1119-24.

88. Pruessner JC, Champagne F, Meaney MJ, Dagher A. Dopamine release in response to a psychological stress in humans and its relationship to early life maternal care: a positron emission tomography study using [11C]raclopride. J Neurosci. 2004 Mar 17;24(11):2825-31.

89. Volkow ND, Wang GJ, Maynard L, Jayne M, Fowler JS, Zhu W, et al. Brain dopamine is associated with eating behaviors in humans. Int J Eat Disord. 2003;33(2):136-42.

90. Garg N, Wansink B, Inman J. The Influence of Incidental Affect on Consumers' Food Intake. Journal of Marketing. 2007;71(1):194-206.

91. Oliver G, Wardle J, Gibson EL. Stress and food choice: a laboratory study. Psychosom Med. 2000 Nov-Dec;62(6):853-65.

92. Zellner DA, Loaiza S, Gonzalez Z, Pita J, Morales J, Pecora D, et al. Food selection changes under stress. Physiol Behav. 2006 Apr 15;87(4):789-93.

93. Kuo LE, Czarnecka M, Kitlinska JB, Tilan JU, Kvetnansky R, Zukowska Z. Chronic stress, combined with a high-fat/high-sugar diet, shifts sympathetic signaling toward neuropeptide $Y$ and leads to obesity and the metabolic syndrome. Ann N Y Acad Sci. 2008 Dec;1148:232-7.

94. Lacroix M, Gaudichon C, Martin A, Morens C, Mathe V, Tome D, et al. A long-term high-protein diet markedly reduces adipose tissue without major side effects in Wistar male rats. Am J Physiol Regul Integr Comp Physiol. 2004 Oct;287(4):R934-42.

95. Martens MJ, Rutters F, Lemmens SG, Born JM, Westerterp-Plantenga MS. Effects of single macronutrients on serum cortisol concentrations in normal weight men. Physiol Behav. 2010; Epub ahead of print.

96. Vicennati V, Ceroni L, Gagliardi L, Gambineri A, Pasquali R. Comment: response of the hypothalamic-pituitary-adrenocortical axis to high-protein/fat and high-carbohydrate meals in women with different obesity phenotypes. J Clin Endocrinol Metab. 2002 Aug;87(8):3984-8.

97. Gibson EL, Checkley S, Papadopoulos A, Poon L, Daley S, Wardle J. Increased Salivary Cortisol Reliably Induced by a Protein-Rich Midday Meal. Psychosom Med. 1999 March 1, 1999;61(2):214-24.

98. Slag MF, Ahmad M, Gannon MC, Nuttall FQ. Meal stimulation of cortisol secretion: a protein induced effect. Metabolism. 1981;30(11):1104-8.

99. Gonzalez-Bono E, Rohleder N, Hellhammer DH, Salvador A, Kirschbaum C. Glucose but Not Protein or Fat Load Amplifies the Cortisol Response to Psychosocial Stress. Horm and Behav. 2002;41(3):328-33.

100. Lovallo WR, Farag NH, Vincent AS, Thomas TL, Wilson MF. Cortisol responses to mental stress, exercise, and meals following caffeine intake in men and women. Pharmacol Biochem Behav. 2006;83(3):441-7.

101. Gibson LE. Emotional influences on food choice: Sensory, physiological and psychological pathways. Physiol Behav. 2006;89(1):53-61.

102. Epel E, Lapidus R, McEwen B, Brownell K. Stress may add bite to appetite in women: a laboratory study of stress-induced cortisol and eating behavior. Psychoneuroendocrinology. 2001 Jan;26(1):37-49.

103. Markus CR, Panhuysen G, Tuiten A, Koppeschaar H, Fekkes D, Peters ML. Does Carbohydraterich, Protein-poor Food Prevent a Deterioration of Mood and Cognitive Performance of Stressprone Subjects when Subjected to a Stressful Task? Appetite. 1998;31(1):49-65.

104. Markus R, Panhuysen G, Tuiten A, Koppeschaar H. Effects of food on cortisol and mood in vulnerable subjects under controllable and uncontrollable stress. Physiol Behav. 2000;70(34):333-42.

105. Firk C, Markus CR. Mood and cortisol responses following tryptophan-rich hydrolyzed protein and acute stress in healthy subjects with high and low cognitive reactivity to depression. Clin Nutr. 2009;28(3):266-71. 


\section{Chapter 2}

\section{Changes in gut hormone and glucose concentrations in relation to hunger and fullness}

Lemmens SG, Martens EA, Kester AD, Westerterp-Plantenga MS

Submitted for publication 


\section{Abstract}

The search for physiological biomarkers of appetite is currently very active.

The aim of this study was to compare the dynamics of hunger/fullness ratings (visual analogue scales (VAS)) with GLP-1, PYY, ghrelin, glucose, and insulin concentrations, using a statistical approach that focuses on within-subject relations of these observations; and to investigate whether appetite ratings are synchronized with, or lag behind/in front of changes in hormone and glucose concentrations.

Subjects $\left(n=38\right.$, age $\left.=24 \pm 6 y, B M I=25.1 \pm 3.1 \mathrm{~kg} / \mathrm{m}^{2}\right)$ came to the university twice for consumption of a four-course lunch (40\% of the daily energy requirements) in $0.5 \mathrm{~h}$, or in $2 \mathrm{~h}$ with three within-meal pauses (randomized cross-over design). Throughout the test sessions VAS scores and hormone and glucose concentrations were measured. For each subject regression slopes and $R^{2}$ values for the regression of VAS scores on hormone and glucose concentrations were calculated. Subsequently we tested whether the means of the regression slopes were different from zero.

VAS scores and hormone and glucose concentrations changed synchronously $\left(p<0.01 ; R^{2}=0.3-0.7\right)$. Changes in ghrelin concentrations lagged behind $(10-30$ min) changes in hunger scores and insulin concentrations $\left(p<0.0001 ; R^{2}=0.6\right.$ 0.7 ), suggesting a role for insulin as negative regulator of ghrelin.

In conclusion, this method may be useful for understanding possible differences in relations between VAS scores and hormone and glucose concentrations between subjects or between conditions. Yet the reported explained variation of $30-70 \%$ seems too small to use hormone or glucose concentrations as appropriate biomarkers for appetite, at least at the individual level and probably at group level. 


\section{Introduction}

The regulation of energy intake and appetite is a complex process involving, besides environmental and behavioral factors, physiological factors such as the dynamics of gastrointestinal hormones and the possibly related feelings of hunger and fullness (1-3). The search for physiological biomarkers of appetite is currently very active. Relevant potential biomarkers related to appetite, i.e. hunger and fullness, may be the anorexigenic peptides glucagon-like peptide (GLP)-1 and peptide tyrosine-tyrosine (PYY), the orexigenic gut peptide ghrelin, and glucose and insulin $(4,5)$. GLP-1 and PYY are released from the endocrine $L$ cells of the ileum and the colon, and appear to reduce appetite $(4,6,7)$. Ghrelin is a peptide secreted primarily by the stomach, and appears to increase appetite $(8,9)$. Glucose is hypothesized to play a role in meal initiation, as feeding is usually preceded by a decrease in blood glucose concentrations. (1013). Glucose triggers insulin secretion by the $\beta$ cells of the pancreatic islets (10, 11). Similar to blood glucose, insulin has been hypothesized to be involved in appetite regulation $(14,15)$.

Measured feelings of appetite expressed as ratings on visual analogue scales (VAS) have shown to be highly reproducible and therefore reliable (16). However, a possible association between VAS appetite ratings and physiological measures remains subject of debate. Several studies showed no relationship between appetite ratings and endogenous GLP-1, PYY, and ghrelin concentrations (17-19), while others found significant correlations $\left(p<0.05, R^{2}<0.3\right)$ at a few time points or for the area under the curve (AUC) $(6,20-22)$. The latter papers suggest a relationship between appetite ratings and gastrointestinal hormone concentrations, although correlation coefficients are mostly too low to presume that the gastrointestinal hormones may serve as a reliable biomarker. Regarding glucose and insulin concentrations, a meta-analysis by Flint et al. showed that insulin concentrations were inversely correlated with feelings of hunger $\left(p<0.02, R^{2}<0.1\right)$, while glucose concentrations were not correlated with feelings of hunger or satiety (5). Literature has indicated that it is not clear yet whether blood glucose and insulin concentrations can act as biomarkers of appetite as the relation is confounded by many metabolic processes $(5,11)$.

In the studies cited above $(5,6,17-22)$ correlation analyses were based upon the calculated AUC or on the measured values per time point, not taking into account the factor time. The objective of our study was to compare the dynamics of VAS hunger and fullness ratings with GLP-1, PYY, ghrelin, glucose, and insulin concentrations, using a statistical approach that includes the factor time by concentrating on the within-subject relations of these observations. Moreover, we investigated whether the changes in VAS scores are synchronized with, or lag behind or in front of the changes in hormone and glucose concentrations. The study design comprised consumption of a four-course lunch spread over two hours (staggered), and consumption of the same four-course lunch in half-an- 
hour (non-staggered). This design gave us the ability to measure and compare postprandial appetite and hormone and glucose dynamics throughout different meal patterns and thereby different timings of nutrient delivery to the gut.

\section{Materials and Methods}

\section{Subjects}

Thirty-eight healthy Caucasian subjects (18m/20f; age $24 \pm 6$ y (mean $\pm S D$, range 18-49 y)) with a body mass index (BMI) of $25.1 \pm 3.1 \mathrm{~kg} / \mathrm{m}^{2}$ (mean $\pm \mathrm{SD}$, range 19.5-30.1 kg/m ${ }^{2}$ ) participated in this study. They were recruited by advertisements in local newspapers and on notice boards at the university. Subjects underwent an initial screening including measurement of body weight, and height, and completion of a questionnaire related to health, use of medication, smoking behavior, alcohol consumption, physical activity and eating behavior (Dutch translation of the Three Factor Eating Questionnaire) (23). All subjects gave written informed consent. The study was approved by the Medical Ethical Committee of the Maastricht University, and was in accordance with the Helsinki Declaration of 1975 as revised in 1983.

\section{Study design}

The study was conducted in a randomized cross-over design. All subjects came to the university twice, on two separate days at least one week apart, in a fasted state for either condition: four-course meal consumption in $0.5 \mathrm{~h}$ without withinmeal pauses (non-staggered meal condition) vs. four-course meal consumption in $2 \mathrm{~h}$ with three within-meal pauses of 20-25 min (staggered meal condition). The order of the two conditions was randomized across the subjects to prevent any order effects.

In the morning $(08: 00 \mathrm{~h})$ all subjects consumed a standardized breakfast drink at home, and were instructed not to consume any foods or beverages following consumption of the drink. Subjects arrived at the university before lunchtime, at 11:00 h. An intravenous catheter was inserted into the antecubital vein for blood sampling, for measurement of plasma GLP-1, PYY, ghrelin, glucose, and insulin concentrations.

Consumption of the four-course lunch started at 12:00 h. During the course of the two test days, subjects were seated separately and remained seated, blood samples were drawn, and VAS on appetite were completed.

All women were tested in the follicular phase, as it has been shown that women have a higher spontaneous energy intake in the luteal phase compared with the follicular phase $(24,25)$. 


\section{Test meals}

Table 1 gives an overview of the nutritional information of the foods consumed on the test days. Beforehand, during screening, subjects had rated the food items for subjective liking (VAS), in order to check whether all food items were acceptable. All food items were scored more then $60 \mathrm{~mm}$ on a $100 \mathrm{~mm}$ VAS.

In the morning, subjects consumed a standardized breakfast drink at home ('Campina Goede morgen ontbijtdrink'). The amount of the breakfast drink subjects had to consume corresponded to $10 \%$ of their individual daily energy requirements (DER). For each subject the DER were calculated by multiplying the basal metabolic rate (BMR) by the appropriate physical activity factor (1.51.8 , derived from the screening questionnaire, (26)). The BMR (kcal/day) was calculated according to the equation of Harris-Benedict (27).

The lunch consisted of a four-course meal, i.e. a salad (iceberg lettuce, mozzarella, tomato, croutons, and dressing) with a slice of white bread as a starter, macaroni Bolognese as the first part of the main course, vegetable lasagna as the second part of the main course, and raspberry pudding as a dessert. The energy density of the total four-course meal was $5.0 \mathrm{~kJ} / \mathrm{g}$ and comprised $14 \%$ protein, $54 \%$ carbohydrate, and $32 \%$ fat. The amount of the four-course meal subjects had to consume corresponded to $40 \%$ of their DER $(5.0 \pm 0.1 \mathrm{MJ}$; starter $8.0 \%$, first part main course $12.0 \%$, second part main course $11.6 \%$, and dessert $8.4 \%$ of the DER).

During the staggered meal condition, the starter and the first part of the main course were consumed between 12:00 $\mathrm{h}$ and 13:00 $\mathrm{h}$, while the second part of the main course and the dessert were consumed between 13:00 $\mathrm{h}$ and 14:00 $\mathrm{h}$. The amount of energy (20\% of the DER) and the energy density $(5.0 \mathrm{~kJ} / \mathrm{g})$ of the foods consumed between 12:00 $\mathrm{h}$ and 13:00 $\mathrm{h}$, and of the foods consumed between 13:00 $\mathrm{h}$ and 14:00 $\mathrm{h}$, were equal.

During the non-staggered meal condition subjects had $0.5 \mathrm{~h}$ to consume the four-course meal. During the staggered meal condition the courses were offered at 12:00 h, 12:35 h, 13:10 h, and 13:40 h (time points 0, 35, 70, and $100 \mathrm{~min}$ ) and subjects had $10 \mathrm{~min}$ to consume each course. All subjects were instructed to consume the entire amount of food presented.

Each participant was given $14.3 \mathrm{ml} / \mathrm{kg}$ water to consume ad libitum throughout the test days (28). 
Table 1. The nutritional information of foods (per $100 \mathrm{~g}$ ) as consumed on the test days.

\begin{tabular}{llcccr}
\hline & & Energy $(\mathrm{kJ})$ & Protein $(\mathrm{g})$ & Carbohydrate $(\mathrm{g})$ & Fat $(\mathrm{g})$ \\
\hline \multirow{3}{*}{ Course 1 } & Breakfast drink & 300 & 70.0 & 3.0 & 11.7 \\
& Iceberg lettuce & 42 & 0.9 & 1.2 & 0.0 \\
& Mozarella & 998 & 18.0 & 1.5 & 18.0 \\
& Tomato & 58 & 0.9 & 1.9 & 0.0 \\
& Croutons & 2370 & 7.0 & 49.0 & 40.0 \\
& Dressing & 950 & 0.6 & 9.6 & 21.0 \\
& White bread & 1144 & 9.7 & 51.3 & 2.9 \\
Course 2 & Macaroni bolognese & 396 & 3.5 & 15.4 & 1.9 \\
Course 3 & Vegetable lasagna & 501 & 4.8 & 12.8 & 5.5 \\
\hline
\end{tabular}

\section{Appetite profile}

One hundred unit VAS $(\mathrm{mm})$ were used to assess the appetite profile. The scales were anchored with 'not at all' at one end and 'extremely' at the other end, and combined with questions on feelings of hunger and fullness.

The VAS were completed five times throughout the test day with the nonstaggered meal condition, at $-10,35,65,95$, and $125 \mathrm{~min}$, and seven times throughout the test day with the staggered meal condition, at $-10,20,50,65,85$, 95 , and $110 \mathrm{~min}$.

\section{Blood sampling}

Venous blood samples were collected into EDTA tubes, five times during the test day with the non-staggered meal condition, at $-5,30,60,90$, and $120 \mathrm{~min}$, and nine times during the test day with the staggered meal condition, at $-5,15,30$, $45,60,75,90,105$, and $120 \mathrm{~min}$. Blood samples were drawn to determine concentrations of plasma GLP-1, PYY, ghrelin, glucose, and insulin.

For GLP-1 analysis, blood was collected into EDTA tubes to which dipeptidyl peptidase IV inhibitor ( $10 \mu \mathrm{l} / \mathrm{mL}$ blood) was added. For PYY analysis, blood was collected into EDTA tubes in which dipeptidyl peptidase IV inhibitor $(10 \mu \mathrm{L} / \mathrm{mL}$ blood) and aprotinin (500 KIU/mL blood) was added. After collection, blood samples were centrifuged for $10 \mathrm{~min}$ at $4{ }^{\circ} \mathrm{C}$ at $3000 \mathrm{rpm}$. For ghrelin analysis, phenylmethylsulfonyl fluoride, dissolved in methanol, and hydrochloric acid were added to the plasma. Plasma samples were immediately frozen in liquid nitrogen and stored at $-80^{\circ} \mathrm{C}$ until analysis. Plasma concentrations of PYY and active ghrelin were measured by RIA (Linco Research Inc, St Charles, MO) and those of active GLP-1 by ELISA (EGLP-35K; Linco Research Inc, St Charles, MO). Plasma glucose concentrations were analyzed enzymatically by using the hexokinase method (ABX Diagnostics, Montpellier, France). Plasma insulin con- 
centrations were measured by means of RIA according to the manufacturer's instructions (Human insulin-specific RIA kit, Millipore, Billerica, 170 Massachusetts, USA).

\section{Statistics}

Data were analyzed using StatView 5.0 (SAS Institute Inc., Cary, NC, USA) To assess the strength of the within-subject relation between changes in VAS scores for hunger and fullness and hormone and glucose concentrations, we calculated, separately for each subject, regression slopes and $R^{2}$ values for the regression of VAS scores on hormone and glucose concentrations, for the corresponding measuring moments (fullness vs. GLP-1, fullness vs. PYY, hunger vs. ghrelin, fullness vs. glucose, fullness vs. insulin). To investigate whether the changes in VAS scores were synchronized with, or lag behind or in front of the changes in hormone and glucose concentrations, the analysis was repeated with the VAS score vs. the hormone and glucose concentration of the previous ('times shift -1 ', 'time shift -2 ') and of the following measuring moments ('time shift +1 ', 'time shift +2 '). We presented the mean, a $95 \%$ confidence interval for the mean and interquartile ranges (Q1-Q3) of the observed slopes and $R^{2}$ values. Student's one-sample t-tests were used to test whether the means of the regression slopes were different from zero. All tests were two-sided and differences were considered significant at $p<0.01$. Values are expressed as mean \pm standard error of the mean (SEM), unless stated otherwise.

\section{Results}

We presented the means, confidence intervals for the means, and interquartile ranges of the observed slopes and $\mathrm{R}^{2}$ values for the within-subject relations between VAS hunger scores and fullness scores and hormone and glucose concentrations, synchronized and with time shifts, in the staggered and nonstaggered meal conditions (Table 2-4). The measured p-values (Student's onesample t-test) indicated whether the means of the regression slopes were different from zero (Table 2-4).

\section{Fullness scores and GLP-1 concentrations over time}

In the staggered meal condition the synchronized relationship between VAS fullness scores and GLP-1 concentrations (Table 2, Figure 1A) became stronger when a time shift ' +1 ' (changes in GLP-1 concentrations lagging behind changes in VAS fullness scores by approximately $10 \mathrm{~min}$ ) was applied (Table 3), though the regression slopes and $R^{2}$ values were not significantly different (synchronized vs. 'time shift +1 '; $p>0.2$; paired Student's t-test). 
In the non-staggered meal condition GLP-1 concentrations changed synchronously with VAS fullness scores (Table 2, Figure 1B).
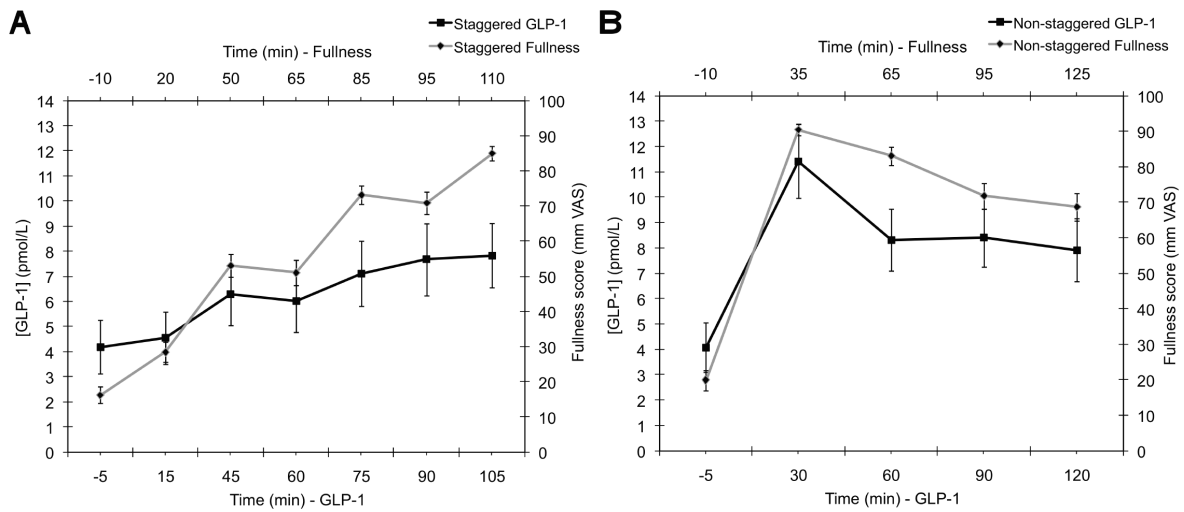

Figure 1. Plasma GLP-1 concentrations and VAS fullness scores (mean $\pm S E M ; n=38$; synchronized) in the staggered $(A)$ and non-staggered $(B)$ meal condition.

\section{Fullness scores and PYY concentrations over time}

In the staggered meal condition the synchronized relationship between VAS fullness scores and PYY concentrations (Table 2, Figure 2A) became stronger when a time shift ' +1 ' and ' +2 ' (changes in PYY concentrations lagging behind changes in VAS fullness scores by approximately 10-25 min) was applied (Table $3)$, though the regression slopes and $R^{2}$ values were not significantly different (synchronized vs. 'time shift+1' and 'time shift +2 '; $p>0.3$; paired Student's t-test). In the non-staggered meal condition PYY concentrations changed synchronously with VAS fullness scores (Table 2, Figure 2B).

A

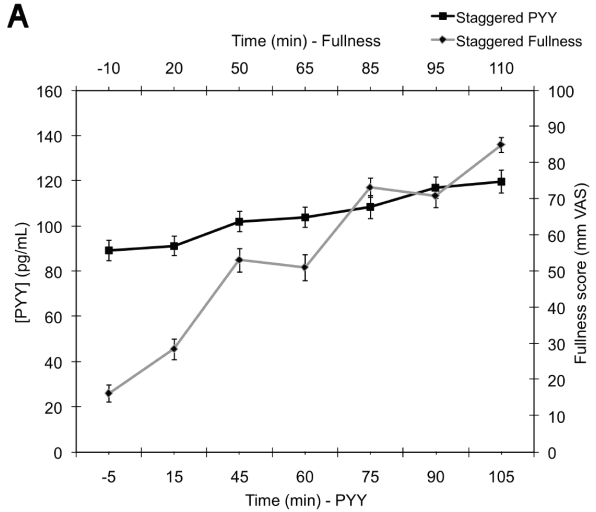

B $\rightarrow$ Non-staggered PYY

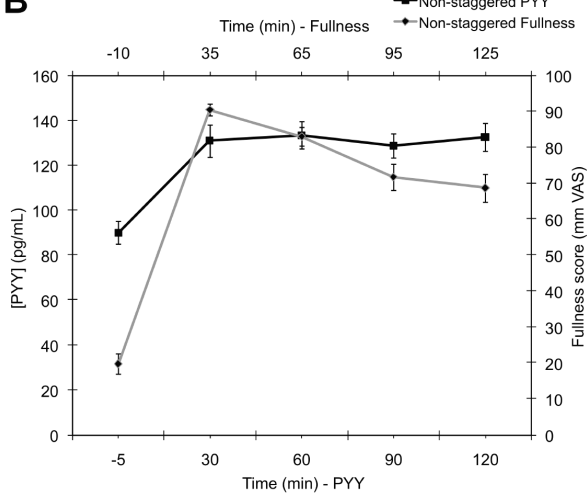

Figure 2. Plasma PYY concentrations and VAS fullness scores (mean $\pm S E M ; n=38$; synchronized) in the staggered $(A)$ and non-staggered $(B)$ meal condition. 


\section{Hunger scores and ghrelin concentrations over time}

In both the staggered and non-staggered meal condition the relationship between VAS hunger scores and ghrelin concentrations was the strongest when a time shift ' +1 ' was applied (Table 3, Figure 3A-D), indicating that the hormone concentrations lag behind the VAS scores by approximately 10-25 min.

A

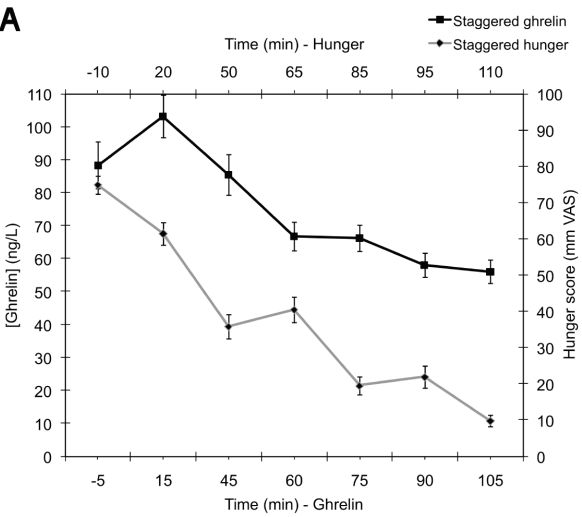

C

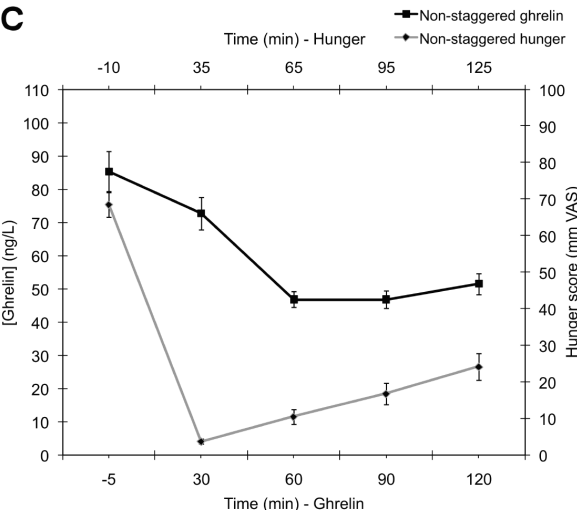

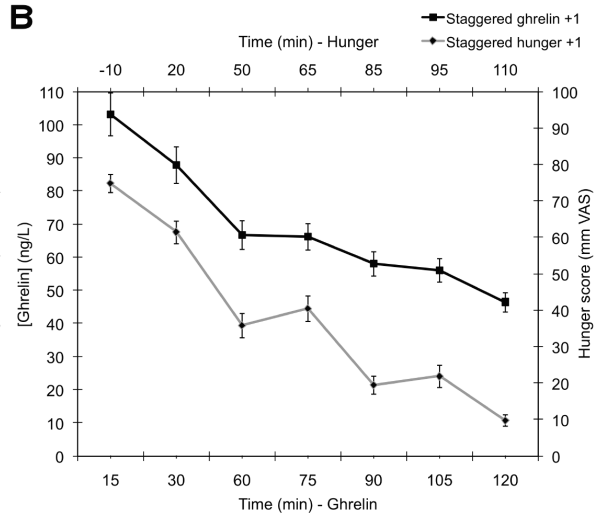
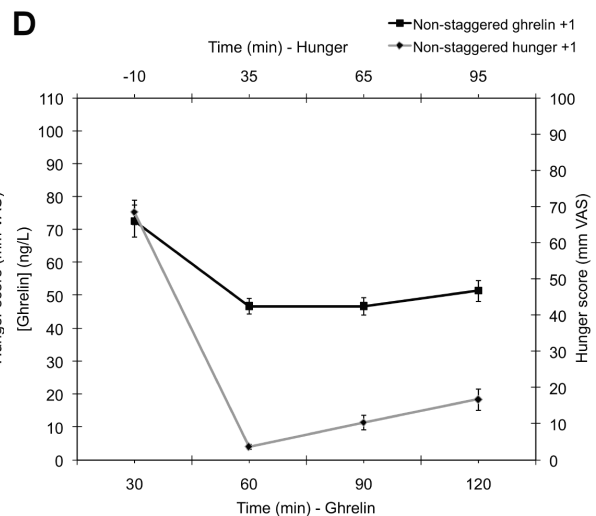

Figure 3. Plasma ghrelin concentrations and VAS hunger scores (mean $\pm S E M ; n=38$ ) in the staggered (synchronized $(A)$ and 'time shift +1 ' $(B)$ ) and non-staggered (synchronized (C) and 'time shift $\left.+1^{\prime}(D)\right)$ meal condition.

\section{Fullness scores and glucose concentrations over time}

In the staggered meal condition the synchronized relationship between VAS fullness scores and glucose concentrations (Table 2, Figure 4A) was the strongest when a time shift ' -1 ' (changes in VAS fullness scores lagging behind changes in glucose concentrations by approximately $20 \mathrm{~min}$ ) was applied (Table 4 ), though the regression slopes were not significantly different (synchronized vs. 'time shift -1'; $p>0.1$; paired Student's t-test). 
In the non-staggered meal condition glucose concentrations changed synchronously with VAS fullness scores (Table 2, Figure 4B).
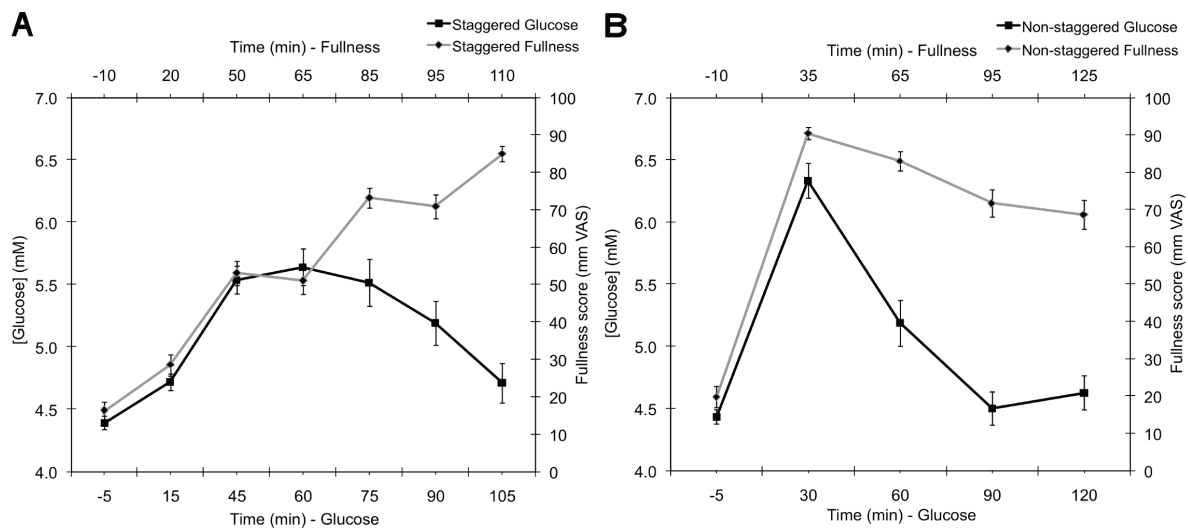

Figure 4. Plasma glucose concentrations and VAS fullness scores (mean $\pm S E M ; n=38$; synchronized) in the staggered $(A)$ and non-staggered meal condition $(B)$.

\section{Fullness scores and insulin concentrations over time}

In both the staggered and non-staggered meal condition insulin concentrations changed synchronously with VAS fullness scores (Table 2, Figure 5A-B).
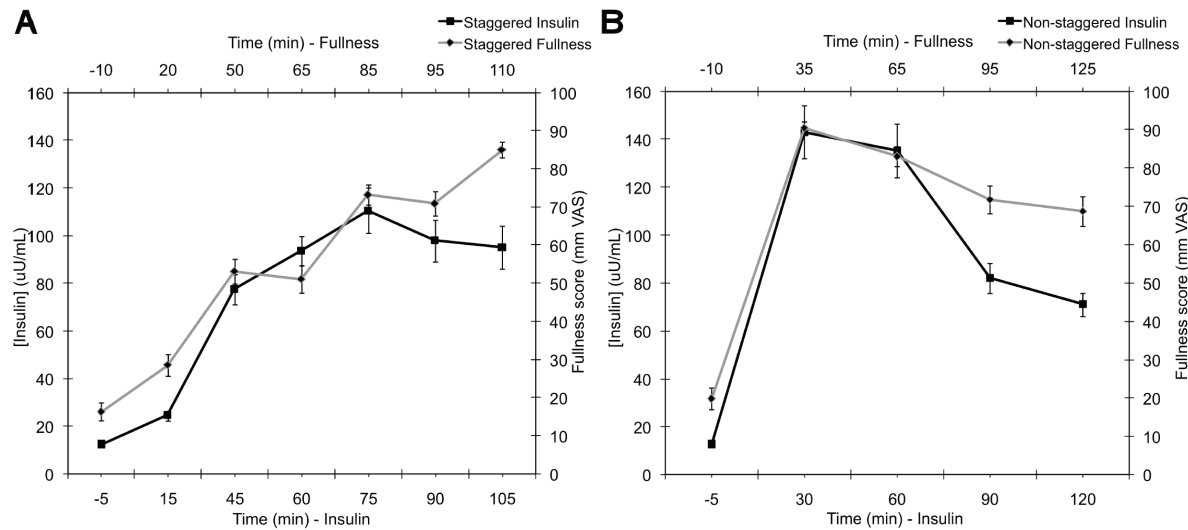

Figure 5. Plasma insulin concentrations and VAS fullness scores (mean $\pm S E M ; n=38$; synchronized) in the staggered $(A)$ and non-staggered meal condition $(B)$.

Regarding the ghrelin response we showed that meal consumption induced a delayed ghrelin suppressive response by 10-25 min. Several studies showed that insulin is required for postprandial ghrelin suppression (29-31). Moreover, Solomon et al. documented that there is a delay (of approximately $20 \mathrm{~min}$ ) between responses of insulin and ghrelin, insulin leading ghrelin (28). Therefore, we analyzed the strength of the within-subject relation between ghrelin and insu- 
lin concentrations, using the same statistics as for the analyses of the strength of the within-subject relation between VAS appetite scores and hormone and glucose concentrations. The analyses revealed that in both the staggered and non-staggered meal condition the synchronized relationship between ghrelin and insulin concentrations (Table 2; Figure 6A, 6C) became stronger when a time shift '-1' was applied (Table 4; Figure 6B, 6D), indicating that the ghrelin concentrations lag behind the insulin concentrations by approximately 15-30 min.

A

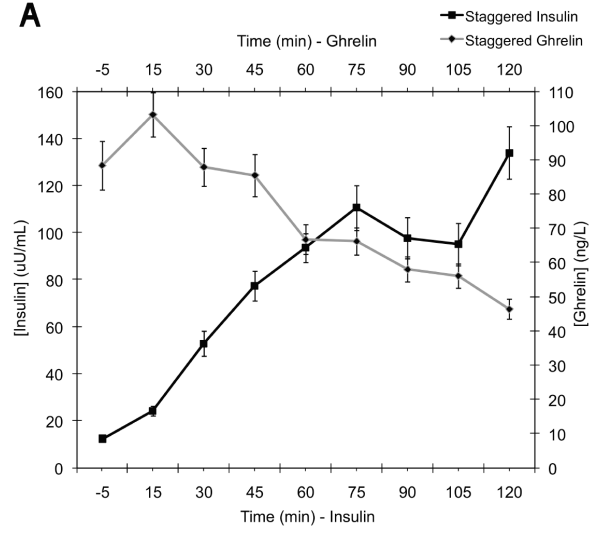

C
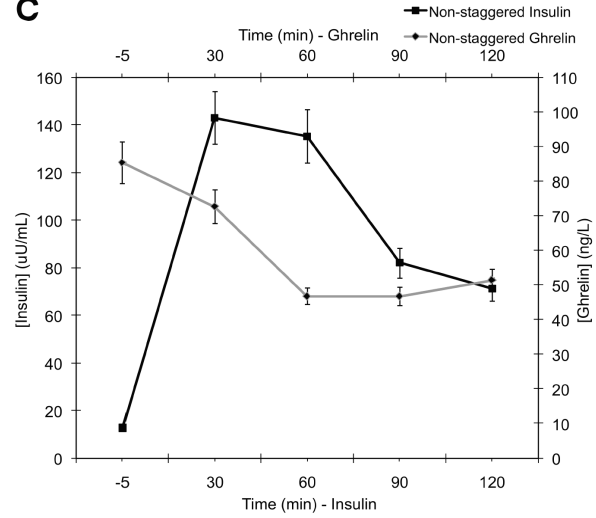

B
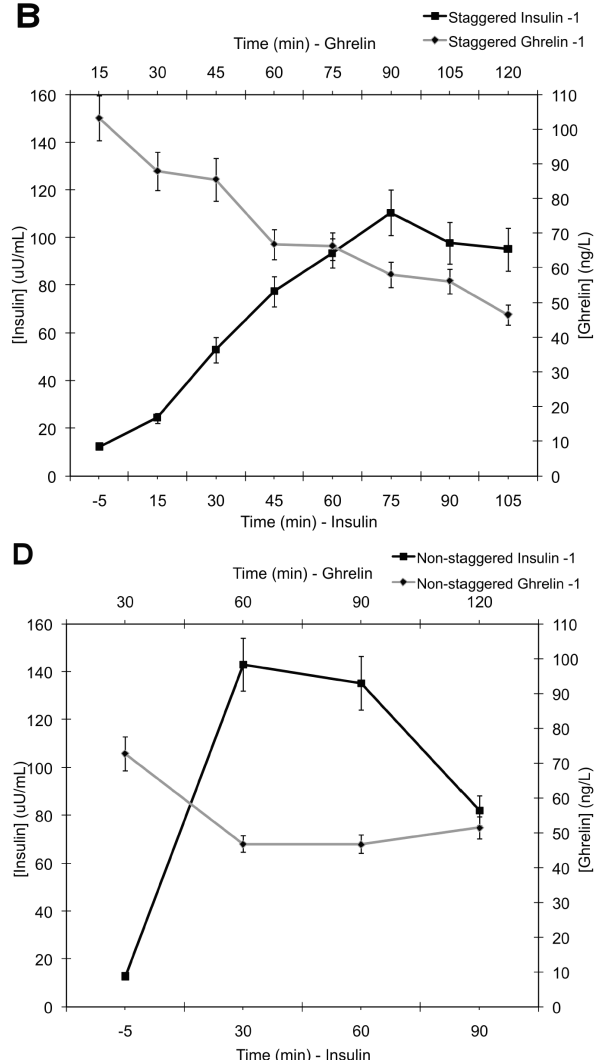

Figure 6. Plasma insulin and ghrelin concentrations (mean $\pm S E M ; n=38$ ) in the staggered (synchronized (A) and 'time shift -1' (B)) and non-staggered (synchronized (C) and 'time shift -1' (D)) meal condition. 


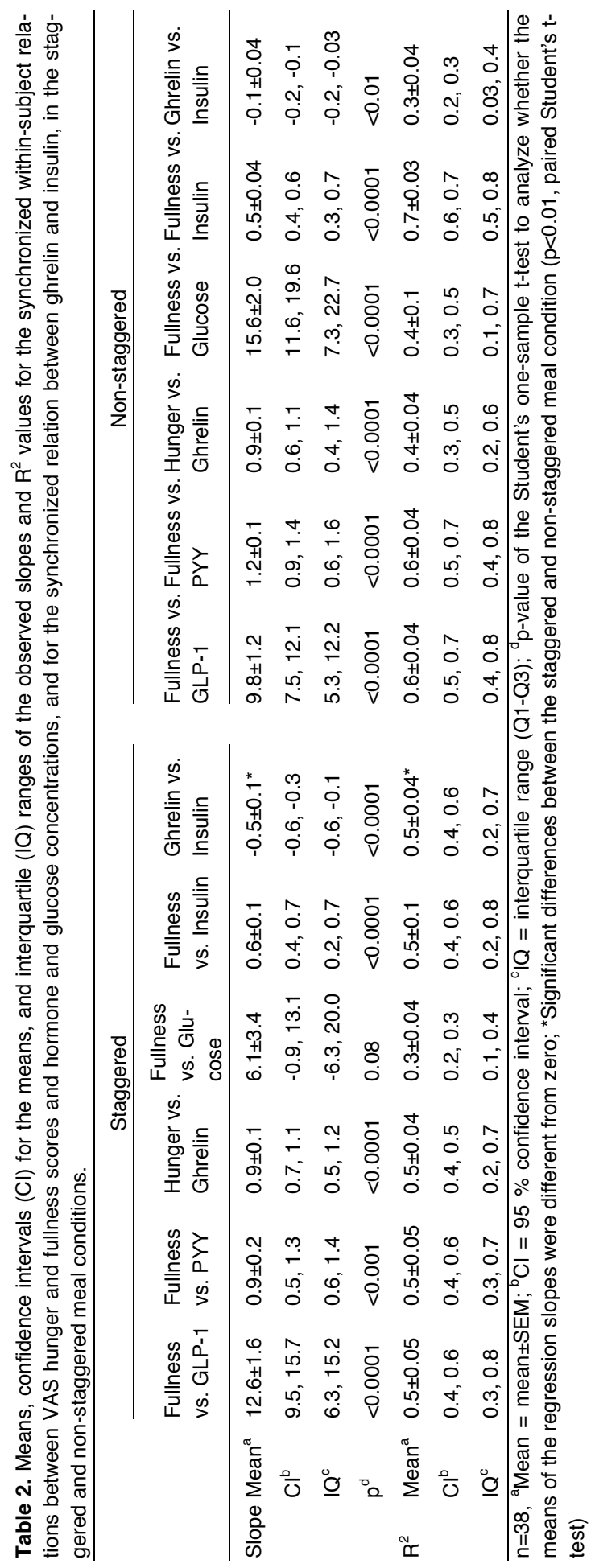




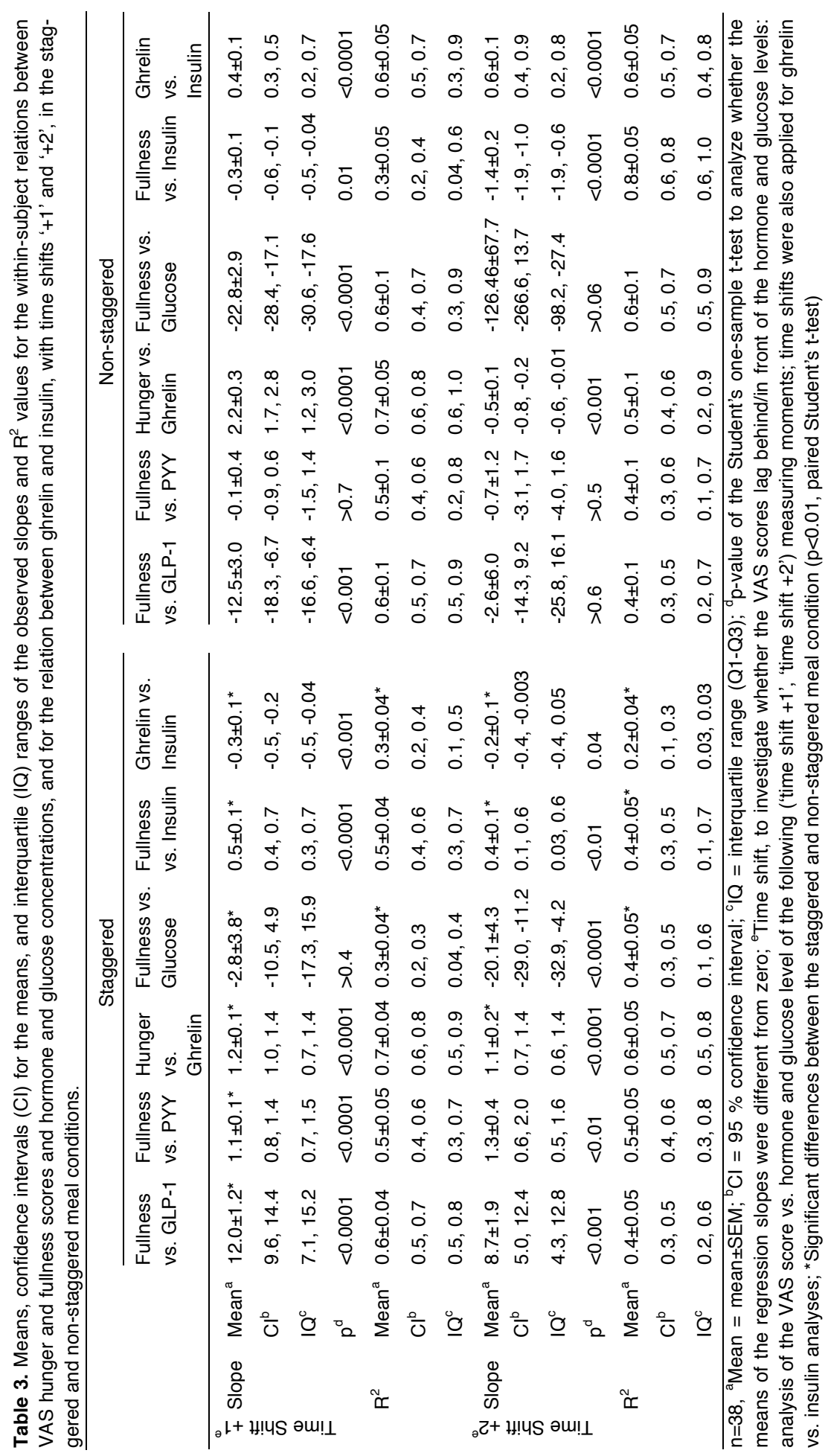




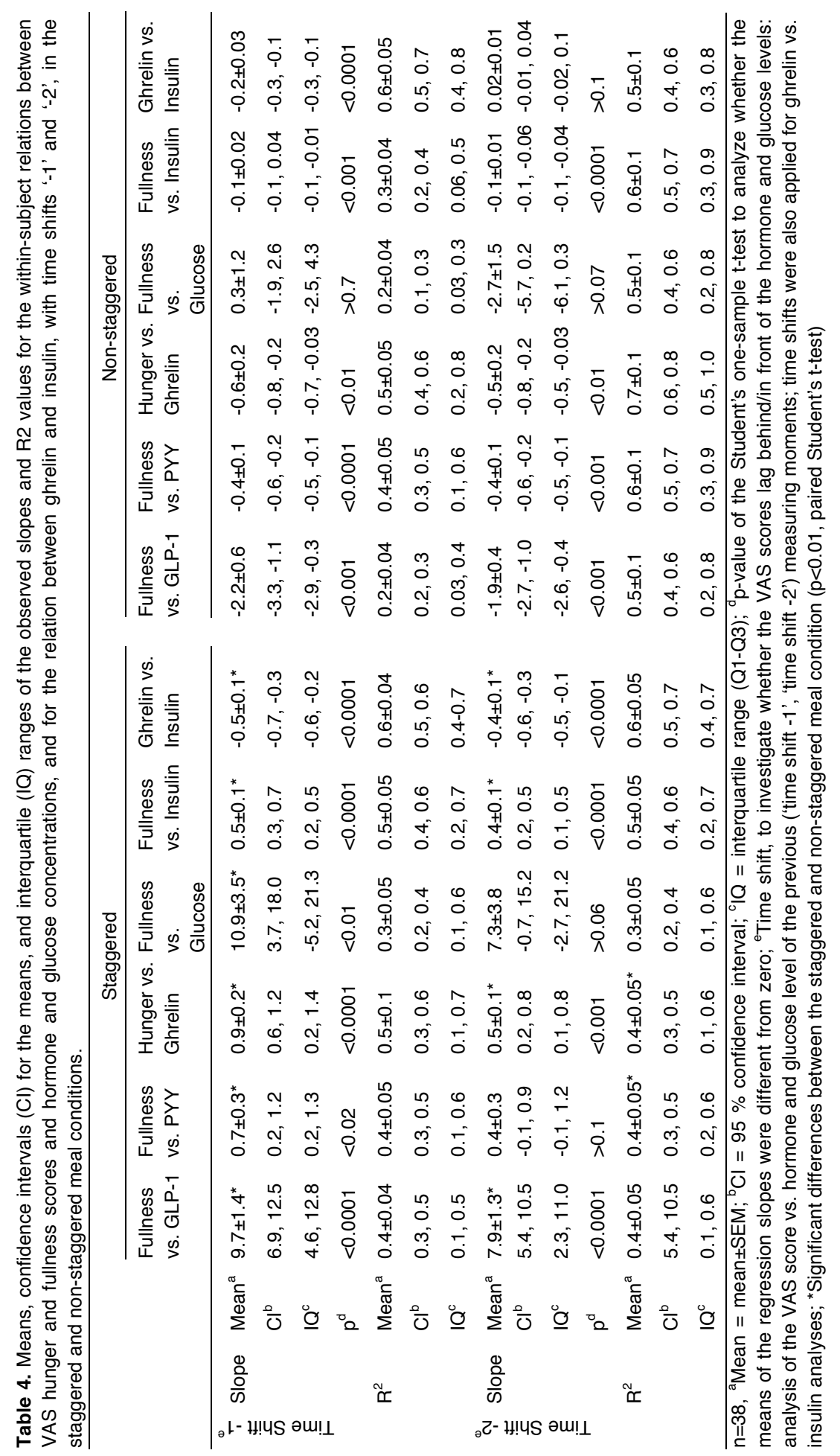




\section{Discussion}

The objective of our study was to compare the dynamics of VAS fullness scores and GLP-1, PYY, glucose, and insulin concentrations, and of VAS hunger scores and ghrelin concentrations, using a statistical approach that includes the factor time. Moreover, we investigated whether the VAS scores are synchronized with, or lag behind or in front of the hormone/glucose concentrations. The study design comprised two different meal patterns (staggered and non-staggered) and thereby different timings of nutrient delivery to the gut.

Analyses of regression slopes and $\mathrm{R}^{2}$ values showed that VAS appetite scores and hormone and glucose concentrations changed synchronously, and that the mean explained variation was $30-70 \%$. The question remains whether this explained variation is sufficient to presume that the hormone and glucose concentrations may serve as a reliable biomarker for appetite at the individual level. A biomarker is in general a substance that can provide reliable early indicators of a biological state (32). For a biomarker of appetite to be useful, it must meet a number of criteria: the measurement of the biomarker must be feasible, measurable without invasive procedures, and reproducible under similar conditions; moreover, the biomarker must clearly relate to appetite physiology and be sensitive to changes in appetite (32). Taking the confidence intervals and interquartile ranges into account, we suggest the explained variation of $30-70 \%$ may be insufficient. However, the hormone and glucose dynamics, in relation to feelings of appetite, may be useful to determine differences between experimental conditions or between different subject groups; yet this still should be executed for other experiments as well, to be able to judge whether certain changes in hormone concentrations may explain certain changes in appetite related feelings, up to a certain degree.

Overall it appeared that GLP-1, PYY, glucose, and insulin concentrations changed synchronously with VAS fullness scores. In contrast, ghrelin concentrations lagged behind the VAS hunger scores, with a delay of $10 \mathrm{~min}$ in the staggered meal condition and $25 \mathrm{~min}$ in the non-staggered meal condition. Meal consumption induced a delayed ghrelin suppressive response by 10-25 min. Several studies showed that insulin is required for postprandial ghrelin suppression (29-31). Moreover, Solomon et al. reported that there is a delay of approximately $20 \mathrm{~min}$ between responses of insulin and ghrelin, insulin leading ghrelin (28). Our study confirmed the findings by Solomon et al. (28): ghrelin concentrations lagged behind the insulin concentrations by approximately 15-30 $\mathrm{min}$ in the staggered meal condition, and $30 \mathrm{~min}$ in the non-staggered meal condition. This suggests a role for insulin as a negative regulator of ghrelin (33).

Comparison of the staggered and non-staggered meal condition revealed that the changes in appetite profile scores and in hormonal/glucose release were more sustained in the staggered vs. non-staggered meal condition. Regarding 
the measured regression slopes and $\mathrm{R}^{2}$ values there were no major differences between the conditions (Table 2-4).

In conclusion, the explained variation of the development of hunger and fullness scores over time by the development of GLP-1, PYY, ghrelin, glucose, and insulin concentrations over time was $30-70 \%$. We suggest that this figure is too small to use the changes in concentrations of GLP-1, PYY, ghrelin, glucose, and insulin as biomarkers for feelings of appetite, at the individual as well as at group level. However, this approach appears to be a useful tool to characterize the processes of hunger and fullness between conditions. Ghrelin concentrations lagged behind the VAS hunger scores and the insulin concentrations, suggesting a role for insulin as a negative regulator of ghrelin.

\section{Acknowledgements}

We thank our subjects for their participation in this study. The study was designed by MSWP and SGL. SGL together with EAM (supervised by MSWP) carried out the study and collected the data. SGL analyzed the data, supervised by ADK, and wrote the largest part of the manuscript. EAM and MSWP reviewed the manuscript. 


\section{References}

1. Caballero B. The Global Epidemic of Obesity: An Overview. Epidemiol Rev. 2007 January 1, 2007;29(1):1-5.

2. Giskes K, Van Lenthe F, Avendano-Pabon M, Brug J. A systematic review of environmental factors and obesogenic dietary intakes among adults: are we getting closer to understanding obesogenic environments? Obes Rev. 2010.

3. Mattes RD, Hollis J, Hayes D, Stunkard AJ. Appetite: Measurement and Manipulation Misgivings. J Am Diet Assoc. 2005;105(5, Supplement 1):87-97.

4. Delzenne N, Blundell J, Brouns F, Cunningham K, De Graaf K, Erkner A, et al. Gastrointestinal targets of appetite regulation in humans. Obes Rev. 2010;11(3):234-50.

5. Flint A, Gregersen NT, Gluud LL, Møller BK, Raben A, Tetens I, et al. Associations between postprandial insulin and blood glucose responses, appetite sensations and energy intake in normal weight and overweight individuals: a meta-analysis of test meal studies. $\mathrm{Br} \mathrm{J}$ Nutr. 2007;95(1):17-25.

6. le Roux CW, Batterham RL, Aylwin SJB, Patterson M, Borg CM, Wynne KJ, et al. Attenuated Peptide YY Release in Obese Subjects Is Associated with Reduced Satiety. Endocrinology. 2006 January 1, 2006;147(1):3-8.

7. Verdich C, Flint A, Gutzwiller JP, Naslund E, Beglinger C, Hellstrom PM, et al. A Meta-Analysis of the Effect of Glucagon-Like Peptide-1 (7-36) Amide on Ad Libitum Energy Intake in Humans. J Clin Endocrinol Metab. 2001 September 1, 2001;86(9):4382-9.

8. Druce MR, Neary NM, Small CJ, Milton J, Monteiro M, Patterson M, et al. Subcutaneous administration of ghrelin stimulates energy intake in healthy lean human volunteers. Int $\mathrm{J}$ Obes (Lond). 2006;30(2):293-6.

9. Druce MR, Wren AM, Park AJ, Milton JE, Patterson M, Frost G, et al. Ghrelin increases food intake in obese as well as lean subjects. Int J Obes (Lond). 2005;29(9):1130-6.

10. Thorens B. Glucose sensing and the pathogenesis of obesity and type 2 diabetes. Int $J$ Obes (Lond). 2008;32 Suppl 6:S62-71.

11. de Graaf C, Blom WAM, Smeets PAM, Stafleu A, Hendriks HFJ. Biomarkers of satiation and satiety. Am J Clin Nutr. 2004 June 1, 2004;79(6):946-61.

12. Mayer J. Regulation of energy intake and the body weight: the glucostatic theory and the lipostatic hypothesis. Ann N Y Acad Sci. 1955;63(1):15-43.

13. Campfield LA, Smith FJ, Rosenbaum M, Hirsch J. Human eating: evidence for a physiological basis using a modified paradigm. Neurosci Biobehav Rev. 1996;20(1):133-7.

14. Lavin JH, Wittert G, Sun WM, Horowitz M, Morley JE, Read NW. Appetite regulation by carbohydrate: role of blood glucose and gastrointestinal hormones. Am J Physiol Endocrinol Metab. 1996;271(2 Pt 1):E209-14.

15. Verdich C, Toubro S, Buemann B, Lysgård Madsen J, Juul Holst J, Astrup A. The role of postprandial releases of insulin and incretin hormones in meal-induced satiety-effect of obesity and weight reduction. Int J Obes Relat Metab Disord. 2001;25(8):1206-14.

16. Flint A, Raben A, Blundell JE, Astrup A. Reproducibility, power and validity of visual analogue scales in assessment of appetite sensations in single test meal studies. Int $\mathrm{J}$ Obes Relat Metab Disord. 2000;25(1):38-48.

17. Diepvens K, Haberer D, Westerterp-Plantenga M. Different proteins and biopeptides differently affect satiety and anorexigenic/orexigenic hormones in healthy humans. Int J Obes (Lond). 2008 Mar;32(3):510-8.

18. Maffeis C, Surano MG, Cordioli S, Gasperotti S, Corradi M, Pinelli L. A High-fat vs. a Moderatefat Meal in Obese Boys: Nutrient Balance, Appetite, and Gastrointestinal Hormone Changes. Obesity. 2009;18(3):449-55. 
19. Smeets AJ, Soenen S, Luscombe-Marsh ND, Ueland O, Westerterp-Plantenga MS. Energy Expenditure, Satiety, and Plasma Ghrelin, Glucagon-Like Peptide 1, and Peptide TyrosineTyrosine Concentrations following a Single High-Protein Lunch. J Nutr. 2008 April 1, 2008;138(4):698-702.

20. Erdmann J, Hebeisen Y, Lippl F, Wagenpfeil S, Schusdziarra V. Food intake and plasma ghrelin response during potato-, rice- and pasta-rich test meals. Eur J Nutr. 2007;46(4):196-203.

21. Guo Y, Ma L, Enriori PJ, Koska J, Franks PW, Brookshire T, et al. Physiological Evidence for the Involvement of Peptide $Y Y$ in the Regulation of Energy Homeostasis in Humans. Obesity. 2006;14(9):1562-70.

22. Adam TC, Westerterp-Plantenga MS. Nutrient-stimulated GLP-1 release in normal-weight men and women. Horm Metab Res. 2005;37(2):111-7.

23. Stunkard AJ, Messick $S$. The three-factor eating questionnaire to measure dietary restraint, disinhibition and hunger. J Psychosom Res. 1985;29(1):71-83.

24. Sorensen LB, Moller P, Flint A, Martens M, Raben A. Effect of sensory perception of foods on appetite and food intake: a review of studies on humans. Int J Obes Relat Metab Disord. 2003 Oct;27(10):1152-66.

25. Vicennati V, Ceroni L, Gagliardi L, Gambineri A, Pasquali R. Comment: response of the hypothalamic-pituitary-adrenocortical axis to high-protein/fat and high-carbohydrate meals in women with different obesity phenotypes. J Clin Endocrinol Metab. 2002 Aug;87(8):3984-8.

26. McArdle WD, Katch FI, Katch VL. Exercise Physiology. 4th ed. Baltimore: Williams and Watkins; 1996.

27. Harris JA, Benedict FG. A Biometric Study of Human Basal Metabolism. Proc Natl Acad Sci U S A. 1918 Dec;4(12):370-3.

28. Solomon TP, Chambers ES, Jeukendrup AE, Toogood AA, Blannin AK. The effect of feeding frequency on insulin and ghrelin responses in human subjects. Br J Nutr. 2008 Oct;100(4):810-9.

29. Flanagan DE, Evans ML, Monsod TP, Rife F, Heptulla RA, Tamborlane WV, et al. The influence of insulin on circulating ghrelin. Am J Physiol Endocrinol Metab. 2003 February 1, 2003;284(2):E313-6.

30. Murdolo G, Lucidi P, Di Loreto C, Parlanti N, De Cicco A, Fatone C, et al. Insulin is required for prandial ghrelin suppression in humans. Diabetes. 2003;52(12):2923-7.

31. Saad MF, Bernaba B, Hwu C-M, Jinagouda S, Fahmi S, Kogosov E, et al. Insulin Regulates Plasma Ghrelin Concentration. J Clin Endocrinol Metab. 2002 August 1, 2002;87(8):3997-4000.

32. Diplock AT, Aggett PJ, M. A, Bornet F, Fern EB, Roberfroid MB. Scientific concepts of functional foods in Europe. Consensus document. Br J Nutr. 1999;81(4):S1-S27.

33. Cummings DE, Frayo RS, Marmonier C, Aubert R, Chapelot D. Plasma ghrelin levels and hunger scores in humans initiating meals voluntarily without time- and food-related cues. Am J Physiol Endocrinol Metab. 2004 August 1, 2004;287(2):E297-304. 


\section{Chapter 3}

\section{Eating what you like induces a stronger decrease of 'wanting' to eat}

Lemmens SG, Schoffelen PF, Wouters L, Born JM, Martens MJ, Rutters F, Westerterp-Plantenga MS

Physiol Behav. 2009 Sep 7;98(3):318-25. Epub 2009 Jun 21 


\begin{abstract}
Human eating behavior may be influenced non-homeostatically by the rewarding value of foods, i.e. 'liking' (pleasure/palatability) and 'wanting' (incentive motivation).

The objectives of this study were to validate a computer test for assessment of rewarding value of food, and to assess how rewarding value of food is affected by eating a dessert-specific (chocolate mousse, CM) vs. dessert non-specific, neutral food item (cottage cheese, CC).

Seventy-three subjects $\left(47 \mathrm{f} / 26 \mathrm{~m}\right.$, age $27.8 \pm 10.0 \mathrm{y}$, BMI $\left.24.1 \pm 3.3 \mathrm{~kg} / \mathrm{m}^{2}\right)$, studied in a randomized cross-over design, came to the university twice, fasted. A computer test was developed to determine rewarding value, i.e. 'liking' and 'wanting', for 72 items divided in six categories (bread, filling, drinks, dessert, sweets, stationery). 'Liking' was measured by indicating relative preference of paired items (within/between categories), 'wanting' by working to earn items to choose from. Subjects completed the computer test before and after consumption of $\mathrm{CM} / \mathrm{CC}$, matched for energy content $(5.6 \mathrm{~kJ} / \mathrm{g})$ and daily energy requirements (10\%).

'Liking' and 'wanting' scores of all fasted subjects on the two test-days showed $62-73 \%$ reproducibility. CM was liked more than CC $(p<0.001)$. Consumption of CM decreased 'wanting' for bread, filling, drinks and dessert $(p<0.03)$. Consumption of CC decreased 'wanting' for bread only $(p<0.05)$. Contrary to $C C, C M$ decreased relative 'liking' for the dessert category $(p<0.001)$.

In conclusion, the computer test for measurement of 'liking' and 'wanting' is sufficiently valid. Eating a highly liked food item induces a more distinct decrease in 'wanting' for food items in general and category-specific 'liking', than eating a sufficiently liked neutral food item.
\end{abstract}




\section{Introduction}

Human eating behavior is not solely regulated by homeostatic mechanisms but also by non-homeostatic mechanisms such as the food reward system. Unraveling this reward system may help us understand the factors that influence the excessive food intake associated with obesity (1-3).

According to the incentive salience theory it is hypothesized that the process of reward consists of two components, i.e. 'liking' and 'wanting' (4). 'Liking' is the hedonic or affective component and refers to the pleasure derived from orosensory stimulation of food $(5,6)$. 'Wanting' is the motivational incentive component and refers to appetite or craving or the motivation to obtain food (1, 4-7). Often 'liking' and 'wanting' go hand-in-hand: we want what we like and like what we want (4). However, humans habitually may select less liked food items, as for example restrained eaters do: they cognitively restrict their food intake to loose weight or to prevent weight gain $(6,8)$. Furthermore, in research on drug addiction a distinction between the two components of reward was observed: some drug addicts are driven to take drugs without liking their effects $(9,10)$. Moreover, 'liking' and 'wanting' are thought to be controlled by different brain mechanisms according to the incentive salience model (7). Mouse models showed that the brain mechanism attributed to 'liking' involves the neurotransmission of mu-opioid in the nucleus accumbens, ventral pallidum, parabrachial nucleus, and nucleus of the solitary tract (1). The brain mechanism attributed to 'wanting' involves the neurotransmission of dopamine in the prefrontal cortex, amygdala, hypothalamus, and projections from the ventral tegmental area to the nucleus accumbens (1). Taking the above into account, it is of importance to differentiate between the possible influence of 'liking' and 'wanting' on food intake (11).

Recent human studies have observed and characterized the distinction between 'liking' and 'wanting' (6). 'Liking' was quantified by either subjective ratings on visual analog scales or objective measures of facial affective expressions $(3,5$, 12). 'Wanting' was quantified by for example the forced choice methodology whereby food items were presented in pairs and responded to according to which food item was most wanted at that moment $(2,5)$. Epstein and colleagues developed an alternative indirect measure for motivation by assessing the reinforcing value of food using progressive schedules of reinforcement $(3,13)$. The motivation was expressed as the willingness to work for amounts of a food of choice or alternate reinforcers such as money or sedentary activities. According to the approach of Epstein et al. the reinforcing value of food is associated with the 'wanting' of food (3).

When current methods for measurements of 'liking' and 'wanting' are applied in humans, culture specific motivation and reinforcement may have to be taken into account. This is especially of importance since distinguishing 'liking' from 'wanting' seems to be present to a different extent among cultures (14). 
Therefore, a computer-based method for the assessment of reward, in terms of 'liking' and 'wanting', was developed for this study. This method is presently applied to a Dutch study population and by using the general principles, a broader application will be possible.

Firstly, the validity, i.e. reproducibility and sensitivity, of the developed computer test for assessment of the rewarding value of food was tested. Secondly, it was assessed how the rewarding value of a consumed food item possibly affects the rewarding value of any other food item in general. Unraveling such a relationship may explain the subject's subsequent food choice and consumption.

\section{Methods}

\section{Subjects}

Seventy-three Caucasian subjects (47 females, 26 males, age 27.8 \pm 10.0 y (mean $\pm S D$, range $18-55 \mathrm{y})$ ) with a $\mathrm{BMl}$ of $24.1 \pm 3.3 \mathrm{~kg} / \mathrm{m}^{2}$ (mean $\pm \mathrm{SD}$, range 18.9-30.6 $\mathrm{kg} / \mathrm{m}^{2}$ ) participated in this study. They were recruited by advertisements in local newspapers and on notice boards at the university and hospital. The subjects underwent an initial screening including measurement of body weight and height and completion of a questionnaire related to health, use of medication, smoking behavior, alcohol consumption and physical activity. All subjects gave written informed consent by the start of the first test day. The study was approved by the Medical Ethical Committee of the Maastricht University.

\section{Study design}

The study was conducted in a randomized cross-over design. All subjects came to the university twice in a fasted state, between 08:00 and 10:00 AM. The test sessions differed only in the presentation of the test meal: either chocolate mousse or cottage cheese.

After arrival at the university, subjects were seated in the laboratory and remained seated throughout the experiment. The test session started by filling out visual analogue scales (VAS) on appetite. Subsequently the researcher gave the instructions on the computer test for measurement of 'liking' and 'wanting'. While completing the test, subjects received further instructions on the computer screen and on a piece of paper. After completing the computer test, subjects had to consume the entire test meal. Immediately post-ingestion subjects filled out the VAS and completed the computer test again. 


\section{Appetite profile}

One hundred unit VAS $(\mathrm{mm})$ were used to assess the appetite profile. The scales were anchored with 'not at all' at one end and 'extremely' at the other end, and combined with questions on feelings of hunger, thirst, fullness, satiety, desire to eat, and on 'liking', 'wanting', creaminess, and fullness of taste of the test meals. Subjects were instructed to make a single vertical mark at the appropriate point between the two anchors on each scale to indicate their subjective feeling. These VAS were completed in the fasted and satiated state. Moreover, at the end of both test sessions, subjects completed VAS on the absolute 'liking' of all the items used in the computer test.

\section{'Liking' and 'wanting' computer test}

A computer test was developed to measure the rewarding value, i.e. 'liking' and 'wanting', for 72 items divided in six categories (bread, filling, drinks, dessert, sweets, and stationery (non-food alternative as placebo)), 12 items per category (Appendix Table A1). Those five food categories were chosen as they gave the subjects the opportunity to compose a full meal according to their wishes. A usual Dutch breakfast/lunch meal consists of bread, filling and drinks. Above this, dessert and sweets can be added. Stationery served as non-food alternative (placebo) in this study. Beforehand, during screening, it was checked whether all food items were acceptable for the subjects. The 72 items were presented as photographic stimuli on a computer screen (13 in. Mac Book, Apple, Cupertino, USA). In a sub-study the pleasantness of taste of all the food items while tasting them and the attractiveness of the photographic stimuli were measured by means of VAS.

The computer test contained two parts, a 'liking' and a 'wanting' part. Both the 'liking' and 'wanting' tasks assessed 'liking' respectively 'wanting' for the same food and stationery items. During the 'liking' part, subjects had to indicate their relative preference of paired items within and between the six categories (Figure $1 \mathrm{~A}, \mathrm{~B})$. Each choice had to be made within four seconds via a mouse click on the preferred item, which triggered the next pair of items. First, all possible pairs of combinations within each category were presented $(\mathrm{N}=6 \times 66)$. The pairs of items were presented in random order, while the categories were presented in the following order: bread, filling, drinks, dessert, sweets and stationery. This resulted in a relative ranking of 'liking' of the items per category. Next, the items from the different categories with the corresponding ranking of 'liking' were presented in pairs, in random order $(\mathrm{N}=12 \times 15)$. This resulted in a relative ranking of 'liking' of the categories.

During the 'wanting' part, subjects had to work to earn items by playing memory games (Figure $1 \mathrm{C}, \mathrm{D}$ ). For each category of items subjects played a five by five memory game (12 pairs of items). Per memory game the shuffled pairs of items were first presented for 10 seconds, giving the subjects the opportunity to locate 
and remember the pairs of matching items. Next the items were turned over and the subjects could start finding the matching pairs by clicking on them using the computer mouse. Matched pairs remained on the screen, while non-matched pairs were turned over again. Subjects had two min to solve the memory game. Each memory game was followed by the indication of the items subjects wanted to acquire at that moment. The more pairs of items were found in the memory game, the more randomly selected items were offered to choose from afterwards, e.g. if eight pairs of items would be found in the memory game of the sweets category, then eight randomly selected sweets would be offered to choose from. Subjects could choose zero, one or two items per category. They were instructed to choose the items while keeping in mind that all the chosen items would be offered to them and had to be eaten completely. To proceed to the next category subjects had to find at least two pairs of items per memory game. The categories were presented in the following order: bread, filling, drinks, dessert, sweets and stationery. From the drinks category onwards, subjects could press a stop-button to stop the 'wanting' part of the computer test, indicating that they would not want to work for and earn any other items. The chosen items obtained a score equal to the number of pairs of items found in the memory game, representing the motivation or workload for the chosen items (score range 2-12). Items not chosen obtained a score of zero. Per category the sum of the scores of the items was calculated and represented the 'wanting' score for each category. A minimum score of zero and a maximum score of 24 was obtained per category.

During screening, subjects were asked whether they were able to play a memory game. All subjects confirmed their ability, there were no drop-outs. Moreover subjects were asked during screening to indicate whether they preferred to choose food items from a larger variety, which they would receive as a fixed amount, or whether they preferred to choose the amount of food from a fixed menu. In both cases subjects were asked to assume that the items offered would be acceptable. Most subjects (76\%) preferred food variety to choose from instead of amount of food. Therefore we decided upon primarily magnitude of food variety per category as reinforcer and secondarily meal size represented by the amount of categories worked for. 

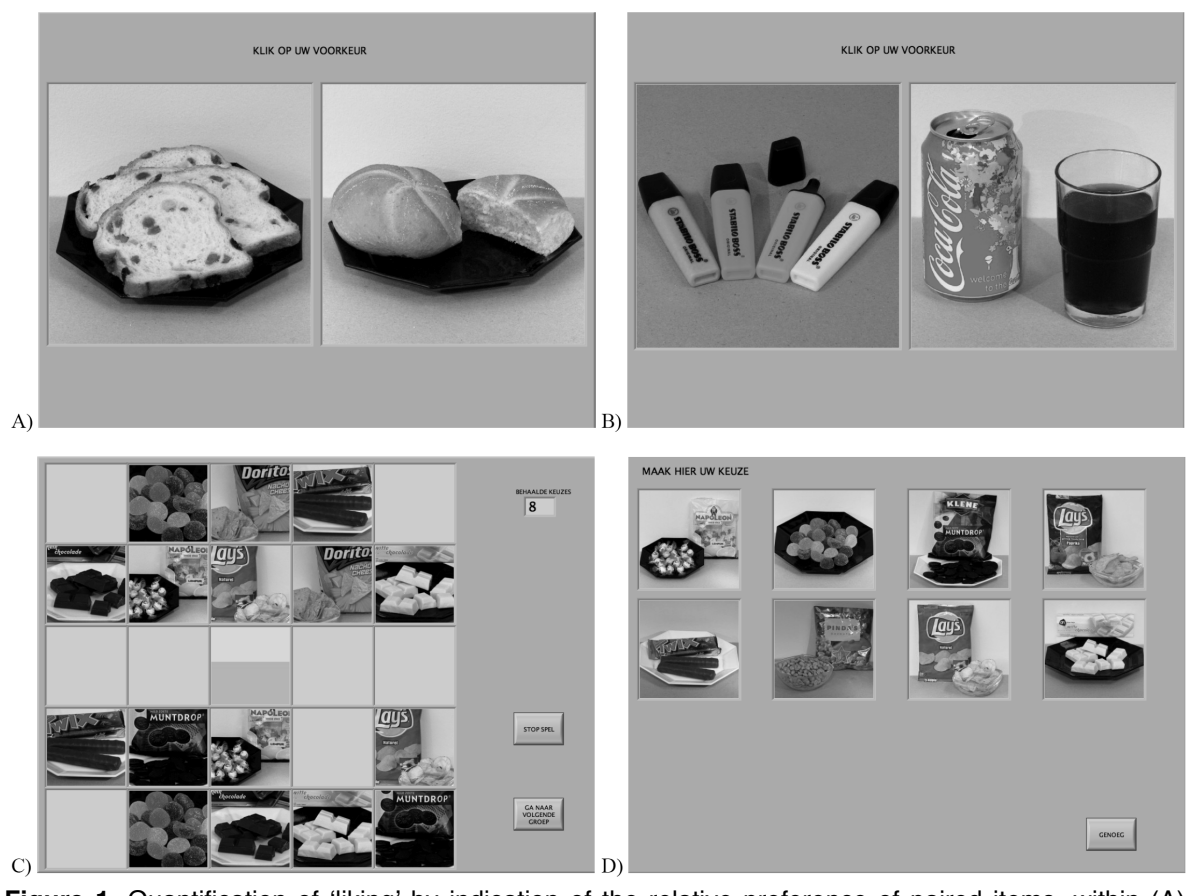

Figure 1. Quantification of 'liking' by indication of the relative preference of paired items, within (A) and between categories (B). Quantification of 'wanting' by working (playing memory games (C)) to earn items to choose from (D).

Software for this computer test was developed using Labview (National Instruments, Austin, USA) excluding express routines, compiled for 13 in. Mac Book and configured to run in Kiosk mode for full control of screen and subject interaction. The software incorporated configurable events and timing tables, allowing the researcher to optimize sequences of events, amount of graphical information and allotted time for choices and instructions. The software logged all events, score and time as well as all user interaction. These data were collected in Excel data sheets. The program used three functions, i.e. a 'liking', memory game and 'wanting' part. These functions where used for each food group in programmed sequence.

Tables generated for 'liking', i.e. 66 selections for 12 items in a category, were evenly randomized in sequence as well as for left-right position on screen. Each item could achieve an initial score of $0-11$, i.e. the count of times the item was preferred over other items in the group. The final score of each item, if the selection was true, was defined as the sum of the initial scores of non-preferred item, times 10 and offset by five, i.e. final score = sum (if selection true (initial score of non-preferred item $\times 10+5$ ) else 0 ). The range of the score was between 0 and 605 per item in each category and incorporated weight of preference. The final score was then used to re-rank items in 12 positions for 
cross category comparison with equal ranking items from the six categories (score range per item 0-125).

Graphical information in the five by five item display of the memory game was also evenly randomized and included a re-seeding routine for preventing side by side or diagonal combinations. The software standard forced a blank image in the middle position as the selected board size was an uneven number. Information gathered for the memory game included counts of pairs found with and without prior viewing as well as other details regarding timing, position and counts of unsuccessful pairs.

\section{Test meal}

The test meal consisted of either chocolate mousse or cottage cheese (both 0.6 MJ per $100 \mathrm{~g}$; energy \% protein/carbohydrate/fat: 21/29/50) and a glass of water $(250 \mathrm{~mL})$. The amount of chocolate mousse or cottage cheese given to the subjects corresponded to $10 \%$ of their daily energy requirements. For each subject the daily energy requirements (DER) were calculated by multiplying the basal metabolic rate (BMR) by the appropriate physical activity factor (1.5-1.8, derived from the screening questionnaire, (15)). The BMR (kCal/day) was calculated according to the equation of Harris-Benedict (16). The order of presentation of the test meal was randomized across the subjects to prevent any order effects. On average subjects received 1.2 $\mathrm{MJ}$ of chocolate mousse or cottage cheese. The chosen meal size of $10 \%$ of DER was based on a study by Diepvens et al. showing that a breakfast of $1 \mathrm{MJ}$, or $10 \%$ of subject specific DER, with a similar macronutrient composition (energy \% protein/carbohydrate/ fat: 25/33/42) induced significant changes in hunger and satiety (17).

Chocolate mousse, a dessert-specific food item and cottage cheese, a dessert non-specific, neutral food item, were both part of the dessert category. These two items were chosen as test meal, as it was expected that they would differ in rewarding value, chocolate mousse being more rewarding than cottage cheese. As appeared during screening, chocolate mousse was mostly described as a delicious food item and cottage cheese as a healthy food item. Consequently consumption of the items was expected to exert different effects on the rewarding value, in terms of 'liking' and 'wanting', of the consumed food item itself, the dessert category and possible other categories.

\section{Validity}

The validity of the computer test was determined by assessing reproducibility and sensitivity. To measure the reproducibility of the 'liking' and 'wanting' part of the computer test and of the absolute 'liking' of all the used items determined by VAS, the percentage reproducibility was calculated, based on two repeated measures from each individual. For the 'liking' and 'wanting' part of the computer 
test the measures in the fasted state of test day 1 and test day 2 were compared. The percentage reproducibility was calculated as the proportion of concordance between the repeated measurements, expressed as percent. A reproducibility of $60 \%$ was accepted as sufficient. The sensitivity of the computer test was evaluated by the ability of the test to detect differences in rewarding value of the used items between pre- to post-consumption of chocolate mousse and cottage cheese.

\section{Statistics}

Data were analysed using StatView 5.0 (SAS Institute Inc., Cary, NC, USA). Differences between pre- to post-meal were determined using paired Student's ttests. Differences over time and between conditions (chocolate mousse and cottage cheese) were determined using two-factor analysis of variance (ANOVA) with repeated measures. The Wilcoxon signed-rank test was used to detect differences in the ranking of 'liking' of items within each category between pre- to post-meal. To analyze which independent variables (hunger, thirst, fullness, satiety, desire to eat, 'liking', creaminess, fullness) predicted the dependent variables 'wanting' for chocolate mousse and 'wanting' for cottage cheese, simple linear regression models were used. To compare the mean absolute and relative 'liking' scores of the food items of all subjects, measured by VAS and the 'liking' part of the computer test, respectively, a simple linear regression model was used. Both measuring scales were normalized to $100 \%$ first.

All tests were two-sided and differences were considered significant at $p<0.05$. Values are expressed as mean \pm standard error of the mean (SEM).

\section{Results}

\section{Reproducibility}

Based on the computer test measurements for all subjects in a fasted state on test day 1 and test day 2, the mean percentage of reproducibility of all subjects was $62.3 \pm 0.6 \%$ for the 'liking' part and $73.3 \pm 2.6 \%$ for the 'wanting' part. For the absolute 'liking' of all the used items determined by VAS, the percentage reproducibility was $76.2 \pm 1.2 \%$.

A positive relationship was observed between mean absolute and relative 'liking' scores of the items of all subjects, measured by VAS and the 'liking' part of the computer test, respectively $\left(R^{2}=0.63, p<0.001\right)$. Figure 2 depicts a scatter plot of the relative 'liking' scores as a function of the absolute 'liking' scores distributed about the line of identity. The scatter plot lies beneath the line of identity, suggesting although the scores are highly correlated, the absolute 'liking' scores are continuously higher than the relative 'liking' scores. 


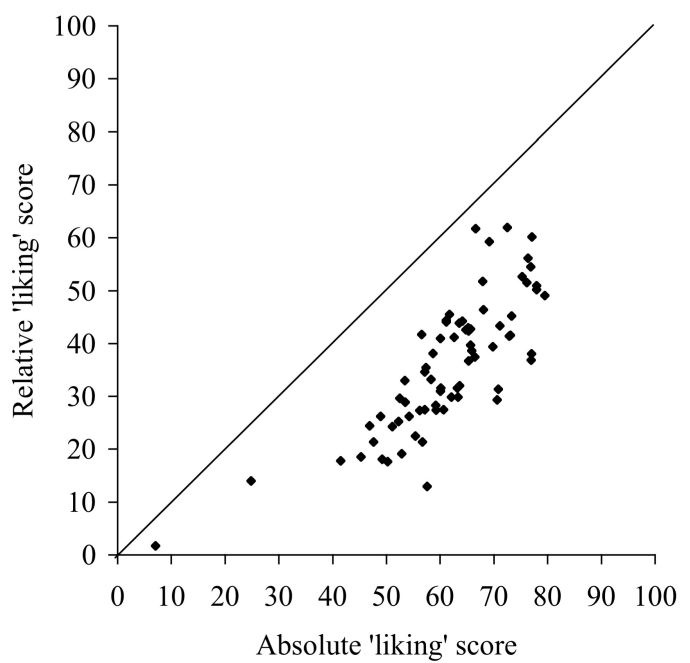

Figure 2. Scatter plot of the mean relative 'liking' scores as a function of the absolute 'liking' scores of the 72 items, distributed about the line of identity $(x=y)$. The relative 'liking' scores of the 72 items were obtained by means of the 'liking' part of the computer test and the absolute 'liking' scores by means of visual analogue scales. Each data point of the scatter plot represents an individual item.

\section{Appetite profile}

High ratings for hunger and desire to eat and low ratings for fullness and satiety confirmed that subjects were in a fasted state at the start of both test sessions (Table 1). Both test meals, chocolate mousse and cottage cheese served with a glass of water, induced a decrease in hunger, thirst and desire to eat $(p<0.001)$ and an increase in fullness and satiety $(p<0.001$, Table 1$)$. These results confirmed that subjects were in a satiated state when they fulfilled the second computer test.

There was a significant time by condition (pre-/post-meal $\mathrm{x}$ chocolate mousse/cottage cheese) interaction for hunger $(p<0.01)$, desire to eat $(p<0.01)$, fullness $(p<0.01)$, satiety $(p<0.001)$ and 'wanting' $(p=0.02$, Table 1$)$. The difference in hunger, desire to eat, fullness and satiety pre- to post- consumption was larger in the chocolate mousse condition than in the cottage cheese condition $(p<0.01)$. Subjects were less hungry, had a lower desire to eat and were more full and satiated after the consumption of chocolate mousse than after the consumption of cottage cheese $(p<0.001)$.

Chocolate mousse was liked more than cottage cheese, before as well as after the consumption of both food items $(p<0.001$, Table 1$)$. The consumption of chocolate mousse induced a decrease in 'liking' and 'wanting' for chocolate mousse $(p<0.001$, Table 1$)$. The consumption of cottage cheese induced a decrease in 'liking' and 'wanting' for cottage cheese $(p<0.001$, Table 1). The difference in 'wanting' for chocolate mousse or cottage cheese pre- to postconsumption was larger in the chocolate mousse condition than in the cottage 
cheese condition ( $p<0.01$, Table 1). Chocolate mousse was perceived as more full of taste than cottage cheese, before and after the consumption of both food items $(p<0.001$, Table 1).

Table 1. Mean ( \pm SEM) visual analogue scale ratings (in $\mathrm{mm}$ ) for hunger, thirst, desire to eat, fullness, satiety, 'liking', 'wanting', creaminess and fullness of taste, pre- and post-meal (chocolate mousse, $\mathrm{CM}$; cottage cheese, CC).

\begin{tabular}{|c|c|c|c|c|c|c|c|}
\hline & \multicolumn{3}{|c|}{$\mathrm{CM}$} & \multicolumn{3}{|c|}{$\mathrm{CC}$} & \multirow[b]{2}{*}{$\begin{array}{l}\mathrm{p}^{\mathrm{b}} \text { time } \mathrm{x} \\
\text { condition }\end{array}$} \\
\hline & Pre & Post & $p^{a}$ & Pre & Post & $\mathrm{p}^{\mathrm{a}}$ & \\
\hline Hunger & $57.0 \pm 2.9$ & $11.4 \pm 1.8$ & $<.001$ & $58.6 \pm 2.5$ & $23.9 \pm 2.4$ & $<.001$ & .01 \\
\hline Thirst & $60.5 \pm 2.5$ & $40.7 \pm 3.1$ & $<.001$ & $61.8 \pm 2.0$ & $38.8 \pm 3.1$ & $<.001$ & n.s. \\
\hline Desire to eat & $59.1 \pm 2.8$ & $13.3 \pm 1.9$ & $<.001$ & $62.4 \pm 2.4$ & $28.6 \pm 2.8$ & $<.001$ & $<.01$ \\
\hline Fullness & $20.0 \pm 2.1$ & $80.1 \pm 2.0$ & $<.001$ & $19.1 \pm 2.2$ & $65.7 \pm 2.7$ & $<.001$ & $<.01$ \\
\hline Satiety & $20.3 \pm 1.9$ & $79.0 \pm 2.3$ & $<.001$ & $21.4 \pm 2.2$ & $63.3 \pm 2.7$ & $<.001$ & $<.001$ \\
\hline 'Liking' & $67.6 \pm 2.9$ & $57.6 \pm 3.3$ & $<.001$ & $49.4 \pm 2.8$ & $40.4 \pm 3.4$ & $<.001$ & n.s \\
\hline 'Wanting' & $47.6 \pm 3.3$ & $9.0 \pm 1.8$ & $<.001$ & $42.6 \pm 3.0$ & $14.1 \pm 2.0$ & $<.001$ & .02 \\
\hline Creaminess & $70.2 \pm 2.7$ & $69.0 \pm 3.3$ & n.s. & $65.2 \pm 3.0$ & $69.9 \pm 2.9$ & n.s. & n.s. \\
\hline Fullness of taste & $78.1 \pm 2.3$ & $75.1 \pm 2.8$ & n.s. & $57.3 \pm 3.3$ & $56.7 \pm 3.9$ & n.s. & n.s. \\
\hline
\end{tabular}

n.s.=non-significant; ${ }^{a} \mathrm{p}$-value: differences pre- to post-meal (t-test); ${ }^{b} \mathrm{p}$-value: time by condition interaction (pre-/post-meal $x$ chocolate mousse/cottage cheese; ANOVA);

Simple linear regression models showed a positive relationship between premeal 'wanting' for chocolate mousse and pre-meal 'liking' for chocolate mousse $\left(R^{2}=0.5, p<0.001\right)$, as well as hunger $\left(R^{2}=0.2, p<0.001\right)$, desire to eat $\left(R^{2}=0.2\right.$, $p<0.001)$, creaminess $\left(R^{2}=0.2, p<0.01\right)$ and fullness of taste $\left(R^{2}=0.2, p<0.01\right)$. There was a negative relationship between pre-meal 'wanting' for chocolate mousse and pre-meal satiety $\left(R^{2}=0.1, p=0.02\right)$.

In the cottage cheese condition, simple linear regression models showed a positive relationship between pre-meal 'wanting' for cottage cheese and premeal 'liking' for cottage cheese $\left(R^{2}=0.6, p<0.001\right)$, as well as hunger $\left(R^{2}=0.1\right.$, $p=0.02)$, desire to eat $\left(R^{2}=0.1, p<0.01\right)$ and fullness of taste $\left(R^{2}=0.3, p<0.001\right)$.

Post-meal 'wanting' for chocolate mousse was positively related to post-meal 'liking' for chocolate mousse $\left(R^{2}=0.07, p=0.03\right)$, hunger $\left(R^{2}=0.07, p=0.02\right)$, desire to eat $\left(R^{2}=0.2, p<0.001\right)$ and negatively to post-meal fullness $\left(R^{2}=0.1\right.$, $p<0.01)$. Post-meal 'wanting' for cottage cheese was positively related to postmeal 'liking' for cottage cheese $\left(R^{2}=0.3, p<0.001\right)$ and desire to eat $\left(R^{2}=0.1\right.$, $\mathrm{p}<0.01)$.

Simple linear regression models showed a positive relationship between the difference in hunger $\left(R^{2}=0.1, p<0.01\right)$ and desire to eat $\left(R^{2}=0.1, p=0.03\right)$ pre- to post-consumption of chocolate mousse as dependent variables and fullness of taste of chocolate mousse pre-meal as independent variable. There was a negative relationship between the difference in fullness pre- to post-consumption 
of chocolate mousse and fullness of taste of chocolate mousse pre-meal $\left(R^{2}=0.1, p=0.02\right)$. A positive relationship was detected between the difference in hunger $\left(R^{2}=0.1, p=0.02\right)$ and desire to eat $\left(R^{2}=0.1, p=0.04\right)$ from pre- to postconsumption of chocolate mousse and 'liking' of chocolate mousse pre-meal. These relationships were not found in the cottage cheese condition.

\section{Computer test sensitivity}

Results of the computer test for relative 'liking' between categories are shown in Figure 3. Pre- to post-consumption of chocolate mousse, a change in the ranking of 'liking' of the six categories was observed, thereby decreasing the dessert category $(p<0.001)$ and increasing the placebo, i.e. the stationery category $(p<0.001)$, and the drinks category $(p<0.01)$. Pre- to post-consumption of cottage cheese, a decrease in the ranking of 'liking' of filling $(p<0.01)$ and an increase in the ranking of 'liking' of stationery $(p<0.001)$ and sweets $(p<0.01)$ was observed. There was a significant influence of the test meal on 'liking' for drinks $(p=0.01)$ and dessert $(p<0.001)$ pre- to post-meal. After consumption of chocolate mousse compared to consumption of cottage cheese, the stationery $(p=0.04)$ and drinks category ( $p=0.01$ ) had a higher ranking of 'liking', while the dessert category had a lower ranking of 'liking' $(p<0.001)$.

The ranking of 'liking' of the items within each category did not change significantly after consumption of chocolate mousse or cottage cheese $(p>0.1)$.

There was no significant time by condition (pre-/post-meal $\mathrm{x}$ chocolate mousse/cottage cheese) interaction for mean 'wanting' for items from any category $(p=0.2)$ and also not for 'wanting' for items per category $(p \geq 0.06)$. The mean 'wanting' for items from any category decreased after consumption of chocolate mousse $(p<0.01)$ as well as cottage cheese $(p=0.03)$. 


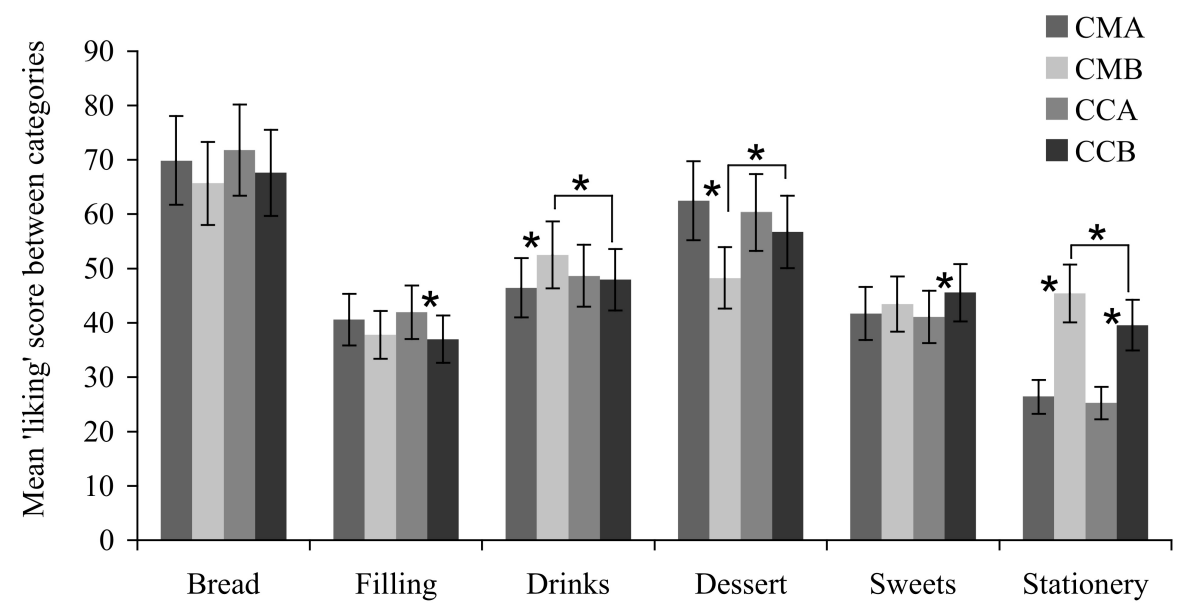

Figure 3. Relative 'liking' score between categories (mean $\pm S E M)$ pre- and post-consumption of chocolate mousse (CMA, CMB) and cottage cheese (CCA, CCB). ${ }^{*} \mathrm{p}<0.05$

Results of the computer test for 'wanting' per category are shown in Figure 4. Consumption of chocolate mousse induced a decrease in 'wanting' for bread $(p<0.001)$, filling $(p<0.001)$, drinks $(p=0.02)$ and dessert $(p<0.01)$. Consumption of cottage cheese induced a decrease in 'wanting' for bread only $(p<0.05)$. After consumption of chocolate mousse 'wanting' for bread $(p=0.04)$ and filling $(p=0.04)$ was lower than after consumption of cottage cheese.

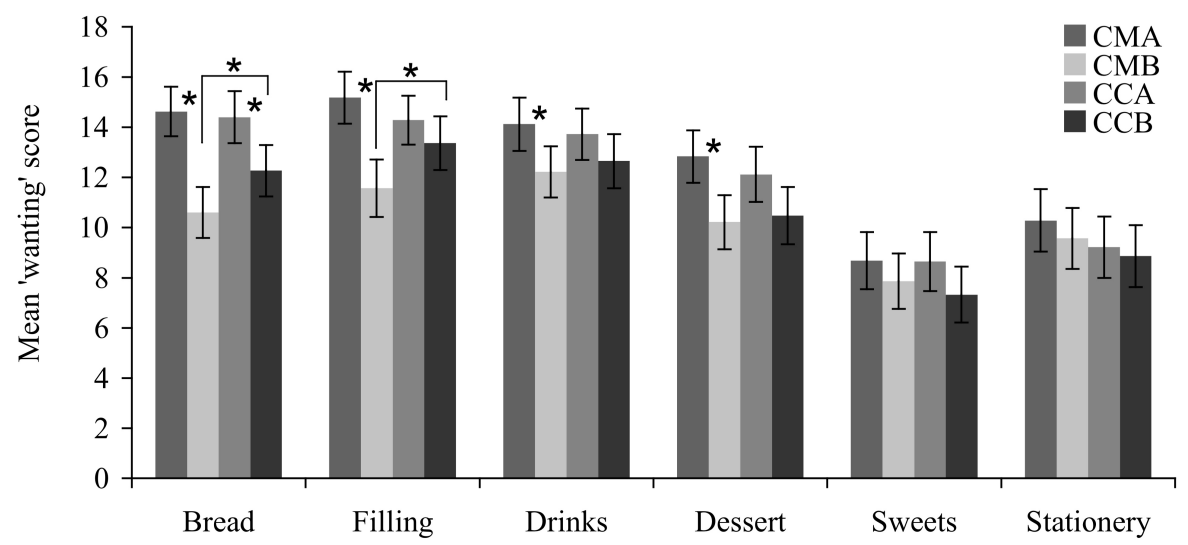

Figure 4. 'Wanting' score per category (mean \pm SEM) pre- and post-consumption of chocolate mousse (CMA, CMB) and cottage cheese (CCA, CCB). ${ }^{*} p<0.05$

Consumption of chocolate mousse decreased the motivation expressed as workload executed (number of items found in the memory game) for the bread $(p=0.04)$ and filling $(p=0.04)$ category. Consumption of cottage cheese did not decrease the motivation for any category. The motivation for the filling category 
was lower after consumption of chocolate mousse than after consumption of cottage cheese $(p=0.04)$.

The computer test showed a pre- to post-meal decrease in relative 'liking' for chocolate mousse by $53 \%$, in relative 'liking' for cottage cheese by $17 \%$, in relative 'wanting' for chocolate mousse by $64 \%$ and in relative 'wanting' for cottage cheese by $54 \%$. Subjective VAS showed a pre- to post-meal decrease in 'liking' for chocolate mousse by $15 \%$, in 'liking' for cottage cheese by $18 \%$, in 'wanting' for chocolate mousse by $81 \%$ and in 'wanting' for cottage cheese by $67 \%$. Both relative and absolute methods showed to be sensitive in detecting pre- to post-meal differences.

The sub-study showed that the attractiveness of the photographic stimuli used in the computer test was positively related to the pleasantness of taste of the food items $\left(R^{2}=0.5, p<0.0001\right.$, Figure 5).

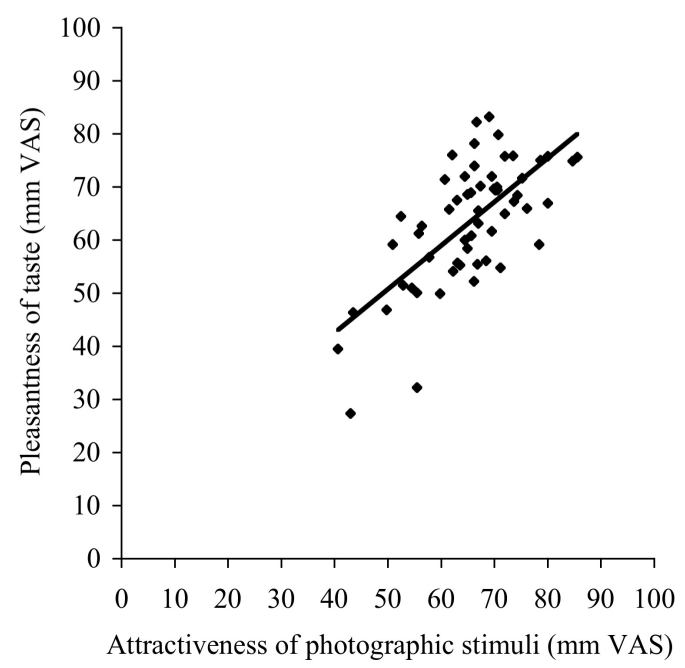

Figure 5. Scatter plot of the mean visual analogue scale (VAS) scores $(\mathrm{mm})$ for pleasantness of taste of the food items as a function of the attractiveness of the photographic stimuli of the same food items.

\section{Discussion}

The main objective of this study was to investigate the validity, i.e. reproducibility and sensitivity, of the developed computer test for assessment of the rewarding value of food in terms of 'liking' and 'wanting'. The 'liking' and 'wanting' part of the computer test showed a reproducibility of $62-73 \%$, still allowing room for variation and sensitivity. The computer test was sensitive to detect differences in 'liking' and 'wanting' for the used categories of items between pre- to postconsumption of chocolate mousse and cottage cheese. Thus, the validity of this test was shown to be sufficient. 
With respect to the findings using the computer test, consumption of chocolate mousse and cottage cheese induced an increase in relative 'liking', but not in 'wanting', for the non-food alternative, i.e. the stationery category. This increase in 'liking', but not in 'wanting', was also detected for the drinks category in the chocolate mousse condition and for the sweets category in the cottage cheese condition. Consumption of chocolate mousse decreased both 'liking' and 'wanting' for the dessert category. This altogether shows a specific decrease in 'liking' for the food category the eaten food belongs to, relative to placebo, the non-food category. Consumption of chocolate mousse appears to induce a more distinct change in 'liking' and 'wanting' for the different categories than consumption of cottage cheese. These findings may be related to some aspects of the concept of 'sensory specific satiety', which refers to the temporary decrease in pleasantness of a consumed food compared with a non-consumed food $(18,19)$. In our study, consumption of chocolate mousse, a dessert-specific food item, induced a stronger decrease in 'liking' and 'wanting' for the whole band-width of the dessert category, relative to the other categories, than consumption of cottage cheese.

Previous studies developed and used techniques to assess 'liking' and 'wanting'. Epstein et al. measured subjective estimates of 'liking' using VAS (3). Objective measures of taste reactivity were obtained by behavioral observation of taste stimuli (3). The reinforcing value of food, associated with the concept of 'wanting' food, was determined using the concurrent schedules of reinforcement paradigm $(3,13,20)$. Subjects completed a computer-generated concurrent schedules task to earn points that at the end of the task were exchanged for amounts of a preferred snack food or alternate reinforcers such as sedentary activities or money. The results showed that the paradigm was sensitive to the effects of food as a reinforcer (13). In another study by Epstein et al. on the interaction of food reinforcement and dopamine genotypes on eating, retesting 20 subjects verified the reliability of the test to measure the reinforcing value of food. A testretest correlation of $80 \%$ was detected (21). The measurement of 'wanting' in our study was comparable to the studies of Epstein et al. in that subjects had to work to gain access to reinforcers as food and stationery as non-food alternative. The difference is that in our study primarily food variety and secondarily amount of food were chosen as reinforcers instead of only amount of food to eat or money to earn. The power of a reinforcer may be influenced by culture: in the Dutch culture the amount of food is a smaller reinforcer than variety to choose from, mainly because in everyday life people in general prefer freedom of choice above hoarding (14). This was also reflected in our data: $76 \%$ of our subjects preferred food variety instead of amount of food. In the present study subjects only received chocolate mousse or cottage cheese, without choice, yet this standardization was used for validation. In future studies subjects will have to choose from a small to large variety of food items and from the number of categories they have worked for, combining food choice and amount of foods. The chosen food items will then have to be consumed. The Maastricht Medical 
Ethical Committee does not allow introducing money as part of an experiment, since all subjects should get paid equally for participation in an experiment.

Finlayson et al. developed a computerized tool to measure 'liking' and 'wanting' $(2,5,22)$. Explicit 'liking' and 'wanting' were measured using VAS combined with the questions "How pleasant would it be to experience a mouthful of this food now?" and "How much do you want some of this food now?" Implicit 'wanting' was measured by means of a forced choice paradigm. Stimuli were presented in pairs and subjects had to respond to according to which food they would most like to eat at that moment. The implicit 'wanting' paradigm was improved by measuring the reaction time of each choice. This provided a quantifiable measure related to the relative 'wanting' for that chosen food item. Food was the only reinforcer used in this paradigm; there were no alternate reinforcers. Whether the validity of this computerized tool was tested, is not completely clear. Finlayson et al. indicate that the forced choice paradigm measures relative behavioral preference and probably contains an element of 'liking'. The incorporation of the reaction time measurement in the studies of Finlayson et al. is an improvement of the paradigm and might give a better indication of the motivation to obtain a desired food. We used the forced choice paradigm for the assessment of relative 'liking' (preference) instead of 'wanting'. Our subjects had to indicate their preference of paired items as a measure of relative 'liking'. In addition, their 'liking' was measured absolutely by means of subjective VAS. A positive relationship was found between the scores of both 'liking' measures, which indicates that outcomes were rather stable within subjects, yet absolute 'liking' scores were continuously higher than relative 'liking' scores. The difference between absolute and relative 'liking' scores is of interest since it indicates the difference between highly liked but still less liked items.

The attractiveness of the visual input used in our computer test was positively related to the pleasantness of taste of the food items. This indicates that the used photographic stimuli are representative for the actual taste of the food items and are cues that can predict 'liking' and possibly 'wanting'.

Chocolate mousse, a dessert-specific food item, was liked more and perceived as more full of taste than cottage cheese, a dessert non-specific and neutral food item. Chocolate mousse induced a larger decrease in hunger and desire to eat than cottage cheese, although the offered amount of both food items was isoenergetic. These findings can be explained by the higher 'liking' and fullness of taste of chocolate mousse compared with cottage cheese. This is in accordance with previous research showing that palatability prolongs satiation (23).

Subjective estimates of 'liking' and 'wanting' for chocolate mousse and cottage cheese were measured using VAS. In the fasted state, 'liking' for chocolate mousse or cottage cheese was the best predictor for 'wanting' for both food items. In the satiated state, 'wanting' for chocolate mousse was predominantly determined by desire to eat in general, and 'wanting' for cottage cheese was determined by 'liking' for cottage cheese. These results may implicate that food 
'wanting' in the satiated state is predominantly determined non-homeostatically by 'liking' or desire to eat: in the absence of hunger, chocolate mousse will only be eaten if there is still a desire to eat, while cottage cheese will only be eaten if it is liked very much.

In summary, the developed computer test for measurement of reward in terms of 'liking' and 'wanting' is valid in that it has a sufficient reproducibility and sensitivity. Consumption of a food item that is highly liked and perceived as highly full of taste induces a more distinct decrease in hunger, desire to eat and 'wanting' of food items in general than consumption of a neutral food item. Moreover, only such a highly liked food item induces a reduction in ranking of its category-specific 'liking', relative to other categories.

Thus, the main goal of the current study, which was the validation of the computer test, appears to have been achieved, and as a methodological contribution this technique seems likely to be useful in the future.

\section{Acknowledgements}

We thank our subjects for their participation in this study and Sanne Verhoef for her help with the practical work. The study was designed by MSWP and SGTL. SGTL (supervised by MSWP) carried out the study, collected and analyzed the data and wrote the largest part of the manuscript. PFMS, together with SGTL and LW, developed the computer test for measurement of 'liking' and 'wanting'. MJI carried out the sub-study measuring the attractiveness of the photographic stimuli and the pleasantness of taste of the food items. FR and JMB reviewed the manuscript. 


\section{Appendix}

Table A1. Description of the 72 items divided in six categories used in this study.

\begin{tabular}{|c|c|c|c|c|c|}
\hline Bread & Filling & Drinks & Dessert & Sweets & Stationery \\
\hline Baguette & Apricot jam & Apple juice & Apple & Cigarette & Blocknote \\
\hline Brown bread & Brie cheese & Buttermilk & Banana & $\begin{array}{l}\text { Doritos (nacho } \\
\text { cheese) }\end{array}$ & Marker \\
\hline Brown hard roll & Chocolate paste & $\begin{array}{l}\text { Carbonated } \\
\text { water }\end{array}$ & Butter cookie & $\begin{array}{l}\text { Lay's natural } \\
\text { chips }\end{array}$ & Paper \\
\hline $\begin{array}{l}\text { Brown soft } \\
\text { bread }\end{array}$ & $\begin{array}{l}\text { Chocolate } \\
\text { sprinkles }\end{array}$ & $\begin{array}{l}\text { Chocolate } \\
\text { milk }\end{array}$ & Cake & $\begin{array}{l}\text { Lay's paprika } \\
\text { chips }\end{array}$ & Pen \\
\hline Cracker & Egg salad & Coca cola & $\begin{array}{l}\text { Chocolate } \\
\text { custard }\end{array}$ & Liquorish & Pencil \\
\hline Croissant & Forest fruit jam & Fanta & $\begin{array}{l}\text { Chocolate } \\
\text { mousse }\end{array}$ & Milk chocolate & $\begin{array}{l}\text { Pencil } \\
\text { eraser }\end{array}$ \\
\hline Currant bread & Fruit sprinkles & Fristi & $\begin{array}{l}\text { Cottage } \\
\text { cheese }\end{array}$ & $\begin{array}{l}\text { Napoleon sour } \\
\text { bon bons }\end{array}$ & $\begin{array}{l}\text { Pritt } \\
\text { correction }\end{array}$ \\
\hline Pumpernickel & Gouda cheese & Milk & $\begin{array}{l}\text { Forest fruit } \\
\text { yoghurt }\end{array}$ & Peanuts & Pritt stick \\
\hline White bread & Ham & Orange juice & Liege waffle & $\begin{array}{l}\text { TUC (original) } \\
\text { biscuits }\end{array}$ & Ruler \\
\hline White hard roll & Peanut butter & Plain water & $\begin{array}{l}\text { Marzipan } \\
\text { cake }\end{array}$ & Twix & Scissors \\
\hline White soft roll & Salami & Schweppes & Orange & White chocolate & Sharpener \\
\hline $\begin{array}{l}\text { Whole wheat } \\
\text { roll }\end{array}$ & Sandwichspread & $\begin{array}{l}\text { White wine } \\
\text { (alcohol free) }\end{array}$ & $\begin{array}{l}\text { Vanilla } \\
\text { custard }\end{array}$ & Wine gums & Tape \\
\hline
\end{tabular}




\section{References}

1. Berthoud HR. Neural control of appetite: cross-talk between homeostatic and non-homeostatic systems. Appetite. 2004 Dec;43(3):315-7.

2. Finlayson G, King N, Blundell JE. Liking vs. wanting food: Importance for human appetite control and weight regulation. Neurosci Biobehav Rev. 2007 Mar 27.

3. Epstein LH, Truesdale R, Wojcik A, Paluch RA, Raynor HA. Effects of deprivation on hedonics and reinforcing value of food. Physiol Behav. 2003 Feb;78(2):221-7.

4. Berridge KC. Food reward: brain substrates of wanting and liking. Neurosci Biobehav Rev. 1996;20(1):1-25.

5. Finlayson G, King N, Blundell JE. Is it possible to dissociate 'liking' and 'wanting' for foods in humans? A novel experimental procedure. Physiol Behav. 2007 Jan 30;90(1):36-42.

6. Mela DJ. Eating for pleasure or just wanting to eat? Reconsidering sensory hedonic responses as a driver of obesity. Appetite. 2006 Jul;47(1):10-7.

7. Berridge KC. Motivation concepts in behavioral neuroscience. Physiol Behav. 2004 Apr;81(2):179-209.

8. Stunkard AJ, Messick S. The three-factor eating questionnaire to measure dietary restraint, disinhibition and hunger. J Psychosom Res. 1985;29(1):71-83.

9. Robinson TE, Berridge KC. Incentive-sensitization and addiction. Addiction. 2001 Jan;96(1):10314.

10. Berridge KC, Robinson TE. The Mind of an Addicted Brain: Neural Sensitization of Wanting Versus Liking. Current Directions in Psychological Science. 1995;4(3):71-6.

11. Epstein LH, Wright SM, Paluch RA, Leddy J, Hawk LW, Jr., Jaroni JL, et al. Food hedonics and reinforcement as determinants of laboratory food intake in smokers. Physiol Behav. 2004 May;81(3):511-7.

12. Steiner JE. Human facial expressions in response to taste and smell stimulation. Adv Child Dev Behav. 1979;13:257-95.

13. Lappalainen R, Epstein LH. A behavioral economics analysis of food choice in humans. Appetite. 1990 Apr;14(2):81-93.

14. Hofstede G. Culture's Consequences, Comparing Values, Behaviors, Institutions, and Organizations Across Nations. Thousand Oaks CA: Sage Publications; 2001.

15. McArdle WD, Katch FI, Katch VL. Exercise Physiology. 4th ed. Baltimore: Williams and Watkins; 1996.

16. Harris JA, Benedict FG. A Biometric Study of Human Basal Metabolism. Proc Natl Acad Sci U S A. $1918 \mathrm{Dec} ; 4(12): 370-3$.

17. Diepvens K, Haberer D, Westerterp-Plantenga M. Different proteins and biopeptides differently affect satiety and anorexigenic/orexigenic hormones in healthy humans. Int $\mathrm{J}$ Obes (Lond). 2008 Mar;32(3):510-8.

18. Rolls BJ. Sensory-specific satiety. Nutr Rev. 1986 Mar;44(3):93-101.

19. Sorensen LB, Moller P, Flint A, Martens M, Raben A. Effect of sensory perception of foods on appetite and food intake: a review of studies on humans. Int J Obes Relat Metab Disord. 2003 Oct;27(10):1152-66.

20. Saelens BE, Epstein LH. Reinforcing value of food in obese and non-obese women. Appetite. 1996 Aug;27(1):41-50.

21. Epstein LH, Temple JL, Neaderhiser BJ, Salis RJ, Erbe RW, Leddy JJ. Food reinforcement, the dopamine D2 receptor genotype, and energy intake in obese and nonobese humans. Behav Neurosci. 2007 Oct;121(5):877-86.

22. Finlayson G, King N, Blundell J. The role of implicit wanting in relation to explicit liking and wanting for food: Implications for appetite control. Appetite. 2008 Jan;50(1):120-7.

23. De Graaf C, De Jong LS, Lambers AC. Palatability affects satiation but not satiety. Physiol Behav. 1999 Jun;66(4):681. 



\section{Chapter 4}

\section{Dietary restraint and control over 'wanting' following consumption of 'forbidden' food}

Lemmens SG, Born JM, Rutters F, Schoffelen PF, Wouters L, Westerterp-

Plantenga MS

Obesity (Silver Spring). 2010 Oct;18(10):1926-31. Epub 2010 Feb 25 


\section{Abstract}

Eating behavior can be influenced by the rewarding value of food, i.e., 'liking' and 'wanting'.

The objective of this study was to assess in normal weight dietary restrained (NR) vs. unrestrained (NU) eaters how rewarding value of food is affected by satiety, and by eating a nonhealthy perceived, dessert-specific food vs. a healthy perceived, neutral food (chocolate mousse vs. cottage cheese).

Subjects $\left(24 \mathrm{NR}\right.$ age $=25.0 \pm 8.2$ years, $\mathrm{BMI}=22.3 \pm 2.1 \mathrm{~kg} / \mathrm{m}^{2} ; 26 \mathrm{NU}$ age $=24.8 \pm 8.0$ years, $B M I=22.1 \pm 1.7 \mathrm{~kg} / \mathrm{m}^{2}$ ) came to the university twice, fasted (randomized crossover design). Per test session 'liking' and 'wanting' for 72 items divided in six categories (bread, filling, drinks, dessert, sweets, stationery (placebo)) was measured, before and after consumption of chocolate mousse/cottage cheese, matched for energy content $(5.6 \mathrm{~kJ} / \mathrm{g})$ and individual daily energy requirements (10\%).

Chocolate mousse was liked more than cottage cheese $(p<0.05)$. After consumption of chocolate mousse or cottage cheese, appetite and 'liking' vs. placebo were decreased in NR and NU ( $p<0.03)$, whereas 'wanting' was only decreased in NR vs. NU ( $p \leq 0.01)$. In NR vs. NU 'wanting' was specifically decreased after chocolate mousse vs. cottage cheese; this decrease concerned especially 'wanting' for bread and filling $(p<0.05)$.

To conclude, despite similar decreases in appetite and 'liking' after a meal in NR and NU, NR decrease 'wanting' in contrast to NU. NR decrease 'wanting' specifically for a nonhealthy perceived, 'delicious', dessert-specific food vs. a nutritional identical, yet healthy perceived, slightly less 'delicious', 'neutral' food. A healthy perceived food may thus impose greater risk for control of energy intake in NR. 


\section{Introduction}

Currently, appetite research is paying attention to the food reward system as an important non-homeostatic regulator of human eating behavior. Unraveling this reward system may help us to understand the factors that influence the excessive food intake associated with obesity (1-3).

According to the incentive salience theory the process of reward consists of two components, i.e., 'liking' and 'wanting', controlled by different brain mechanisms (4). 'Liking', under control of opioids, is the hedonic or affective component and refers to the pleasure derived from orosensory stimulation of food $(5,6)$. 'Wanting', under control of dopamine, is the motivational incentive component and refers to appetite or craving or the motivation to obtain food $(1,4-7)$. Although 'liking' and 'wanting' often go hand-in-hand, humans may want less liked food items, cultivated as a habit, as for instance restrained eaters do: they cognitively restrict their food intake to lose weight or to prevent weight gain $(6,8)$. Furthermore, in research on drug addiction it was observed that drug addicts are driven to take drugs without 'liking' their effects $(9,10)$. Taking the above into account, it is of importance to differentiate between the influences of 'liking' and 'wanting' on food intake. Moreover, since successful dietary restrained eaters control their food intake more cognitively, it is relevant to assess whether effects of 'liking' and 'wanting' on food intake differ between dietary restrained and unrestrained eaters (11).

The aim of this study was to assess in normal weight, and thus successful, dietary restrained eaters (NR) vs. normalweight dietary unrestrained (NU) eaters how the rewarding value of food in general, and more specific in terms of 'liking' and 'wanting', is affected by satiety, and by the consumption of food items that may differ in rewarding value: a dessert-specifc food item, i.e., chocolate mousse, vs. a dessert nonspecifc, 'neutral' food item, i.e., cottage cheese. A computer test for measurement of 'liking' and 'wanting', developed and validated in a previous study, was used (12). That previous study indicated that chocolate mousse was mostly described as a delicious but less healthy food item and cottage cheese as a healthy food item, whereas both items had the same energy content and density (12). Foods classified as unhealthy are commonly considered to contain more calories than healthy foods (13).

However, the caloric content of 'healthy foods' may often be underestimated and consumption of those foods may influence the amount of intake or the subsequent food choice, possibly related to individual differences (14). Hence, a possible pitfall for restrained eaters to regulate their body weight cognitively may be the consumption of 'healthy foods'. Consumption of those foods may not be perceived as a violation of adhering to their dieting rules and consequently may lead to an increased food and energy intake.

Terefore, consumption of chocolate mousse and cottage cheese, as examples of nonhealthy respectively healthy food items, may exert different effects on the 
rewarding value of foods, in terms of 'liking' and 'wanting', in NR subjects compared with NU subjects. We hypothesize that in NR subjects in contrast to NU subjects consumption of chocolate mousse may prevent further 'wanting' of foods, whereas consumption of cottage cheese may still allow further 'wanting' of foods.

\section{Methods and procedures}

\section{Subjects}

Fifty normal weight white subjects (15 males and 35 females, age $24.9 \pm 8.0$ years (mean $\pm S D$, range $18-51$ years)) with a $B M I$ of $22.2 \pm 1.9 \mathrm{~kg} / \mathrm{m}^{2}($ mean $\pm S D$, range $18.9-25.3 \mathrm{~kg} / \mathrm{m}^{2}$ ) participated in this study. They were recruited by advertisements in local newspapers and on notice boards at the university and hospital. Subjects underwent an initial screening including measurement of body weight and height and completion of a questionnaire related to health, use of medication, smoking behavior, alcohol consumption and physical activity. Eating behavior was analyzed using a validated Dutch translation of the Three Factor Eating Questionnaire (TFEQ) which measures three components: 'cognitive restraint of eating' (factor 1), 'disinhibition of restraint' (factor 2) and 'hunger' (factor 3) (8). Factor 1 describes the tendency to which individuals attempt to cognitively control their food intake. Factor 2 describes the loss of control over eating in situations that make the cognitive control more difficult. Factor 3 describes the subjective feeling of hunger (8). On the basis of the median for the TFEQ scores in the south of the Netherlands, subjects were characterized as unrestraint when dietary restraint scores were $<9$, and as restraint when scores were $\geq 9$. Subjects were characterized as having low disinhibition when disinhibition scores were $<5$, and as having high disinhibition when scores were $\geq 5$ (15). Subjects were divided into two groups according to their scores on the TFEQ restraint scale: a restrained group $(n=24)$ and an unrestrained group $(n=26)$. All subjects gave written informed consent by the start of the first test day. The study was approved by the Medical Ethical Committee of the Maastricht University.

\section{Study design}

The study was conducted in a randomized cross-over design as described previously by Lemmens et al. (12). All subjects came to the university twice in a fasted state, between 08:00 and 10:00 AM. The test sessions differed only in the presentation of the test meal: either chocolate mousse or cottage cheese.

The test session started by filling out visual analogue scales (VAS) on appetiterelated parameters. Subsequently the researcher gave the instructions on the computer test for measurement of 'liking' and 'wanting'. After completing the 
computer test, subjects had to consume the entire test meal. Immediately postingestion subjects filled out the VAS and completed the computer test again.

\section{Appetite profile}

One hundred unit VAS $(\mathrm{mm})$ were used to assess the appetite profile. The scales were anchored with 'not at all' at one end and 'extremely' at the other end, and combined with questions on feelings of hunger, thirst, fullness, satiety, desire to eat, and on 'liking', 'wanting', creaminess, and fullness of taste of chocolate mousse and cottage cheese. These VAS were completed in the fasted and satiated state. Subjects received a full tutorial on the completion of VAS on appetite-related parameters before the start of the actual experiment.

\section{Test meal}

The test meal consisted of either chocolate mousse or cottage cheese (both 0.6 MJ per 100 g; energy \% protein/carbohydrate/fat: 21/29/50) and a glass of water $(250 \mathrm{~mL})$. The amount of chocolate mousse or cottage cheese given to the subjects corresponded to $10 \%$ of their daily energy requirements. For each subject the daily energy requirements were calculated by multiplying the basal metabolic rate (BMR) by the appropriate physical activity factor (1.5-1.8, derived from the screening questionnaire, (16)). The BMR (MJ/d) was calculated according to the equation of Harris-Benedict (17). On average subjects received 1.1 $\mathrm{MJ}$ (range 0.8-1.6 MJ) of chocolate mousse or cottage cheese, corresponding to an average of $204 \mathrm{~g}$ (range 148-290 g). This range was present because of the subject-specific calculated energy requirements. The order of presentation of the test meal was randomized across the subjects to prevent any order effects. Factorial ANOVA analysis showed no significant effect of the order the subjects received the test meals, chocolate mousse or cottage cheese, respectively, concerning the data of the appetite profile measurements and of the 'liking' and 'wanting' computer test ( $p>0.05)$.

\section{'Liking' and 'wanting' computer test}

The computer test described and validated by Lemmens et al. was used to measure the rewarding value, i.e. 'liking' and 'wanting', for 72 items divided in six categories: bread, filling, drinks, dessert, sweets, and stationery (non-food alternative as placebo) (12). Each category contained 12 items. The 72 items were presented as photographic stimuli on a computer screen (13-inch Mac Book, Apple, Cupertino, USA).

During the 'liking' part of the computer test subjects had to indicate their relative preference of paired items within and between categories, resulting in a ranking of 'liking' of the items per category and of the categories. 
During the 'wanting' part of the computer test subjects had to work to earn items to choose from by playing memory games. For each category of items subjects played a five by five memory game (12 pairs of items) followed by the indication of the items subjects wanted to acquire at that moment. If for example eight pairs of items would be found in the memory game of the sweets category, then eight randomly selected sweets would be offered to choose from. Subjects could choose zero, one or two items per category. They were instructed to choose the items while keeping in mind that all the chosen items would be offered to them and had to be eaten completely. The chosen items obtained a score equal to the number of pairs of items found in the memory game, representing the motivation or workload for the chosen items. Items not chosen obtained a score of zero. Per category the sum of the scores of the items was calculated and represented the 'wanting' score for each category. The reward consisted primarily of magnitude of food variety offered per category and secondarily of meal size consisting of the number of different categories that subjects had worked for.

\section{Statistics}

Data were analysed using StatView 5.0 (SAS Institute, Cary, NC, USA). Differences over time (pre- to post-meal), between subject groups (NR and NU) and between conditions (chocolate mousse and cottage cheese) were analyzed using paired Student's t-tests, factorial ANOVA or two-factor ANOVA with repeated measures. The Wilcoxon signed-rank test was used to detect differences in the ranking of 'liking' of items within each category between pre- to post-meal. Simple linear regression models were used to determine relationships between TFEQ scores and mean 'wanting' for items from any category. All tests were two-sided and differences were considered significant at $p<0.05$. Values are expressed as mean \pm standard error of the mean (SEM).

\section{Results}

\section{Subject characteristics}

The characteristics of the subjects are summarized in Table 1. Age, BMI, and disinhibition scores did not differ between NR and NU subjects. NU subjects had a higher height and body weight compared with NR subjects $(p<0.01)$, due to the higher number of men in the NU group. NR subjects had higher dietary restraint and lower feeling of hunger scores than NU subjects $(p<0.05)$.

Taking gender into account, male subjects showed an overall higher mean 'wanting' for items from any category in the chocolate mousse and cottage cheese condition $(p<0.02)$. There was no gender effect for the change in appetite profile ratings and in 'liking' and 'wanting' scores pre- to post-consumption of 
chocolate mousse and cottage cheese. Therefore those results for male and female subjects were analyzed together.

Table 1. Characteristics of normal weight dietary restrained (NR) and unrestrained (NU) subjects.

\begin{tabular}{|c|c|c|c|}
\hline & $\begin{array}{c}N R \\
(n=24 ; 3 m / 21 f)\end{array}$ & $\begin{array}{c}\text { NU } \\
(n=26 ; 12 m / 14 f)\end{array}$ & $\mathrm{p}^{\mathrm{a}}$ \\
\hline Age (years) & $25.0 \pm 8.2$ & $24.8 \pm 8.0$ & 1.0 \\
\hline Height $(\mathrm{cm})$ & $168.6 \pm 8.1$ & $177.6 \pm 7.1$ & $<0.001$ \\
\hline Body weight (kg) & $63.3 \pm 7.9$ & $69.9 \pm 7.1$ & $<0.01$ \\
\hline BMI $\left(\mathrm{kg} / \mathrm{m}^{2}\right)$ & $22.3 \pm 2.1$ & $22.1 \pm 1.7$ & 0.8 \\
\hline Dietary restraint score & $11.8 \pm 2.2$ & $4.0 \pm 2.4$ & $<0.001$ \\
\hline Disinhibition score & $4.5 \pm 2.0$ & $4.5 \pm 2.0$ & 1.0 \\
\hline Feeling of hunger score & $3.2 \pm 1.8$ & $4.7 \pm 2.9$ & 0.04 \\
\hline
\end{tabular}

Values are means $\pm S D ;{ }^{a} p$-value: differences between subject groups (factorial ANOVA)

\section{Appetite profile}

Table 2 shows the results of the appetite profile measurements by means of VAS in the NR and NU subject groups and in the chocolate mousse and cottage cheese condition. In both subject groups high ratings for hunger, thirst and desire to eat and low ratings for fullness and satiety were measured at the start of the two test sessions, confirming their fasted state. In both subject groups and both conditions, meal consumption induced a decrease in hunger, thirst and desire to eat and an increase in fullness and satiety $(p<0.02)$, confirming that subjects were in a satiated state when they fulfilled the second computer test.

Both subject groups liked chocolate mousse more than cottage cheese $(p<0.02)$ and perceived chocolate mousse as more full of taste than cottage cheese $(p<0.01)$, before as well as after consumption of both food items. In both groups and both conditions 'liking' and 'wanting' for chocolate mousse respectively cottage cheese decreased after test meal consumption $(p<0.03)$.

The changes in these appetite profile parameters pre- to post-consumption did not differ between NR and NU subjects $(p>0.1)$. 


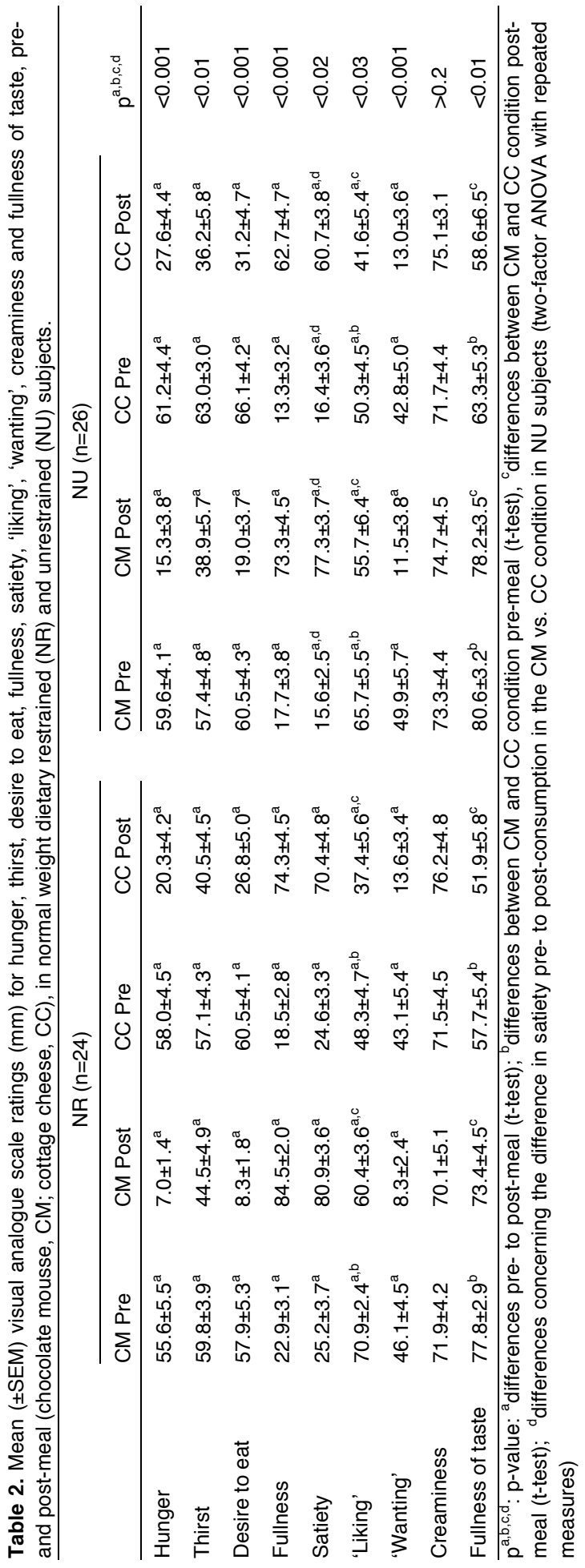




\section{'Liking' and 'wanting' computer test}

Table 3 shows the results of the computer test for relative 'liking' between categories in NR and NU subjects and in the chocolate mousse and cottage cheese condition. Pre- to post-consumption of chocolate mousse, a change in the ranking of 'liking' of the six categories was observed in both subject groups, thereby decreasing the dessert category and increasing placebo, the stationery category $(p<0.001)$. This decrease in 'liking' for the dessert category was larger in the chocolate mousse condition than in the cottage cheese condition in both subject groups $(p<0.05)$. Pre- to post-consumption of cottage cheese an increase in the ranking of 'liking' of stationery $(p<0.001)$ was observed in both subject groups. The changes in the ranking of 'liking' of the categories pre- to post-consumption of both test meals did not differ between subject groups $(p>0.1)$. The ranking of 'liking' of the items within each category did not change significantly in both conditions and in both subject groups $(p>0.1)$.

Figure 1 shows mean 'wanting' for items from any category in NR and NU subjects and in the chocolate mousse and cottage cheese condition. In both conditions there was a significant time by group interaction (pre-/post-meal $x$ NR/NU subject group) for mean 'wanting' for items from any category $(p \leq 0.01)$. Mean 'wanting' for items decreased pre- to post-consumption of chocolate mousse and cottage cheese in the NR subjects $(p<0.01)$ but not in the NU subjects. Therefore, the decrease in mean 'wanting' for items from any category pre- to postconsumption of chocolate mousse $(p<0.01)$ and cottage cheese $(p=0.01)$ was higher in NR subjects than in UR subjects.

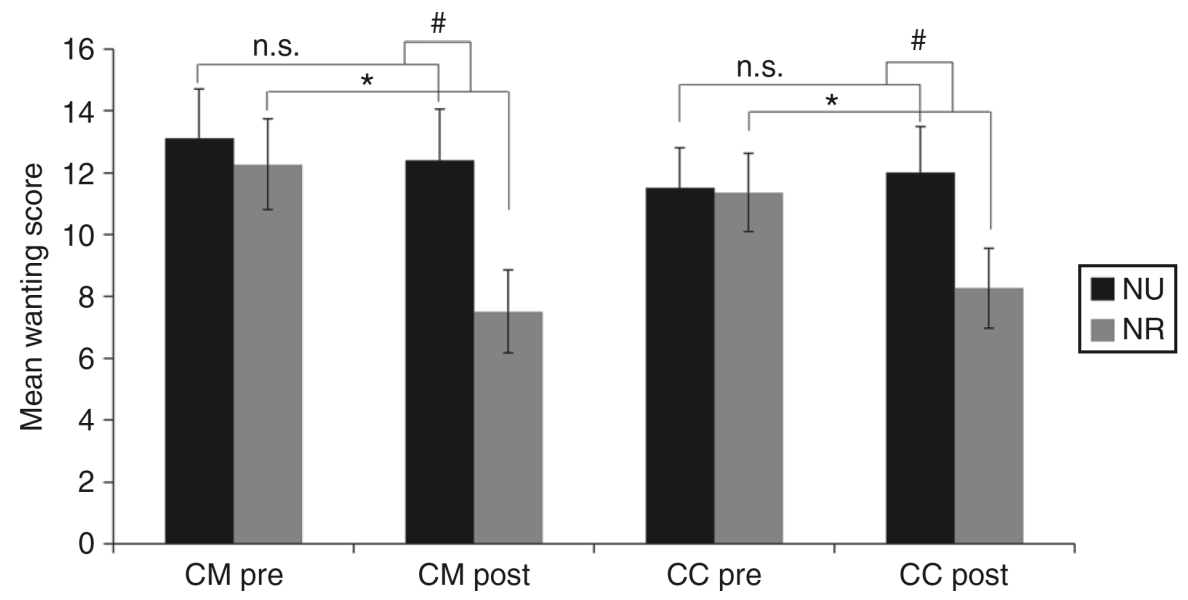

Figure 1. Mean 'wanting' score $( \pm S E M)$ for items from any category pre- and post-consumption of chocolate mousse (CM) and cottage cheese (CC) in normal weight dietary restrained (NR) and unrestrained (NU) subjects. ${ }^{*} p<0.01$ for differences pre- to post-meal (t-test), $\# p<0.01$ for differences between NR and NU subjects concerning the difference in 'wanting' pre- to post-consumption of CM and CC (factorial ANOVA) 


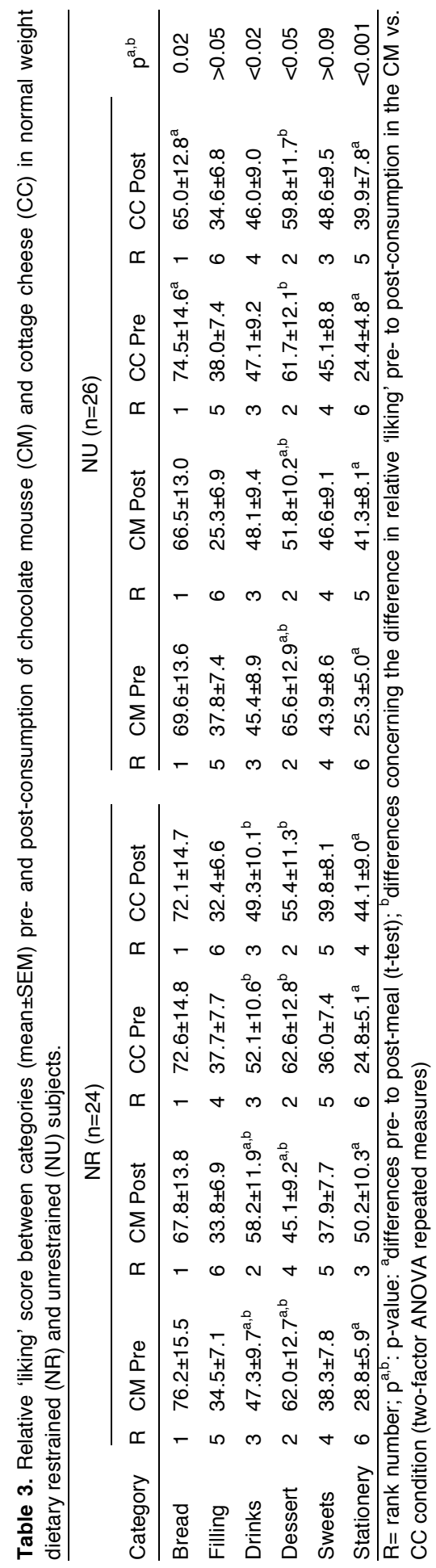


Moreover (Table 4), in NR subjects consumption of chocolate mousse induced a decrease in 'wanting' for bread $(p<0.001)$, filling $(p<0.001)$, drinks $(p=0.01)$, dessert $(p=0.01)$ and stationery $(p=0.03)$. Consumption of cottage cheese induced a decrease in 'wanting' for drinks $(p<0.01)$ and dessert $(p=0.02)$. The decrease in 'wanting' for bread and filling pre- to post-consumption of chocolate mousse and cottage cheese was higher in the chocolate mousse condition compared with the cottage cheese condition ( $p<0.02$; Figure 2$)$. NU subjects did not show a significant change in 'wanting' per category in both conditions. Consequently, the decrease in 'wanting' for bread and filling pre- to post-consumption of chocolate mousse was higher in NR subjects compared with NU subjects.

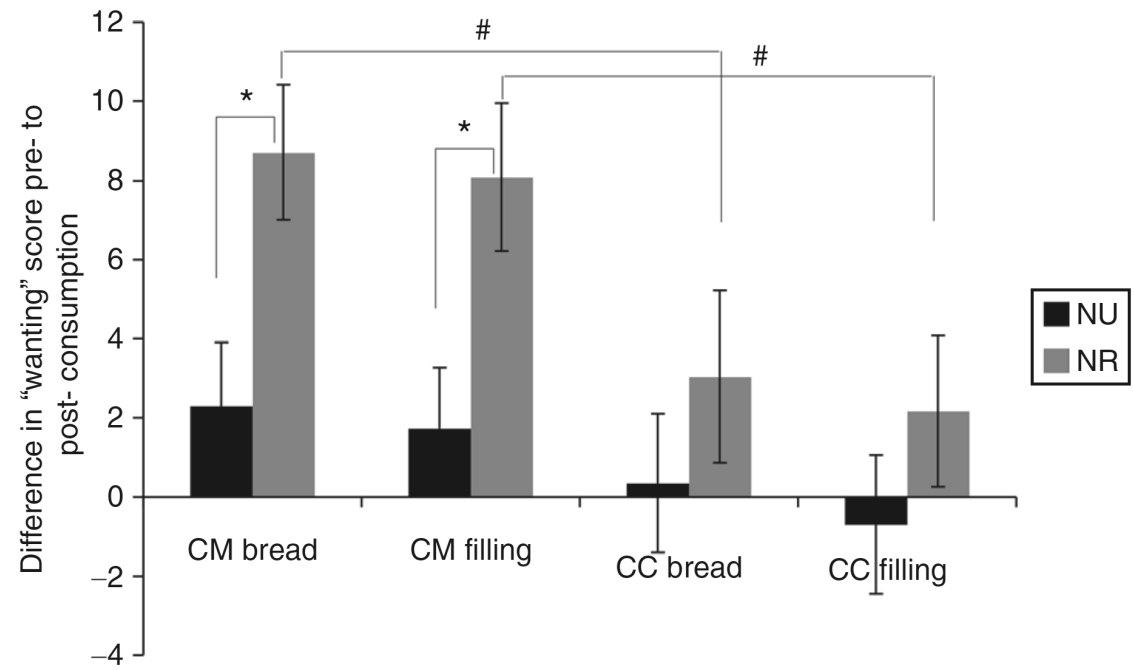

Figure 2. Difference in mean 'wanting' score $( \pm$ SEM) pre- to post-consumption of chocolate mousse (CM) and cottage cheese (CC), for the bread and filling category in normal weight dietary restrained (NR) and unrestrained (NU) subjects. ${ }^{*} \mathrm{p} \leq 0.01$ for differences between NR and NU subject groups (factorial ANOVA), $\# \mathrm{p}<0.05$ for differences between CM and CC condition (two-factor ANOVA repeated measures)

A simple linear regression model showed a negative relationship between dietary restraint scores (factor 1 TFEQ) and mean 'wanting' for items from any category after chocolate mousse consumption $\left(R^{2}=0.1, p=0.04\right)$. 


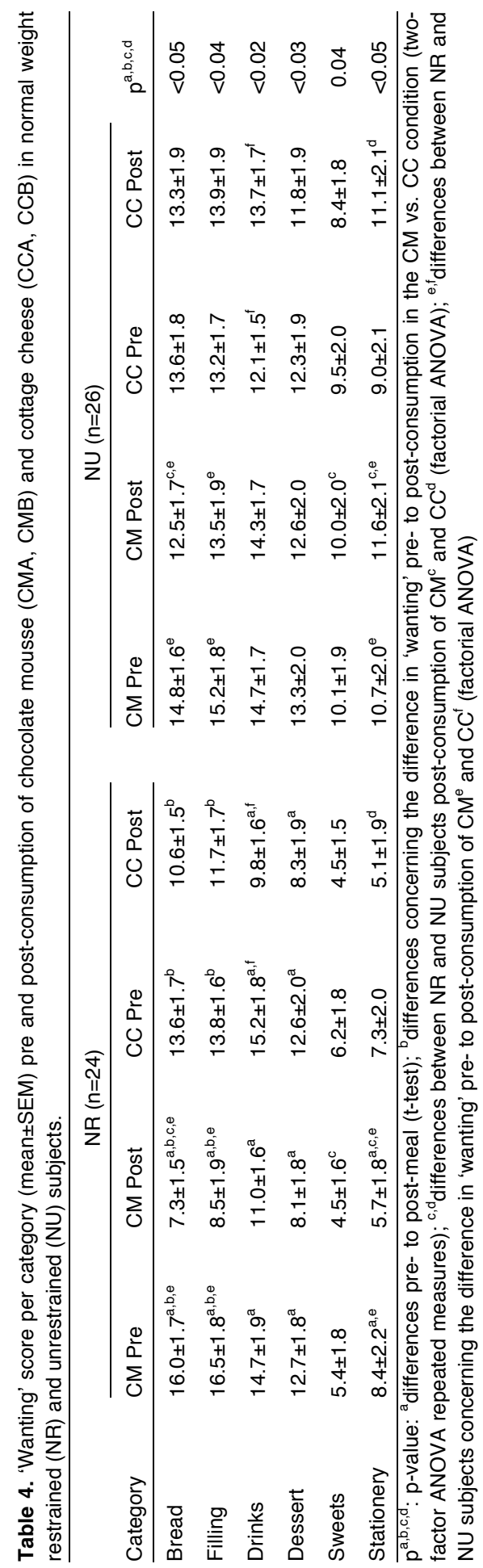




\section{Discussion}

The objective of this study was to assess pre- to post-meal changes in the rewarding value of food, in terms of 'liking' and 'wanting', as a function of dietary restraint. Two contrasting, but otherwise similar and iso-energetic foods, mostly consumed as a dessert, were used as a meal. One of the foods, cottage cheese, was perceived as a healthy food, while the other food, chocolate mousse, was perceived as a non-healthy food, and often avoided by dieters. Subjects perceived chocolate mousse as more full of taste than cottage cheese and scored it higher on the VAS 'liking' scale.

Pre- to post-meal changes in appetite profile parameters consisted of a similar decrease in appetite in both NR and NU subjects.

Also ranking of 'liking' of the used categories of items (bread, filling, drinks, dessert, sweets, stationery) changed similarly in both subject groups pre- to post-meal. In both conditions (chocolate mousse and cottage cheese) and in both subject groups, test meal consumption induced an increase in relative 'liking' for the non-food alternative, i.e. the stationery category. Consumption of chocolate mousse induced a decrease in relative 'liking' for the dessert category, which is the food category the eaten food belongs to. While ranking of 'liking' changed between categories, within each category there was no significant change in ranking of 'liking' of the items in both conditions and subject groups.

Despite these similarities between NR and NU subjects concerning appetite and 'liking' pre- to post-consumption of chocolate mousse and cottage cheese, there was a large difference in the change in 'wanting' pre- to post-meal. NU subjects showed no decrease in 'wanting' after eating either chocolate mousse or cottage cheese. In contrast to NU subjects, restrained subjects showed a decrease in mean 'wanting' for items from any category after test meal consumption. In particular consumption of chocolate mousse induced a more distinct decrease in 'wanting', especially for the bread and filling category, than consumption of cottage cheese. NU subjects seem to be unaffected by the type of food eaten (i.e. chocolate mousse/cottage cheese), while NR subjects seem to be less successful in cognitively controlling their subsequent 'wanting' when a healthy perceived food item (cottage cheese) is consumed than when a highly palatable and less healthy perceived food item (chocolate mousse) is consumed, as their decrease in 'wanting' was more distinct after chocolate mousse consumption than after cottage cheese consumption. This is in line with Fishbach et al. indicating that exposing restrained eaters to tempting and 'forbidden' foods may make them more conscious about their weight and eating behavior when planning future food consumption (18). This also implies that dietary restraint subjects are very much focused on unhealthy 'forbidden' foods. Therefore, when one follows a diet, it may well be more satisfactory to consume in this case a real dessert thereby decreasing not only 'wanting' for dessert but also for many other 
food items, instead of consuming a 'healthy' food that does not limit consumption of other foods.

NR subjects in our study had a relatively low mean disinhibition score and were normal weight, indicating they are successful restraint (19). Testing for possible effects of subject's disinhibition scores (factor 2 TFEQ) by means of ANOVA and regression analyses, showed that disinhibition had no effect on relative 'liking' and 'wanting' in the chocolate mousse and cottage cheese condition.

A regression analysis indicated that mean 'wanting' for items from any category after chocolate mousse consumption, but not after cottage cheese consumption, was inversely related to restraint scores (Factor 1 TFEQ). This may again implicate that the type of food consumed has got influence on subsequent 'wanting' when being dietary restraint, and the more restraint a subject's attitude is, the stronger the decrease in 'wanting'.

In summary, in NR subjects as well as in NU subjects, eating a highly liked food item induces a lower ranking of category-specific 'liking' vs. placebo. The type of food consumed during a meal has a larger influence on subsequent 'wanting' of food in NR eaters than in NU eaters. In those NR eaters, compared with NU eaters, consumption of a food item which is highly liked and perceived as less healthy decreases 'wanting' for food more compared with consumption of a food item which is less liked, neutral, and perceived as healthy.

Thus, for successfully restrained eaters the consumption of a highly rewarding food may result in better control of eating behavior than consumption of a healthy perceived but less rewarding food. Restrained eaters have a similar control over appetite and 'liking' as unrestrained eaters, although they use cognitive cues, but they have a stronger control over 'wanting' in case of 'delicious' foods.

\section{Acknowledgements}

We thank our subjects for their participation in this study and Sanne Verhoef for her help with the practical work. The study was designed by MSWP and SGL. SGL (supervised by MSWP) carried out the study, collected and analyzed the data and wrote the largest part of the manuscript. PFS, together with SGL and LW, developed the computer test for measurement of 'liking' and 'wanting'. FR and JMB reviewed the manuscript. 


\section{References}

1. Berthoud HR. Neural control of appetite: cross-talk between homeostatic and non-homeostatic systems. Appetite. 2004 Dec;43(3):315-7.

2. Finlayson G, King N, Blundell JE. Liking vs. wanting food: Importance for human appetite control and weight regulation. Neurosci Biobehav Rev. 2007 Mar 27.

3. Epstein LH, Truesdale R, Wojcik A, Paluch RA, Raynor HA. Effects of deprivation on hedonics and reinforcing value of food. Physiol Behav. 2003 Feb;78(2):221-7.

4. Berridge KC. Food reward: brain substrates of wanting and liking. Neurosci Biobehav Rev. 1996;20(1):1-25.

5. Finlayson G, King N, Blundell JE. Is it possible to dissociate 'liking' and 'wanting' for foods in humans? A novel experimental procedure. Physiol Behav. 2007 Jan 30;90(1):36-42.

6. Mela DJ. Eating for pleasure or just wanting to eat? Reconsidering sensory hedonic responses as a driver of obesity. Appetite. 2006 Jul;47(1):10-7.

7. Berridge KC. Motivation concepts in behavioral neuroscience. Physiol Behav. 2004 Apr;81(2):179-209.

8. Stunkard AJ, Messick S. The three-factor eating questionnaire to measure dietary restraint, disinhibition and hunger. J Psychosom Res. 1985;29(1):71-83.

9. Robinson TE, Berridge KC. Incentive-sensitization and addiction. Addiction. 2001 Jan;96(1):10314.

10. Berridge KC, Robinson TE. The Mind of an Addicted Brain: Neural Sensitization of Wanting Versus Liking. Current Directions in Psychological Science. 1995;4(3):71-6.

11. Epstein LH, Wright SM, Paluch RA, Leddy J, Hawk LW, Jr., Jaroni JL, et al. Food hedonics and reinforcement as determinants of laboratory food intake in smokers. Physiol Behav. 2004 May;81(3):511-7.

12. Lemmens SG, Schoffelen PF, Wouters L, Born JM, Martens MJ, Rutters F, et al. Eating what you like induces a stronger decrease of 'wanting' to eat. Physiol Behav. 2009 Sep 7;98(3):318-25.

13. Carels RA, Konrad K, Harper J. Individual differences in food perceptions and calorie estimation: an examination of dieting status, weight, and gender. Appetite. 2007 Sep;49(2):450-8.

14. Provencher V, Polivy J, Herman CP. Perceived healthiness of food. If it's healthy, you can eat more! Appetite. 2009 Apr;52(2):340-4.

15. Westerterp-Plantenga MS. Eating behavior in humans, characterized by cumulative food intake curves--a review. Neurosci Biobehav Rev. 2000 Mar;24(2):239-48.

16. McArdle WD, Katch FI, Katch VL. Exercise Physiology. 4th ed. Baltimore: Williams and Watkins; 1996.

17. Harris JA, Benedict FG. A Biometric Study of Human Basal Metabolism. Proc Natl Acad Sci U S A. 1918 Dec;4(12):370-3.

18. Fishbach A, Friedman RS, Kruglanski AW. Leading us not unto temptation: momentary allurements elicit overriding goal activation. J Pers Soc Psychol. 2003 Feb;84(2):296-309.

19. Westerterp-Plantenga MS, Wouters L, ten Hoor F. Restrained eating, obesity, and cumulative food intake curves during four-course meals. Appetite. 1991 Apr;16(2):149-58. 



\section{Chapter 5}

\section{Staggered meal consumption facilitates appetite control without affecting postprandial energy intake}

Lemmens SG, Martens EA, Born JM, Martens MJ, Westerterp-Plantenga MS

J Nutr, 2010. In press. 


\begin{abstract}
Meal pattern may influence hormone and appetite dynamics and food intake. The objective of the study was to determine the effects of staggered vs. nonstaggered meal consumption on hormone and appetite dynamics, food reward (i.e. 'liking', 'wanting'), and subsequent energy intake.

The study was conducted in a randomized cross-over design. Participants $\left(\mathrm{n}=38\right.$, age $\left.=24 \pm 6 \mathrm{y}, \mathrm{BMl}=25.0 \pm 3.1 \mathrm{~kg} / \mathrm{m}^{2}\right)$ came to the university twice for consumption of a four-course lunch ( $40 \%$ of the daily energy requirements) in $0.5 \mathrm{~h}$ (non-staggered), or in $2 \mathrm{~h}$ with three within-meal pauses (staggered), followed by ad libitum food intake. Throughout the test sessions glucagon-like peptide (GLP)-1, peptide tyrosine-tyrosine ( $\left.P Y Y_{3-36}\right)$, ghrelin, appetite, and food reward were measured.

In the staggered vs. non-staggered meal condition peak values of GLP-1, $\mathrm{PYY}_{3-}$ ${ }_{36}$, and satiety were lower and time to peak values were higher $(P<0.02)$; the nadir value of hunger was higher, and time to nadir values of ghrelin and hunger were higher $(\mathrm{P}<0.0001)$. Prior to ad libitum food intake GLP-1 concentrations and satiety ratings were larger, ghrelin concentrations and hunger ratings were smaller, and food 'wanting' was smaller in the staggered vs. non-staggered meal condition $(P<0.05)$. However, this did not affect ad libitum energy intake $(1.7 \pm 0.3$ vs. $1.9 \pm 0.2 \mathrm{MJ}$, n.s.).

In conclusion, staggered vs. non-staggered meal consumption induces less pronounced hormone and appetite dynamics. Moreover, it results in higher final GLP-1 concentrations and satiety ratings, lower ghrelin concentrations and hunger ratings, and lower food 'wanting' prior to ad libitum food intake. However, this was not translated into a lower energy intake.
\end{abstract}




\section{Introduction}

The prevalence of overweight and obesity has increased worldwide to epidemic proportions (1, 2). Genetic, environmental, socioeconomic, cultural and behavioral factors all may play a major role in the development of obesity $(3,4)$. Among cultural and behavioral factors, eating out has become an important aspect (4). Out-of-home consumption, compared with eating at home, often results in a larger food intake, which may be due to external factors such as meal duration, the availability of palatable high caloric foods, large portion sizes, the atmosphere, the presence of other people, or distraction, which lowers the possibility of estimating the energy density of the foods resulting in less well adaptation of portion sizes (5-8). On the other hand, physiological factors such as the dynamics of hunger and satiety and of related hormones during the meal may exert their feedback already during the meal and consequently influence food and energy intake.

In habitual situations, e.g. at home, people consume a standard three- or fourcourse meal in about half-an-hour, but when people are having their meal served in a restaurant, consumption of the meal takes longer, e.g. two hours with withinmeal pauses of 20-30 min. Meal pattern manipulation might influence energy homeostasis, involving metabolic hunger and satiety signals produced in the hypothalamus and peripheral organs (9), as well as the concept of reward, processed in cortico-limbic structures (10).

Relevant hormones that may sustain these meal patterns are the anorexigenic peptides glucagon-like peptide (GLP)-1 and peptide tyrosine-tyrosine (PYY), and the orexigenic gut peptide ghrelin. GLP-1 and PYY are released from the endocrine $L$ cells of the ileum and the colon, and appear to reduce appetite (11, 12). Their plasma concentrations are low in the fasting state and rise during a meal (12-14). Ghrelin is a peptide secreted primarily by the stomach, and appears to increase appetite. Ghrelin plasma concentrations peak before a meal and rapidly drop postprandially (11).

Concerning the hormone dynamics, a study of Solomon et al. (15) investigated the hormonal effects of meal frequency (two vs. twelve meals (equi-energetic) in an eight hour intervention period), and showed a prolonged elevation of insulin and ghrelin concentrations in the high-frequency meal condition. Kokkinos et al. (16) investigated the effect of consumption of $300 \mathrm{~mL}$ ice cream in five min (two equal portions) or in $30 \mathrm{~min}$ (seven equal portions) on the postprandial response of PYY, GLP-1 and ghrelin. Total area under the curve for PYY and GLP-1 were higher in the 30 -min meal condition. Studies by Jenkins et al. $(17,18)$ and Wolever (19) revealed greater hormone fluctuations (e.g. glucose, insulin) following larger meals, than after smaller, more frequent meals.

Concerning energy intake, Speechly et al. $(20,21)$ showed that obese and lean males fed an isoenergetic pre-load sub-divided into a multi-meal plan (five equal portions, given hourly) consumed $27 \%$ less at a subsequent ad libitum test meal 
than did the same men when given the pre-load as a single meal. A study by Taylor et al. (22) showed that in women, in the short term, consumption of six vs. two meals (equi-energetic, $4.2 \mathrm{MJ} / 24 \mathrm{~h}$ ) had no major impact on subsequent energy intake. Taking the above into account, there are still inconsistencies in the literature concerning the effects of meal pattern manipulation. On the one hand eating slowly by increasing meal duration may exert more control over food and energy intake through physiological feedback signals that appear already during the meal $(15,16,20,21)$. On the other hand, increased meal duration when eating out can exert less control over food and energy intake $(4,8)$. The question remains whether stimulated food intake through the social context of eating out is facilitated by a slower appearance of satiation signals, or whether it takes place despite greater appetite control by possibly more sustained satiety signals.

The objective of our study was to determine in a laboratory setting, thus excluding the environmental factors of eating out, whether consumption of a four-course lunch spread over two hours, with three within-meal pauses (staggered), facilitates or controls food intake by affecting hormone (GLP-1, $\mathrm{PYY}_{3-36}$, and ghrelin concentrations) and appetite dynamics, food reward, i.e. 'liking' and 'wanting' (23), compared with consumption of the same four-course meal in half-an-hour, without within-meal pauses (non-staggered). We hypothesized that the release of GLP-1, PYY ${ }_{3-36}$, and ghrelin would be less pronounced and steadier, in the condition of staggered meal consumption compared with the condition of non-staggered meal consumption, thereby sustaining the appetite profile and controlling food intake more, thus decreasing subsequent food 'wanting' and energy intake.

\section{Materials and Methods}

\section{Participants}

Thirty-eight healthy participants (18 men and 20 women; age $24 \pm 6$ y (mean $\pm S D$ ) with a BMI of $25.0 \pm 3.1 \mathrm{~kg} / \mathrm{m}^{2}$ (mean $\pm \mathrm{SD}$ ) participated in this study. They were recruited by advertisements in local newspapers and on notice boards at the university. Participants underwent an initial screening including measurement of body weight, height, waist circumference and hip circumference, and completion of a questionnaire related to health, use of medication, smoking behavior, alcohol consumption, physical activity and eating behavior. Eating behavior was analyzed using a validated Dutch translation of the Three Factor Eating Questionnaire (TFEQ) which measures three components: 'cognitive restraint of eating' (factor 1), 'disinhibition of restraint' (factor 2) and 'subjective feeling of hunger' (factor 3) (24). All participants gave written informed consent. The study was approved by the Medical Ethical Committee of the Maastricht University, and was in accordance with the Declaration of Helsinki. 


\section{Study design}

The study was conducted in a randomized crossover design. All participants came to the university twice, on two separate days at least one week apart, in a fasted state for either condition: four-course meal consumption in $0.5 \mathrm{~h}$ without within-meal pauses (test day A; non-staggered meal condition) vs. four-course meal consumption in $2 \mathrm{~h}$ with three within-meal pauses of 20-25 min (test day B; staggered meal condition). The order of the two conditions was randomized across the participants to prevent any order effects.

In the morning (08:00 h) all participants consumed a standardized breakfast drink at home, and were instructed not to consume any foods or beverages following consumption of the drink. Participants arrived at the university before lunchtime, at 11:00 h. An intravenous catheter was inserted into the antecubital vein for blood sampling, for measurement of plasma GLP-1, PYY ${ }_{3-36}$, and ghrelin concentrations.

Consumption of the four-course lunch started at 12:00 h. Following consumption of the lunch (14:35 h), participants were served sweet and savory food items ad libitum. This gave us the opportunity to measure energy intake and food reward in terms of 'liking' and 'wanting' in the absence of hunger, thus eating beyond energy homeostasis.

During the course of the test days $A$ and $B$, participants were seated separately and remained seated, blood samples were drawn, visual analogue scales (VAS) on appetite were completed and the computer test for measurement of 'liking' and 'wanting' was executed (25).

All women were tested in the follicular phase, as it has been shown that women have a higher spontaneous energy intake in the luteal phase compared with the follicular phase $(26,27)$.

\section{Test meals}

An overview of the nutritional information of the foods consumed on the test days can be found in the Online Supporting Material (Supplemental Table 1). Beforehand, during screening, participants had rated the food items for subjective liking (VAS), in order to check whether all food items were acceptable. All food items were scored more then $60 \mathrm{~mm}$ on a $100 \mathrm{~mm}$ VAS.

In the morning, participants consumed a standardized breakfast drink at home ('Campina Goede morgen ontbijtdrink'). The amount of the breakfast drink participants had to consume corresponded to $10 \%$ of their individual daily energy requirements (DER). For each participant the DER were calculated by multiplying the basal metabolic rate (BMR) by the appropriate physical activity factor (1.5-1.8, derived from the screening questionnaire, (28)). The BMR (kJ/day) was calculated according to the equation of Harris-Benedict (29).

The lunch consisted of a four-course meal, i.e. a salad (iceberg lettuce, mozzarella, tomato, croutons, and dressing) with a slice of white bread as a starter, 
macaroni Bolognese as the first part of the main course, vegetable lasagna as the second part of the main course, and raspberry pudding as a dessert. The energy density of the total four-course meal was $5.0 \mathrm{~kJ} / \mathrm{g}$ and comprised $14 \%$ protein, $54 \%$ carbohydrate, and $32 \%$ fat. The amount of the four-course meal participants had to consume corresponded to $40 \%$ of their DER $(5.0 \pm 0.1 \mathrm{MJ}$; starter $8 \%$, first part main course $12 \%$, second part main course $12 \%$, and dessert $8 \%$ of the DER).

During test day $\mathrm{B}$, the starter and the first part of the main course were consumed between 12:00 $\mathrm{h}$ and 13:00 $\mathrm{h}$, while the second part of the main course and the dessert were consumed between 13:00 $\mathrm{h}$ and 14:00 $\mathrm{h}$. The amount of energy ( $20 \%$ of the DER) and the energy density $(5.0 \mathrm{~kJ} / \mathrm{g})$ of the foods consumed between 12:00 $\mathrm{h}$ and 13:00 $\mathrm{h}$, and of the foods consumed between 13:00 $\mathrm{h}$ and 14:00 h, were equal.

During test day A participants had $0.5 \mathrm{~h}$ to consume the four-course meal. During test day $B$ the courses were offered at 12:00 h, 12:35 h, 13:10 h, and 13:40 $\mathrm{h}$ (time points $0,35,70$, and $100 \mathrm{~min}$ ) and participants had $10 \mathrm{~min}$ to consume each course. All participants were instructed to consume the entire amount of food presented. All participants consumed the whole of the offered lunch. No participants were excluded.

Two-and-a-half hours after the start of consumption of the four-course meal (time point $155 \mathrm{~min}$ ), participants were presented a tray with generous pre-weighed portions of sweet and savory food items: Dutch syrup waffles, banana-chew candy, chocolate-coated marshmallow treats, apple cakes, peanuts, potato crisps, and salty sticks. The participants were instructed to eat as much as they wished of any of the foods. After the participants left, each of the portions of the food items were weighed to determine food choice and the amount eaten. We chose for this selection of common energy dense foods, as in the Dutch population those food items are often consumed following a meal, with the afternoon tea. Moreover, those food items are highly rewarding, easy to consume, and often offered at the restaurant following a three- or four-course meal.

During the $2 \mathrm{~h}$ waiting period on test day $\mathrm{A}$ (from the end of lunch until the start of the ad libitum food consumption) participants remained seated, completed VAS for appetite on appropriate time points, and had the chance to read a book/magazine, or to study.

Each participant was given $14.3 \mathrm{~mL} / \mathrm{kg}$ water to consume ad libitum throughout the test days (15).

\section{Appetite profile}

One hundred unit VAS $(\mathrm{mm})$ were used to assess the appetite profile. The scales were anchored with 'not at all' at one end and 'extremely' at the other end, and combined with questions on feelings of hunger, 'desire to eat', satiety, fullness, and thirst. 
The VAS were completed eight times throughout test day A, at $-45,-10,35,65$, $95,125,150$, and $175 \mathrm{~min}$, and ten times throughout test day $B$, at $-45,-10,20$, $50,65,85,95,110,150$, and $175 \mathrm{~min}$.

\section{Blood sampling}

Venous blood samples were collected into EDTA tubes, five times during test day $A$, at $-5,30,60,90$, and $120 \mathrm{~min}$, and nine times during test day $B$, at $-5,15$, $30,45,60,75,90,105$, and $120 \mathrm{~min}$. Blood samples were drawn to determine concentrations of plasma GLP-1, PYY ${ }_{3-36}$, and ghrelin.

For GLP-1 analysis, blood was collected into EDTA tubes to which dipeptidyl peptidase IV inhibitor (10 mL/L blood) was added. For the analysis of PYY ${ }_{3-36}$, blood was collected into EDTA tubes in which dipeptidyl peptidase IV inhibitor (10 $\mathrm{mL} / \mathrm{L}$ blood) and aprotinin $\left(50.10^{4} \mathrm{KIU} / \mathrm{L}\right.$ blood) was added. After collection, blood samples were centrifuged for $10 \mathrm{~min}$ at $4{ }^{\circ} \mathrm{C}$ at $1428 \times \mathrm{g}$. For ghrelin analysis, PMSF, dissolved in methanol, and hydrochloric acid were added to the plasma. Plasma samples were immediately frozen in liquid nitrogen and stored at $-80{ }^{\circ} \mathrm{C}$ until analysis. Plasma concentrations of $P Y Y_{3-36}$ and active ghrelin were measured by RIA (Linco Research Inc, St Charles, MO) and those of active GLP-1 by ELISA (EGLP-35K; Linco Research Inc, St Charles, MO).

\section{'Liking' and 'wanting' computer test}

The computer test described and validated by Lemmens et al. (25) was used to measure the rewarding value, i.e. 'liking' and 'wanting', for 72 items divided in six categories: bread, filling, drinks, dessert, snacks, and stationery (non-food alternative as placebo). Each category contained 12 items. The 72 items were presented as photographic stimuli on a computer screen (13-inch Mac Book, Apple, Cupertino, USA). This computer test has been elaborately described and validated by Lemmens et al. (25), therefore a short summary is given here.

The computer test contained two parts, a 'liking' part and a 'wanting' part. Both the 'liking' and 'wanting' tasks assessed 'liking' respectively 'wanting' for the same food and stationery items. During the 'liking' part, participants had to indicate their relative preference of paired items within and between the six categories. This resulted in a relative ranking of 'liking' of the items per category (score range 0-605), and of the categories (score range 0-125).

During the 'wanting' part, participants had to work to earn items by playing memory games. For each category of items participants played a five by five memory game (12 pairs of items), which was followed by the indication of the items participants wanted to acquire at that moment. The more pairs of items were found in the memory game, the more randomly selected items were offered to choose from afterwards. Participants could choose zero, one or two items per category. The chosen items obtained a score equal to the number of pairs of 
items found in the memory game, representing the motivation or workload for the chosen items (score range 2-12). Items not chosen obtained a score of zero. Per category the sum of the scores of the items was calculated and represented the 'wanting' score for each category. A minimum score of zero and a maximum score of 24 was obtained per category.

The 'liking' and 'wanting' computer test was completed three times throughout the test days: before and after consumption of the four-course meal and after the ad libitum consumption of sweet and savory food items (time points test day A: $-40,100,180 \mathrm{~min}$; test day B: $-40,115,180)$. The food items presented for ad libitum consumption were different from those pictured in the 'liking' and 'wanting' computer test.

\section{Statistics}

Data were analyzed using StatView 5.0 (SAS Institute Inc., Cary, NC, USA). ANOVA with repeated measures was used to study the conditional effects of staggered vs. non-staggered meal consumption, and the effects of time, on hormone (GLP-1, PYY $3-36$, and ghrelin) concentrations, on VAS appetite scores, on food reward, i.e. 'liking' and 'wanting', and on energy intake. Paired and unpaired Student's t-tests were used as post hoc analyses for significant interactions. Unpaired Student's t-tests were used to analyze differences in participant characteristics between men and women. Postprandial response curves of the hormone concentrations and appetite ratings were evaluated by comparing baseline values, peak/nadir values, time to peak/nadir values, and endpoint values in the staggered vs. non-staggered meal condition using paired Student's t-tests.

Simple linear regression models were used for correlation analysis between the following parameters: food 'wanting' vs. GLP-1/ghrelin concentrations, food 'wanting' vs. satiety/hunger ratings, ad libitum energy intake vs. satiety/hunger ratings, and ad libitum energy intake vs. 'wanting' for dessert/snacks.

All tests were two-sided and differences were considered significant at $\mathrm{P}<0.05$. Values are expressed as mean \pm SEM, unless stated otherwise.

\section{Results}

\section{Participant characteristics}

No significant differences were shown between men and women in age, BMI, hip circumference and dietary restraint and feeling of hunger score (Table 1). Men showed significantly larger height, body weight, and waist circumference when compared with women (Table 1). Women showed a significantly higher disinhibition score when compared with men (Table 1). 
Both normal weight and visceral overweight participants were included in the study, though no differences were detected regarding conditional effects of staggered vs. non-staggered meal consumption on hormone dynamics, appetite, reward, and energy intake, which is in accordance with studies by Speechly et al. $(20,21)$ and Kokkinos et al. (16). Moreover, no differences were observed between men and women regarding conditional effects of staggered vs. nonstaggered meal consumption on hormone dynamics, appetite, reward, and energy intake. Consequently, the data were analyzed for all participants together.

Table 1. Characteristics of men and women.

\begin{tabular}{lccc}
\hline & Men & Women & $\mathrm{P}^{1}$ \\
\hline Age $(\mathrm{y})$ & $25.0 \pm 7.1$ & $24.0 \pm 6.0$ & $>0.5$ \\
Height $(\mathrm{cm})$ & $185.0 \pm 7.1$ & $169.0 \pm 7.1$ & $<0.0001$ \\
Body weight $(\mathrm{kg})$ & $86.0 \pm 13.0$ & $72.0 \pm 9.9$ & $<0.001$ \\
BMI $\left(\mathrm{kg} / \mathrm{m}^{2}\right)$ & $25.0 \pm 2.9$ & $25.0 \pm 3.2$ & $>0.9$ \\
Waist circumference $(\mathrm{cm})$ & $88.0 \pm 11.0$ & $79.0 \pm 9.2$ & $<0.02$ \\
Hip circumference $(\mathrm{cm})$ & $105.0 \pm 6.0$ & $106.0 \pm 5.6$ & $>0.4$ \\
Dietary restraint score & $5.2 \pm 3.3$ & $6.9 \pm 3.5$ & $>0.1$ \\
Disinhibition score & $3.3 \pm 1.4$ & $4.9 \pm 2.6$ & $<0.04$ \\
Feeling of hunger score & $3.7 \pm 2.5$ & $4.1 \pm 2.7$ & $>0.6$ \\
\hline
\end{tabular}

Values are means $\pm S D$, men: $n=18$, women: $n=20 ;{ }^{1} P$-value: differences between men and women (Unpaired Student's t-tests)

\section{Endocrine responses}

Baseline values of plasma GLP-1 (Figure 1A), PYY $3-36$ (Figure 1B), and ghrelin (Figure 1C) concentrations (-5 min, before meal consumption) did not differ between the staggered and non-staggered meal condition.

\section{GLP-1}

Plasma GLP-1 concentrations changed over time $(P<0.0001)$. Moreover, there was a time by condition interaction $(P<0.0001)$ when comparing the plasma GLP-1 concentrations of the corresponding time points in the staggered and non-staggered meal condition.

The peak value for GLP-1 was lower in the staggered vs. non-staggered meal

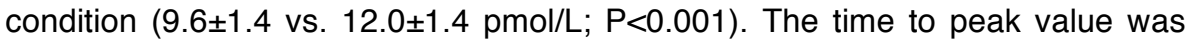
higher in the staggered vs. non-staggered meal condition (120.0 \pm 2.1 vs. $42.0 \pm 2.9 \mathrm{~min} ; \mathrm{P}<0.0001)$. The end point value $(120 \mathrm{~min})$ was higher in the staggered vs. non-staggered meal condition $(P<0.01$, Figure $1 A)$. 
$P Y Y_{3-36}$

Plasma $\mathrm{PYY}_{3-36}$ concentrations changed over time $(\mathrm{P}<0.0001)$. Moreover, there was a time by condition interaction $(P<0.0001)$ when comparing the plasma $\mathrm{PYY}_{3-36}$ concentrations of the corresponding time points in the staggered and non-staggered meal condition.

The peak value for $\mathrm{PYY}_{3-36}$ was lower in the staggered vs. non-staggered meal condition (132.0 \pm 6.1 vs. $147.0 \pm 7.2 \mathrm{ng} / \mathrm{L} ; \mathrm{P}=0.01)$. The time to peak value was higher in the staggered vs. non-staggered meal condition (114.0 \pm 3.6 vs. $76.0 \pm 6.4 \mathrm{~min} ; \mathrm{P}<0.0001)$. The end point value $(120 \mathrm{~min})$ did not differ between the staggered and non-staggered meal condition (Figure 1B).

\section{Ghrelin}

Plasma ghrelin concentrations changed over time $(P<0.0001)$. Moreover, there was a time by condition interaction $(\mathrm{P}<0.0001)$ when comparing the ghrelin concentrations of the corresponding time points in the staggered and non-staggered meal condition.

The nadir value for ghrelin did not differ between the staggered vs. nonstaggered meal condition ( $45.0 \pm 2.8$ vs. $43.0 \pm 2.2 \mathrm{ng} / \mathrm{L} ; \mathrm{P}>0.1)$. The time to nadir value was higher in the staggered vs. non-staggered meal condition $(116.0 \pm 4.7$ vs. $80.0 \pm 6.3 \mathrm{~min} ; \mathrm{P}<0.0001)$. The end point value $(120 \mathrm{~min})$ was lower in the staggered vs. non-staggered meal condition ( $P=0.04$, Figure $1 \mathrm{C})$.

In the staggered meal condition a peak value was reached following consumption of the first course (15 min). Furthermore, significant decreases in ghrelin concentrations were consistently measured 10-20 min following the consumption of a meal course. 

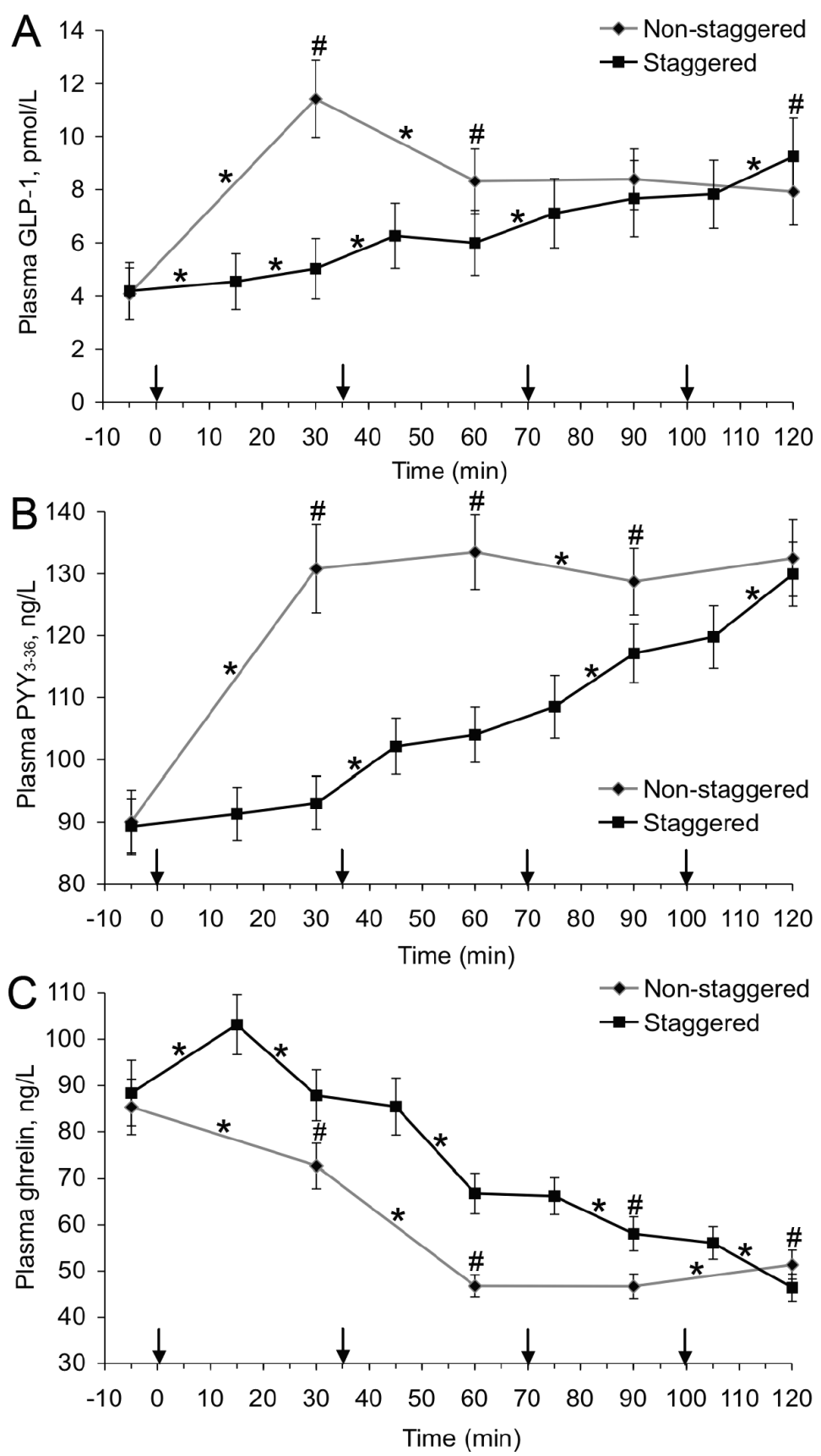

Figure 1 A-C. Plasma GLP-1 (A), PYY3-36 (B), and ghrelin (C) concentrations in participants who consumed staggered and non-staggered meals. Values are mean $\pm S E M, n=38$. ${ }^{*} T$ The two consecutive time points differ, $\mathrm{P}<0.03$; \#different from Staggered at that time, $\mathrm{P}<0.04$. Arrows indicate the start of meal consumption. 


\section{Appetite profile}

Baseline VAS scores for hunger, 'desire to eat', satiety, fullness, and thirst (-5 min, before meal consumption) did not differ between the staggered and nonstaggered meal condition. As VAS appetite scores for hunger and 'desire to eat' and for satiety and fullness did not differ, only the VAS scores for hunger and satiety will be presented (Figure 2 A-B).

There was a main effect of time $(\mathrm{P}<0.0001)$, and a time by condition interaction $(\mathrm{P}<0.0001)$ for hunger and satiety scores, when comparing the scores of the corresponding time points in the staggered and non-staggered meal condition. For thirst there was only a main effect of time $(P<0.0001)$.

The nadir value for VAS hunger scores was higher in the staggered vs. nonstaggered meal condition ( $8.8 \pm 1.5$ vs. $3.4 \pm 0.7$ mmVAS; $\mathrm{P}<0.0001)$. The time to nadir value was higher in the staggered vs. non-staggered meal condition $(154.0 \pm 3.4$ vs. $84.5 \pm 3.5 \mathrm{~min}$; $\mathrm{P}<0.0001)$. The end point value (150 min, before ad lib consumption) was lower in the staggered vs. non-staggered meal condition ( $\mathrm{P}<0.01$, Figure 2A).

The peak value for VAS satiety scores was lower in the staggered vs. nonstaggered meal condition ( $87.0 \pm 1.9$ vs. $91.0 \pm 1.6$ mmVAS; $P<0.02)$. The time to peak value was higher in the staggered vs. non-staggered meal condition (159.0 \pm 3.5 vs. $80.0 \pm 4.2 \mathrm{~min} ; \mathrm{P}<0.0001)$. The end point value $(150 \mathrm{~min}$, before ad lib consumption) was higher in the staggered vs. non-staggered meal condition $(\mathrm{P}<0.001$, Figure $2 \mathrm{~B})$. 

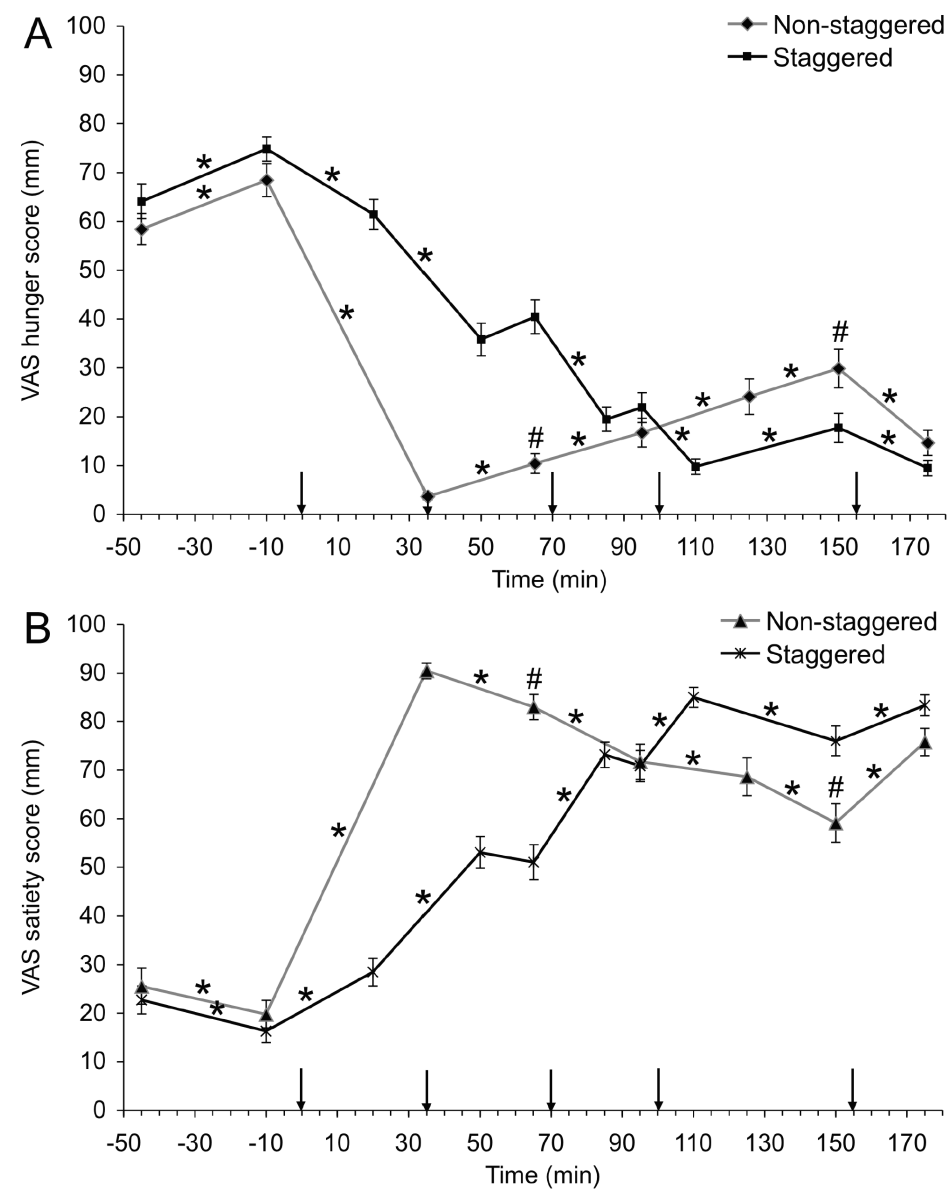

Figure 2 A-B. Visual analogue scale ratings for hunger (A) and satiety (B) in participants who consumed staggered and non-staggered meals. Values are mean $\pm S E M, n=38$. ${ }^{*} T$ the two consecutive time points differ, $\mathrm{P}<0.05$; \#different from Staggered at that time, \#P<0.02. Arrows indicate the start of meal consumption.

\section{'Liking' and 'wanting' computer test}

There was a main effect of time for 'liking' between categories, for all the categories $(P<0.0001)$, except for snacks. There were no time by condition interactions. Consumption of the four-course meal decreased ranking of 'liking' of bread, filling, and dessert, and increased ranking of 'liking' of placebo (stationery) and drinks $(P<0.0001)$.

For average food 'wanting' ('wanting' for food items from all the five food categories taken together) there was a main effect of time $(P<0.0001)$, but there was no time by condition interaction. Consumption of the four-course meal decreased average food 'wanting' $(P<0.0001)$. Paired Student's t-tests revealed a lower average food 'wanting' after consumption of the complete meal (scores $5.2 \pm 0.9$ 
vs. $7.6 \pm 1.2 ; \mathrm{P}<0.01)$ as well as after the subsequent ad libitum consumption (scores $3.7 \pm 0.8$ vs. $5.1 \pm 0.8 ; \mathrm{P}<0.02$ ) in the staggered vs. non-staggered meal condition.

For 'wanting' per category there was a main effect of time $(P<0.0001)$ for all the categories, except for placebo (stationery). There were no time by condition interactions. Consumption of the four-course meal decreased 'wanting' for bread, filling, drinks, dessert, and snacks $(P<0.0001)$. Paired Student's t-tests revealed a lower 'wanting' for bread, filling, and snacks after consumption of the complete meal $(\mathrm{P}<0.04)$, as well as a lower 'wanting' for snacks after the subsequent ad libitum consumption $(P=0.01)$, in the staggered vs. non-staggered meal condition.

\section{Ad libitum energy intake}

There was no effect of staggered vs. non-staggered meal consumption on total energy intake during the subsequent ad libitum consumption of sweet and savory food items $(p>0.3)$. Although not significant, the energy intake was $10 \%$ lower in the staggered vs. non-staggered meal condition. Participants consumed $90.0 \pm 14.0 \mathrm{~g}$ or $1.7 \pm 0.3 \mathrm{MJ}$ in the staggered meal condition and $100.0 \pm 11.0 \mathrm{~g}$ or $1.9 \pm 0.2 \mathrm{MJ}$ in the non-staggered meal condition. There was also no conditional effect on the ad libitum amount of proteins, carbohydrates, and fats consumed $(P>0.08)$.

\section{Simple linear regression analyses}

As GLP-1 concentrations and satiety ratings were larger and ghrelin concentrations and hunger ratings were smaller in the staggered vs. non-staggered meal condition at the end of consumption of the four-course meal, we hypothesized that this might have contributed to the lower food 'wanting' following the fourcourse meal. However, in both the staggered and non-staggered meal condition simple linear regression models showed no relationships between food 'wanting' following the four-course meal and GLP-1 concentrations $\left(P>0.4, R^{2}<0.02\right)$, ghrelin concentrations $\left(P>0.5, R^{2}<0.01\right)$, satiety ratings $\left(P>0.1, R^{2}<0.07\right)$, and hunger ratings $\left(P>0.06, R^{2}<0.1\right)$ at the end of consumption of the four-course meal.

In both the staggered and non-staggered meal condition there was a positive relationship between the ad libitum energy intake and hunger ratings prior to the ad libitum food intake $\left(P<0.01, R^{2}>0.2\right)$, and a negative relationship between the ad libitum energy intake and satiety ratings prior to the ad libitum food intake $\left(P<0.04, R^{2}>0.1\right)$. Correlation analyses of the ad libitum energy intake vs. 'wanting' for dessert/snacks prior to the ad libitum food intake showed that only in the non-staggered meal condition there was a weak positive relationship 
between energy intake and 'wanting' for snacks prior to the ad libitum food intake $\left(P=0.03, R^{2}=0.1\right)$.

\section{Discussion}

The objective of our study was to assess whether stimulated food intake through the social context of eating out is facilitated by a slower appearance of satiation signals, or whether it takes place despite greater appetite control by possibly more sustained satiety signals. Therefore, in a laboratory setting, thus excluding the environmental factors of eating out, it was determined whether consumption of a four-course lunch spread over two hours, with three within-meal pauses (staggered), facilitates or controls food intake by affecting hormone (GLP-1, $\mathrm{PYY}_{3-36}$, and ghrelin concentrations) and appetite dynamics, and food reward, i.e. 'liking' and 'wanting', compared with consumption of the same four-course meal in half-an-hour, without within-meal pauses (non-staggered). We hypothesized that the release of GLP-1, PYY ${ }_{3-36}$, and ghrelin would be less pronounced and steadier in the condition of staggered meal consumption compared with the condition of non-staggered meal consumption, thereby sustaining the appetite profile and controlling food intake more, thus decreasing subsequent food 'wanting' and energy intake.

Following this hypothesis, the GLP-1, $\mathrm{PYY}_{3-36}$, and ghrelin concentrations and the appetite profile ratings changed more steadily in the staggered vs. nonstaggered meal condition. Hormone concentrations and appetite ratings showed comparable dynamics, in both the staggered as well as the non-staggered meal condition. Non-staggered meal consumption induced a rapid increase, reaching a peak value, in GLP-1 and $\mathrm{PYY}_{3-36}$ concentrations as well as in satiety ratings, and a rapid decrease, reaching a nadir value, in ghrelin concentrations as well as in hunger ratings. Staggered meal consumption induced a gradual increase in GLP-1 and PYY ${ }_{3-36}$ concentrations and in satiety ratings, and a gradual decrease in ghrelin concentrations and hunger ratings.

While 'liking' was not affected by the different meal patterns, 'wanting' was affected by the different meal patterns: food 'wanting' was lower following the four-course meal and prior to the ad libitum consumption of sweet and savory food items, in the staggered vs. non-staggered meal condition.

Regardless of the differences between the staggered and non-staggered meal condition concerning hormone and appetite dynamics and food 'wanting', energy intake during the ad libitum consumption of sweet and savory food items did not differ between both meal patterns. The energy intake was $10 \%$ lower in staggered vs. non-staggered meal condition, however this difference was not significant.

Concerning the hormone dynamics, Solomon et al. (15) showed a prolonged elevation of ghrelin concentrations in the high-frequency meal condition, which is in accordance with our findings. The time to nadir value was higher in the staggered vs. non-staggered meal condition. This may be explained by the 
findings described by Callahan et al. (30), showing that the larger the caloric intake, the larger the suppression of ghrelin. Eating a large meal in half-an-hour induces a rapid decline in ghrelin concentrations, while eating the same meal spread over two hours induces a more gradual decline in ghrelin concentrations and an increase in time to reach the nadir value. In the staggered meal condition we detected an increase in ghrelin concentrations following consumption of the first course, which still may be an extension of the fasting ghrelin pre-meal peak. Kokkinos et al. (16) showed an overall larger PYY and GLP-1 response following the 30-min meal condition compared with the five-min meal condition, which is in contrast with our findings. Though, in accordance with the study by Kokkinos et al. (16), we detected a higher GLP-1 endpoint value in the staggered meal condition.

A limitation of the present study was that blood samples were collected for a too short period of time, preventing the measurement of hormone concentrations when they returned back to baseline values. Because of medical ethical reasons we were limited in the amount of blood to collect.

Regarding appetite ratings, Kokkinos et al. (16) detected no conditional differences for hunger and fullness ratings, while Speechly et al. $(20,21)$ showed that participants felt more hungry in the single-meal vs. multi-meal condition prior to the ad libitum test meal, which is in accordance with our findings. Staggered meal consumption, compared with non-staggered meal consumption, may be more beneficial regarding appetite feelings as it induces greater control of hunger and satiety.

To our knowledge no previous study has shown the effect of meal duration on food reward, i.e. 'liking' and 'wanting'. We hypothesized that the larger GLP-1 concentrations and satiety ratings and the smaller ghrelin concentrations and hunger ratings, in the staggered vs. non-staggered meal condition, at the end of consumption of the four-course meal, might have contributed to the lower food 'wanting' following the four-course meal. However, simple linear regression models showed in both the staggered and non-staggered meal condition neither relation between 'wanting' scores and GLP-1/ghrelin levels nor between 'wanting' scores and satiety/hunger levels. Thus, food 'wanting' following a fourcourse lunch, i.e. eating beyond energy homeostasis, is not determined by physiological signals. Obviously, in the presence of palatable foods, the food reward system may have overruled and promoted food 'wanting' and food intake, similar to previous reports $(9,31)$.

As regards the ad libitum energy intake, which did not differ significantly in the staggered vs. non-staggered meal condition, our results are in contrast with the results of Speechly et al. $(20,21)$. However, in the studies by Speechly et al. $(20$, 21) the single pre-load meal was followed by a five hour fast, which to our opinion might have been too long and might be the cause of detection of differences in energy intake between both feeding regimens.

Regression analysis showed that the ad libitum energy intake was mainly determined by feelings of hunger and satiety. We suggest that energy intake is very 
much due to habit, and that the detected conditional differences in hunger (40\%) and satiety $(20 \%)$ in the present study were too small to exert an effect on subsequent energy intake. Veldhorst et al. (32) remarked that satiety ratings have to increase considerably, $\sim 40 \%$, to induce significant effects on energy intake. Several studies have shown a suppressive effect of a preload on appetite ratings, whereas there was no effect on subsequent ad libitum energy intake (3337). Moreover, large standard deviations suggest that participant characteristics might have influenced the detection of a possible significant difference in energy intake between both meal patterns.

Although the difference in ad libitum energy intake was small and non-significant, $10 \%$ could add up over time to produce long-term reductions in energy intake.

Overall the results imply that in a laboratory setting, staggered meal consumption facilitates greater appetite control. In a restaurant setting however, staggered meal consumption and increased meal duration often result in a larger food intake (4). From our results we now hypothesize that the larger food intake in a restaurant setting is not due to physiological factors such as the dynamics of hunger and satiety and of related hormones, but rather due to external factors such as the availability of palatable high caloric foods, the atmosphere, the presence of other people, or distraction (5-8). In order to assess the role of environmental factors, it would be of interest to repeat the study in a restaurant setting, where besides timing also the factor of social setting and distraction can influence food reward and subsequent energy intake.

In conclusion, in a laboratory setting staggered vs. non-staggered meal consumption induces greater appetite control, indicated by less pronounced hormone and appetite dynamics and more control over subsequent food 'wanting', yet does not affect postprandial energy intake. Thus, the stimulated food intake in a restaurant setting with staggered meal consumption may take place despite greater appetite control.

\section{Acknowledgements}

All authors read and approved the final version of the paper. The study was designed by MSWP and SGL. SGL together with EAM (supervised by MSWP) carried out the study and collected the data. SGL analyzed the data and wrote the largest part of the manuscript. JMB, EAM, MJM, and MSWP reviewed the manuscript. 


\section{Online Supporting Material}

Supplemental Table 1. The nutritional information of foods as consumed on the test days.

\begin{tabular}{|c|c|c|c|c|c|}
\hline & & Energy & Protein & Carbohydrate & Fat \\
\hline & & $\mathrm{kJ} / 100 \mathrm{~g}$ & -------. & ---g/100g--.-- & ----- \\
\hline & Breakfast drink & 300 & 70.0 & 3.0 & 11.7 \\
\hline Course 1 & Iceberg lettuce & 42 & 0.9 & 1.2 & 0.0 \\
\hline & Mozarella & 998 & 18.0 & 1.5 & 18.0 \\
\hline & Tomato & 58 & 0.9 & 1.9 & 0.0 \\
\hline & Croutons & 2370 & 7.0 & 49.0 & 40.0 \\
\hline & Dressing & 950 & 0.6 & 9.6 & 21.0 \\
\hline & White bread & 1140 & 9.7 & 51.3 & 2.9 \\
\hline Course 2 & Macaroni bolognese & 396 & 3.5 & 15.4 & 1.9 \\
\hline Course 3 & Vegetable lasagna & 501 & 4.8 & 12.8 & 5.5 \\
\hline Course 4 & Raspberry pudding & 520 & 3.2 & 20.3 & 2.5 \\
\hline Foods & Dutch syrup waffles & 1860 & 3.2 & 62.2 & 20.3 \\
\hline consumed & Banana-chew candy & 1540 & 2.5 & 88.0 & 0.0 \\
\hline & $\begin{array}{l}\text { Chocolate-coated marshmallow } \\
\text { treats }\end{array}$ & 1850 & 2.0 & 57.0 & 22.0 \\
\hline & Apple cake & 1710 & 3.4 & 45.9 & 18.1 \\
\hline & Peanuts & 2210 & 15.0 & 41.0 & 34.0 \\
\hline & Potato crisps & 2240 & 6.3 & 53.0 & 33.1 \\
\hline & Salty sticks & 1940 & 15.0 & 62.0 & 16.0 \\
\hline
\end{tabular}




\section{References}

1. Caballero B. The Global Epidemic of Obesity: An Overview. Epidemiol Rev. 2007 January 1, 2007;29(1):1-5.

2. Trayhurn P, Bing C, Wood IS. Adipose Tissue and Adipokines ᄀóEnergy Regulation from the Human Perspective. J Nutr. 2006 July 1, 2006;136(7):1935S-9S.

3. Giskes K, Van Lenthe F, Avendano-Pabon M, Brug J. A systematic review of environmental factors and obesogenic dietary intakes among adults: are we getting closer to understanding obesogenic environments? Obes Rev. 2010.

4. Naska A, Orfanos P, Trichopoulou A, May AM, Overvad K, Jakobsen MU, et al. Eating out, weight and weight gain. A cross-sectional and prospective analysis in the context of the EPICPANACEA study. Int J Obes. 2010.

5. Hetherington MM, Anderson AS, Norton GN, Newson L. Situational effects on meal intake: A comparison of eating alone and eating with others. Physiol Behav. 2006 Jul 30;88(4-5):498-505.

6. Hetherington MM. Cues to overeat: psychological factors influencing overconsumption. Proc Nutr Soc. 2007 Feb;66(1):113-23.

7. Bellisle F, Dalix AM, Slama G. Non food-related environmental stimuli induce increased meal intake in healthy women: comparison of television viewing versus listening to a recorded story in laboratory settings. Appetite. 2004;43(2):175-80.

8. Stroebele N, De Castro JM. Effect of ambience on food intake and food choice. Nutrition. 2004;20(9):821-38.

9. Erlanson-Albertsson C. How palatable food disrupts appetite regulation. Basic Clin Pharmacol Toxicol. 2005 Aug;97(2):61-73.

10. Berthoud HR. Homeostatic and non-homeostatic pathways involved in the control of food intake and energy balance. Obesity (Silver Spring). 2006 Aug;14 Suppl 5:197S-200S.

11. Delzenne N, Blundell J, Brouns F, Cunningham K, De Graaf K, Erkner A, et al. Gastrointestinal targets of appetite regulation in humans. Obes Rev. 2010;11(3):234-50.

12. Burcelin R, Cani PD, Knauf C. Glucagon-Like Peptide-1 and Energy Homeostasis. J Nutrition. 2007 November 1, 2007;137(11):2534S-8S.

13. Steinert RE, Poller B, Castelli MC, Drewe J, Beglinger C. Oral administration of glucagon-like peptide 1 or peptide YY 3-36 affects food intake in healthy male subjects. Am J Clin Nutr. 2010 August 18, 2010;92(4):810-7.

14. Cegla J, Tan TM, Bloom SR. Gut-brain cross-talk in appetite regulation. Curr Opin Clin Nutr Metab Care. 2010;13(5):588-93.

15. Solomon TP, Chambers ES, Jeukendrup AE, Toogood AA, Blannin AK. The effect of feeding frequency on insulin and ghrelin responses in human subjects. $\mathrm{Br} \mathrm{J}$ Nutr. $2008 \mathrm{Oct} ; 100(4): 810-9$.

16. Kokkinos A, le Roux CW, Alexiadou K, Tentolouris N, Vincent RP, Kyriaki D, et al. Eating slowly increases the postprandial response of the anorexigenic gut hormones, peptide $Y Y$ and glucagon-like peptide-1. J Clin Endocrinol Metab. 2010 Jan;95(1):333-7.

17. Jenkins DJ, Ocana A, Jenkins AL, Wolever TM, Vuksan V, Katzman L, et al. Metabolic advantages of spreading the nutrient load: effects of increased meal frequency in non-insulindependent diabetes. Am J Clin Nutr. 1992 February 1, 1992;55(2):461-7.

18. Jenkins DJA, Wolever TMS, Vuksan V, Brighenti F, Cunnane SC, Rao AV, et al. Nibbling versus Gorging: Metabolic Advantages of Increased Meal Frequency. N Engl J Med. 1989;321(14):92934.

19. Wolever TMS. Metabolic effects of continuous feeding. Metabolism. 1990;39(9):947-51.

20. Speechly DP, Rogers GG, Buffenstein R. Acute appetite reduction associated with an increased frequency of eating in obese males. Int J Obes Relat Metab Disord. 1999 Nov;23(11):1151-9.

21. Speechly DP, Buffenstein R. Greater appetite control associated with an increased frequency of eating in lean males. Appetite. 1999 Dec;33(3):285-97. 
22. Taylor MA, Garrow JS. Compared with nibbling, neither gorging nor a morning fast affect shortterm energy balance in obese patients in a chamber calorimeter. Int $\mathrm{J}$ Obes Relat Metab Disord. $2001 \mathrm{Apr} ; 25(4): 519-28$.

23. Berridge KC. Food reward: brain substrates of wanting and liking. Neurosci Biobehav Rev. 1996;20(1):1-25.

24. Stunkard AJ, Messick S. The three-factor eating questionnaire to measure dietary restraint, disinhibition and hunger. J Psychosom Res. 1985;29(1):71-83.

25. Lemmens SG, Schoffelen PF, Wouters L, Born JM, Martens MJ, Rutters F, et al. Eating what you like induces a stronger decrease of 'wanting' to eat. Physiol Behav. 2009 Sep 7;98(3):318-25.

26. Sorensen LB, Moller P, Flint A, Martens M, Raben A. Effect of sensory perception of foods on appetite and food intake: a review of studies on humans. Int J Obes Relat Metab Disord. 2003 Oct;27(10):1152-66.

27. Vicennati V, Ceroni L, Gagliardi L, Gambineri A, Pasquali R. Comment: response of the hypothalamic-pituitary-adrenocortical axis to high-protein/fat and high-carbohydrate meals in women with different obesity phenotypes. J Clin Endocrinol Metab. 2002 Aug;87(8):3984-8.

28. McArdle WD, Katch FI, Katch VL. Exercise Physiology. 4th ed. Baltimore: Williams and Watkins; 1996.

29. Harris JA, Benedict FG. A Biometric Study of Human Basal Metabolism. Proc Natl Acad Sci U S A. $1918 \mathrm{Dec} ; 4(12): 370-3$.

30. Callahan HS, Cummings DE, Pepe MS, Breen PA, Matthys CC, Weigle DS. Postprandial Suppression of Plasma Ghrelin Level Is Proportional to Ingested Caloric Load but Does Not Predict Intermeal Interval in Humans. J Clin Endocrinol Metab. 2004 March 1, 2004;89(3):131924.

31. Blundell JE, Finlayson $\mathrm{G}$. Is susceptibility to weight gain characterized by homeostatic or hedonic risk factors for overconsumption? Physiol Behav. 2004 Aug;82(1):21-5.

32. Veldhorst MAB, Nieuwenhuizen AG, Hochstenbach-Waelen A, Westerterp KR, Engelen MPKJ, Brummer R-JM, et al. A breakfast with alpha-lactalbumin, gelatin, or gelatin†+†TRP lowers energy intake at lunch compared with a breakfast with casein, soy, whey, or whey-GMP. Clin Nutr. 2009;28(2):147-55.

33. Almiron-Roig E, Drewnowski A. Hunger, thirst, and energy intakes following consumption of caloric beverages. Physiology \& Behavior. 2003;79(4-5):767-73.

34. Diepvens K, Steijns J, Zuurendonk P, Westerterp-Plantenga MS. Short-term effects of a novel fat emulsion on appetite and food intake. Physiol Behav. 2008;95(1-2):114-7.

35. Harper A, James A, Flint A, Astrup A. Increased satiety after intake of a chocolate milk drink compared with a carbonated beverage, but no difference in subsequent ad libitum lunch intake. Br J Nutr. 2007;97(03):579-83.

36. Kamphuis MMJW, Lejeune MPGM, Saris WHM, Westerterp-Plantenga MS. Effect of conjugated linoleic acid supplementation after weight loss on appetite and food intake in overweight subjects. Eur J Clin Nutr. 2003;57(10):1268-74.

37. Veldhorst MAB, Nieuwenhuizen AG, Hochstenbach-Waelen A, Westerterp KR, Engelen MPKJ, Brummer R-JM, et al. Comparison of the effects of a high- and normal-casein breakfast on satiety, satiety hormones, plasma amino acids and subsequent energy intake. $\mathrm{Br} \mathrm{J}$ Nutr. 2009;101(02):295-303. 


\section{Chapter 6}

\section{Stress augments food 'wanting' and energy intake in visceral overweight subjects in the absence of hunger}

Lemmens SG, Rutters F, Born JM, Westerterp-Plantenga MS

Physiol Behav. 2011. In press. 


\section{Abstract}

Stress may induce eating in the absence of hunger, possibly involving changes in food reward, i.e. 'liking' and 'wanting'.

The objective of this study was to assess the effects of acute psychological stress on food reward, and on energy intake, in visceral overweight (VO) vs. normal weight (NW) subjects.

Subjects $\left(27 \mathrm{NW}\right.$, age $=26 \pm 9 \mathrm{y}, \mathrm{BMl}=22 \pm 2 \mathrm{~kg} / \mathrm{m}^{2} ; 15 \mathrm{VO}$, age $=36 \pm 12 \mathrm{y}$, $\mathrm{BMI}=28 \pm 1 \mathrm{~kg} / \mathrm{m}^{2}$ ) came to the university twice, fasted, for either a rest or stress condition (randomized cross-over design). Per test session 'liking' and 'wanting' for 72 items divided in six categories (bread, filling, drinks, dessert, snacks, stationery (control)) were measured twice, each time followed by a wanted meal. Appetite profile (visual analogue scales, VAS), heart rate, mood state and level of anxiety (POMS/STAI questionnaires) were measured.

High hunger and low satiety $(64 \pm 19,22 \pm 20$ mmVAS) confirmed the fasted state. Elevated heart rate, anger and confusion scores $(p \leq 0.03)$ confirmed the stress vs. rest condition. Consumption of the first meal decreased hunger, increased satiety, and decreased ranking of 'liking' of bread vs. increased ranking of 'liking' of the control $(p<0.001)$. 'Wanting' for dessert and snacks, energy intake, carbohydrate and fat intake for the second meal stress vs. rest relatively increased in VO vs. decreased in NW ( $p<0.02)$. During stress vs. rest VO showed a $6 \pm 9 \%$ increase in percentage of daily energy requirements consumed over the two meals $(p=0.01)$.

To conclude, visceral overweight subjects showed stress-induced food intake in the absence of hunger, resulting in an increased energy intake. 


\section{Introduction}

The current epidemic of overweight and obesity results from a positive energy balance, with energy intake exceeding energy expenditure (1). It has been shown that physical activity energy expenditure in Europe and North America did not decrease between the 1980s and 2005, a period during which obesity rates increased (2). This suggests that the recent rise in obesity may not result from a lowered physical activity, but rather from an increased energy intake.

The regulation of food intake and energy homeostasis involves 'hunger' and 'satiety' signals produced in the hypothalamus as well as in peripheral organs (3). Besides those 'hunger' and 'satiety' signals, factors such as food reward, environmental cues, and cognitive factors, processed in cortico-limbic structures (e.g. prefrontal cortex, amygdala, and ventral striatum) are involved in the regulation of food intake and energy homeostasis (4). Both pathways (hypothalamic and cortico-limbic) interact in the neuro-regulatory control of feeding (4-6). In some situations, e.g. stress or the abundance of palatable foods, the food reward system may overrule and promote excessive food intake and consequently in the long-term a positive energy balance $(3,7)$. According to the incentive salience theory, it is hypothesized that the process of reward consists of two components controlled by different brain mechanisms, i.e. 'liking' and 'wanting' (8). 'Liking', under control of opioids, is the hedonic or affective component and refers to the pleasure derived from oro-sensory stimulation of food ( 9 , 10). 'Wanting', under control of dopamine, is the motivational incentive component and refers to craving or the motivation to obtain food $(5,8-11)$.

Recent human studies have shown a possible relationship between stress and the increased prevalence of obesity (15-19). It appears that psychosocial stress is associated with greater weight gain among subjects who are overweight or obese, but less among subjects who are normal weight or underweight $(7,20$, 21). The food choice in stress is often shifted towards sweet and fat foods, possibly because they are perceived as highly rewarding (22-24). Rutters et al. (25) showed that acute psychological stress can lead to eating in the absence of hunger, which can be described as eating beyond energy homeostasis, possibly involving the food reward system (26). Evidence for the involvement of the reward system in stress-induced eating can be found in both rodent and human studies (27-34). The fMRI study by Born et al. (35) assessing the effects of acute stress on food choice and food choice reward related brain activity in normal weight women, showed a lower activation in the amygdala, hippocampus and cingulate cortex and an increased energy intake in the stress condition compared with the rest condition postprandially. It seems that stress decreases the sensitivity of the reward system to food cues, which was reflected in a decreased activation of food reward associated brain areas. It is likely that there is a relationship, though still complex, between stress, reward and eating behavior. 
The aim of our study was to assess in visceral overweight vs. normal weight subjects the effects of acute psychological stress on the rewarding value of food, in terms of 'liking' and 'wanting', and on food intake in a fasted as well as satiated state. A computer test, which was developed and validated in a previous study, was used to measure 'liking' and 'wanting': 'liking' was defined as the relative preference of two food items, and 'wanting' as the motivation to obtain food items by working (playing memory games) to earn items to choose from (36). Regarding this 'wanting' part of the computer test, the more pairs of items were found in the memory game, representing the motivation to obtain items, the more items were offered to choose from afterwards.

We hypothesized that in the fasted state food reward and food intake would not differ between the rest and stress condition and between normal weight and visceral overweight subjects, as in the fasted state the homeostatic control system may dominate. In the satiated state, however, we hypothesized that under the influence of acute stress the reward system may overrule the homeostatic control system in visceral overweight subjects compared with normal weight subjects, leading to an increased food intake. Acute stress may diminish food reward, inducing an increased intake of high caloric foods to compensate for the reward deficiency (35). Visceral overweight subjects, compared with normal weight subjects, might be more vulnerable to stress-induced eating and consequently the development of obesity $(20,37,38)$.

\section{Material and methods}

\section{Subjects}

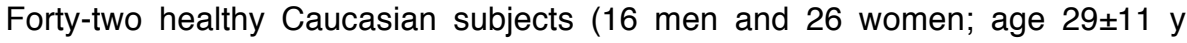
$($ mean $\pm S D$, range $19-55 \mathrm{y})$ ) with a $\mathrm{BMl}$ of $24.5 \pm 3.4 \mathrm{~kg} / \mathrm{m}^{2}$ (mean $\pm \mathrm{SD}$, range $18.9-30.5 \mathrm{~kg} / \mathrm{m}^{2}$ ) participated in this study. They were recruited by advertisements in local newspapers and on notice boards at the university. Subjects underwent an initial screening including measurement of body weight, height, waist circumference and hip circumference, and completion of a questionnaire related to health, and use of medication. Inclusion criteria comprised BMI $19-30 \mathrm{~kg} / \mathrm{m}^{2}$, both genders, and no use of medication (except contraception). Regarding overweight subjects only visceral overweight subjects were included, as chronic stress has been associated with visceral fat accumulation and obesity $(15,39$, 40 ). Visceral overweight was defined as having a waist circumference of $\geq 80 \mathrm{~cm}$ in women and $\geq 94 \mathrm{~cm}$ in men (41).

Eating behavior was analyzed using a validated Dutch translation of the Three Factor Eating Questionnaire (TFEQ) which measures three components: 'cognitive restraint of eating', 'disinhibition of restraint', and 'hunger' (12). Subjects were divided into two groups according to their BMI: a normal weight (NW) group $(n=27)$ and a visceral overweight (VO) group $(n=15)$. 
This study was conducted according to the guidelines laid down in the Declaration of Helsinki and was approved by the Medical Ethical Committee of the Maastricht University. All subjects gave written informed consent. Subjects received a monetary compensation after completion of the two test days.

\section{Study design}

The study was conducted in a randomized cross-over design. All subjects came to the university twice in a fasted state between 08:00 and 09:00 AM, once for a stress test session and once for a rest (control) test session.

Figure 1 gives a schematic overview of the study design per test session. After arrival at the university, subjects were seated in the laboratory and remained seated throughout the whole experiment $(230 \mathrm{~min})$. A mathematical test was used to create the stress vs. rest condition in subjects $(25,35,42)$. The mathematical test has been described and validated before by Peters et al. (42) and Rutters et al. (25). In a previous study by Born et al., we measured cortisol concentrations with the same mathematical test, showing that cortisol concentrations were increased in the stress condition $(\triangle \mathrm{AUC}=+2.2 \times 104 \mathrm{nmol} / \mathrm{min} . \mathrm{l}$, $\mathrm{p}<0.05$ ) (35).

Two versions of the math test were used: an unsolvable stress version combined with irritating music and background noises and a solvable control version without music and background noises. Subjects were given the math test before completing the computer test (36), developed to measure 'liking' and 'wanting', which was followed by a wanted meal. After this first meal, subjects completed the math test and the 'liking' and 'wanting' computer test again, followed by a second meal. Both the first and the second meal were composed by the subjects themselves by means of the 'wanting' part of the computer test.

The tests were completed pre- and post-meal to be able to measure effects of stress on food choice and food intake in hunger as well as in the absence of hunger. During the rest test session subjects completed twice the control (rest) version of the math test, and during the stress test session they completed twice the stress version of the math test.

To investigate whether the stress condition inflicted psychological or physiological changes, we used Profile Of Mood State (POMS) and State Trait Anxiety Inventory (STAl) questionnaires as well as heart rate measurements. One hundred unit visual analogue scales (VAS; in $\mathrm{mm}$ ) were used to assess the appetite profile. Questionnaires were collected five times per test session. Heart rate (b.p.m.) was measured every five seconds during the whole test session by means of a Polar RS400 heart rate monitor. 


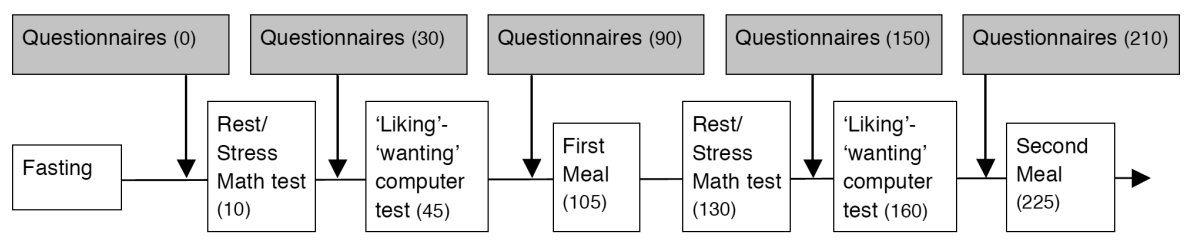

Figure 1. Schematic overview of the study design per test session. Numbers in brackets represent the time points (in $\mathrm{min}$ ) at which data was collected or tasks were completed.

\section{Questionnaires}

One hundred unit VAS $(\mathrm{mm})$ were used to assess the appetite profile. The scales were anchored with 'not at all' at one end and 'extremely' at the other end, and combined with questions on feelings of hunger, thirst, fullness, satiety and desire to eat.

Mood states were assessed using a modified version of the Dutch translation of the POMS (43). This questionnaire contains 35 adjectives that are rated on a five-point scale and is divided into five subscales (depression, tension, confusion, fatigue, and anger). The Dutch translation of the state scale of the STAI questionnaire was used to measure state anxiety (44). Subjects had to rate 20 statements on how they felt at that moment on a four-point scale. An increase in POMS and STAI scores is associated with a worsening in mood.

The VAS, POMS and STAI questionnaires were completed five times throughout the test sessions at 0, 30, 90, 150 and 210 min (Figure 1).

\section{'Liking' and 'wanting' computer test}

The computer test described and validated by Lemmens et al. (36) was used to measure the rewarding value, i.e. 'liking' and 'wanting', for 72 items divided in six categories: bread, filling, drinks, dessert, snacks, and stationery (non-food alternative as control). Those five food categories were chosen as they gave the subjects the opportunity to compose a full meal according to their wishes. A usual Dutch breakfast/lunch consists of bread, filling and drinks. Above this, dessert and sweets can be added. Each category contained 12 items. The 72 items were presented as photographic stimuli on a computer screen (13-inch Mac Book, Apple, Cupertino, USA).

The computer test contained two parts, a 'liking' and a 'wanting' part. Both the 'liking' and 'wanting' tasks assessed 'liking' respectively 'wanting' for the same food and stationery items. During the 'liking' part, subjects had to indicate their relative preference of paired items within and between the six categories. Each choice had to be made within four seconds via a mouse click on the preferred item, which triggered the next pair of items. First, all possible pairs of combinations within each category were presented $(\mathrm{N}=6 \times 66)$. The pairs of items were presented in random order, while the categories were presented in the following 
order: bread, filling, drinks, dessert, sweets and stationery. This resulted in a relative ranking of 'liking' of the items per category (score range 0-605). Next, the items from the different categories with the corresponding ranking of 'liking' were presented in pairs, in random order $(\mathrm{N}=12 \times 15)$. This resulted in a relative ranking of 'liking' of the categories (score range $0-125$ ).

During the 'wanting' part, subjects had to work to earn items by playing memory games. For each category of items subjects played a five by five memory game (12 pairs of items). Per memory game the shuffled pairs of items were first presented for 10 seconds, giving the subjects the opportunity to locate and remember the pairs of matching items. Next the items were turned over and the subjects could start finding the matching pairs by clicking on them using the computer mouse. Matched pairs remained on the screen, while nonmatched pairs were turned over again. Subjects had two min to solve the memory game. Each memory game was followed by the indication of the items subjects wanted to acquire at that moment. The more pairs of items were found in the memory game, the more randomly selected items were offered to choose from afterwards, e.g. if eight pairs of items would be found in the memory game of the snacks category, then eight randomly selected snacks would be offered to choose from. Subjects could choose zero, one or two items per category. They were instructed to choose the items while keeping in mind that all the chosen items would be offered to them and had to be eaten completely. To proceed to the next category subjects had to find at least two pairs of items per memory game. The categories were presented in the following order: bread, filling, drinks, dessert, sweets and stationery. From the drinks category onwards, subjects could press a stop-button to stop the 'wanting' part of the computer test, indicating that they would not want to work for and earn any other items. The chosen items obtained a score equal to the number of pairs of items found in the memory game, representing the motivation or workload for the chosen items (score range 2-12). Items not chosen obtained a score of zero. Per category the sum of the scores of the items was calculated and represented the 'wanting' score for each category. A minimum score of zero and a maximum score of 24 was obtained per category.

All the chosen items were offered to the subjects in a fixed amount, which was described to the subjects beforehand, and food items were eaten completely. Total energy content and macronutrient composition of the consumed meals were calculated.

\section{Statistics}

Data were analyzed using StatView 5.0 (SAS Institute Inc., Cary, NC, USA). Factorial ANOVA with repeated measures was used to study the effects between subject groups (visceral overweight vs. normal weight) of the conditions of stress vs. rest, and of time, on questionnaire data, on food reward, i.e. 'liking' and 
'wanting', and on energy intake. Paired and unpaired Student's t-tests were used as Post hoc analyses for significant interactions.

The Wilcoxon signed-rank test was used to detect differences in the ranking of 'liking' of items within each category from the first to the second computer test. Areas under the curve (AUC) for questionnaire data were calculated using the trapezoid method. All tests were two-sided and differences were considered significant at $p<0.05$. Values are expressed as mean \pm standard error of the mean (SEM), unless stated otherwise.

\section{Results}

\section{Subject characteristics}

The characteristics of the subjects are summarized in Table 1. Visceral overweight subjects were older than normal weight subjects $(p<0.01)$, however simple linear regression models (age as independent variable and relevant parameters, such as 'liking', 'wanting' and energy intake, as dependent variable) and ANOVA analyses (age as covariate) showed that this did not influence the results $(p>0.05)$. Visceral overweight subjects had a higher body weight, BMI, and waist/hip ratio than normal weight subjects $(p<0.0001)$. Eating behavior, in terms of the three factors of the TFEQ (dietary restraint, disinhibition and feeling of hunger), did not differ between normal weight and visceral overweight subjects.

There were no gender effects for the different parameters of questionnaire data, 'liking', 'wanting', and energy intake (3-factor ANOVA repeated measures gender $\mathrm{x}$ group $\mathrm{x}$ condition $\mathrm{x}$ time).

Table 1. Characteristics of normal weight (NW) and visceral overweight (VO) subjects.

\begin{tabular}{lccc}
\hline & NW & VO & $p^{a}$ \\
& $(\mathrm{n}=27 ; 8 \mathrm{~m} / 19 f)$ & $(\mathrm{n}=15 ; 8 \mathrm{~m} / 7 \mathrm{f})$ & \\
\hline Age $(\mathrm{y})$ & $25.6 \pm 8.9$ & $35.7 \pm 11.7$ & $<.01$ \\
Height $(\mathrm{cm})$ & $173.9 \pm 8.1$ & $174.8 \pm 7.7$ & 0.7 \\
Body weight $(\mathrm{kg})$ & $67.6 \pm 7.9$ & $86.8 \pm 6.7$ & $<.0001$ \\
BMI $\left(\mathrm{kg} / \mathrm{m}^{2}\right)$ & $22.4 \pm 1.9$ & $28.4 \pm 1.4$ & $<.0001$ \\
Waist circumference $(\mathrm{cm})$ & $73.6 \pm 7.1$ & $91.5 \pm 6.2$ & $<.0001$ \\
Hip circumference $(\mathrm{cm})$ & $98.6 \pm 4.3$ & $109.6 \pm 4.6$ & $<.0001$ \\
Dietary restraint score & $7.9 \pm 4.8$ & $6.3 \pm 4.7$ & 0.3 \\
Disinhibition score & $4.7 \pm 2.1$ & $4.9 \pm 2.1$ & 0.7 \\
Feeling of hunger score & $4.6 \pm 2.6$ & $3.8 \pm 3.2$ & 0.3 \\
\hline
\end{tabular}

Values are means $\pm S D ;{ }^{a} p$-value: differences between NW and VO subjects (Unpaired Student's ttests) 


\section{Appetite profile}

The fasted state was confirmed on both test days by low satiety and fullness scores $(22.5 \pm 3.0 ; 19.3 \pm 2.7 \mathrm{mmVAS})$, and high hunger, 'desire to eat' and thirst scores $(63.6 \pm 2.9 ; 65.0 \pm 3.1 ; 65.5 \pm 3.1 \mathrm{mmVAS})$. Consumption of the first meal resulted in an increase in satiety and fullness scores $(\Delta=57.1 \pm 3.8 ; 51.2 \pm 4.0$ mmVAS, $p<0.001$, Paired Student's t-tests), and a decrease in hunger, 'desire to eat' and thirst scores $(\Delta=54.2 \pm 3.6 ; 54.6 \pm 3.6 ; 37.7 \pm 4.5$ mmVAS, $p<0.001$, Paired Student's t-tests), on both test days. These results confirmed that subjects were in a satiated state when they completed the second part of the test session. There were no differences in appetite profile measures between normal weight and visceral overweight subjects and between the stress and rest condition (2factor ANOVA repeated measures group $x$ condition $x$ time).

\section{Stress parameters}

The POMS questionnaire indicated increased scores for the subscales 'confusion' ( $\triangle \mathrm{AUC}=130.7, \mathrm{p}=0.02, \mathrm{t}=2.4, \mathrm{df}=41$, Paired Student's t-test) and 'anger' $(\triangle A U C=140.0, p=0.03, t=2.2, d f=41$, Paired Student's t-test) in the stress vs. rest test condition. Moreover, after the first mathematical test, increased scores for the subscales 'depression' $(16.9 \pm 0.7$ vs. $15.7 \pm 0.6, p=0.01, t=2.7$, $\mathrm{df}=41$, Paired Student's t-test) and 'anxiety' (15.7 \pm 0.8 vs. $13.3 \pm 0.7, p<0.0001$, $t=4.6, d f=41$, Paired Student's t-test) were detected in the stress vs. rest condition. After the second mathematical test, increased scores for the subscale 'confusion' (15.9 \pm 0.6 vs.15.1 $\pm 0.7, \mathrm{p}<0.04, \mathrm{t}=2.1, \mathrm{df}=41$, Paired Student's t-test) were detected in the stress vs. rest condition. The state anxiety scores (STAI), immediately after the first mathematical test, were higher in the stress condition compared with the rest condition $(34.7 \pm 1.4$ vs. $32.0 \pm 1.3, p<0.01, t=3.2, d f=41$, Paired Student's t-test). These results of the POMS and STAI questionnaires confirmed that the stress version of the math test inflicted psychological changes.

The average heart rate was increased in the stress vs. rest test condition (72.1 \pm 1.4 vs. $70.4 \pm 1.3$ b.p.m.; $p=0.03, t=2.3, d f=38$, Paired Student's t-test). The minimum heart rate value reached was higher in the stress vs. rest test condition (56.7 \pm 1.4 vs. $55.1 \pm 1.3$ b.p.m.; $p=0.04, t=3.2, d f=38$, Paired Student's t-test). The maximum heart rate value reached did not differ in the stress vs. rest test condition (103.6 \pm 2.1 vs. $104.8 \pm 3.4$ b.p.m.; $p=0.7, t=-0.4, d f=37$, Paired Student's $t-$ test).

There were no differences in heart rate values, POMS and STAI scores between normal weight and visceral overweight subjects (Factorial ANOVA). 


\section{'Liking' and 'wanting' computer test}

Regarding the results of the computer test for relative 'liking' between categories, there was an overall effect of time $(p<0.0001 ; 2$-factor ANOVA repeated measures group $\mathrm{x}$ condition $\mathrm{x}$ time, per category): consumption of the first meal induced a shift in the ranking of 'liking' of the six categories, thereby decreasing the bread category $(p<0.0001, F=30.5, d f=1)$ vs. increasing the stationery (control) category $(p<0.0001, F=35.3, d f=1)$. There was no effect of group (visceral overweight vs. normal weight) or condition (stress vs. rest) on 'liking' between categories ( $p>0.4)$. The ranking of 'liking' of the items within each category did not change significantly ( $p>0.1$, Wilcoxon signed-rank test) in both subject groups and in both conditions.

Regarding mean 'wanting' for food items from all the five food categories taken together, there was an overall effect of time $(p<0.0001, F=52.6, d f=1,2$-factor ANOVA repeated measures group $x$ condition $x$ time): mean food 'wanting' decreased from the first to the second meal (Figure 2). Mean food 'wanting' for the second meal, stress vs. rest, shifted differently between visceral overweight subjects (relatively higher) and normal weight subjects (relatively lower; $p<0.02$, $\mathrm{F}=6.4$, $\mathrm{df}=1$, ANOVA repeated measures group $\mathrm{x}$ condition). In visceral overweight subjects mean food 'wanting' for the second meal was higher in the stress vs. rest condition ( $p=0.04, t=2.2, d f=14$, Paired Student's t-test; Figure 2).

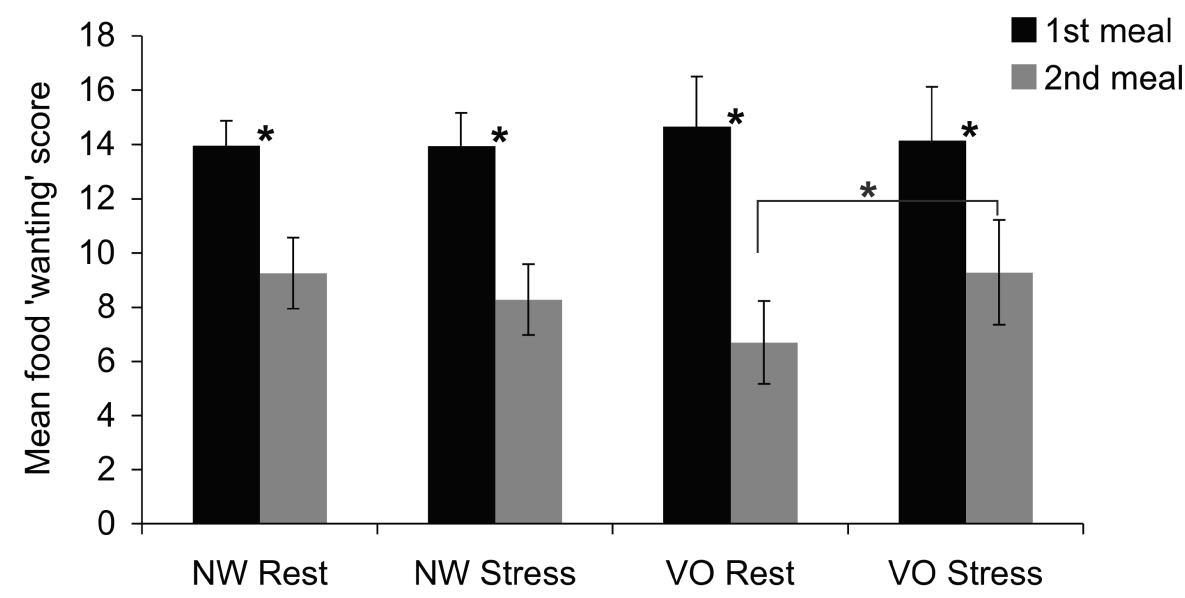

Figure 2. Mean food 'wanting' score (mean $\pm S E M)$ for items from all the five food categories taken together, for the first and second meal, in normal weight (NW) and visceral overweight (VO) subjects, in the rest and stress condition. * $\mathrm{p}<0.05$

Regarding the results of the computer test for 'wanting' per category, there was an overall effect of time (2-factor ANOVA repeated measures group $\mathrm{x}$ condition $\mathrm{x}$ time) for 'wanting' for bread $(p<0.0001, F=52.5$, $d f=1)$, filling $(p<0.0001, F=37.1$, $d f=1)$, and drinks $(p<0.0001, F=40.2, d f=1)$, which decreased after the first meal (Figure 3 ). There was a group $x$ condition $x$ time interaction for 'wanting' for 
dessert $(p<0.03, F=5.0, d f=1)$ and snacks $(p<0.01, F=7.3, d f=1)$. 'Wanting' for dessert and snacks for the second meal, stress vs. rest, shifted differently between visceral overweight subjects (relatively higher) and normal weight subjects (relatively lower; 'wanting' for dessert: $p<0.02, F=6.1$, $d f=1$; 'wanting' for snacks: $\mathrm{p}<0.001, \mathrm{~F}=15.9, \mathrm{df}=1$; ANOVA repeated measures group $\mathrm{x}$ condition). In visceral overweight subjects 'wanting' for dessert and snacks for the second meal was higher in the stress vs. rest condition (dessert: $p<0.03, t=2.5, d f=14$; snacks: $p<0.01, t=3.7, d f=14$; Paired Student's t-tests; Figure 3). During stress, 'wanting' for snacks for the second meal was larger in visceral overweight subjects compared with normal weight subjects $(p<0.01, F=7.5, d f=1$, Factorial ANOVA; Figure 3).

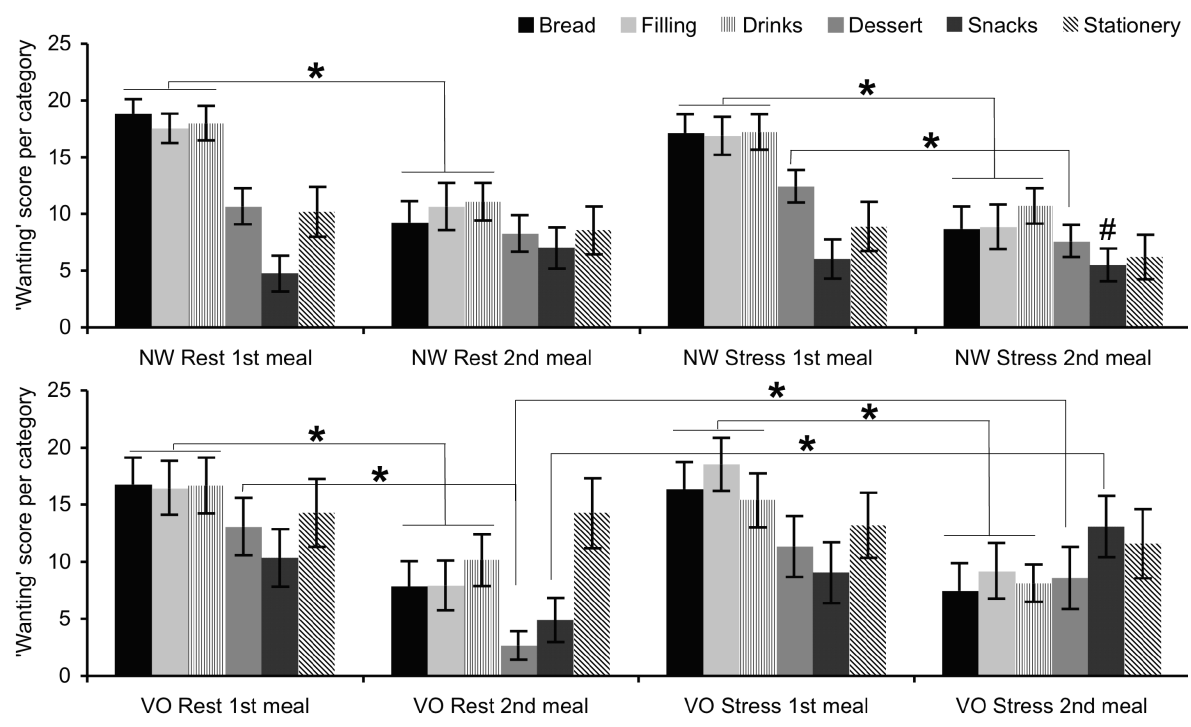

Figure 3. 'Wanting' score (mean \pm SEM) per category for the first and second meal in normal weight (NW; upper part) and visceral overweight (VO; lower part) subjects, in the rest and stress condition. ${ }^{*} p<0.05, \# p<0.01$ for differences between NW and VO (factorial ANOVA)

\section{Energy and macronutrient intake}

Regarding energy intake there was an overall effect of time $(p<0.0001, F=54.7$, $\mathrm{df}=1,2$-factor ANOVA repeated measures group $\mathrm{x}$ condition $\mathrm{x}$ time): energy intake decreased from the first to the second meal in normal weight subjects in the rest condition $(p<0.01, t=3.5, d f=26$, Paired Student's $t$-test $)$ and in the stress condition $(p<0.001, t=4.4, d f=26$, Paired Student's $t$-test) and in visceral overweight subjects in the rest condition $(p<0.0001, t=5.4, d f=14$, Paired Student's $t-$ test) but not in the stress condition $(p=0.12, t=1.7, d f=14$, Paired Student's t-test; Figure 4).

There was a group $x$ condition $x$ time interaction for energy intake $(p=0.01$, $F=6.8, d f=14)$. The energy intake for the second meal, stress vs. rest, shifted 
differently between visceral overweight subjects (relatively higher) and normal weight subjects (relatively lower; ANOVA repeated measures group $\mathrm{x}$ condition, $p=0.001, F=12.0, d f=1)$. In visceral overweight subjects the energy intake for the second meal was higher in the stress vs. rest condition $(p=0.02, t=2.6, d f=14$, Paired Student's t-test; Figure 4).

There was a group $\mathrm{x}$ time interaction for the energy intake in the rest condition $(p<0.001, F=14.4, d f=1)$ : the decrease in energy intake from the first to the second meal was larger in visceral overweight subjects compared with normal weight subjects. In visceral overweight subjects, compared with normal weight subjects, the energy intake for the first meal was larger during rest $(p=0.01$, $\mathrm{F}=7.0, \mathrm{df}=1$, Factorial ANOVA; Figure 4).

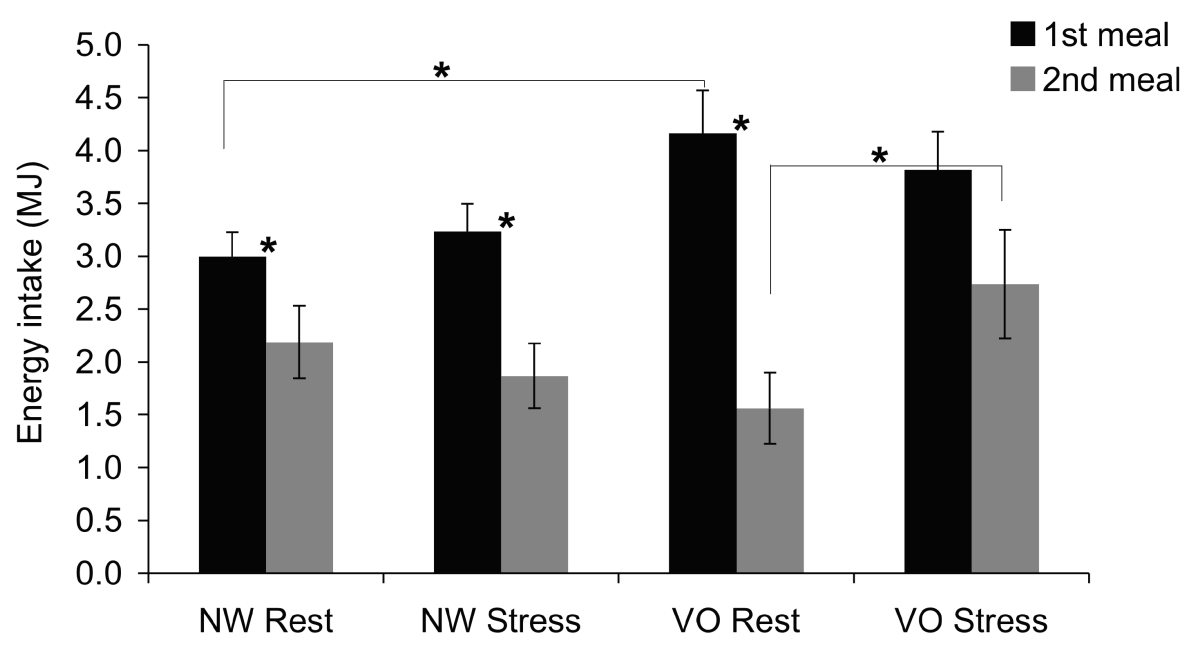

Figure 4. Energy intake (MJ, mean \pm SEM) for the first and second meal in normal weight (NW) and visceral overweight (VO) subjects, in the rest and stress condition. ${ }^{*} \mathrm{p}<0.05$

When representing the total energy intake of the first and second meal together as percentage of the daily energy requirements (DER) consumed (normal weight, stress vs. rest: $44.6 \pm 3.7 \%$ vs. $45.6 \pm 4.3 \%$; visceral overweight, stress vs. rest: $54.2 \pm 4.9 \%$ vs. $47.7 \pm 5.0 \%$ ), a group $x$ condition interaction was detected $(p=0.01, F=6.8, d f=1)$ : the percentage of DER consumed stress vs. rest shifted differently between visceral overweight subjects (relatively higher) and normal weight subjects (relatively lower). During stress vs. rest visceral overweight subjects showed an increase in percentage of DER consumed over the two meals by $6.5 \pm 2.3 \%(p=0.01, t=2.8, d f=14$, Paired Student's t-test). The DER were calculated by multiplying the basal metabolic rate (BMR) by the appropriate physical activity factor (1.5-1.8, derived from the screening questionnaire (45)). The BMR (kcal/day) was calculated according to the equation of Harris-Benedict (46). 
Regarding protein, carbohydrate, and fat intake there was an overall effect of time $(p<0.0001,2$-factor ANOVA repeated measures group $x$ condition $x$ time): protein intake decreased from the first to the second meal in both conditions and both subject groups ( $p<0.001$, Paired Student's t-tests), and carbohydrate and fat intake decreased from the first to the second meal in normal weight subjects in both conditions ( $p<0.001$, Paired Student's t-tests), and in visceral overweight subjects in the rest condition ( $p<0.001$, Paired Student's t-tests) but not in the stress condition ( $p>0.1$, Paired Student's t-test; Figure 5). There was a group $x$ condition $x$ time interaction for carbohydrate $(p=0.01, F=6.9, d f=1)$ and fat intake $(p=0.02, F=5.3, d f=1)$. The carbohydrate and fat intake for the second meal, stress vs. rest, shifted differently between visceral overweight subjects (relatively higher) and normal weight subjects (relatively lower; carbohydrate: $p<0.01$, $F=8.7, d f=1$; fat: $p<0.01, F=9.5, d f=1$; ANOVA repeated measures group $x$ condition). In visceral overweight subjects the carbohydrate intake $(p<0.03$, $t=2.4, d f=14$, Paired Student's t-test $)$ and fat intake $(p=0.02, t=2.6, d f=14$, Paired Student's t-test) was higher in the absence of hunger in the stress vs. rest condition (Figure 5).

There was a group $x$ time interaction for the protein intake $(p=0.01, F=7.0, d f=1)$, carbohydrate intake $(p<0.01, F=12.3, d f=1)$, and fat intake $(p<0.001, F=13.9$, $\mathrm{df}=1$ ) in the rest condition: the decrease in protein, carbohydrate and fat intake from the first to the second meal was larger in visceral overweight subjects compared with normal weight subjects. In visceral overweight subjects, compared with normal weight subjects, the protein intake $(p=0.04, F=4.5, d f=1)$, carbohydrate intake $(p<0.02, F=6.0, d f=1)$, and fat intake $(p<0.02, F=6.2, d f=1)$ for the first meal was larger during rest (Factorial ANOVA; Figure 5).
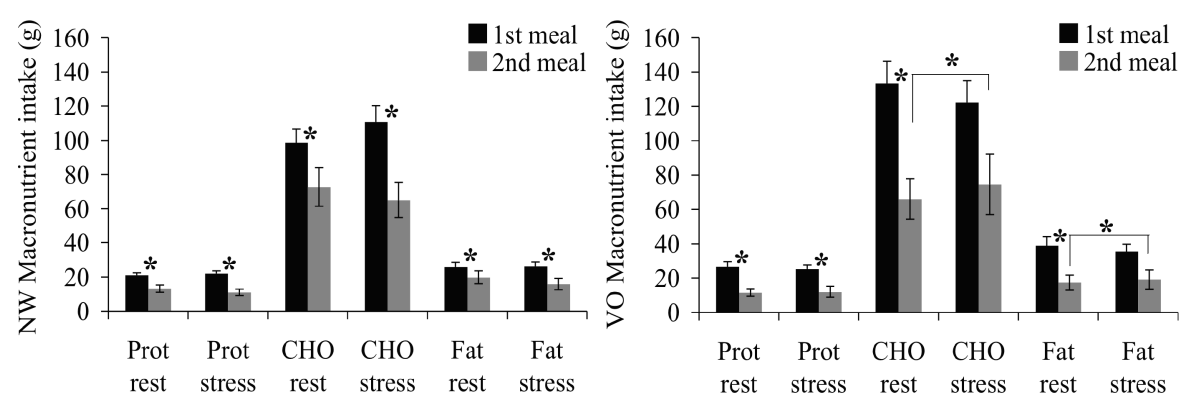

Figure 5. Protein (prot), carbohydrate $(\mathrm{CHO})$ and fat intake $(\mathrm{g}$, mean $\pm \mathrm{SEM})$ for the first and second meal in normal weight (NW; left) and visceral overweight (VO; right) subjects, in the rest and stress condition. ${ }^{*} \mathrm{p}<0.05$ 


\section{Discussion}

The main objective of this study was to assess in visceral overweight vs. normal weight subjects the effects of acute psychological stress on the rewarding value of food, in terms of 'liking' and 'wanting', and on food intake in a fasted as well as satiated state.

Appetite profile measurements confirmed that subjects were in a satiated state after the first meal, which made it possible to test the effects of acute stress on food choice and food intake in the absence of hunger. The acute psychological stress condition was confirmed by POMS and STAI questionnaires and heart rate.

Ranking of 'liking' of the used categories of items (bread, filling, drinks, dessert, snacks, stationery (control)) was not affected by the induced stress in both normal weight and visceral overweight subjects. Consumption of a meal induced an increased relative 'liking' of the non-food alternative, i.e. the stationery category, and a decreased relative 'liking' of the bread category. While ranking of 'liking' changed between categories, within each category there was no significant change in ranking of 'liking' of the items.

Food 'wanting' and energy intake differed clearly between normal weight and visceral overweight subjects and between the rest and stress condition. Normal weight subjects seemed not to be affected by the induced stress: in both conditions, rest and stress, mean food 'wanting' and energy intake decreased in the absence of hunger. Visceral overweight subjects on the other hand showed a higher mean food 'wanting' and energy intake in the absence of hunger, in the stress vs. rest condition. Their mean food 'wanting', 'wanting' for dessert and snacks, and their energy intake, carbohydrate and fat intake was higher in the absence of hunger in the stress vs. rest condition. From prospective studies it appears that psychosocial stress is associated with greater weight gain among subjects who are overweight or obese, but less among subjects who are normal weight or underweight $(20,21)$. The latter subjects normally are not interested anymore in eating while stressed, whereas the visceral overweight subjects seem to eat to suppress stress $(20,21)$.

'Wanting' for snacks in the absence of hunger and in the stress condition was higher in visceral overweight subjects compared with normal weight subjects. The snacks category contained highly palatable foods with a high fat/carbohydrate macronutrient content (36). Consumption of those 'comfort foods' may be a way to cope with stress (24). However, the risk is that chronic stress combined with a high-fat, high-carbohydrate diet may lead to abdominal obesity (47).

In the rest condition and fasted state visceral overweight subjects consumed more energy than normal weight subjects. When representing the total energy intake over the two meals as percentage of DER consumed, there was no difference between normal weight and visceral overweight subjects in the rest 
condition. However, in the stress condition visceral overweight subjects seemed to lose control over their energy intake and consequently increased their energy intake in the absence of hunger. During stress vs. rest, visceral overweight subjects increased the percentage of DER consumed over the two meals by $6 \pm 9$ $\%$, in contrast to normal weight subjects. As we hypothesized, in a 'normal' situation without stress the homeostatic control system may dominate the control of feeding to maintain energy balance. However, in a stressful situation the reward system may overrule the homeostatic control system in visceral overweight subjects compared with normal weight subjects, leading to an increased intake of energy dense and highly palatable foods $(22,23)$.

The above described findings suggest that acute stress influences food 'wanting' and eating in the absence of hunger when being viscerally overweight.

Previous research has shown that food 'liking' and 'wanting' are independent processes regulated by different neurobiological systems $(22,23,25)$. Food 'wanting' may be a stronger determinant of energy intake than is food 'liking' or food hedonics (48-50). Results of this current study show that food 'liking' appears relatively uninfluenced by stress or increasing weight status. 'Wanting' on the other hand is influenced by stress and weight status, as visceral overweight subjects in stress and in the absence of hunger want and consume foods that are high in fat and carbohydrate, in contrast to normal weight subjects. This suggests that during stress 'wanting' in the absence of hunger might be an important process in developing an obese state.

Summarizing, we hypothesized that under influence of acute stress the food reward system may overrule the homeostatic control system in the absence of hunger in visceral overweight subjects compared with normal weight subjects. Our study showed that in visceral overweight subjects, in contrast to normal weight subjects, 'wanting' for dessert and snacks, and energy intake (carbohydrate and fat), in the absence of hunger, was higher in the stress vs. rest condition. Moreover, under stress visceral overweight subjects showed an increase in percentage of daily energy requirements consumed over two meals by $6 \pm 2 \%$, in contrast to normal weight subjects. In conclusion, visceral overweight subjects showed stress-induced food intake in the absence of hunger, resulting in an increased energy intake.

\section{Acknowledgements}

We thank our subjects for their participation in this study and Sanne Verhoef for her help with the practical work. The study was designed by MSWP and SGL. SGL (supervised by MSWP) carried out the study, collected and analyzed the data and wrote the largest part of the manuscript. MSWP, FR and JMB reviewed the manuscript. 


\section{References}

1. Caballero B. The Global Epidemic of Obesity: An Overview. Epidemiol Rev. 2007 January 1, 2007;29(1):1-5.

2. Westerterp KR, Speakman JR. Physical activity energy expenditure has not declined since the 1980s and matches energy expenditures of wild mammals. Int J Obes. 2008;32:1256-63.

3. Erlanson-Albertsson C. How palatable food disrupts appetite regulation. Basic Clin Pharmacol Toxicol. 2005 Aug;97(2):61-73.

4. Berthoud HR. Homeostatic and non-homeostatic pathways involved in the control of food intake and energy balance. Obesity (Silver Spring). 2006 Aug;14 Suppl 5:197S-200S.

5. Berthoud HR. Neural control of appetite: cross-talk between homeostatic and non-homeostatic systems. Appetite. 2004 Dec;43(3):315-7.

6. Blundell JE, Finlayson $\mathrm{G}$. Is susceptibility to weight gain characterized by homeostatic or hedonic risk factors for overconsumption? Physiol Behav. 2004 Aug;82(1):21-5.

7. Dallman MF. Stress-induced obesity and the emotional nervous system. Trends Endocrinol Metab. 2010;21(3):159-65.

8. Berridge KC. Food reward: brain substrates of wanting and liking. Neurosci Biobehav Rev. 1996;20(1):1-25.

9. Finlayson G, King N, Blundell JE. Is it possible to dissociate 'liking' and 'wanting' for foods in humans? A novel experimental procedure. Physiol Behav. 2007 Jan 30;90(1):36-42.

10. Mela DJ. Eating for pleasure or just wanting to eat? Reconsidering sensory hedonic responses as a driver of obesity. Appetite. 2006 Jul;47(1):10-7.

11. Berridge KC. Motivation concepts in behavioral neuroscience. Physiol Behav. 2004 Apr;81(2):179-209.

12. Stunkard AJ, Messick S. The three-factor eating questionnaire to measure dietary restraint, disinhibition and hunger. J Psychosom Res. 1985;29(1):71-83.

13. Robinson TE, Berridge KC. Incentive-sensitization and addiction. Addiction. 2001 Jan;96(1):10314.

14. Berridge KC, Robinson TE. The Mind of an Addicted Brain: Neural Sensitization of Wanting Versus Liking. Current Directions in Psychological Science. 1995;4(3):71-6.

15. Torres SJ, Nowson CA. Relationship between stress, eating behavior, and obesity. Nutrition. 2007 Nov-Dec;23(11-12):887-94.

16. Adam TC, Epel ES. Stress, eating and the reward system. Physiol Behav. 2007 Apr 14;91(4):449-58.

17. Nieuwenhuizen AG, Rutters $F$. The hypothalamic-pituitary-adrenal-axis in the regulation of energy balance. Physiol Behav. 2007 Dec 23;94(2):169-77.

18. Kyrou I, Chrousos GP, Tsigos C. Stress, visceral obesity, and metabolic complications. Ann N Y Acad Sci. 2006 Nov;1083:77-110.

19. Brunner EJ, Chandola T, Marmot MG. Prospective effect of job strain on general and central obesity in the Whitehall II Study. Am J Epidemiol. 2007;165(7):828-37.

20. Block JP, He Y, Zaslavsky AM, Ding L, Ayanian JZ. Psychosocial stress and change in weight among US adults. Am J Epidemiol. 2009;170(2):181-92.

21. Kivimäki M, Head J, Ferrie JE, Shipley MJ, Brunner EJ, Vahtera J, et al. Work stress, weight gain and weight loss: evidence for bidirectional effects of job strain on body mass index in the Whitehall II study. Int J Obes (Lond). 2006;30(6):982-7.

22. Oliver G, Wardle J, Gibson EL. Stress and food choice: a laboratory study. Psychosom Med. 2000 Nov-Dec;62(6):853-65.

23. Zellner DA, Loaiza S, Gonzalez Z, Pita J, Morales J, Pecora D, et al. Food selection changes under stress. Physiol Behav. 2006 Apr 15;87(4):789-93.

24. Garg N, Wansink B, Inman J. The Influence of Incidental Affect on Consumers' Food Intake. Journal of Marketing. 2007;71(1):194-206. 
25. Rutters F, Nieuwenhuizen AG, Lemmens SG, Born JM, Westerterp-Plantenga MS. Acute stressrelated changes in eating in the absence of hunger. Obesity (Silver Spring). 2009 Jan;17(1):72-7.

26. Berthoud HR. Mind versus metabolism in the control of food intake and energy balance. Physiol Behav. 2004 Jul;81(5):781-93.

27. Volkow ND, Wang GJ, Fowler JS, Telang F. Overlapping neuronal circuits in addiction and obesity: evidence of systems pathology. Philos Trans R Soc Lond B Biol Sci. 2008;363(1507):3191-200.

28. Berridge KC. 'Liking' and 'wanting' food rewards: Brain substrates and roles in eating disorders. Physiology \& Behav. 2009;97(5):537-50.

29. Dallman MF, Pecoraro NC, La Fleur SE, Warne JP, Ginsberg AB, Akana SF, et al. Glucocorticoids, chronic stress, and obesity. Prog Brain Res. 2006;153:75-105.

30. Reynolds SM, Berridge KC. Emotional environments retune the valence of appetitive versus fearful functions in nucleus accumbens. Nat Neurosci. 2008;11(4):423-5.

31. O'Hare E, Shaw DL, Tierney KJ, E-M K, Levine AS, Shephard RA. Behavioral and neurochemical mechanisms of the action of mild stress in the enhancement of feeding. Behav Neurosci. 2004 Feb;118(1):173-7.

32. Yoshida M, Koyanagi S, Matsuo A, Fujioka T, To H, Higuchi S, et al. Glucocorticoid hormone regulates the circadian coordination of micro-opioid receptor expression in mouse brainstem. $J$ Pharmacol Exp Ther. 2005 Dec;315(3):1119-24.

33. Pruessner JC, Champagne F, Meaney MJ, Dagher A. Dopamine release in response to a psychological stress in humans and its relationship to early life maternal care: a positron emission tomography study using [11C]raclopride. J Neurosci. 2004 Mar 17;24(11):2825-31.

34. Volkow ND, Wang GJ, Maynard L, Jayne M, Fowler JS, Zhu W, et al. Brain dopamine is associated with eating behaviors in humans. Int J Eat Disord. 2003;33(2):136-42.

35. Born JM, Lemmens SGT, Rutters F, Nieuwenhuizen AG, Formisano E, Goebel R, et al. Acute stress and food-related reward activation in the brain during food choice during eating in the absence of hunger. Int J Obes. 2009 Oct 20.

36. Lemmens SG, Schoffelen PF, Wouters L, Born JM, Martens MJ, Rutters F, et al. Eating what you like induces a stronger decrease of 'wanting' to eat. Physiol Behav. 2009 Sep 7;98(3):318-25.

37. Davis C, Strachan S, Berkson M. Sensitivity to reward: implications for overeating and overweight. Appetite. 2004 Apr;42(2):131-8.

38. Saelens BE, Epstein LH. Reinforcing value of food in obese and non-obese women. Appetite. 1996 Aug;27(1):41-50.

39. Bjorntorp P, Rosmond R. Obesity and cortisol. Nutrition. 2000 Oct;16(10):924-36.

40. Bjorntorp P. Do stress reactions cause abdominal obesity and comorbidities? Obes Rev. 2001 May;2(2):73-86.

41. Obesity: preventing and managing the global epidemic. Report of a WHO consultation. World Health Organ Tech Rep Ser. 2000;894(i-xii):1-253.

42. Peters ML, Godaert GL, Ballieux RE, van Vliet M, Willemsen JJ, Sweep FC, et al. Cardiovascular and endocrine responses to experimental stress: effects of mental effort and controllability. Psychoneuroendocrinology. 1998 Jan;23(1):1-17.

43. Albrecht RR, Ewing SJ. Standardizing the administration of the Profile of Mood States (POMS): development of alternative word lists. J Pers Assess. 1989 Spring;53(1):31-9.

44. Tenenbaum G, Furst D, Weingarten G. A statistical reevaluation of the STAl anxiety questionnaire. J Clin Psychol. 1985 Mar;41(2):239-44.

45. McArdle WD, Katch FI, Katch VL. Exercise Physiology. 4th ed. Baltimore: Williams and Watkins; 1996.

46. Harris JA, Benedict FG. A Biometric Study of Human Basal Metabolism. Proc Natl Acad Sci U S A. $1918 \mathrm{Dec} ; 4(12): 370-3$.

47. Kuo LE, Czarnecka M, Kitlinska JB, Tilan JU, Kvetnansky R, Zukowska Z. Chronic stress, combined with a high-fat/high-sugar diet, shifts sympathetic signaling toward neuropeptide $Y$ and leads to obesity and the metabolic syndrome. Ann N Y Acad Sci. 2008 Dec;1148:232-7. 
48. Epstein LH, Leddy JJ, Temple JL, Faith MS. Food reinforcement and eating: a multilevel analysis. Psychol Bull. 2007 Sep;133(5):884-906.

49. Cox DN, Perry L, Moore PB, Vallis L, Mela DJ. Sensory and hedonic associations with macronutrient and energy intakes of lean and obese consumers. Int J Obes Relat Metab Disord. 1999 Apr;23(4):403-10.

50. Ouwehand C, de Ridder DT. Effects of temptation and weight on hedonics and motivation to eat in women. Obesity (Silver Spring). 2008 Aug;16(8):1788-93. 


\section{Chapter 7}

\section{Influence of consumption of a high- protein vs. high-carbohydrate meal on the physiological cortisol and psychological mood response in men and women}

Lemmens SG, Born JM, Martens EA, Martens MJ, Westerterp-Plantenga MS PLoS One 2011. In press. 


\section{Abstract}

Consumption of meals with different macronutrient contents, especially high in carbohydrates, may influence the stress-induced physiological and psychological response.

The objective of this study was to investigate effects of consumption of a highprotein vs. high-carbohydrate meal on the physiological cortisol response and psychological mood response.

Subjects $\left(n=38,19 \mathrm{~m} / 19 \mathrm{f}\right.$, age $=25 \pm 9 \mathrm{yrs}, B M \mathrm{~B}=25.0 \pm 3.3 \mathrm{~kg} / \mathrm{m}^{2}$ ) came to the university four times, fasted, for either condition: rest-protein, stress-protein, restcarbohydrate, stress-carbohydrate (randomized cross-over design). Stress was induced by means of a psychological computer test. The test meal was either a high-protein meal (En\% P/C/F 65/5/30) or a high-carbohydrate meal (En\% P/C/F $6 / 64 / 30)$, both meals were matched for energy density $(4 \mathrm{~kJ} / \mathrm{g})$ and daily energy requirements (30\%). Per test session salivary cortisol levels, appetite profile, mood state and level of anxiety were measured.

High hunger, low satiety $(81 \pm 16,12 \pm 15 \mathrm{mmVAS})$ confirmed the fasted state. The stress condition was confirmed by increased feelings of depression, tension, anger, anxiety (AUC stress vs. rest $\mathrm{p}<0.02$ ). Consumption of the high-protein vs. high-carbohydrate meal did not affect feelings of depression, tension, anger, anxiety. Cortisol levels did not differ between the four test sessions in men and women (AUC $\mathrm{nmol} \cdot \mathrm{min} / \mathrm{L} \mathrm{p}>0.1$ ). Consumption of the test meals increased cortisol levels in men in all conditions $(p<0.01)$, and in women in the rest-protein and stress-protein condition $(p<0.03)$. Men showed higher cortisol levels than women (AUC nmol.min/L $\mathrm{p}<0.0001$ ).

Consumption of meals with different macronutrient contents, i.e. high-protein vs. high-carbohydrate, does not influence the physiological and psychological response differentially. Men show a higher meal-induced salivary cortisol response compared with women. 


\section{Introduction}

Recent human studies have shown a possible relationship between stress and the increased prevalence of obesity (1-4). The stress response involves the hypothalamus pituitary adrenal (HPA) axis, which regulates the secretion of its end-product cortisol (3). Chronic stress is associated with hyperactivity of the HPA axis and consequently increased cortisol levels, which have been associated with visceral fat accumulation and obesity $(1,5,6)$. During stress, food choice is often shifted towards sweet and fat foods, possibly because they are perceived as highly rewarding (7-9). However, consumption of some of these preferred or highly rewarding foods, namely carbohydrates, may not reduce stress but even increase stress, i.e. increased HPA axis activity, represented by cortisol concentrations. A study by Vicennati et al. (10) showed that, in contrast to a high-protein/fat meal, a high-carbohydrate meal significantly increased the plasma cortisol levels in visceral obese subjects. Lacroix et al. (11) showed that high-protein/high-fat foods reduce cortisol concentrations remarkably in rats. Moreover, a study by Martens et al. (12) investigating the effects of single macronutrients on serum cortisol concentrations in normal weight men showed that the cortisol response to consumption of carbohydrates was higher than the cortisol response to consumption of fats or proteins. Carbohydrates increased serum cortisol concentrations while fat as well as protein did not relative to water (12).

On the other hand, Gibson et al. (13) and Slag et al. (14) showed increased cortisol levels induced by a protein-rich meal. A study by Gonzalez-Bono et al. (15) showed neither a difference between the effects of macronutrients on salivary cortisol levels, nor a cortisol response to meal consumption. Lovallo et al. (16) showed no meal-induced salivary cortisol response in the case of a mental stressor followed by a meal but did show a meal-induced cortisol response in the case of a physical stressor followed by a meal.

These studies show that the effects of macronutrients on the response of the HPA axis are still controversial. Little is known about the response of a physiological challenge such as food intake following a psychological stress challenge. This study was, therefore, carried out to investigate possible effects of consumption of comparable meals with different macronutrient contents (high-protein vs. high-carbohydrate) on the physiological cortisol response under stress. Moreover, we wanted to investigate the possible effects of high-protein vs. highcarbohydrate meals on the psychological mood response. Increases in negative mood in response to stressors can lead to greater food intake $(9,17)$. Consumption of foods that improve the stress-induced mood state may prevent further intake of energy-dense foods. Studies by Markus et al. $(18,19)$ showed that carbohydrate-rich, protein-poor foods improve mood and stress coping following acute stress-inducing tasks, only in stress-vulnerable subjects, possibly due to increased levels of brain tryptophan and serotonin. Firk et al. (20) showed that 
intake of tryptophan-rich hydrolyzed protein increased positive mood and dampened the cortisol response to acute stress.

We hypothesized that high-protein foods, in contrast to comparable highcarbohydrate foods, would not increase salivary cortisol concentrations more under stress and consequently would improve mood.

\section{Methods}

\section{Ethics Statement}

All procedures were carried out with the adequate understanding and written consent of the subjects. The study was approved by the Medical Ethical Committee of the Maastricht University, and was in compliance with the Declaration of Helsinki. The study was registered in the Dutch Trial Register (NTR, TC=1904). The protocol described here in this study deviates from the trial protocol approved by the Medical Ethical Committee of the Maastricht University as it comprises only a part of the approved trial protocol.

\section{Subjects}

Thirty-eight Caucasian subjects (19m/19f; age $25 \pm 9$ yrs (mean $\pm S D$, range 18-51 yrs)) with a body mass index (BMI) of $25.0 \pm 3.3 \mathrm{~kg} / \mathrm{m}^{2}$ (mean $\pm \mathrm{SD}$, range 18.9$30.5 \mathrm{~kg} / \mathrm{m}^{2}$ ) participated in this study. Based upon the study by Vicennati et al. (10), power analysis showed that with an a of 0.0125 (taking into account the Bonferroni correction for multiple testing) and $\beta$ of 0.10 (power=1- $\beta=0.90$ ), at least 31 subjects were needed. Subjects were recruited by advertisements in local newspapers and on notice boards at the university. They underwent an initial screening including measurement of body weight, height, waist circumference and hip circumference, and completion of a questionnaire related to health, use of medication, smoking behavior, alcohol consumption, physical activity, and eating behavior. Eating behavior was analyzed using a validated Dutch translation of the Three Factor Eating Questionnaire (TFEQ) which measures three components: 'cognitive restraint of eating' (factor 1), 'disinhibition of restraint' (factor 2), and 'subjective feeling of hunger' (factor 3) (21).

\section{Study design}

The study was conducted in a randomized cross-over design. All subjects came to the university four times in a fasted state between 08:00 and 9:00 AM, once for a stress test session receiving a high-protein meal, once for a rest test session receiving a high-protein meal, once for a stress test session receiving a high-carbohydrate meal, and once for a rest test session receiving a high- 
carbohydrate meal. The order of the four conditions was randomized across the subjects to prevent any order effects.

Figure 1 gives a schematic overview of the study design. After arrival at the university, subjects were seated in the laboratory and remained seated throughout the experiment. All subjects received $50 \mathrm{~g}$ of yoghurt ('Campina magere yoghurt naturel', 84 kJ, Energy\% Protein/Carbohydrate/Fat (En\% P/C/F) $53 / 44 / 2$ ) to prevent extreme hunger feelings. The test sessions started two hours later, to overcome the high cortisol morning peak and consequently to prevent the more difficult detection in salivary cortisol changes. Moreover, the two-hour waiting period gave the subjects the chance to adapt to the laboratory environment. During those two hours subjects remained seated and read a book or magazine.

An ego threatening computer test containing elements of an IQ-test was used to create the stress vs. rest conditions in subjects $(9,22,23)$. Two versions of the computer test were used: a difficult stress version with not enough time to solve the assignments and an easier control version with enough time to solve the assignments. This computer test was an updated version of the test used by Rutters et al. (9) and Born et al. (24) and had a duration of $20 \mathrm{~min}$. Subjects were given the computer test before consumption of the test meal. This test meal (lunch) was either a high-protein meal or a high-carbohydrate meal, which had to be consumed entirely within $30 \mathrm{~min}$. After the meal subjects rinsed their mouth thoroughly with cold water, prior to salivary sample collection.

The stress response was determined by means of salivary cortisol concentrations, Profile Of Mood State (POMS) and State Trait Anxiety Inventory (STAI) questionnaires. One hundred unit visual analogue scales (VAS; in mm) were used to assess the appetite profile. Salivary samples and questionnaires were collected six times per test session.

All women were tested in the follicular phase, as it has been shown that women have a higher spontaneous energy intake in the luteal phase compared with the follicular phase $(10,25)$.

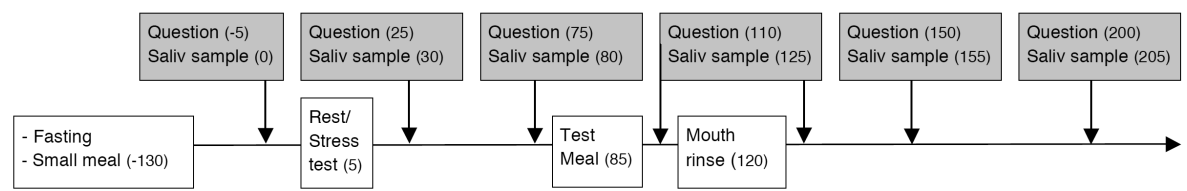

Figure 1. Schematic overview of the study design. Numbers in brackets represent the time points (in min) at which data was collected or tasks were completed. 'Question', questionnaires; 'Saliv sample', salivary sample

\section{Test meals}

The test meal was either a high-protein lunch (En\% P/C/F 65/5/30) or a highcarbohydrate lunch (En\% P/C/F 6/64/30). Both meals were comparable and matched for energy density: $4 \mathrm{~kJ} / \mathrm{g}$. The amount of the meals that was given to 
the subjects corresponded to $30 \%$ of their daily energy requirements (DER). For each subject the DER were calculated by multiplying the basal metabolic rate (BMR) by the appropriate physical activity factor (1.5-1.8, derived from the screening questionnaire, (26)). The BMR (kcal/day) was calculated according to the equation of Harris-Benedict (27).

The high-protein meal consisted of a salad (iceberg lettuce, cucumber, mushroom, and sunflower oil), Gouda cheese, salami, and a strawberry protein shake. The high-carbohydrate meal consisted of a salad (iceberg lettuce, cucumber, green pepper, and sunflower oil), savory cheese biscuits and TUC bacon biscuits, and a strawberry carbohydrate shake. In both meals the shakes represented $47 \mathrm{En} \%$ of the total meal. Beforehand, during screening, subjects had to taste and rate the food items for subjective liking (VAS), in order to check whether all food items were acceptable.

\section{Questionnaires}

One hundred unit VAS $(\mathrm{mm})$ were used to assess the appetite profile. The scales were anchored with 'not at all' at one end and 'extremely' at the other end, and combined with questions on feelings of hunger, thirst, fullness, satiety, and desire to eat, and on subjective liking and wanting of the test meals.

Mood states were assessed using a modified version of the Dutch translation of the POMS (28). This questionnaire contains 35 adjectives that are rated on a five-point scale and is divided into five subscales (depression, tension, confusion, fatigue, and anger). The Dutch translation of the state scale of the STAI questionnaire was used to measure state anxiety (29). Subjects had to rate 20 statements on how they felt at that moment on a four-point scale. An increase in POMS and STAI scores is associated with a worsening in mood.

The VAS, POMS and STAI questionnaires were completed six times throughout the test sessions at $-5,25,75,110,150$, and 200 min (Figure 1).

Beforehand, during screening, subjects were familiarized with the questionnaires.

\section{Saliva samples}

To determine salivary cortisol levels, six saliva samples were collected at 0,30 , $80,125,155$, and 205 min (Figure 1) with the help of cotton swabs (Salivettes, Sarstedt, Etten-Leur, The Netherlands). Subjects were instructed to gently chew on the swab for one min. Cotton swabs were then transferred to the plastic containers and stored at $-20^{\circ} \mathrm{C}$ until analysis. During screening subjects had the chance to chew on a swab in order to get used to the procedure.

Salivary cortisol concentrations were measured by the laboratory of Prof. Dr. C. Kirschbaum, Dresden University of Technology, Germany. After thawing, saliva samples were centrifuged at $3000 \mathrm{rpm}$ for $10 \mathrm{~min}$. Luminescence Immunoassay 
(IBL, Hamburg, Germany) with intra- and inter-assay precision of $2.5 \%$ and 4.7 $\%$, respectively, was used to measure salivary cortisol concentrations.

\section{Statistics}

Data were analyzed using StatView 5.0 (SAS Institute Inc., Cary, NC, USA). ANOVA with repeated measures was used to study the conditional effects of stress vs. rest and of high-protein vs. high-carbohydrate, and the effects of time, on cortisol level measurements and questionnaire data (POMS, STAI, VAS). Factorial ANOVA was used to analyze differences between men and women. Paired and unpaired Student's t-tests were used as Post hoc analyses for significant interactions. Simple linear regression models were used for correlation analysis between parameters. Areas under the curve (AUC) for cortisol and questionnaire data were calculated using the trapezoid method. All tests were two-sided and differences were considered significant at $p<0.05$. Values are expressed as mean \pm standard error of the mean (SEM), unless stated otherwise.

\section{Results}

\section{Subject characteristics}

The characteristics of the subjects are summarized in Table 1. No significant differences were shown between men and women in age, BMI, hip circumference, and disinhibition score. Women showed a significantly higher dietary restraint score and feeling of hunger score when compared with men $(p<0.05)$. Men showed significantly higher height, body weight, waist circumference, and salivary cortisol concentrations (AUC) when compared with women $(p<0.05)$. Therefore, the results of men and women were analyzed separately. 
Table 1. Characteristics of men and women.

\begin{tabular}{lccc}
\hline & Men $(\mathrm{n}=19)$ & Women $(\mathrm{n}=19)$ & $\mathrm{p}^{\mathrm{a}}$ \\
\hline Age $(\mathrm{y})$ & $25.6 \pm 8.6$ & $24.9 \pm 9.3$ & n.s. \\
Height $(\mathrm{cm})$ & $180.2 \pm 7.7$ & $168.6 \pm 6.4$ & $<.0001$ \\
Body weight $(\mathrm{kg})$ & $80.1 \pm 8.8$ & $71.6 \pm 9.4$ & $<.01$ \\
BMI $\left(\mathrm{kg} / \mathrm{m}^{2}\right)$ & $24.8 \pm 3.4$ & $25.2 \pm 3.2$ & n.s. \\
Waist circumference $(\mathrm{cm})$ & $86.4 \pm 9.7$ & $79.9 \pm 9.9$ & $<.05$ \\
Hip circumference $(\mathrm{cm})$ & $103.7 \pm 5.5$ & $105.5 \pm 5.1$ & n.s. \\
Dietary restraint score & $4.7 \pm 3.7$ & $7.5 \pm 4.0$ & $<.05$ \\
Disinhibition score & $3.9 \pm 1.4$ & $5.1 \pm 2.9$ & n.s. \\
Feeling of hunger score & $3.1 \pm 2.3$ & $5.6 \pm 3.4$ & $<.01$ \\
\hline
\end{tabular}

Values are means $\pm S D ;{ }^{a} p$-value: differences between men and women (factorial ANOVA); n.s.=nonsignificant

\section{Stress parameters}

Salivary cortisol levels were analyzed for men and women separately. Salivary cortisol levels did not differ between the conditions of stress vs. rest and highprotein vs. high-carbohydrate in men and women (AUC and per time point, Figure 2). There was an overall effect of time on salivary cortisol levels in men and women $(p<0.0001)$. Consumption of the test meals (time point 80-125 min, Figure 2) induced increased salivary cortisol levels in men in all conditions $(p<0.01)$ and in women in the rest-protein and stress-protein condition $(p<0.03)$. This meal-induced increase in cortisol levels was higher in men compared with women in all conditions $(p<0.05)$. Men showed overall higher salivary cortisol levels compared with women (AUC $p<0.0001$; Figure 2), in all conditions. Cortisol baseline values (time point 0 min, Figure 2) did not differ between men and women, in all conditions.

Men had a higher waist-to-hip ratio compared with women $(\mathrm{p}<0.01)$ and simple regression analysis showed a positive relationship between cortisol levels (AUC) and waist-to-hip ratio $\left(p<0.04, R^{2}=0.1\right)$.

POMS and STAI questionnaires showed higher feelings of depression, tension, anger, and anxiety during the stress vs. rest test sessions, (ANOVA repeated measures: AUC of POMS and STAI scores rest-stress $x$ carbohydrate-protein, main effect of stress, $p<0.02$ ), indicating that the applied stressor was effective in inducing psychological stress, regardless of the dietary condition. Consumption of the high-protein vs. high-carbohydrate meal did not affect feelings of depression, tension, anger, and anxiety differently (ANOVA repeated measures: change in POMS and STAI scores pre- to post-meal rest-stress $x$ carbohydrateprotein, $p>0.1$. There were no differences in POMS and STAI scores between men and women, in all conditions. 
Simple linear regression models showed that salivary cortisol concentrations were not related to POMS and STAI scores in men and women, in all conditions, when analyzing the AUC, and the change in cortisol concentrations and POMS and STAI scores pre- to post-meal.

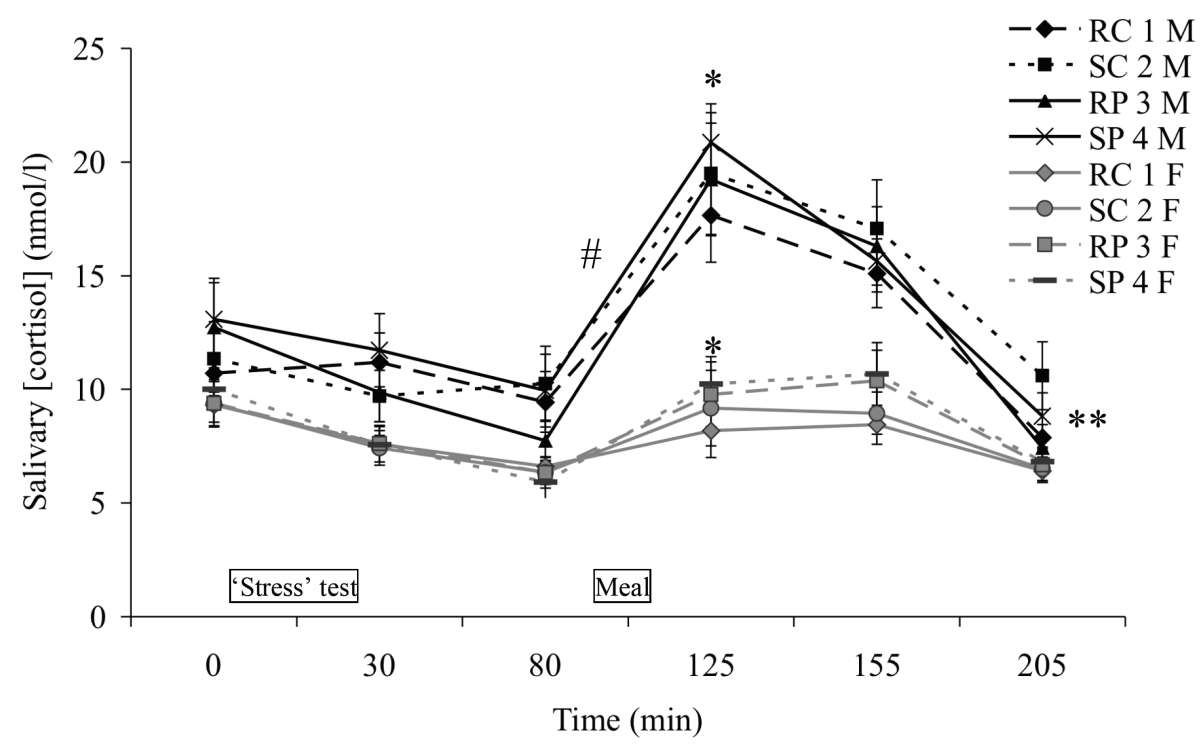

Figure 2. Salivary cortisol concentrations (mean \pm SEM) at six time points $(0,30,80,125,155$, and 205 $\mathrm{min}$ ) throughout the four test sessions: rest-carbohydrate $(\mathrm{RC})$, stress-carbohydrate (SC), rest-protein $(R P)$, stress-protein (SP); for men $(n=19, M)$ and women $(n=19, F)$. ${ }^{* *} p<0.0001$ for overall (AUC) higher cortisol levels in men vs. women; $\# p<0.05$ for higher meal-induced increase in cortisol levels in men vs. women (time point 80-125 min); ${ }^{*} p<0.03$ for increased cortisol levels in men in all conditions, in women in RP and SP (time point 80 vs. $125 \mathrm{~min}$ )

\section{Appetite profile}

The fasted state was confirmed by low satiety and fullness scores $(11.8 \pm 2.5$, $9.6 \pm 1.9 \mathrm{mmVAS})$, and high hunger, 'desire to eat', and thirst scores $(80.6 \pm 2.6$, $83.9 \pm 2.2,68.1 \pm 3.7 \mathrm{mmVAS})$. Consumption of the lunch resulted in an increase in satiety and fullness scores $(\Delta=63.2 \pm 4.6,69.9 \pm 3.7 \mathrm{mmVAS}, \mathrm{p}<0.001)$, and a decrease in hunger, 'desire to eat', and thirst scores $(\Delta=67.8 \pm 3.3,68.5 \pm 3.3$, $33.8 \pm 4.3 \mathrm{mmVAS}, p<0.001$ ). Conditions of stress vs. rest and of high-protein vs. high-carbohydrate did not affect feelings of hunger, thirst, desire to eat, satiety, and fullness (AUC and per time point).

Consumption of the test meals decreased their subjective liking and wanting $(p<0.001$; average liking scores pre- and post-meal: $53.5 \pm 3.7,43.4 \pm 4.0 \mathrm{mmVAS}$; average wanting score pre- and post-meal: $65.3 \pm 4.3,8.7 \pm 2.0 \mathrm{mmVAS}$ ). Conditions of stress vs. rest and of high-protein vs. high-carbohydrate did not influence liking of the test meals pre- and post-meal, confirming that the meals were comparable. The condition of stress vs. rest did not influence wanting of 
the test meals pre- and post-meal, though during stress the change in wanting pre- to post-meal was larger in the high-protein condition compared with the high-carbohydrate condition ( $p=0.03$ ).

The changes in VAS scores for the appetite profile parameters pre- to postconsumption of the test meals did not differ between men and women.

\section{Discussion}

The main objective of this study was to investigate the possible effects of consumption of meals with different macronutrient contents (high-protein vs. highcarbohydrate) on the physiological cortisol response and on the psychological mood response under stress. Based upon studies of Vicennati et al. (10), Lacroix et al. (11), and Martens et al. (12), we hypothesized that high-protein foods, in contrast to high-carbohydrate foods, would not increase salivary cortisol concentrations more under stress and consequently would improve mood.

In our study the acute psychological stress condition was confirmed by means of POMS and STAI questionnaires, but not endocrinologically by increased salivary cortisol levels. The type of stressor used in the laboratory context might have been too light to elicit a physiological cortisol response (30).

Our study showed a clear meal-induced salivary cortisol response, though no difference in response was detected between consumption of a high-protein lunch and a high-carbohydrate lunch. Some studies have shown that food intake, particularly at lunch, increases cortisol secretion (13, 31-33). In contrast, a study by Bray et al. (34) assessing the hormonal responses to a fast-food meal compared with nutritionally comparable meals of different composition, showed no significant salivary cortisol response to meal ingestion. Lovallo et al. (16) showed no meal-induced salivary cortisol response in the case of a mental stressor followed by a meal but did show a meal-induced cortisol response in the case of a physical stressor followed by a meal. This response was higher in women compared with men (16). The cortisol response to mental stress was smaller in women compared with men (16).

In contrast to our findings, some studies indicated that the macronutrient composition of a meal may influence the magnitude of the cortisol response. Studies by Vicennati et al. (10) and Martens et al. (12) showed higher cortisol levels following a high-carbohydrate meal compared with a high-protein/fat meal. Studies by Gibson et al. (13) and Slag et al. (14) showed increased cortisol levels induced by a protein-rich meal. On the other hand, the study by Bourrilhon et al. (35), investigating the influence of protein- vs. carbohydrate-enriched feedings on physiological responses during an ultra endurance climbing race, showed no effect of diet on serum cortisol levels. It is not clear yet whether the macronutrient composition of a meal can indeed influence cortisol levels. The use of mixed meals instead of single macronutrients, as used in the study by 
Martens et al. (12), might limit the detection of possible effects of macronutrients on cortisol levels.

Men compared with women participating in our study, showed higher mealinduced salivary cortisol levels and higher overall salivary cortisol levels. According to the review by Kudielka et al. (36), it seems that adult men show higher cortisol responses to psychological stress tasks compared with women, though there are still inconsistencies in literature. Kirschbaum et al. (37) showed sex differences for free salivary cortisol but not for total cortisol stress responses: women taking oral contraceptives and women in the follicular phase had significantly lower free cortisol stress responses than men. In our study there were no differences in salivary cortisol levels between women taking oral contraceptives $(n=11)$ and women taking no oral contraceptives $(n=8)$, which is in accordance with studies of e.g. Kirschbaum et al. (37) and Liening et al. (38). Based on the study of Kirschbaum et al. (37) we hypothesize that the lower salivary cortisol levels in women compared with men might be explained by the fact that women in our study participated during the follicular phase, though the effect seen in the study of Kirschbaum et al. (37) was induced by the psychological stressor, which was not the case in our study. Literature on gender differences concerning meal-induced cortisol increases is scarce.

Men in our study had a larger waist circumference and waist-to-hip ratio compared with women. The meta-regression analysis by de Koning et al. (39) indicated that waist circumference and waist-to-hip ratio are associated with the risk of cardiovascular diseases. It can be hypothesized that the greater cortisol response observed in men may be associated with visceral fat accumulation and an elevated risk for cardiovascular diseases and diabetes and may help explain the higher prevalence for these diseases in men $(1,4,36,40)$.

In contrast to significant gender differences concerning physiological cortisol levels, the psychological mood state did not differ between men and women in our study and physiological cortisol levels were not related to the psychological mood state scores. Moreover, the mood state was not affected by macronutrient composition of the diets. This might be explained by the fact that the high-protein meal and the high-carbohydrate meal were highly comparable, as shown by the VAS scores for the appetite profile parameters. Liking of the test meals and feelings of hunger, thirst, desire to eat, satiety and fullness did not differ between the high-protein and high-carbohydrate condition. It is known from literature that protein is the most satiating macronutrient, and that high-protein meals are more satiating than high-carbohydrate meals (41). However, our results showed no greater feelings of satiety in the high-protein vs. high-carbohydrate condition. A possible explanation might be that the morning consumption of $50 \mathrm{~g}$ of yoghurt was relatively high in protein, and due to this high protein content the lower protein intake and higher carbohydrate intake two hours later might not have resulted in a difference in feelings of satiety at that moment.

In summary, consumption of comparable meals with different macronutrient contents, i.e. high-protein vs. high-carbohydrate, does not influence the physio- 
logical cortisol response and the psychological mood response differentially. In our everyday life where stress is a pervasive factor, the development of functional foods, able to regulate the stress response, would be helpful to improve or maintain quality of life, as suggested in the review by Takeda et al. (42). Foods with the macronutrient contents used in our study seem ineffective in regulating the physiological and psychological stress response. Men in our study showed a higher waist-to-hip ratio and elevated salivary cortisol levels compared with women, which may be associated with an increased risk for cardiovascular diseases and diabetes.

To conclude, consuming a high-protein vs. a high-carbohydrate meal does not influence the physiological cortisol response and the psychological mood response differentially. Men show a higher meal-induced salivary cortisol response compared with women.

\section{Acknowledgements}

We thank our subjects for their participation in this study. The study was designed by MSWP and SGL. SGL together with EAM (supervised by MSWP) carried out the study and collected the data. JMB updated the psychological computer test to create the stress vs. rest condition in subjects. SGL analyzed the data and wrote the largest part of the manuscript. JMB and MJM reviewed the manuscript. 


\section{References}

1. Torres SJ, Nowson CA. Relationship between stress, eating behavior, and obesity. Nutrition. 2007 Nov-Dec;23(11-12):887-94.

2. Adam TC, Epel ES. Stress, eating and the reward system. Physiol Behav. 2007 Apr 14;91(4):449-58.

3. Nieuwenhuizen AG, Rutters F. The hypothalamic-pituitary-adrenal-axis in the regulation of energy balance. Physiol Behav. 2007 Dec 23;94(2):169-77.

4. Kyrou I, Chrousos GP, Tsigos C. Stress, visceral obesity, and metabolic complications. Ann N Y Acad Sci. 2006 Nov;1083:77-110.

5. Bjorntorp P, Rosmond R. Obesity and cortisol. Nutrition. 2000 Oct;16(10):924-36.

6. Bjorntorp P. Do stress reactions cause abdominal obesity and comorbidities? Obes Rev. 2001 May;2(2):73-86.

7. Oliver G, Wardle J, Gibson EL. Stress and food choice: a laboratory study. Psychosom Med. 2000 Nov-Dec;62(6):853-65.

8. Zellner DA, Loaiza S, Gonzalez Z, Pita J, Morales J, Pecora D, et al. Food selection changes under stress. Physiol Behav. 2006 Apr 15;87(4):789-93.

9. Rutters F, Nieuwenhuizen AG, Lemmens SG, Born JM, Westerterp-Plantenga MS. Acute stressrelated changes in eating in the absence of hunger. Obesity (Silver Spring). 2009 Jan;17(1):72-7.

10. Vicennati V, Ceroni L, Gagliardi L, Gambineri A, Pasquali R. Comment: response of the hypothalamic-pituitary-adrenocortical axis to high-protein/fat and high-carbohydrate meals in women with different obesity phenotypes. J Clin Endocrinol Metab. 2002 Aug;87(8):3984-8.

11. Lacroix M, Gaudichon C, Martin A, Morens C, Mathe V, Tome D, et al. A long-term high-protein diet markedly reduces adipose tissue without major side effects in Wistar male rats. Am J Physiol Regul Integr Comp Physiol. 2004 Oct;287(4):R934-42.

12. Martens MJ, Rutters F, Lemmens SG, Born JM, Westerterp-Plantenga MS. Effects of single macronutrients on serum cortisol concentrations in normal weight men. Physiol Behav. 2010;Epub ahead of print.

13. Gibson EL, Checkley S, Papadopoulos A, Poon L, Daley S, Wardle J. Increased Salivary Cortisol Reliably Induced by a Protein-Rich Midday Meal. Psychosom Med. 1999 March 1, 1999;61(2):214-24.

14. Slag MF, Ahmad M, Gannon MC, Nuttall FQ. Meal stimulation of cortisol secretion: a protein induced effect. Metabolism. 1981;30(11):1104-8.

15. Gonzalez-Bono E, Rohleder N, Hellhammer DH, Salvador A, Kirschbaum C. Glucose but Not Protein or Fat Load Amplifies the Cortisol Response to Psychosocial Stress. Horm and Behav. 2002;41(3):328-33.

16. Lovallo WR, Farag NH, Vincent AS, Thomas TL, Wilson MF. Cortisol responses to mental stress, exercise, and meals following caffeine intake in men and women. Pharmacol Biochem Behav. 2006;83(3):441-7.

17. Epel E, Lapidus R, McEwen B, Brownell K. Stress may add bite to appetite in women: a laboratory study of stress-induced cortisol and eating behavior. Psychoneuroendocrinology. 2001 Jan;26(1):37-49.

18. Markus CR, Panhuysen G, Tuiten A, Koppeschaar H, Fekkes D, Peters ML. Does Carbohydraterich, Protein-poor Food Prevent a Deterioration of Mood and Cognitive Performance of Stressprone Subjects when Subjected to a Stressful Task? Appetite. 1998;31(1):49-65.

19. Markus R, Panhuysen G, Tuiten A, Koppeschaar H. Effects of food on cortisol and mood in vulnerable subjects under controllable and uncontrollable stress. Physiol Behav. 2000;70(34):333-42.

20. Firk C, Markus CR. Mood and cortisol responses following tryptophan-rich hydrolyzed protein and acute stress in healthy subjects with high and low cognitive reactivity to depression. Clin Nutr. 2009;28(3):266-71. 
21. Stunkard AJ, Messick S. The three-factor eating questionnaire to measure dietary restraint, disinhibition and hunger. J Psychosom Res. 1985;29(1):71-83.

22. Peters ML, Godaert GL, Ballieux RE, van Vliet M, Willemsen JJ, Sweep FC, et al. Cardiovascular and endocrine responses to experimental stress: effects of mental effort and controllability. Psychoneuroendocrinology. 1998 Jan;23(1):1-17.

23. Hemmink GJM, Bredenoord AJ, Weusten BLAM, Timmer R, Smout AJPM. Does acute psychological stress increase perception of oesophageal acid? Neurogastroenterol Motil. 2009;21(10):1055-86.

24. Born JM, Lemmens SGT, Rutters F, Nieuwenhuizen AG, Formisano E, Goebel R, et al. Acute stress and food-related reward activation in the brain during food choice during eating in the absence of hunger. Int J Obes. 2009 Oct 20.

25. Sorensen LB, Moller P, Flint A, Martens M, Raben A. Effect of sensory perception of foods on appetite and food intake: a review of studies on humans. Int J Obes Relat Metab Disord. 2003 Oct;27(10):1152-66.

26. McArdle WD, Katch FI, Katch VL. Exercise Physiology. 4th ed. Baltimore: Williams and Watkins; 1996.

27. Harris JA, Benedict FG. A Biometric Study of Human Basal Metabolism. Proc Natl Acad Sci U S A. 1918 Dec;4(12):370-3.

28. Albrecht RR, Ewing SJ. Standardizing the administration of the Profile of Mood States (POMS): development of alternative word lists. J Pers Assess. 1989 Spring;53(1):31-9.

29. Tenenbaum G, Furst D, Weingarten G. A statistical reevaluation of the STAI anxiety questionnaire. J Clin Psychol. 1985 Mar;41(2):239-44.

30. Michaud K, Matheson $\mathrm{K}$, Kelly $\mathrm{O}$, Anisman $\mathrm{H}$. Impact of stressors in a natural context on release of cortisol in healthy adult humans: A meta-analysis. Stress. 2008;11(3):177-97.

31. Peeters F, Nicholson NA, Berkhof J. Cortisol Responses to Daily Events in Major Depressive Disorder. Psychosom Med. 2003 September 1, 2003;65(5):836-41.

32. Van Cauter E, Shapiro ET, Tillil H, Polonsky KS. Circadian modulation of glucose and insulin responses to meals: relationship to cortisol rhythm. Am J Physiol Endocrinol Metab. 1992 April 1, 1992;262(4):467-75.

33. Svec F, Shawar A-L. The acute effect of a noontime meal on the serum levels of cortisol and DHEA in lean and obese women. Psychoneuroendocrinology. 1997;22(Supplement 1):S115-S9.

34. Bray GA, Most M, Rood J, Redmann S, Smith SR. Hormonal Responses to a Fast-Food Meal Compared with Nutritionally Comparable Meals of Different Composition. Ann Nutr Metab. 2007;51(2):163-71.

35. Bourrilhon C, Lepers R, Philippe M, Beers PV, Chennaoui M, Drogou C, et al. Influence of protein- versus carbohydrate-enriched feedings on physiological responses during an ultraendurance climbing race. Horm Metab Res. 2010;42(1):31-7.

36. Kudielka BM, Kirschbaum C. Sex differences in HPA axis responses to stress: a review. Biol Psychol. 2005;69(1):113-32.

37. Kirschbaum C, Kudielka BM, Gaab J, Schommer NC, Hellhammer DH. Impact of Gender, Menstrual Cycle Phase, and Oral Contraceptives on the Activity of the Hypothalamus-PituitaryAdrenal Axis. Psychosom Med. 1999 March 1, 1999;61(2):154-62.

38. Liening SH, Stanton SJ, Saini EK, Schultheiss OC. Salivary testosterone, cortisol, and progesterone: Two-week stability, interhormone correlations, and effects of time of day, menstrual cycle, and oral contraceptive use on steroid hormone levels. Physiol Behav. 2010;99(1):8-16.

39. de Koning L, Merchant AT, Pogue J, Anand SS. Waist circumference and waist-to-hip ratio as predictors of cardiovascular events: meta-regression analysis of prospective studies. Eur Heart J. 2007;28(7):850-6.

40. Rutters F, Nieuwenhuizen AG, Lemmens SG, Born JM, Westerterp-Plantenga MS. Hypothalamic-Pituitary-Adrenal (HPA) axis functioning in relation to body fat distribution. Clin Endocrinol (Oxf). 2010;72(6):738-43. 
41. Westerterp-Plantenga MS, Nieuwenhuizen A, Tomé D, Soenen S, Westerterp KR. Dietary protein, weight loss, and weight maintenance. Annu Rev Nutr. 2009;29:21-41.

42. Takeda E, Terao J, Nakaya Y, Miyamoto K, Baba Y, Chuman H, et al. Stress control and human nutrition. J Med Invest. 2004;51(3-4):139-45. 



\section{Chapter 8}

\section{Eating in the absence of hunger: interaction between stress, macronutrient intake and disinhibition}

Lemmens SG, Martens EA, Born JM, Martens MJ, Westerterp-Plantenga MS

Submitted for publication 


\begin{abstract}
We aimed to investigate whether consumption of high-protein vs. highcarbohydrate meals influences stress-related mood, food 'liking' and 'wanting', and energy intake (EI).

Subjects $\left(n=38,19 \mathrm{~m} / 19 \mathrm{f}\right.$, age $\left.=25 \pm 9 \mathrm{y}, \mathrm{BMI}=25.0 \pm 3.3 \mathrm{~kg} / \mathrm{m}^{2}\right)$ came to the university four times, fasted, for either condition: rest-protein, stress-protein, restcarbohydrate, stress-carbohydrate (randomized cross-over design). Stress was induced using an ego-threatening test. Per test session 'liking' and 'wanting' (for bread, filling, drinks, dessert, snacks, stationery (placebo)) was measured twice, each time followed by a meal. The first meal was a high-protein or highcarbohydrate meal (En\% P/C/F 65/5/30 vs. 6/64/30), matched for energy density $(4 \mathrm{~kJ} / \mathrm{g})$ and daily energy requirements $(30 \%)$. The second meal was chosen by the subjects. Appetite profile (visual analogue scales), mood state (POMS, STAI questionnaires), and El from the second meal were measured.

Subjects showed increased feelings of depression and anxiety during stress $(\mathrm{P}<0.01)$. Consumption of the first meal decreased hunger, increased satiety, decreased 'liking' of bread and filling, and increased 'liking' of placebo and drinks $(\mathrm{P}<0.0001)$. Food 'wanting' decreased pre- to post-meal $(\mathrm{P}<0.0001)$. The highprotein vs. high-carbohydrate meal induced lower subsequent 'wanting' and El $(1.7 \pm 0.3 \mathrm{MJ}$ vs. $2.5 \pm 0.4 \mathrm{MJ})$ only in individuals characterized by disinhibited eating behavior (factor 2 Three Factor Eating Questionnaire), during rest $(\mathrm{P} \leq 0.01)$. This reduction in 'wanting' and El following the high-protein meal disappeared during stress.
\end{abstract}

To conclude, a high-protein vs. high-carbohydrate meal induced lower subsequent 'wanting' and El in subjects with high disinhibition; this difference disappeared under stress. Acute stress overruled effects of consumption of highprotein foods. 


\section{Introduction}

Recent human studies have shown a possible relationship between stress and the increased prevalence of obesity (1-4). Rutters et al. (5) showed that acute psychological stress leads to eating in the absence of hunger, especially in vulnerable individuals characterized by disinhibited eating behavior; then food choice is directed towards rewarding sweet and fat foods (5-7), to cope with stress (8). However, some of these rewarding foods high in carbohydrates may increase stress, i.e. hypothalamus pituitary adrenal (HPA) axis activity, represented by cortisol concentrations (9-11). Moreover, chronic stress combined with a high-fat, high-carbohydrate diet may lead to abdominal obesity (8).

According to the incentive salience theory, the process of reward, possibly playing a role in eating in the absence of hunger, consists of 'liking' and 'wanting' $(12,13)$. 'Liking', under control of opioids, is the hedonic or affective component and refers to the pleasure derived from oro-sensory stimulation of food $(14,15)$. 'Wanting', under control of dopamine, is the motivational incentive component and refers to the motivation to obtain food (12, 14-17).

Several studies indicated that high-protein meals may help to cope with stress, for instance Lacroix et al. (9), Vicenatti et al. (10), and Martens et al. (11). Firk and Markus (18) showed that intake of tryptophan-rich hydrolyzed protein increased positive mood under acute stress. Therefore, we hypothesized that a high-protein meal may reduce food 'wanting' and eating in the absence of hunger during stress, while consumption of a high-carbohydrate meal may increase food 'wanting' and eating in the absence of hunger during stress.

A computer test, which was developed and validated in a previous study, was used to measure 'liking' and 'wanting': 'liking' was defined as the relative preference of two food items, and 'wanting' as the motivation to obtain food items by working to earn items to choose from (19).

\section{Materials and Methods}

\section{Subjects}

Thirty-eight healthy Caucasian subjects (19 men and 19 women; age 25 \pm 9 y; BMI $25.0 \pm 3.3 \mathrm{~kg} / \mathrm{m}^{2}$ ) participated in this study. They were recruited by advertisements in local newspapers and on notice boards at the university. Subjects underwent an initial screening including measurement of body weight, height, waist and hip circumference, and completed a questionnaire related to health, use of medication, physical activity and eating behavior. Regarding overweight subjects only visceral overweight subjects (waist circumference $\geq 80$ $\mathrm{cm}$ in women and $\geq 94 \mathrm{~cm}$ in men (20)) were included, as chronic stress has been associated with visceral fat accumulation and obesity $(1,21,22)$. Regarding the 'wanting' computer test, subjects were screened on their ability to 
play a five by five memory game within two min. Subjects also had to taste and rate the food items, which would have to be consumed on the test-days, beforehand using visual analogue scales (VAS), in order to control for acceptability.

Eating behavior was analyzed using a validated Dutch translation of the Three Factor Eating Questionnaire (TFEQ) which measures three components: 'cognitive restraint of eating' (factor 1, F1), 'disinhibition of restraint' (factor 2, F2) and 'hunger' (factor 3, F3) (23). The cut-off points in our population are F1=9, $F 2=5$, and $F 3=5$ (24). All subjects gave written informed consent and the study was approved by the Medical Ethical Committee of the Maastricht University.

\section{Study design}

The study was conducted in a randomized cross-over design (Figure 1). Subjects came to the university four times in a fasted state between 08:00 and 9:00 AM: two times for a stress session receiving a high-protein or highcarbohydrate meal, and two times for a rest session receiving a high-protein or high-carbohydrate meal.

After arrival at the university, subjects were seated in the laboratory and remained seated throughout the experiment. First subjects received $50 \mathrm{~g}$ yoghurt ('Campina magere yoghurt naturel', 84 kJ, Energy\% Protein/Carbohydrate/Fat (En\% P/C/F) 53/44/2) to prevent large hunger feelings. Then, two computer tests containing elements of an IQ-test were used to create the stress vs. rest conditions in subjects $(5,25,26)$ : a difficult stress version with limited time and an easier control version with ample time to solve the assignments. The test was an updated version of the test used by Rutters et al. (5) and Born et al. (27). Third, the computer test developed to measure 'liking' and 'wanting' (19) was completed and followed by consumption of the test meal (lunch). After the test meal, subjects executed the IQ-test and the 'liking' and 'wanting' computer test again, followed by a second meal. The test meal was either a high-protein meal or a high-carbohydrate meal, which had to be consumed entirely. The second meal ('wanted meal' (Figure 1)) was composed by the subjects themselves by means of the 'wanting' part of the computer test.

To investigate whether the stress condition inflicted psychological changes, we used Profile Of Mood State (POMS) and State Trait Anxiety Inventory (STAI) questionnaires. One hundred unit visual analogue scales (VAS; in mm) were used to assess the appetite profile. Questionnaires were collected seven times per test session.

All women were tested in the follicular phase, as it has been shown that women have a higher spontaneous energy intake in the luteal phase compared with the follicular phase $(10,28)$. 


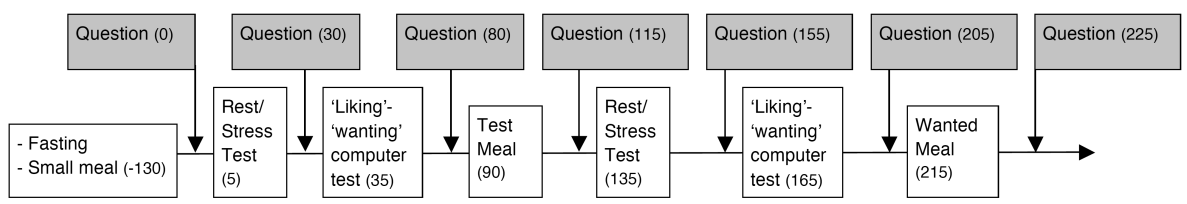

Figure 1. Schematic overview of the study design. Numbers in brackets represent the time points (in $\min$ ) at which data was collected or tasks were completed. 'Question': questionnaires

\section{Test meals}

The high-protein meal (En\% P/C/F 65/5/30) consisted of a salad (iceberg lettuce, cucumber, mushroom and sunflower oil), Gouda cheese, salami, and a strawberry protein shake. The high-carbohydrate meal (En\% P/C/F 6/64/30) consisted of a salad (iceberg lettuce, cucumber, green pepper and sunflower oil), savory cheese biscuits and TUC bacon biscuits, and a strawberry carbohydrate shake. Both meals were isocaloric and matched for energy density $(4 \mathrm{~kJ} / \mathrm{g})$. Amounts corresponded to $30 \%$ of subjects' individual daily energy requirements (DER). This was calculated by multiplying the basal metabolic rate (BMR; (29)) by the appropriate physical activity factor (1.5-1.8, derived from the screening questionnaire (30)). The shakes represented $47 \mathrm{En} \%$ of the total meal.

\section{Questionnaires}

One hundred unit VAS (mm), anchored with 'not at all' and 'extremely', were used to assess the appetite profile, implying questions on feelings of hunger, thirst, fullness, satiety and desire to eat, and on subjective liking and wanting of the test meals.

Mood states were assessed using a modified version of the Dutch translation of the POMS (31), which contains 35 adjectives that are rated on a five-point scale and is divided into five subscales (depression, tension, confusion, fatigue, and anger). The Dutch translation of the state scale of the STAI questionnaire was used to measure state anxiety on a four-point scale (32). An increase in POMS and STAI scores is associated with a worsening in mood.

The questionnaires were completed seven times throughout the test sessions at 0, 30, 80, 115, 155, 205 and 225 min (Figure 1). The VAS on subjective liking and wanting of the test meals were completed pre- and post-meal (at 80 and 115 $\min )$.

\section{'Liking' and 'wanting' computer test}

The computer test (19) measured the rewarding value, i.e. 'liking' and 'wanting', for 72 items divided in six categories: bread, filling, drinks, dessert, snacks, and stationery (non-food alternative as control). Each category contained 12 items. 
The 72 items were presented as photographic stimuli on a computer screen (13inch Mac Book, Apple, Cupertino, USA).

In short, the computer test contains a 'liking' part and a 'wanting' part for the same food and stationery items. For 'liking', subjects indicate their relative preference of paired items within and between the six categories, resulting in a relative ranking of 'liking' of the items per category (score range 0-605), and of the categories (score range 0-125).

For 'wanting', subjects work to earn items by playing memory games. For each category participants play a five by five memory game. The more pairs of items are found, the more randomly selected items are offered to choose from. Subjects choose zero, one or two items per category. All these chosen items are offered to them afterwards to be eaten completely. These items obtain a score equal to the success score of the memory game, representing the motivation or workload for the chosen items (score range 2-12). Per category the sum of the scores represents the 'wanting' score for each category. Scores range from zero to 24 per category. The energy content and macronutrient composition of the thus obtained 'wanted' and consumed meal is calculated.

\section{Statistics}

Data were analyzed using StatView 5.0 (SAS Institute Inc., Cary, NC, USA). Factorial ANOVA with repeated measures was used to study effects between subject groups, conditions of stress vs. rest, of high-protein vs. highcarbohydrate, over time. Thus, scores on the questionnaires (VAS, POMS, STAI) and on the 'liking' and 'wanting' computer test were tested. Paired and unpaired Student's t-tests were used as Post hoc analyses for significant interactions. Areas under the curve (AUC) for questionnaire data were calculated using the trapezoid method. All tests were two-sided and differences were considered significant at $P<0.05$. Values are expressed as mean \pm standard error of the mean (SEM), unless stated otherwise.

\section{Results}

\section{Subject characteristics}

No significant differences were shown between men and women concerning age, BMI, hip circumference and disinhibition scores (Table 1). Women had higher scores for dietary restraint and feeling of hunger when compared with men $(\mathrm{P}<0.05)$. Men had a larger height, body weight, and waist circumference when compared with women $(\mathrm{P}<0.05)$.

Since there were neither gender differences, nor differences according to weight status concerning possible conditional effects of stress vs. rest and of highprotein vs. high-carbohydrate on scores from the questionnaires (POMS, STAI, 
VAS) and the 'liking' and 'wanting' computer test, and on energy intake, data were analyzed for all subjects together.

After analyses for all subjects together, a second analysis for individuals divided by the disinhibition score $(n=16)$ was executed (5). These subjects also differed in hunger score (F2 score $6.4 \pm 2.2$ vs. $3.0 \pm 0.8$ and $F 3$ score $5.8 \pm 4.0$ vs. $3.3 \pm 1.9$ $($ mean $\pm S D), P<0.02)$. Their BMl did not differ $\left(25.7 \pm 3.7 \mathrm{~kg} / \mathrm{m}^{2}\right.$ vs. $24.5 \pm 2.9$ $\left.\mathrm{kg} / \mathrm{m}^{2}\right)$.

Table 1. Characteristics of men and women.

\begin{tabular}{lccc}
\hline & Men $(\mathrm{n}=19)$ & Women $(\mathrm{n}=19)$ & $\mathrm{P}^{\mathrm{a}}$ \\
\hline Age $(\mathrm{y})$ & $25.6 \pm 8.6$ & $24.9 \pm 9.3$ & n.s. \\
Height $(\mathrm{cm})$ & $180.2 \pm 7.7$ & $168.6 \pm 6.4$ & $<.0001$ \\
Body weight $(\mathrm{kg})$ & $80.1 \pm 8.8$ & $71.6 \pm 9.4$ & $<.01$ \\
BMI $\left(\mathrm{kg} / \mathrm{m}^{2}\right)$ & $24.8 \pm 3.4$ & $25.2 \pm 3.2$ & n.s. \\
Waist circumference $(\mathrm{cm})$ & $86.4 \pm 9.7$ & $79.9 \pm 9.9$ & $<.05$ \\
Hip circumference $(\mathrm{cm})$ & $103.7 \pm 5.5$ & $105.5 \pm 5.1$ & n.s. \\
Dietary restraint score & $4.7 \pm 3.7$ & $7.5 \pm 4.0$ & $<.05$ \\
Disinhibition score & $3.9 \pm 1.4$ & $5.1 \pm 2.9$ & n.s. \\
Feeling of hunger score & $3.1 \pm 2.3$ & $5.6 \pm 3.4$ & $<.01$ \\
\hline
\end{tabular}

Values are means $\pm \mathrm{SD}$; ${ }^{2} \mathrm{P}$-value: differences between men and women (unpaired Student's t-tests); n.s.=non-significant

\section{Stress parameters}

Scores of POMS and STAI questionnaires showed higher feelings of depression (POMS $\left.\triangle A U C=+210.8 \pm 76.4 \times \mathrm{min}^{-1}, \mathrm{P}<0.01\right)$, tension (POMS $\triangle \mathrm{AUC}=$ $+227.7 \pm 74.0 \times \mathrm{min}^{-1}, \mathrm{P}<0.01$ ), confusion (POMS, $\triangle \mathrm{AUC}=+180.7 \pm 71.7 \times \mathrm{min}^{-1}$, $\mathrm{P}<0.02$ ), anger (POMS $\triangle \mathrm{AUC}=+211.5 \pm 74.3 \times \mathrm{min}^{-1}, \mathrm{P}<0.01$ ), and anxiety (STAI $\left.\triangle \mathrm{AUC}=+415.5 \pm 126.8 \times \mathrm{min}^{-1}, \mathrm{P}<0.01\right)$, during the stress vs. rest sessions, (ANOVA repeated measures: stress vs. rest, controlled for dietary condition; main effect of stress, $\mathrm{P}<0.02$ ), indicating that the applied stressor was effective in inducing psychological stress, regardless of the dietary condition. Consumption of the high-protein vs. high-carbohydrate meal did not affect feelings of depression, tension, anger and anxiety differently.

There were no differences in POMS and STAI scores between subjects with high vs. low disinhibition, in all conditions (AUC and per time point).

\section{Appetite profile}

The fasted state was confirmed by low satiety and fullness scores $(11.8 \pm 2.5$, $9.6 \pm 1.9 \mathrm{mmVAS})$, and high hunger, 'desire to eat' and thirst scores $(80.6 \pm 2.6$, $83.9 \pm 2.2,68.1 \pm 3.7 \mathrm{mmVAS})$. Consumption of the first meal resulted in an 
increase in satiety and fullness scores $(\Delta=-63.2 \pm 4.6,-69.9 \pm 3.7 \mathrm{mmVAS}$, $\mathrm{P}<0.001$ ), and a decrease in hunger, 'desire to eat' and thirst scores $(\Delta=+67.8 \pm 3.3,+68.5 \pm 3.3,+33.8 \pm 4.3 \mathrm{mmVAS}, \mathrm{P}<0.001)$. Conditions of stress vs. rest and of high-protein vs. high-carbohydrate did not affect feelings of hunger, thirst, desire to eat, satiety and fullness (AUC and per time point). VAS scores for the appetite profile parameters hunger, 'desire to eat', thirst, satiety, and fullness, did not differ between subjects with high vs. low disinhibition, in all conditions ( $A \cup C$, per time point, and change in score pre- to post-consumption). Consumption of the test meals decreased VAS-liking and wanting scores for the test meals (average liking scores pre- and post-meal: 53.5 $\pm 3.7,43.4 \pm 4.0$ mmVAS; average wanting score pre- and post-meal: $65.3 \pm 4.3,8.7 \pm 2.0 \mathrm{mmVAS}$; $\mathrm{P}<0.001)$. Conditions of stress vs. rest and of high-protein vs. high-carbohydrate did not influence liking and wanting (VAS) of the test meals pre- and post-meal, confirming that the meals were comparably liked and wanted. Liking (VAS) of the test meals did not differ between subjects with high vs. low disinhibition, in all conditions. Post-meal wanting (VAS) of the high-protein meal was lower in subjects with high vs. low disinhibition during stress $(P<0.01)$.

\section{'Liking' and 'wanting' computer test}

'Liking' between categories, average food 'wanting' ('wanting' for food items from all the five food categories taken together) and 'wanting' per category were not influenced by the conditions of stress vs. rest and high-protein vs. highcarbohydrate. There was an overall effect of time on 'liking' for bread, filling, drinks and placebo, and on average food 'wanting' and 'wanting' per category $(\mathrm{P}<0.0001)$. Consumption of the first meal decreased ranking of 'liking' of bread and filling and increased ranking of 'liking' of placebo and drinks, in all conditions $(\mathrm{P}<0.0001)$. Consumption of the first meal decreased average food 'wanting' in all conditions $(P<0.0001$, Figure 2$)$. More specifically, there was a pre- to postmeal decrease in 'wanting' for bread, filling, drinks, dessert and snacks $(P<0.04)$. 


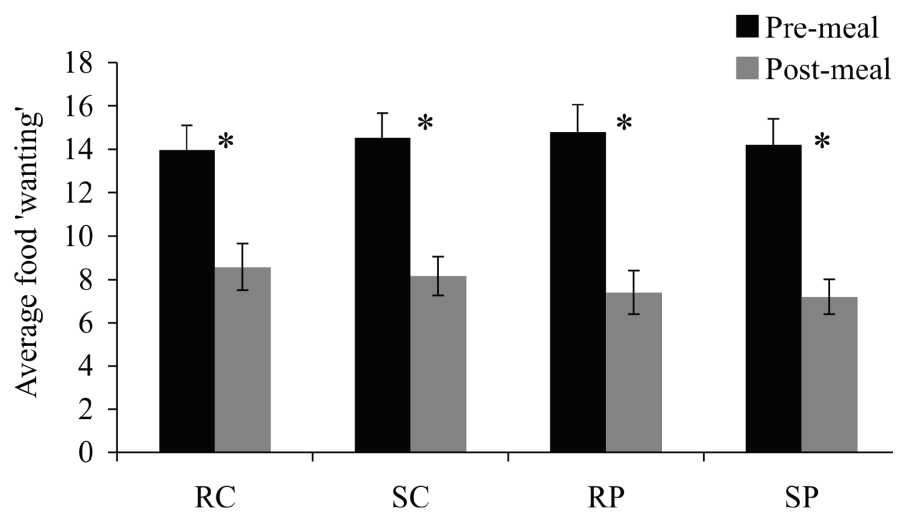

Figure 2. Average food 'wanting' score (mean $\pm S E M, n=38$ ) for items from all the five food categories taken together, pre- and post-meal, in the four conditions: rest-carbohydrate $(\mathrm{RC})$, stress-carbohydrate $(\mathrm{SC})$, rest-protein $(\mathrm{RP})$, stress-protein $(\mathrm{SP}) .{ }^{*} \mathrm{P}<0.0001$

An effect of disinhibited eating behavior was detected for average food 'wanting' (ANOVA repeated measures of post-meal food 'wanting' stress vs. rest $x$ highprotein vs. high-carbohydrate $\mathrm{x}$ high vs. low disinhibition; $\mathrm{P}<0.04$ ). The highprotein meal, vs. high-carbohydrate meal, induced lower subsequent average food 'wanting' in individuals with high disinhibition, during the rest condition $(P<0.01)$, but not during the stress condition (Figure 3 ).

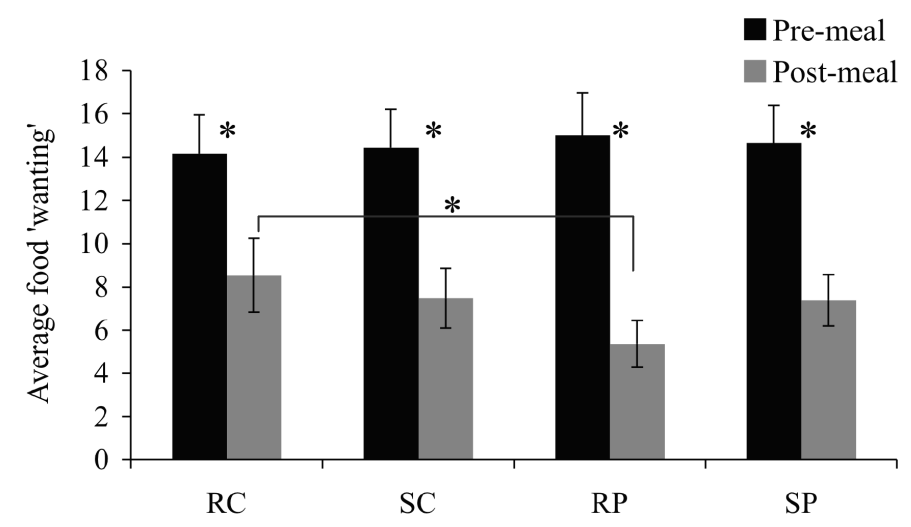

Figure 3. Average food 'wanting' score (mean \pm SEM) for items from all the five food categories taken together, for subjects with high disinhibition $(\mathrm{n}=16)$, pre- and post-meal, in the four conditions: restcarbohydrate $(R C)$, stress-carbohydrate $(S C)$, rest-protein $(R P)$, stress-protein $(S P) .{ }^{*} P<0.01$ 


\section{Energy and macronutrient intake}

Post-meal energy intake ('wanted meal') was not influenced by the conditions of stress vs. rest and high-protein vs. high-carbohydrate (Figure 4).

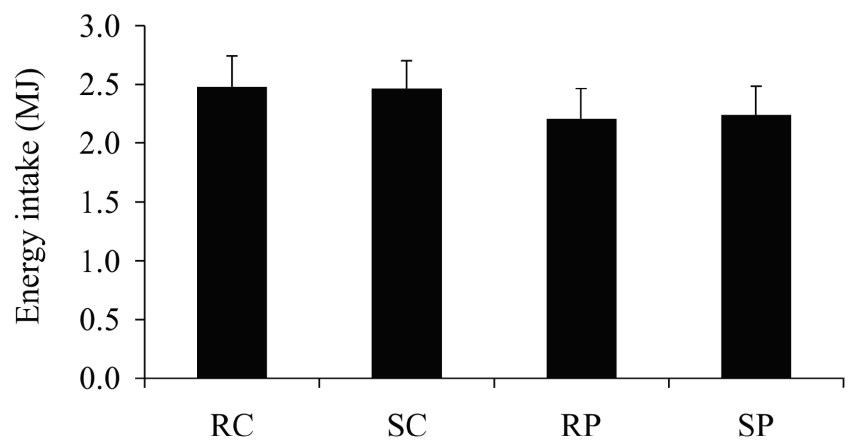

Figure 4. Post-meal energy intake (MJ, mean $\pm S E M, n=38$, 'wanted meal') in the four conditions: restcarbohydrate $(R C)$, stress-carbohydrate $(S C)$, rest-protein (RP), stress-protein (SP).

An effect of disinhibited eating behavior was detected for post-meal energy intake (ANOVA repeated measures of post-meal energy intake stress vs. rest $x$ high-protein vs. high-carbohydrate $x$ high vs. low disinhibition; $P=0.01$ ). The high-protein meal, vs. high-carbohydrate meal, induced lower subsequent energy intake in individuals with high disinhibition, during rest $(P<0.01)$, but not during stress (Figure 5). Moreover, subjects with high disinhibition showed higher energy intake in the stress vs. rest condition following the high-protein meal ( $P=0.01$, Figure 5).

The high-protein meal, vs. high-carbohydrate meal, induced lower subsequent intake of carbohydrates, fat, and proteins in individuals with high disinhibition, during the rest condition $(P<0.05)$, but not during the stress condition.

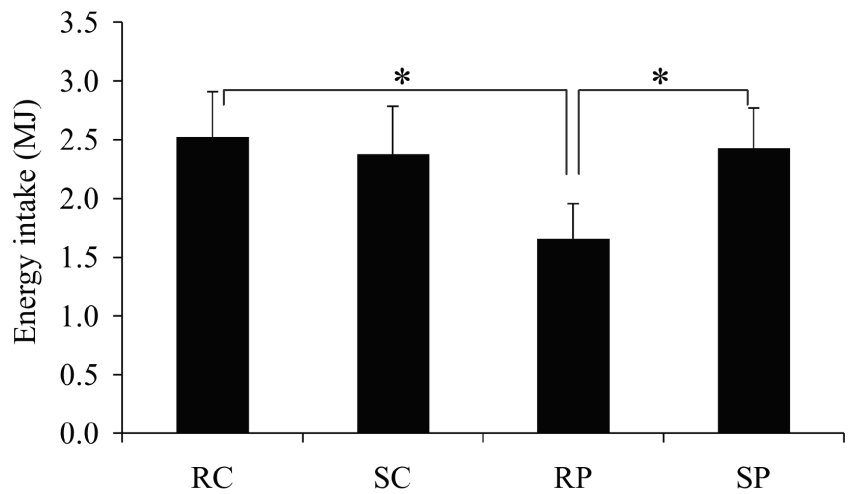

Figure 5. Post-meal energy intake (MJ, mean \pm SEM, 'wanted meal') for subjects with high disinhibition $(n=16)$, in the four conditions: rest-carbohydrate $(R C)$, stress-carbohydrate $(S C)$, rest-protein $(R P)$, stress-protein (SP). *P $\leq 0.01$ 


\section{Discussion}

The main objective of the study was to investigate possible effects of consumption of a high-protein vs. high-carbohydrate meal on the stress-induced psychological mood response, the rewarding value of food, i.e. 'liking' and 'wanting', and the stress-induced food choice and food intake in the absence of hunger.

Consumption of isocaloric meals with different macronutrient contents did not influence the stress-induced psychological mood response, the rewarding value of food, and the stress-induced food choice and food intake in the absence of hunger differently. However, only in subjects characterized by disinhibited eating behavior a conditional effect of high-protein vs. high-carbohydrate was detected. Average food 'wanting' and energy intake was lower following the high-protein meal, compared with the high-carbohydrate meal, during rest. This reduction in average food 'wanting' and energy intake following the high-protein meal disappeared during stress. In our everyday life stress is a pervasive factor, and the development of functional foods, able to regulate the stress response, would be helpful to improve or maintain quality of life, as suggested in the review by Takeda et al. (33). However, foods with the macronutrient contents used in our study seem ineffective in regulating the psychological stress response, the rewarding value of food, and the stress-induced food choice and food intake.

The conditions of the satiated vs. hungry state and of stress vs. rest were confirmed. No effects of macronutrient composition of the diets on stress, characterized by the psychological mood state, were shown. This contrasts the study by Firk and Markus (18) showing that intake of tryptophan-rich hydrolyzed protein increased positive mood to acute stress.

Conditions of stress vs. rest and of high-protein vs. high-carbohydrate did not affect ranking of 'liking' of the used categories of items, nor average food 'wanting' and 'wanting' per category, and subsequent energy intake. Surprisingly, an effect of disinhibited eating behavior was detected as individuals with high disinhibition showed lower average food 'wanting' and energy intake following the high-protein vs. high-carbohydrate meal, during rest but not during the stress. Post-meal wanting (VAS) of the high-protein meal during stress, was lower in subjects with high vs. low disinhibition. It seems that during stress the high-protein meal was less rewarding for subjects with high disinhibition, compared with subjects with low disinhibition. This may explain why during stress, in contrast to rest, the high-protein meal did not induce a decreased post-meal 'wanting' and energy intake of other food items in subjects with high disinhibition. Previous research has shown that subjects with high disinhibition may be vulnerable to ego-threatening stress, leading to an increased energy intake $(5,34)$. Disinhibited eating behavior can be a possible risk factor for overweight and obesity (35). Results of our study show a higher energy intake in subjects with high disinhibition in the stress vs. rest condition following the high-protein meal. Acute stress overruled the effect of the reduced 'wanting' and energy intake 
following consumption of a high-protein vs. high-carbohydrate meal. Why subjects with high-disinhibition show lower food 'wanting' and energy intake following a high-protein meal, compared with a high-carbohydrate meal, during rest, remains questionable. It cannot be explained by the appetite profile parameters, as they were not affected by the different conditions.

In conclusion, consumption of a high-protein meal, compared with a highcarbohydrate meal, appears to have limited impact on stress-related eating behavior. Only subjects with high disinhibition showed decreased subsequent 'wanting' and energy intake during rest; this effect disappeared under stress. Acute stress overruled food intake suppression effects of consumption of highprotein foods.

\section{Acknowledgements}

The study was designed by MSWP and SGL. SGL together with EAM (supervised by MSWP) carried out the study and collected the data. JMB updated the psychological computer test to create the stress vs. rest condition. SGL analyzed the data and wrote the largest part of the manuscript. JMB and MJM reviewed the manuscript. 


\section{References}

1. Torres SJ, Nowson CA. Relationship between stress, eating behavior, and obesity. Nutrition. 2007 Nov-Dec;23(11-12):887-94.

2. Adam TC, Epel ES. Stress, eating and the reward system. Physiol Behav. 2007 Apr 14;91(4):449-58.

3. Nieuwenhuizen AG, Rutters F. The hypothalamic-pituitary-adrenal-axis in the regulation of energy balance. Physiol Behav. 2007 Dec 23;94(2):169-77.

4. Kyrou I, Chrousos GP, Tsigos C. Stress, visceral obesity, and metabolic complications. Ann N Y Acad Sci. 2006 Nov;1083:77-110.

5. Rutters F, Nieuwenhuizen AG, Lemmens SG, Born JM, Westerterp-Plantenga MS. Acute stressrelated changes in eating in the absence of hunger. Obesity (Silver Spring). 2009 Jan;17(1):72-7.

6. Oliver G, Wardle J, Gibson EL. Stress and food choice: a laboratory study. Psychosom Med. 2000 Nov-Dec;62(6):853-65.

7. Zellner DA, Loaiza S, Gonzalez Z, Pita J, Morales J, Pecora D, et al. Food selection changes under stress. Physiol Behav. 2006 Apr 15;87(4):789-93.

8. Kuo LE, Czarnecka M, Kitlinska JB, Tilan JU, Kvetnansky R, Zukowska Z. Chronic stress, combined with a high-fat/high-sugar diet, shifts sympathetic signaling toward neuropeptide $Y$ and leads to obesity and the metabolic syndrome. Ann N Y Acad Sci. 2008 Dec;1148:232-7.

9. Lacroix M, Gaudichon C, Martin A, Morens C, Mathe V, Tome D, et al. A long-term high-protein diet markedly reduces adipose tissue without major side effects in Wistar male rats. Am J Physiol Regul Integr Comp Physiol. 2004 Oct;287(4):R934-42.

10. Vicennati V, Ceroni L, Gagliardi L, Gambineri A, Pasquali R. Comment: response of the hypothalamic-pituitary-adrenocortical axis to high-protein/fat and high-carbohydrate meals in women with different obesity phenotypes. J Clin Endocrinol Metab. 2002 Aug;87(8):3984-8.

11. Martens MJ, Rutters F, Lemmens SG, Born JM, Westerterp-Plantenga MS. Effects of single macronutrients on serum cortisol concentrations in normal weight men. Physiol Behav. 2010; Epub ahead of print.

12. Berridge KC. Food reward: brain substrates of wanting and liking. Neurosci Biobehav Rev. 1996;20(1):1-25.

13. Berthoud HR. Mind versus metabolism in the control of food intake and energy balance. Physiol Behav. 2004 Jul;81(5):781-93.

14. Finlayson G, King N, Blundell JE. Is it possible to dissociate 'liking' and 'wanting' for foods in humans? A novel experimental procedure. Physiol Behav. 2007 Jan 30;90(1):36-42.

15. Mela DJ. Eating for pleasure or just wanting to eat? Reconsidering sensory hedonic responses as a driver of obesity. Appetite. 2006 Jul;47(1):10-7.

16. Berthoud HR. Neural control of appetite: cross-talk between homeostatic and non-homeostatic systems. Appetite. 2004 Dec;43(3):315-7.

17. Berridge KC. Motivation concepts in behavioral neuroscience. Physiol Behav. 2004 Apr;81(2):179-209.

18. Firk C, Markus CR. Mood and cortisol responses following tryptophan-rich hydrolyzed protein and acute stress in healthy subjects with high and low cognitive reactivity to depression. Clin Nutr. 2009;28(3):266-71.

19. Lemmens SG, Schoffelen PF, Wouters L, Born JM, Martens MJ, Rutters F, et al. Eating what you like induces a stronger decrease of 'wanting' to eat. Physiol Behav. 2009 Sep 7;98(3):318-25.

20. WHO. Obesity: preventing and managing the global epidemic. Report of a WHO consultation. World Health Organ Tech Rep Ser. 2000;894(i-xii):1-253.

21. Bjorntorp P, Rosmond R. Obesity and cortisol. Nutrition. 2000 Oct;16(10):924-36.

22. Bjorntorp P. Do stress reactions cause abdominal obesity and comorbidities? Obes Rev. 2001 May;2(2):73-86.

23. Stunkard AJ, Messick S. The three-factor eating questionnaire to measure dietary restraint, disinhibition and hunger. J Psychosom Res. 1985;29(1):71-83. 
24. Westerterp-Plantenga MS. Eating behavior in humans, characterized by cumulative food intake curves--a review. Neurosci Biobehav Rev. 2000 Mar;24(2):239-48.

25. Hemmink GJM, Bredenoord AJ, Weusten BLAM, Timmer R, Smout AJPM. Does acute psychological stress increase perception of oesophageal acid? Neurogastroenterol Motil. 2009;21(10):1055-86.

26. Peters ML, Godaert GL, Ballieux RE, van Vliet M, Willemsen JJ, Sweep FC, et al. Cardiovascular and endocrine responses to experimental stress: effects of mental effort and controllability. Psychoneuroendocrinology. 1998 Jan;23(1):1-17.

27. Born JM, Lemmens SGT, Rutters F, Nieuwenhuizen AG, Formisano E, Goebel R, et al. Acute stress and food-related reward activation in the brain during food choice during eating in the absence of hunger. Int J Obes. 2009 Oct 20.

28. Sorensen LB, Moller P, Flint A, Martens M, Raben A. Effect of sensory perception of foods on appetite and food intake: a review of studies on humans. Int J Obes Relat Metab Disord. 2003 Oct;27(10):1152-66.

29. Harris JA, Benedict FG. A Biometric Study of Human Basal Metabolism. Proc Natl Acad Sci U S A. 1918 Dec;4(12):370-3.

30. McArdle WD, Katch FI, Katch VL. Exercise Physiology. 4th ed. Baltimore: Williams and Watkins; 1996.

31. Albrecht RR, Ewing SJ. Standardizing the administration of the Profile of Mood States (POMS): development of alternative word lists. J Pers Assess. 1989 Spring;53(1):31-9.

32. Tenenbaum G, Furst D, Weingarten G. A statistical reevaluation of the STAI anxiety questionnaire. J Clin Psychol. 1985 Mar;41(2):239-44.

33. Takeda E, Terao J, Nakaya Y, Miyamoto K, Baba Y, Chuman H, et al. Stress control and human nutrition. J Med Invest. 2004;51(3-4):139-45.

34. Lattimore P, Maxwell L. Cognitive load, stress, and disinhibited eating. Eating Behaviors. 2004;5(4):315-24.

35. Wilkinson LL, Rowe AC, Bishop RJ, Brunstrom JM. Attachment anxiety, disinhibited eating, and body mass index in adulthood. Int J Obes. 2010:1-4. 
Chapter 9

General Discussion 
The research presented in this thesis focused on the role of energy and reward homeostasis in food intake behavior, and more specifically on hormone and appetite dynamics, in relation to meal pattern, as well as on the concept of reward, and hypothalamus pituitary adrenal (HPA) axis activity.

\section{Appetite in relation to hormone and glucose concentrations}

The regulation of food intake and energy homeostasis involves physiological factors such as the dynamics of gastrointestinal hormones and the possibly related feelings of appetite $(1,2)$. The search for physiological biomarkers of appetite is currently very active. Relevant potential biomarkers related to appetite may be glucagon-like peptide (GLP)-1 and peptide tyrosine-tyrosine (PYY), ghrelin, glucose and insulin $(3,4)$. Previous studies $(5-11)$ have based their correlation analyses of visual analogue scale (VAS) ratings for appetite and gut hormone and glucose concentrations upon the calculated area under the curve or on the measured values per time point, not taking into account the factor time. For validation of VAS appetite ratings with hormone and glucose concentrations we used a statistical approach including the factor time by concentrating on the within-subject relations of these observations. Per subject regression slopes and $\mathrm{R}^{2}$ values for the regression of VAS ratings on gut hormone and glucose concentrations were calculated. Moreover, we investigated whether changes in VAS appetite scores are synchronized with, or lag behind or in front of changes in gut hormone and glucose concentrations.

Analyses of regression slopes and $\mathrm{R}^{2}$ values revealed that VAS appetite scores and hormone and glucose concentrations changed synchronously, and that the mean explained variation of the development of hunger and fullness scores over time by the development of GLP-1, PYY, ghrelin, glucose, and insulin concentrations over time was 30-70\%. The question remains whether this explained variation is sufficient to presume that the hormone and glucose concentrations may serve as a reliable biomarker for appetite at the individual level. We suggest this explained variation may be insufficient to use hormone or glucose concentrations as appropriate biomarkers for appetite, at least at the individual level and probably as well at group level. To our opinion, the applied statistical approach may be useful for understanding possible differences in relations between VAS appetite scores and hormone and glucose concentrations between subject groups or between experimental conditions, e.g. exploring the effects of specific nutrients or ingredients. The relationship between VAS appetite ratings and PYY concentrations for example may be stronger in the case of ingestion of a high-fat or high-protein meal, as increasing both fat and protein content of a meal may induce an immediate and prolonged increase in PYY and possibly may result in increased satiety (12).

In addition, from our research it appeared that GLP-1, PYY, glucose, and insulin concentrations changed synchronously with VAS fullness scores. In contrast, 
ghrelin concentrations lagged behind the VAS hunger scores, with a delay of 1025 min. Moreover, meal consumption induced a delayed ghrelin suppressive response by 10-25 min. Several studies showed that insulin is required for postprandial ghrelin suppression (13-15), and that there is a delay of approximately $20 \mathrm{~min}$ between responses of insulin and ghrelin, insulin leading ghrelin (16). Our study confirmed that ghrelin concentrations lagged behind the insulin concentrations by approximately 15-30 min. This suggests a role for insulin as a negative regulator of ghrelin (17).

\section{Energy homeostasis and reward homeostasis}

Besides physiological factors such as the dynamics of gastrointestinal hormones and the possibly related feelings of appetite, factors such as food reward may play an essential role in the regulation of food intake and energy homeostasis $(18,19)$. Regarding the concept of reward, we needed a valid tool to measure the rewarding value of food, i.e. 'liking' and 'wanting' (20), in a Dutch study population and applicable in different study designs. We developed a computer test and showed that it was valid to measure 'liking' and 'wanting', in that it had a sufficient reproducibility and sensitivity (21). In addition we assessed how the rewarding value of a consumed food item possibly affects the rewarding value of any other food item in general (21). It appeared that eating a highly liked food item induces a more distinct decrease in hunger, desire to eat and 'wanting' for food items in general and category-specific 'liking', than eating a sufficiently liked 'neutral' food item.

Subsequently, the computer test was applied in the assessment of the role of dietary restraint in control over 'wanting' following consumption of 'forbidden' food (22). Successfully restrained eaters decreased food 'wanting' specifically after consumption of a non-healthy perceived, 'delicious', dessert-specific food vs. a nutritional identical, yet healthy perceived, slightly less 'delicious', 'neutral' food. A healthy perceived food may thus impose greater risk for control of energy intake in successfully restrained eaters. Restrained eaters have a similar control over appetite and 'liking' as unrestrained eaters, although they use cognitive cues, but they have a stronger control over 'wanting' in case of 'delicious' foods. Exposing restrained eaters to tempting and 'forbidden' foods may make them more conscious about their weight and eating behavior when planning future food consumption (23).

From the above described research it appears that in the hungry state appetite, i.e. hunger and satiety, as well as food reward, i.e. 'liking' and 'wanting', dominate the control of feeding to maintain energy and reward homeostasis. In the satiated state, compared with the hungry state, hunger and food 'wanting' are reduced, and food 'liking' changes, depending on the type of food that has been consumed. Food 'wanting' in the absence of hunger, thus 'wanting' beyond energy homeostasis, may be a way to compensate for a possible reward 
deficiency and may be a way to reach the target reward homeostasis. Eating a highly rewarding food, compared with a less rewarding food, may prevent consumption beyond energy homeostasis, as the target reward homeostasis has already been reached.

\section{Role of meal pattern in relation to hormone and appetite dynamics, and reward}

Eating out has become an important aspect in the development of obesity, and often involves a different meal pattern (24). The stimulated food intake through the social context of eating out may be facilitated by a slower appearance of satiation signals, or it may take place despite greater appetite control by possibly more sustained satiety signals. In a laboratory setting, thus excluding the environmental factors of eating out, we investigated the effect of two different meal patterns, i.e. staggered vs. non-staggered meal consumption, on hormone and appetite dynamics, as well as on the concept of reward and subsequent ad libitum energy intake. Results showed that staggered vs. non-staggered meal consumption induced a less pronounced and steadier hormonal and appetite response. Moreover, staggered meal consumption resulted in higher final GLP-1 concentrations and satiety ratings and lower ghrelin concentrations and hunger ratings. These results are in accordance with findings of previous studies (16, 25-27).

To our knowledge no previous study has shown the effect of meal duration on food reward, i.e. 'liking' and 'wanting'. While 'liking' was not affected by the different meal patterns, for 'wanting' we did detect differences between the two conditions. Staggered vs. non-staggered meal consumption resulted in a lower food 'wanting' prior to and following ad libitum food intake. Although not significant, ad libitum energy intake was $10 \%$ lower in the staggered vs. nonstaggered meal condition.

Overall the results imply that in a laboratory setting staggered meal consumption facilitates greater appetite control. The stimulated food intake in a restaurant setting with staggered meal consumption may take place despite greater appetite control.

\section{Role of hypothalamus pituitary adrenal (HPA) axis activity in relation to reward}

The homeostasis of reward may appear more clearly in certain subject groups, such as the visceral obese, or under certain circumstances, such as stress, involving the activity of the HPA axis (28-34). Therefore we assessed in visceral overweight vs. normal weight subjects the effects of acute psychological stress on the rewarding value of food, in terms of 'liking' and 'wanting', and on food intake in a fasted as well as satiated state. Our research indicated that visceral 
overweight subjects, in contrast to normal weight subjects, showed stressinduced food intake in the absence of hunger, resulting in an increased energy intake. In those visceral overweight subjects, 'wanting' for dessert and snacks, and carbohydrate and fat intake, was higher in the absence of hunger in the stress vs. rest condition. Moreover, under stress visceral overweight subjects showed an increase in percentage of daily energy requirements consumed over two meals by $6 \pm 2 \%$.

Previous research has shown that in vulnerable subjects, such as individuals scoring high on dietary restraint or disinhibition, stress can induce an increased energy intake and change in food choice towards sweet and fat foods (35-38). It appears that psychosocial stress is associated with greater weight gain among subjects who are overweight or obese, but less among subjects who are normal weight or underweight $(39,40)$. The latter subjects normally are not interested anymore in eating while stressed, whereas the visceral overweight subjects seem to eat to suppress stress. However, the risk is that chronic stress combined with a high-fat, high-carbohydrate diet may lead to abdominal obesity (41). From our research it appears that in a stressful situation the food reward system may overrule and promote excessive food intake in visceral overweight subjects $(28,42)$. Based on the study by Born et al. (30), showing that stress decreased reward related brain activity and increased energy intake postprandially, we hypothesized that stress may diminish the sensitivity of the reward system to food cues, leading to an increased energy intake to compensate for the reward deficiency.

Furthermore, our research showed that food 'liking' was relatively uninfluenced by stress or increasing weight status. 'Wanting' on the other hand was influenced by stress and weight status, as visceral overweight subjects in stress and in the absence of hunger want and consume foods that are high in fat and carbohydrate, in contrast to normal weight subjects. Previous research has shown that food 'liking' and 'wanting' are independent processes regulated by different neurobiological systems (35-37). Food 'wanting' may be a stronger determinant of energy intake than is food 'liking' or food hedonics (43-45). Our study suggests that during stress 'wanting' in the absence of hunger might be an important process in developing an obese state.

The food choice in stress is often shifted towards sweet and fat foods, possibly because they are perceived as highly rewarding $(35-37,46)$. However, several endocrinological human and rodent studies showed that some of these preferred or highly rewarding foods, namely carbohydrates, may not reduce but even increase HPA axis activity, i.e. cortisol concentrations (47-49). In our everyday life where stress is a pervasive factor, the development of functional foods, able to regulate the physiological and psychological stress response and consequently preventing stress-induced eating beyond energy homeostasis, would be helpful to improve or maintain quality of life (50). Regarding the possible effects of macronutrients on HPA axis activity and on the stress-induced mood response 
there are still inconsistencies in literature $(47-49,51-57)$. Our research revealed that consumption of isocaloric meals with different macronutrient contents, i.e. high-protein vs. high-carbohydrate, did not influence the physiological cortisol response and psychological mood response differentially. It is not clear yet whether the macronutrient composition of a meal can indeed influence cortisol levels. The use of mixed meals instead of single macronutrients (48), might limit the detection of possible effects of macronutrients on cortisol levels.

Furthermore we observed that men showed a higher meal-induced salivary cortisol response compared with women. Literature on gender differences concerning meal-induced cortisol increases is scarce. The lower salivary cortisol levels in women compared with men might be explained by the fact that women in our study participated during the follicular phase (58).

In addition, to our knowledge we were the first to investigate how consumption of high-protein vs. high-carbohydrate foods influences the rewarding value of food, i.e. 'liking' and 'wanting', and subsequent food choice and food intake, in an acute stressful situation. Consumption of a high-protein meal, compared with a high-carbohydrate meal, appeared to have limited impact on stress-related eating behavior. Only subjects characterized by disinhibited eating behavior showed decreased subsequent 'wanting' and energy intake during rest; this effect disappeared under stress. Acute stress overruled the effects of consumption of high-protein foods. Previous research has shown that subjects with high disinhibition may be vulnerable to ego threatening stress, leading to an increased energy intake $(37,59)$. Disinhibited eating behavior can be a possible risk factor for overweight and obesity (60). Results of our study show a higher energy intake in subjects with high disinhibition in the stress vs. rest condition following the high-protein meal.

All in all, from our research it appears that intake of isocaloric meals with different macronutrient contents does not affect stress-related eating behavior to a great extent, neither exaggerating nor diminishing food intake beyond energy homeostasis.

\section{Conclusions}

Regarding physiological biomarkers of appetite, our research shows that the mean explained variation of the development of hunger and fullness scores over time by the development of GLP-1, PYY, ghrelin, glucose, and insulin concentrations over time is $30-70 \%$. This figure may be too small to use the changes in gut hormone and glucose concentrations as biomarkers for feelings of appetite, at the individual level as well as at group level. Furthermore, ghrelin concentrations lag behind VAS hunger scores and insulin concentrations, suggesting a role for insulin as a negative regulator of ghrelin. Physiological 'biomarkers', such as GLP-1, PYY, ghrelin, glucose, and insulin, cannot replace feelings of appetite. 
With regard to the concept of reward, i.e. 'liking' and 'wanting', the computer test developed for measurement of 'liking' and 'wanting' proves to be sufficiently valid. Application of the computer test in the assessment of how the rewarding value of a consumed food item possibly affects the rewarding value of any other food item in general, shows that eating a highly liked food item induces a more distinct decrease in 'wanting' for food items in general and category-specific 'liking', than eating a sufficiently liked 'neutral' food item. In addition, successfully restrained eaters decrease 'wanting' specifically for a non-healthy perceived, 'delicious' food vs. a nutritional identical, yet healthy perceived, slightly less 'delicious' food. A healthy perceived food may thus impose greater risk for control of energy intake in successfully restrained eaters. Thus, eating what you like contributes to less wanting of more food.

Concerning the role of meal pattern manipulation (staggered vs. non-staggered meal consumption) in relation to hormone and appetite dynamics, reward and energy intake, our research shows that staggered vs. non-staggered meal consumption induces greater appetite control, indicated by less pronounced hormone and appetite dynamics and more control over subsequent food 'wanting'. Moreover, it results in higher final GLP-1 concentrations and satiety ratings, lower ghrelin concentrations and hunger ratings, and lower subsequent food 'wanting'. However, this may not be translated into a lower energy intake. Staggered meal consumption induces a sustained hormonal and appetite response and decreases wanting to eat more.

Research on the role of the HPA axis activity in relation to the concept of reward reveals that acute stress augments food 'wanting' and energy intake in visceral overweight subjects in the absence of hunger. Furthermore, consumption of meals with different macronutrient contents, i.e. high-protein vs. highcarbohydrate, does not influence the physiological cortisol and psychological mood response differentially. Men show a higher meal-induced salivary cortisol response compared with women. A high-protein vs. high-carbohydrate meal induces lower subsequent 'wanting' and energy intake in subjects with high disinhibition during rest; this difference disappears under stress. Acute stress overrules the effects of consumption of high-protein foods. A high-protein meal is ineffective in regulating the physiological and psychological stress response, and has limited impact on stress-related eating behavior.

\section{Future Research}

In the light of the current obesity epidemic further understanding of the role of energy and reward homeostasis is fundamental. The regulation of appetite and energy intake is a complex process involving, besides physiological factors such as the dynamics of gastrointestinal hormones and the possibly related feelings of appetite, factors such as food reward, environmental cues, and cognitive factors $(1,2)$. 
Brain pathways involved in energy and reward homeostasis, i.e. hypothalamic and cortico-limbic brain areas respectively, interact in the neuro-regulatory control of feeding $(18,61,62)$. It would be highly relevant to investigate the relationship between gut hormones and the brain areas controlling appetite, ingestion, food reward and body weight (63), as gut hormones may modulate perceived food reward $(64,65)$.

Regarding meal pattern manipulation in relation to hormone and appetite dynamics and reward, we showed that, at least in a laboratory setting, increasing meal duration can exert greater appetite control. However, increased meal duration in a restaurant setting often results in a larger food intake, which may be due to external factors such as the atmosphere, the presence of other people, or distraction, which lowers the possibility of estimating the energy density of the foods resulting in less well adaptation of portion sizes (66-69). It would be of interest to repeat the study in a restaurant setting, where besides timing also the factor of social setting and distraction can influence food reward and energy intake in the absence of hunger.

Throughout the whole of this thesis it appeared that energy and reward homeostasis both play a role in food intake behavior in the hungry state. However, in the satiated state, i.e. in the absence of hunger, it is mainly reward homeostasis that plays a role in food intake behavior, and this role becomes even more of importance in conditions of acute stress. Chronically eating in the absence of hunger, i.e. eating beyond energy homeostasis, may lead to the development of overweight and obesity. Thus, future studies should pay attention to the fundamental role of reward homeostasis in eating in the absence of hunger.

In our everyday life where stress is a pervasive factor, it would be helpful to develop highly rewarding healthy foods, able to regulate the physiological and psychological stress response and consequently preventing stress-induced eating beyond energy homeostasis, i.e. eating for reward homeostasis (50). We showed that a high-protein meal is ineffective in regulating the physiological and psychological stress response, and has limited impact on stress-related eating behavior. However, it would be of interest to further elucidate the effect of different nutrients, e.g. tryptophan-rich hydrolyzed protein (57), on stressinduced eating behavior. In addition, we revealed that the meal-induced salivary cortisol response is higher in men compared with women. Literature on gender differences concerning meal-induced cortisol increases is scarce, and more research is needed to explain this gender difference. It can be hypothesized that the greater cortisol response observed in men may be associated with visceral fat accumulation and an elevated risk for cardiovascular diseases and diabetes and may help explain the higher prevalence for these diseases in males $(29,70-$ 72). 


\section{References}

1. Giskes K, Van Lenthe F, Avendano-Pabon M, Brug J. A systematic review of environmental factors and obesogenic dietary intakes among adults: are we getting closer to understanding obesogenic environments? Obes Rev. 2010.

2. Mattes RD, Hollis J, Hayes D, Stunkard AJ. Appetite: Measurement and Manipulation Misgivings. J Am Diet Assoc. 2005;105(5, Supplement 1):87-97.

3. Delzenne N, Blundell J, Brouns F, Cunningham K, De Graaf K, Erkner A, et al. Gastrointestinal targets of appetite regulation in humans. Obes Rev. 2010;11(3):234-50.

4. Flint A, Gregersen NT, Gluud LL, Møller BK, Raben A, Tetens I, et al. Associations between postprandial insulin and blood glucose responses, appetite sensations and energy intake in normal weight and overweight individuals: a meta-analysis of test meal studies. $\mathrm{Br} \mathrm{J}$ Nutr. 2007;95(1):17-25.

5. Diepvens K, Haberer D, Westerterp-Plantenga M. Different proteins and biopeptides differently affect satiety and anorexigenic/orexigenic hormones in healthy humans. Int J Obes (Lond). 2008 Mar;32(3):510-8.

6. Maffeis C, Surano MG, Cordioli S, Gasperotti S, Corradi M, Pinelli L. A High-fat vs. a Moderatefat Meal in Obese Boys: Nutrient Balance, Appetite, and Gastrointestinal Hormone Changes. Obesity. 2009;18(3):449-55.

7. Smeets AJ, Soenen S, Luscombe-Marsh ND, Ueland O, Westerterp-Plantenga MS. Energy Expenditure, Satiety, and Plasma Ghrelin, Glucagon-Like Peptide 1, and Peptide TyrosineTyrosine Concentrations following a Single High-Protein Lunch. J Nutr. 2008 April 1, 2008;138(4):698-702.

8. Erdmann J, Hebeisen Y, Lippl F, Wagenpfeil S, Schusdziarra V. Food intake and plasma ghrelin response during potato-, rice- and pasta-rich test meals. Eur J Nutr. 2007;46(4):196-203.

9. Guo Y, Ma L, Enriori PJ, Koska J, Franks PW, Brookshire T, et al. Physiological Evidence for the Involvement of Peptide $\mathrm{YY}$ in the Regulation of Energy Homeostasis in Humans. Obesity. 2006;14(9):1562-70.

10. le Roux CW, Batterham RL, Aylwin SJB, Patterson M, Borg CM, Wynne KJ, et al. Attenuated Peptide YY Release in Obese Subjects Is Associated with Reduced Satiety. Endocrinology. 2006 January 1, 2006;147(1):3-8.

11. Verdich C, Flint A, Gutzwiller JP, Naslund E, Beglinger C, Hellstrom PM, et al. A Meta-Analysis of the Effect of Glucagon-Like Peptide-1 (7-36) Amide on Ad Libitum Energy Intake in Humans. J Clin Endocrinol Metab. 2001 September 1, 2001;86(9):4382-9.

12. Helou N, Obeid O, Azar ST, Hwalla N. Variation of Postprandial PYY<sub>3,Äỉ6</sub>Response following Ingestion of Differing Macronutrient Meals in Obese Females. Ann Nutr Metab. 2008;52(3):188-95.

13. Flanagan DE, Evans ML, Monsod TP, Rife F, Heptulla RA, Tamborlane WV, et al. The influence of insulin on circulating ghrelin. Am J Physiol Endocrinol Metab. 2003 February 1, 2003;284(2):E313-6.

14. Murdolo G, Lucidi P, Di Loreto C, Parlanti N, De Cicco A, Fatone C, et al. Insulin is required for prandial ghrelin suppression in humans. Diabetes. 2003;52(12):2923-7.

15. Saad MF, Bernaba B, Hwu C-M, Jinagouda S, Fahmi S, Kogosov E, et al. Insulin Regulates Plasma Ghrelin Concentration. J Clin Endocrinol Metab. 2002 August 1, 2002;87(8):3997-4000.

16. Solomon TP, Chambers ES, Jeukendrup AE, Toogood AA, Blannin AK. The effect of feeding frequency on insulin and ghrelin responses in human subjects. $\mathrm{Br} \mathrm{J}$ Nutr. 2008 Oct;100(4):810-9.

17. Cummings DE, Frayo RS, Marmonier C, Aubert R, Chapelot D. Plasma ghrelin levels and hunger scores in humans initiating meals voluntarily without time- and food-related cues. Am J Physiol Endocrinol Metab. 2004 August 1, 2004;287(2):E297-304.

18. Berthoud HR. Homeostatic and non-homeostatic pathways involved in the control of food intake and energy balance. Obesity (Silver Spring). 2006 Aug;14 Suppl 5:197S-200S.

19. Berridge KC, Ho CY, Richard JM, DiFeliceantonio AG. The tempted brain eats: pleasure and desire circuits in obesity and eating disorders. Brain Res. 2010;1350:53-64. 
20. Berridge KC. Food reward: brain substrates of wanting and liking. Neurosci Biobehav Rev. 1996;20(1):1-25.

21. Lemmens SG, Schoffelen PF, Wouters L, Born JM, Martens MJ, Rutters F, et al. Eating what you like induces a stronger decrease of 'wanting' to eat. Physiol Behav. 2009 Sep 7;98(3):318-25.

22. Lemmens SG, Born JM, Rutters F, Schoffelen PF, Wouters L, Westerterp-Plantenga MS. Dietary Restraint and Control Over "Wanting" Following Consumption of "Forbidden" Food. Obesity. 2010;18(10):1926-31.

23. Fishbach A, Friedman RS, Kruglanski AW. Leading us not unto temptation: momentary allurements elicit overriding goal activation. J Pers Soc Psychol. 2003 Feb;84(2):296-309.

24. Naska A, Orfanos P, Trichopoulou A, May AM, Overvad K, Jakobsen MU, et al. Eating out, weight and weight gain. A cross-sectional and prospective analysis in the context of the EPICPANACEA study. Int J Obes. 2010.

25. Kokkinos A, le Roux CW, Alexiadou K, Tentolouris N, Vincent RP, Kyriaki D, et al. Eating slowly increases the postprandial response of the anorexigenic gut hormones, peptide $Y Y$ and glucagon-like peptide-1. J Clin Endocrinol Metab. 2010 Jan;95(1):333-7.

26. Speechly DP, Buffenstein R. Greater appetite control associated with an increased frequency of eating in lean males. Appetite. 1999 Dec;33(3):285-97.

27. Speechly DP, Rogers GG, Buffenstein R. Acute appetite reduction associated with an increased frequency of eating in obese males. Int J Obes Relat Metab Disord. 1999 Nov;23(11):1151-9.

28. Dallman MF. Stress-induced obesity and the emotional nervous system. Trends Endocrinol Metab. 2010;21(3):159-65.

29. Rutters F, Nieuwenhuizen AG, Lemmens SG, Born JM, Westerterp-Plantenga MS. Hypothalamic-Pituitary-Adrenal (HPA) axis functioning in relation to body fat distribution. Clin Endocrinol (Oxf). 2010;72(6):738-43.

30. Born JM, Lemmens SGT, Rutters F, Nieuwenhuizen AG, Formisano E, Goebel R, et al. Acute stress and food-related reward activation in the brain during food choice during eating in the absence of hunger. Int J Obes. 2009 Oct 20.

31. Volkow ND, Wang GJ, Fowler JS, Telang F. Overlapping neuronal circuits in addiction and obesity: evidence of systems pathology. Philos Trans R Soc Lond B Biol Sci. 2008;363(1507):3191-200.

32. Berridge KC. 'Liking' and 'wanting' food rewards: Brain substrates and roles in eating disorders. Physiology \& Behav. 2009;97(5):537-50.

33. Dallman MF, Pecoraro NC, La Fleur SE, Warne JP, Ginsberg AB, Akana SF, et al. Glucocorticoids, chronic stress, and obesity. Prog Brain Res. 2006;153:75-105.

34. Reynolds SM, Berridge KC. Emotional environments retune the valence of appetitive versus fearful functions in nucleus accumbens. Nat Neurosci. 2008;11(4):423-5.

35. Oliver G, Wardle J, Gibson EL. Stress and food choice: a laboratory study. Psychosom Med. 2000 Nov-Dec;62(6):853-65.

36. Zellner DA, Loaiza S, Gonzalez Z, Pita J, Morales J, Pecora D, et al. Food selection changes under stress. Physiol Behav. 2006 Apr 15;87(4):789-93.

37. Rutters F, Nieuwenhuizen AG, Lemmens SG, Born JM, Westerterp-Plantenga MS. Acute stressrelated changes in eating in the absence of hunger. Obesity (Silver Spring). 2009 Jan;17(1):72-7.

38. Heatherton TF, Herman CP, Polivy J. Effects of Physical Threat and Ego Threat on Eating Behavior. J Pers Soc Psychol. 1991;60(1):138-43.

39. Block JP, He Y, Zaslavsky AM, Ding L, Ayanian JZ. Psychosocial stress and change in weight among US adults. Am J Epidemiol. 2009;170(2):181-92.

40. Kivimäki M, Head J, Ferrie JE, Shipley MJ, Brunner EJ, Vahtera J, et al. Work stress, weight gain and weight loss: evidence for bidirectional effects of job strain on body mass index in the Whitehall II study. Int J Obes (Lond). 2006;30(6):982-7.

41. Kuo LE, Czarnecka M, Kitlinska JB, Tilan JU, Kvetnansky R, Zukowska Z. Chronic stress, combined with a high-fat/high-sugar diet, shifts sympathetic signaling toward neuropeptide $Y$ and leads to obesity and the metabolic syndrome. Ann N Y Acad Sci. 2008 Dec;1148:232-7. 
42. Erlanson-Albertsson C. How palatable food disrupts appetite regulation. Basic Clin Pharmacol Toxicol. 2005 Aug;97(2):61-73.

43. Epstein LH, Leddy JJ, Temple JL, Faith MS. Food reinforcement and eating: a multilevel analysis. Psychol Bull. 2007 Sep;133(5):884-906.

44. Cox DN, Perry L, Moore PB, Vallis L, Mela DJ. Sensory and hedonic associations with macronutrient and energy intakes of lean and obese consumers. Int J Obes Relat Metab Disord. 1999 Apr;23(4):403-10.

45. Ouwehand C, de Ridder DT. Effects of temptation and weight on hedonics and motivation to eat in women. Obesity (Silver Spring). 2008 Aug;16(8):1788-93.

46. Garg N, Wansink B, Inman J. The Influence of Incidental Affect on Consumers' Food Intake. Journal of Marketing. 2007;71(1):194-206.

47. Lacroix M, Gaudichon C, Martin A, Morens C, Mathe V, Tome D, et al. A long-term high-protein diet markedly reduces adipose tissue without major side effects in Wistar male rats. Am J Physiol Regul Integr Comp Physiol. 2004 Oct;287(4):R934-42.

48. Martens MJ, Rutters F, Lemmens SG, Born JM, Westerterp-Plantenga MS. Effects of single macronutrients on serum cortisol concentrations in normal weight men. Physiol Behav. 2010;Epub ahead of print.

49. Vicennati V, Ceroni L, Gagliardi L, Gambineri A, Pasquali R. Comment: response of the hypothalamic-pituitary-adrenocortical axis to high-protein/fat and high-carbohydrate meals in women with different obesity phenotypes. J Clin Endocrinol Metab. 2002 Aug;87(8):3984-8.

50. Takeda E, Terao J, Nakaya Y, Miyamoto K, Baba Y, Chuman H, et al. Stress control and human nutrition. J Med Invest. 2004;51(3-4):139-45.

51. Gibson EL, Checkley S, Papadopoulos A, Poon L, Daley S, Wardle J. Increased Salivary Cortisol Reliably Induced by a Protein-Rich Midday Meal. Psychosom Med. 1999 March 1, 1999;61(2):214-24.

52. Slag MF, Ahmad M, Gannon MC, Nuttall FQ. Meal stimulation of cortisol secretion: a protein induced effect. Metabolism. 1981;30(11):1104-8.

53. Gonzalez-Bono E, Rohleder N, Hellhammer DH, Salvador A, Kirschbaum C. Glucose but Not Protein or Fat Load Amplifies the Cortisol Response to Psychosocial Stress. Horm and Behav. 2002;41(3):328-33.

54. Lovallo WR, Farag NH, Vincent AS, Thomas TL, Wilson MF. Cortisol responses to mental stress, exercise, and meals following caffeine intake in men and women. Pharmacol Biochem Behav. 2006;83(3):441-7.

55. Markus CR, Panhuysen G, Tuiten A, Koppeschaar H, Fekkes D, Peters ML. Does Carbohydraterich, Protein-poor Food Prevent a Deterioration of Mood and Cognitive Performance of Stressprone Subjects when Subjected to a Stressful Task? Appetite. 1998;31(1):49-65.

56. Markus R, Panhuysen G, Tuiten A, Koppeschaar H. Effects of food on cortisol and mood in vulnerable subjects under controllable and uncontrollable stress. Physiol Behav. 2000;70(34):333-42.

57. Firk C, Markus CR. Mood and cortisol responses following tryptophan-rich hydrolyzed protein and acute stress in healthy subjects with high and low cognitive reactivity to depression. Clin Nutr. 2009;28(3):266-71.

58. Kirschbaum C, Kudielka BM, Gaab J, Schommer NC, Hellhammer DH. Impact of Gender, Menstrual Cycle Phase, and Oral Contraceptives on the Activity of the Hypothalamus-PituitaryAdrenal Axis. Psychosom Med. 1999 March 1, 1999;61(2):154-62.

59. Lattimore P, Maxwell L. Cognitive load, stress, and disinhibited eating. Eating Behaviors. 2004;5(4):315-24.

60. Wilkinson LL, Rowe AC, Bishop RJ, Brunstrom JM. Attachment anxiety, disinhibited eating, and body mass index in adulthood. Int J Obes. 2010:1-4.

61. Berthoud HR. Neural control of appetite: cross-talk between homeostatic and non-homeostatic systems. Appetite. 2004 Dec;43(3):315-7.

62. Blundell JE, Finlayson $\mathrm{G}$. Is susceptibility to weight gain characterized by homeostatic or hedonic risk factors for overconsumption? Physiol Behav. 2004 Aug;82(1):21-5. 
63. Gibson CD, Carnell S, Ochner CN, Geliebter A. Neuroimaging, Gut Peptides and Obesity: Novel Studies of the Neurobiology of Appetite. J Neuroendocrinol. 2010;22(8):833-45.

64. Batterham RL, ffytche DH, Rosenthal JM, Zelaya FO, Barker GJ, Withers DJ, et al. PYY modulation of cortical and hypothalamic brain areas predicts feeding behaviour in humans. Nature. 2007;450(7166):106-9.

65. Pannacciulli N, Le DSNT, Salbe AD, Chen K, Reiman EM, Tataranni PA, et al. Postprandial glucagon-like peptide-1 (GLP-1) response is positively associated with changes in neuronal activity of brain areas implicated in satiety and food intake regulation in humans. Neurolmage. 2007;35(2):511-7.

66. Hetherington MM, Anderson AS, Norton GN, Newson L. Situational effects on meal intake: A comparison of eating alone and eating with others. Physiol Behav. 2006 Jul 30;88(4-5):498-505.

67. Hetherington MM. Cues to overeat: psychological factors influencing overconsumption. Proc Nutr Soc. 2007 Feb;66(1):113-23.

68. Bellisle F, Dalix AM, Slama G. Non food-related environmental stimuli induce increased meal intake in healthy women: comparison of television viewing versus listening to a recorded story in laboratory settings. Appetite. 2004;43(2):175-80.

69. Stroebele N, De Castro JM. Effect of ambience on food intake and food choice. Nutrition. 2004;20(9):821-38.

70. Kudielka BM, Kirschbaum C. Sex differences in HPA axis responses to stress: a review. Biol Psychol. 2005;69(1):113-32.

71. Torres SJ, Nowson CA. Relationship between stress, eating behavior, and obesity. Nutrition. 2007 Nov-Dec;23(11-12):887-94.

72. Kyrou I, Chrousos GP, Tsigos C. Stress, visceral obesity, and metabolic complications. Ann N Y Acad Sci. 2006 Nov;1083:77-110. 


\section{Summary}


The regulation of energy intake is a complex process involving numerous factors such as genetic, physiological, environmental, and cognitive factors. This thesis, entitled 'Food intake meeting energy and reward homeostasis', encompasses the role of hormone and appetite dynamics, in relation to meal pattern, as well as the concept of reward, and hypothalamus pituitary adrenal (HPA) axis activity, in food intake behavior. The research is executed against the background of the current epidemic of overweight and obesity.

The search for physiological biomarkers of appetite is currently very active. Previous studies that based their correlation analyses of visual analogue scale (VAS) ratings for appetite with gut hormone and glucose concentrations, and energy intake, upon the calculated area under the curve or on the measured values per time point, showed a very low explained variation or no correlation at all. For validation of VAS ratings with gut hormone and glucose concentrations and energy intake the factor time needs to be taken into account. Thus, it was investigated whether changes in VAS appetite scores are synchronized with, or lag behind or in front of changes in gut hormone and glucose concentrations (Chapter 2). Results indicate that the mean explained variation of the development of hunger and fullness scores over time by the development of glucagon-like peptide (GLP)-1, peptide tyrosine-tyrosine (PYY), ghrelin, glucose, and insulin concentrations over time is $30-70 \%$. This figure is too small to use the changes in gut hormone and glucose concentrations as biomarkers for feelings of appetite, at least at the individual level and probably at group level depending on the aim of the study. Furthermore, ghrelin concentrations lag behind VAS hunger scores and insulin concentrations, suggesting a role for insulin as a negative regulator of ghrelin.

Regarding the concept of reward, a computer test was developed and validated that measures the rewarding value of food, i.e. 'liking' and 'wanting', in a Dutch study population and applicable in different study designs. In addition, we assessed how the rewarding value of a consumed food item possibly affects the rewarding value of any other food item in general (Chapter 3). Subsequently, the computer test was applied in the assessment of the role of dietary restraint in control over 'wanting' following consumption of 'forbidden' food (Chapter 4). The computer test for measurement of 'liking' and 'wanting' proved to be sufficiently valid. Application of the computer test shows that eating a highly liked food item induces a more distinct decrease in 'wanting' for food items in general and category-specific 'liking', than eating a sufficiently liked 'neutral' food item. In addition, successfully restrained eaters decrease food 'wanting' specifically after consumption of a non-healthy perceived, 'delicious' food vs. a nutritional identical, yet healthy perceived, slightly less 'delicious' food. A healthy perceived food may thus impose greater risk for control of energy intake in successfully restrained eaters. Thus, eating what you like contributes to less wanting of more food.

Eating out has become an important aspect in the development of obesity, and often involves a different meal pattern. The stimulated food intake through the 
social context of eating out may be facilitated by a slower appearance of satiation signals, or it may take place despite greater appetite control by possibly more sustained satiety signals. The effects of two different meal patterns, i.e. staggered vs. non-staggered meal consumption, on hormone (GLP-1, PYY, and ghrelin) and appetite dynamics, on the concept of reward, and on subsequent ad libitum energy intake, was investigated in a laboratory setting, thus excluding the environmental factors of eating out (Chapter 5). It was shown that staggered vs. non-staggered meal consumption induces greater appetite control, indicated by higher final GLP-1 concentrations and satiety ratings, lower ghrelin concentrations and hunger ratings, and lower subsequent food 'wanting'. However, this was not translated into a lower energy intake.

In addition to meal pattern manipulation, the activity of the HPA axis ('stress') may play a role in excessive energy intake, in relation to the food reward system. It appears that psychosocial stress is associated with greater weight gain among subjects who are overweight or obese, but less among subjects who are normal weight or underweight. In visceral overweight vs. normal weight subjects the effects of acute psychological stress on the rewarding value of food, in terms of 'liking' and 'wanting', and on food intake in a fasted as well as satiated state were assessed (Chapter 6). Acute stress augments food 'wanting' and energy intake in visceral overweight subjects in the absence of hunger. In a stressful situation the food reward system overrules and promotes excessive food intake in visceral overweight subjects.

In everyday life where stress is a pervasive factor, the development of functional foods, able to regulate the physiological and psychological stress response, would be helpful to improve or maintain quality of life. Inconsistencies regarding the possible effects of macronutrients on HPA axis activity and on the stressinduced mood response exist in the literature. Therefore it was investigated whether consumption of comparable meals with different macronutrient contents, i.e. high-protein vs. high-carbohydrate, affect the physiological cortisol and psychological mood response (Chapter 7). Moreover it was investigated how consumption of high-protein vs. high-carbohydrate foods influences the rewarding value of food, i.e. 'liking' and 'wanting', and food choice and food intake, in an acute stressful situation (Chapter 8). Consumption of meals with different macronutrient contents, i.e. high-protein vs. high-carbohydrate, does not influence the physiological cortisol and psychological mood response differentially. A high-protein vs. high-carbohydrate meal induces lower subsequent 'wanting' and energy intake in subjects with high disinhibition during rest; this difference disappears under stress. Acute stress overrules the effects of consumption of high-protein foods.

In conclusion, from the studies described in this thesis it appears that physiological 'biomarkers', such as GLP-1, PYY, ghrelin, glucose, and insulin, cannot replace feelings of appetite, at least at the individual level and probably at group level depending on the aim of the study. Furthermore, increased meal duration 
by staggered meal consumption can exert greater appetite control. The stimulated food intake in a restaurant setting with staggered meal consumption therefore takes place despite greater appetite control.

Energy and reward homeostasis both play a role in food intake behavior in the hungry state. However, in the satiated state it is mainly reward homeostasis that plays a role in food intake behavior, and this role becomes even more important in conditions of acute stress. Chronically eating in the absence of hunger, i.e. eating beyond energy homeostasis, may lead to the development of overweight and obesity. With regard to functional foods able to regulate the stress response, high-protein foods are ineffective in regulating the physiological and psychological stress response, and have limited impact on stress-related eating behavior. Stress dominates the satiating effect of protein.

Energy and reward homeostasis act together in the hungry state, while reward homeostasis overrules in the satiated state. 


\section{Samenvatting}


De regulatie van de voedselinname is een complex proces dat talrijke factoren omvat zoals genetische, fysiologische, cognitieve, en omgevingsfactoren. Dit proefschrift, getiteld 'Voedselinname in relatie tot energie homeostase en beloning', behandelt de rol van eetlust en relevante hormonen, in relatie tot maaltijdpatroon, evenals het concept van 'belonende waarde' van voeding. Daarnaast wordt de samenhang tussen voedselinname en de activiteit van de hypothalamus-hypofyse-bijnier as (HPA-as) belicht. Het onderzoek is verricht in het kader van de huidige obesitas epidemie.

Wat betreft de energie-homeostatische voedselinname, is onderzoek naar mogelijke fysiologische biomarkers voor honger, verzadiging, en energie-inname zeer actueel. Correlatie analyses tussen de scores voor eetlust, gemeten m.b.v. van visueel analoge schalen (VAS), de concentraties van gastro-intestinale (GI) hormonen, glucose, en de energie-inname zijn gebaseerd op de oppervlakte onder de curve of op de gemeten waarden per tijdstip, en hebben tot nu toe weinig opgeleverd. Cruciaal is dat de factor tijd hierin wordt meegenomen. Als zodanig werd onderzocht hoe de veranderingen in de tijd van de VAS scores voor eetlust en van de concentraties van GI hormonen en glucose synchroniseren (Hoofdstuk 2). De resultaten laten zien dat de verklaarde variantie van de veranderingen in de tijd van de eetlust scores met de veranderingen in de tijd van de concentraties van 'glucagon-like peptide' (GLP)-1, peptide tyrosinetyrosine (PYY), ghreline, glucose, en insuline 30-70 \% bedraagt. Naar onze mening is deze verklaarde variantie te laag voor gebruik van Gl hormonen en glucose als biomarkers voor eetlust op individueel niveau. In hoeverre dat groepsniveau kan worden gehanteerd, hangt af van het doel van het onderzoek. Voorts werd aangetoond dat de veranderingen in ghreline concentraties niet synchroon verlopen met, maar volgen op de veranderingen in honger scores en insuline concentraties. Dit suggereert een mogelijke rol van insuline als negatieve regulator van ghreline.

Betreffende het concept van 'belonende waarde' van voeding werd een computertest ontwikkeld om de twee componenten van belonende waarde, d.i. 'liking' (hedonische waarde) en 'wanting' (de motivatie om iets te willen hebben), te kunnen meten. De computertest werd gevalideerd en daarnaast gebruikt om na te gaan hoe de belonende waarde verschuift na het eten van bepaalde voedingsitems (Hoofdstuk 3). Vervolgens werd de computertest gebruikt om het effect van geremd eetgedrag op 'wanting' na consumptie van een 'verboden' voedingsitem te onderzoeken (Hoofdstuk 4). De resultaten laten zien dat consumptie van een voedingsitem met een hoge belonende waarde grotere reductie van 'wanting' impliceert dan consumptie van een 'neutraal', maar als 'gezond' gepercipieerd voedingsitem. Met name bij proefpersonen met geremd eetgedrag induceert de consumptie van een belonend voedingsitem, dat als ongezond en 'verboden' ervaren wordt, een grotere afname in 'wanting' van andere voedingsitems dan consumptie van een minder lekker doch nutritioneel identiek voedingsitem, dat als gezond ervaren wordt. Consumptie van 'gezonde' voedingsitems vormt dus een verhoogd risico voor personen met geremd eetgedrag 
bij de beheersing van hun voedselinname. Uit dit onderzoek werd geconcludeerd dat als men de voedselkeuze laat bepalen door wat men wil, voorkomen wordt dat men na de keuze voor het alternatief alsnog het gewenste consumeert.

Uit eten gaan, waarbij vaak een gewijzigd maaltijdpatroon van toepassing is, is een belangrijk hedendaags aspect dat bijdraagt aan de ontwikkeling van obesitas. De verhoogde voedselinname door de sociale context van uit eten gaan, kan gestimuleerd worden door het vertraagd ontstaan van verzadigingssignalen, of wordt gestimuleerd ondanks de grotere beheersing van de eetlust door een meer graduele stijging van verzadigingssignalen. In het laboratorium, waarbij de omgevingsfactoren zijn uitgesloten, werd het effect van twee verschillende maaltijdpatronen onderzocht (consumptie van een viergangen maaltijd verspreid over twee uur vs. consumptie van dezelfde viergangen maaltijd in een half uur), op de verandering van hormoonconcentraties (GLP-1, PYY, en ghreline), eetlust, en belonende waarde van voeding, en op de ad libitum voedselinname erna (Hoofdstuk 5). De resultaten tonen aan dat consumptie van een maaltijd gespreid in de tijd tot een verhoogde beheersing van de eetlust leidt. Dit werd aangetoond door verhoogde GLP-1 concentraties en gevoelens van verzadiging, verlaagde ghreline concentraties en gevoelens van honger, en verlaagde 'wanting' van andere voedingsitems erna. Desondanks vertaalde dit zich niet in een significante reductie in voedselinname na de viergangen maaltijd.

Naast de rol van maaltijdpatroon bij overmatige voedselinname, speelt de activiteit van de HPA-as ('stress') in relatie tot het concept van 'belonende waarde' een belangrijke rol. Uit studies blijkt dat psychosociale stress geassocieerd wordt met een grotere gewichtstoename bij personen met overgewicht of obesitas, in vergelijking met personen met een normaal gewicht of ondergewicht. Bij personen met visceraal overgewicht vs. normaal gewicht werd het effect onderzocht van acuut psychologische stress op de belonende waarde van voeding en op voedselinname in een gevaste en verzadigde toestand (Hoofdstuk 6). Acute stress verhoogde de 'wanting' van voedingsitems en de energieinname bij visceraal overgewichtigen in de verzadigde toestand. Hierbij blijkt dat in een stressvolle situatie het concept van 'belonende waarde' de overhand neemt in visceraal overgewichtigen.

In de huidige samenleving is stress alomtegenwoordig. Het ontwikkelen van functionele voeding die de fysiologische en psychologische stress respons kan reguleren, zou gunstig zijn om de levenskwaliteit te verbeteren. In de literatuur zijn er tegenstrijdigheden betreffende de mogelijke effecten van macronutriënten op de activiteit van de HPA-as en op de stress-geïnduceerde gemoedstoestand. In de volgende studie werd getest of vergelijkbare en iso-energetische maaltijden met een verschillende macronutriëntensamenstelling, d.i. hoog-eiwit vs. hoog-koolhydraat, de fysiologische cortisol respons en de psychologische gemoedstoestand beïnvloeden (Hoofdstuk 7). Daarnaast werd onderzocht of de consumptie van deze maaltijden in een stressvolle situatie invloed heeft op de belonende waarde van voeding, en op de voedselkeuze en -inname erna (Hoofdstuk 8). Consumptie van maaltijden met een verschillende macronutriën- 
tensamenstelling, d.i. hoog-eiwit vs. hoog-koolhydraat, bleek geen invloed te hebben op de fysiologische cortisol respons en psychologische gemoedstoestand. Consumptie van een maaltijd hoog in eiwit induceert een verlaagde 'wanting' van andere voedingsitems en een verlaagde energie-inname erna, enkel in proefpersonen met ontremd eetgedrag en in een niet-stressvolle situatie. Dit effect verdwijnt in een stressvolle situatie. Stress blijkt het verzadigende effect van eiwit te domineren.

Uit de resultaten van de studies beschreven in dit proefschrift werd geconcludeerd dat fysiologische 'biomarkers' zoals GLP-1, PYY, ghreline, glucose, en insuline de gevoelens van eetlust niet geheel kunnen vervangen op individueel niveau, en in zeer beperkte mate op groepsniveau. Verder blijkt dat een verhoogde maaltijdduur, door het verspreiden van consumptie van een maaltijd in de tijd, een sterkere beheersing van de eetlust faciliteert. De gestimuleerde voedselinname bij het uit eten gaan, vindt kennelijk plaats ondanks de grotere beheersing van de eetlust.

In de gevaste toestand spelen zowel het bereiken van energiebalans als de belonende waarde van voeding een rol in voedselinname. In de verzadigde toestand daarentegen is het voornamelijk de belonende waarde die een rol speelt in voedselinname. Deze rol wordt versterkt in condities van acute stress. Omtrent functionele voeding die de stress respons zou kunnen beïnvloeden, blijkt dat voeding hoog in eiwit ineffectief is in het reguleren van de fysiologische en psychologische stress respons, en weinig impact heeft op stressgerelateerde voedselinname. Integendeel, stress blijkt het verzadigende effect van eiwit te domineren.

Homeostase van energie en beloning vallen samen in de gevaste toestand, terwijl homeostase van beloning de overhand neemt in de verzadigde toestand. 


\section{Dankwoord}


Hoewel mijn naam op de kaft van dit proefschrift staat, is dit uiteraard niet het resultaat van één persoon. Bij deze wil ik dan ook iedereen bedanken die zijn steentje heeft bijgedragen.

Allereerst dank aan mijn promotor. Beste Margriet, bedankt om me de kans te geven bij $u$ te promoveren en me uitstekend te begeleiden. Ik bewonder $u$ voor uw enthousiasme, voor de snelheid waarmee u manuscripten nakijkt, en voor het feit dat u altijd en overal bereikbaar bent voor uw AIO's. Ik heb erg genoten van de vele congressen in het buitenland en de leuke uitjes.

Next, I would like to thank all the members of the reviewing committee, Prof. dr. K.R. Westerterp, Prof. dr. H.R. Berthoud, Prof. dr. M. Laville, Prof. dr. A. Masclee, and Prof. dr. ir. R.P. Mensink, for their evaluation of my thesis. Femke en Kristien, ik ben heel blij dat jullie me willen bijstaan als mijn persoonlijke paranimfjes! Dankjewel allebei!

Femke, aan het begin van mijn traject heb je me meteen onder je hoede genomen. Ik had al snel door dat achter die 'strenge tante' ;-) een lieve meid zat met een hart van goud! Als kamergenoten hebben we veel plezier beleefd en onze trip naar de Bahamas zal ik nooit vergeten!

Kristien, mijn zusje, steeds goedlachs, ik waardeer dat je altijd voor me klaar staat, net zoals een grote zus ;-). Binnenkort ga je van start met je eigen AIO project. Hier zal ik je zeker bij steunen!

Mijn (oud)clustergenoten bedank ik voor o.a. de goede werksfeer en erg gezellige theepauzes en congressen: Mieke, Jurriaan, Sanne, Stefan, Hanne, Rick, Eveline, Siti, Alberto, Stijn, Guy, Astrid, Anneke, Margriet, Marcel, Arie, Ananda, Helene, Manuela, Kristel, Freeha, ... Door jullie kwam ik steeds met plezier werken!

Mieke en Jurriaan, mijn huidige kamergenootjes, wij vormden de B1001'tjes van de $3^{\text {de }}$ verdieping :-). Bedankt voor jullie luisterend oor en hulp als ik het even niet zag zitten! Sanne, superstagiaire en vandaag AIO, samen met Femke deed je me op tijd en stond eraan herinneren dat ik niet moest uitdrogen :-). Ik wens jou en Mark veel geluk met het kleine boeleke en Roda JC-supporter in spe ;-). Rick, altijd in voor een 'goede' grap ;-), we hebben tegelijkertijd de laatste eindjes van ons proefschrift aan mekaar geknoopt. Nu wachten we in spanning af op D-Day! Veel succes met je promotie! Eveline, zonder jou was ik mijn laatste jaar nooit zo snel opgeschoten. Je hebt me super geholpen! Nu zal ik op mijn beurt mijn uiterste best doen om jou te begeleiden bij je AIO traject. Hanne, jouw komst versterkte ons Belgenfront :-)! Stijn, soms erg geheimzinnig ;-), nu husband en daddy van twee schattige meisjes in het verre Australië. Doe dat goed ginder en laat af en toe eens iets van je horen! Alberto Giovanni Bonomi, thank you for being our personal Italian jacuzzi-guy ;-).

Paul en Loek, bedankt voor jullie hulp bij het ontwerpen van de 'liking' en 'wanting' computertest en bij het oplossen van computerproblemen. Jos, Wendy, en Martine, bedankt voor het uitvoeren van de vele analyses! Verder wil ik de 'engeltjes' van het HB-secretariaat bedanken voor de administratieve 
ondersteuning, en iedereen van $\mathrm{HB}$ voor de gezelligheid tijdens de vele uitjes, recepties, en feestjes.

Leden van het B1001 Top Institute Food and Nutrition projectteam, werkzaam in Wageningen, Nicolien, Pleunie, Natasja, Monica, Annette, en Kees, samen hebben we vele meetings doorstaan. Veel succes met jullie verdere carrière! Lieve papa en mama, zonder jullie was ik nooit zo ver gekomen, mijn dank is groot! Jullie hebben me de ruimte gegeven mijn eigen weg te volgen, belangstelling getoond voor al mijn bezigheden, en me telkens opnieuw met raad en daad bijgestaan.

Martijn, merci voor je humor ten huize Lemmens-Duysens, en voor je deelname aan één van de onderzoeken beschreven in dit proefschrift. Samen met Kristien en Giel gaan we nog leuke tijden tegemoet ;-).

Anne-Marie, Jef, en Jeroen, bedankt voor het tonen van interesse in mijn onderzoek en om me een tweede thuis te geven!

Sara, mijn creatief nichtje, dank je voor het ontwerpen van de mooie kaft en de uitnodiging!

Vrienden en familie, bedankt voor jullie interesse en de nodige ontspannende feestjes, uitstapjes, activiteiten, ...

My South-African family, Rose-Anne, Janine, Gillian, and Bernadette, thank you for your interest and support! I'm glad we keep in touch! Never forget that you are always welcome!

Allerleefste Giel, het laatste jaar van mijn promotietraject heb je een heel speciale plek in mijn hart gekregen. Je bent altijd geïnteresseerd in alles wat ik doe en steeds bereid om me te helpen. Bedankt voor jouw liefde en steun! Ik kijk uit naar onze toekomst samen! 



\section{List of publications}




\section{Publications}

Lemmens SG, Schoffelen PF, Wouters L, Born JM, Martens MJ, Rutters F, Westerterp-Plantenga MS. Eating what you like induces a stronger decrease of 'wanting' to eat. Physiol Behav. 2009 Sep 7;98(3):318-25. Epub 2009 Jun 21.

Lemmens SG, Born JM, Rutters F, Schoffelen PF, Wouters L, WesterterpPlantenga MS. Dietary Restraint and Control Over "Wanting" Following Consumption of "Forbidden" Food. Obesity (Silver Spring). 2010 Oct;18(10):1926-31. Epub 2010 Feb 25.

Lemmens SG, Martens EA, Born JM, Martens MJ, Westerterp-Plantenga MS. Staggered meal consumption facilitates appetite control without affecting postprandial energy intake. J Nutr. 2010. In press.

Lemmens SG, Born JM, Martens EA, Martens MJ, Westerterp-Plantenga MS. Influence of consumption of a high-protein vs. high-carbohydrate meal on the physiological cortisol and psychological mood response in men and women. PLoS One 2011. In press.

Lemmens SG, Rutters F, Born JM, Westerterp-Plantenga MS. Stress augments food 'wanting' and energy intake in visceral overweight subjects in the absence of hunger. Physiol Behav. 2011. In press.

Born JM, Lemmens SG, Rutters F, Nieuwenhuizen AG, Formisano E, Goebel R, Westerterp-Plantenga MS. Acute stress and food-related reward activation in the brain during food choice during eating in the absence of hunger. Int $\mathrm{J}$ Obes (Lond). 2010 Jan;34(1):172-81. Epub 2009 Oct 20.

Rutters F, Lemmens SG, Born JM, Bouwman F, Nieuwenhuizen AG, Mariman E, Westerterp-Plantenga MS. Genetic associations with acute stress-related changes in eating in the absence of hunger. Patient Educ Couns. 2010 Jun;79(3):367-71. Epub 2010 Apr 20.

Martens MJ, Lemmens SG, Born JM, Westerterp-Plantenga MS. A Solid HighProtein Meal Evokes Stronger Hunger Suppression Than a Liquefied HighProtein Meal. Obesity (Silver Spring). 2010 Oct 21.

Rutters F, Nieuwenhuizen AG, Lemmens SG, Born JM, Westerterp-Plantenga MS. Acute stress-related changes in eating in the absence of hunger. Obesity (Silver Spring). 2009 Jan;17(1):72-7. Epub 2008 Nov 6. 
Rutters F, Nieuwenhuizen AG, Lemmens SG, Born JM, Westerterp-Plantenga MS. Hyperactivity of the HPA axis is related to dietary restraint in normal weight women. Physiol Behav. 2009 Feb 16;96(2):315-9. Epub 2008 Oct 29.

Rutters F, Nieuwenhuizen AG, Lemmens SG, Born JM, Westerterp-Plantenga MS. Hypothalamic-pituitary-adrenal (HPA) axis functioning in relation to body fat distribution. Clin Endocrinol (Oxf). 2010 Jun;72(6):738-43. Epub 2009 Sep 21.

Martens MJ, Rutters F, Lemmens SG, Born JM, Westerterp-Plantenga MS. Effects of single macronutrients on serum cortisol concentrations in normal weight men. Physiol Behav. 2010 Dec 2;101(5):563-7. Epub 2010 Sep 16.

Rutters F, Nieuwenhuizen AG, Lemmens SG, Bouwman F, Mariman E Westerterp-Plantenga MS. Associations between anthropometrical measurements, body composition, single nucleotide polymorphisms of the Hypothalamus/Pituitary/Adrenal (HPA) axis and HPA axis functioning. Clin Endocrinol (Oxf). 2011. In press.

Rutters F, Nieuwenhuizen AG, Verhoef SP, Lemmens SG, Vogels N, Westerterp-Plantenga MS. The relationship between leptin, gonadotropic hormones, and body composition during puberty in a Dutch children cohort. Eur $\mathrm{J}$ Endocrinol. 2009 Jun;160(6):973-8. Epub 2009 Mar 30.

Lemmens SG, Martens EA, Kester AD, Westerterp-Plantenga MS. Changes in gut hormone and glucose concentrations in relation to hunger and fullness. Submitted for publication

Lemmens SG, Martens EA, Born JM, Martens MJ, Westerterp-Plantenga MS. Eating in the absence of hunger: interaction between stress, macronutrient intake and disinhibition. Submitted for publication

Born JM, Lemmens SG, Martens MJ, Formisano E, Goebel R, WesterterpPlantenga MS. Differences between liking and wanting signals in the human brain and relations with cognitive dietary restraint and BMI. Submitted for publication

Martens MJ, Lemmens SG, Born JM, Westerterp-Plantenga MS. Liking and perception of food in a stress versus rest condition in overweight and normal weight subjects. Submitted for publication

Martens MJ, Lemmens SG, Born JM, Westerterp-Plantenga MS. Differences in satiating capacity of solid and liquefied carbohydrate meals, a physiological approach. Submitted for publication 


\section{Abstracts and Presentations}

Lemmens SG, Nieuwenhuizen AG, Schoffelen PF, Wouters L, Born JM, Rutters F, Westerterp-Plantenga MS. Effects of eating a specific vs. a neutral food item on the rewarding value of foods in general. European Congress on Obesity; 1317 May 2008; Geneva, Switzerland. Int J Obesity 2008; 32 suppl. 1; S169. Poster presentation

Lemmens SG, Nieuwenhuizen AG, Schoffelen PF, Wouters L, Born JM, Rutters F, Westerterp-Plantenga MS. Effects of eating dessert-specific vs. dessert nonspecific food on the rewarding value of food in general. Congress of the Society for the Studies of Ingestive Behavior; 15-18 July 2008; Paris, France. Appetite 2008; 51 (2); 350-412. Poster presentation

Lemmens SG, Schoffelen PF, Born JM, Rutters F, Westerterp-Plantenga MS. Effects of eating dessert-specific vs. dessert non-specific food on the rewarding value of foods as a function of dietary restraint and visceral overweight. European Congress on Obesity; 6-9 May 2009; Amsterdam, Netherlands. Obesity Facts 2009; 2 suppl. 2; 1-256. Poster presentation

Lemmens SG, Born JM, Rutters F, Martens MJ, Westerterp-Plantenga MS. Effects of stress on food choice and intake in the absence of hunger. Benjamin Franklin Lafayette Seminar; 22-26 June 2009; Frejus, France. Invited speaker

Lemmens SG, Born JM, Rutters F, Martens MJ, Westerterp-Plantenga MS. Effects of stress on food choice and intake in the absence of hunger. Congress of the Society for the Studies of Ingestive Behavior; 29 July - 1 August 2009; Portland, USA. Appetite 2009; 52; 815-868. Poster presentation

Lemmens SG, Born JM, Rutters F, Martens MJ, Westerterp-Plantenga MS. Effects of stress on food choice and food intake in the absence of hunger. NWO Werkgemeenschap Voeding; 8-9 October 2009; Deurne, The Netherlands. Oral presentation

Lemmens SG, Born JM, Rutters F, Martens MJ, Westerterp-Plantenga MS. Stress and food reward. Swiss Winter Conference on Ingestive Behavior; 28 February - 4 March 2010; St. Moritz, Switzerland. Invited speaker

Lemmens SG, Born JM, Martens EA, Martens MJ, Westerterp-Plantenga MS. Eating in the absence of hunger as a function of previous macronutrient intake, stress and disinhibition. International Congress on Obesity; 11-15 July 2010; Stockholm, Sweden. Obesity Reviews 2010; 11 Suppl. 1; 313. Poster presentation 
About the author 
Sofie Lemmens was born on November $3^{\text {rd }} 1983$ in Oupeye, Belgium. In 2001 she completed secondary school at the 'Provinciale Secundaire School' in 's Gravenvoeren, Belgium. The same year she participated in the AFS intercultural exchange program to Port Elizabeth, South Africa. September 2002 Sofie started her study Biomedical Sciences at the University of Hasselt, where she graduated in 2006 as Master in Clinical Molecular Life Sciences. October 2006 Sofie started the Initial Teacher Training Course in the field of chemistry and biology at the University of Hasselt, which she completed in 2008.

November 2006 Sofie started her PhD research as part of a project of Top Institute Food and Nutrition (TIFN) at the department of Human Biology, Maastricht University. The research performed during this project, under supervision of Prof. dr. MS Westerterp-Plantenga, is described in this thesis entitled 'Food intake meeting energy and reward homeostasis' and was approved in December 2010. During her PhD project Sofie presented several abstracts at international conferences. She was awarded with the EASO Poster prize at the 16th European Congress on Obesity, May 2008, in Geneva, Switzerland.

Currently, Sofie started as a post-doc at the department of Human Biology, Maastricht University, to continue her work in the field of food intake regulation. 